\title{
Three Essays on the Economics and Market of Higher Education
}

by

\author{
Muhammad I. Ariffin \\ A thesis submitted to the Faculty of Graduate and Postdoctoral Affairs \\ in partial fulfillment of the requirements for the degree of
}

Doctor of Philosophy

in

Economics

Carleton University
ttawa, Ontario, Canada

(C) 2014

Muhammad I. Ariffin 


\section{Abstract}

This thesis consists of three essays on university behavior in the higher education market. The first essay examines factors that determine the enrollment of international undergraduate students at 116 U.S. universities from 2003 to 2011. Several endogeneity tests performed indicate that published tuition may be treated as exogenous to international students. The relationship between price and international students is best described by a dynamic model, where published tuition positively affects enrollment through the signalling effect. Female international students are more sensitive to price changes than male international students.

Price competition between 528 U.S. universities from 2004 to 2011 is analyzed in the remaining two essays. The proximity of competitors in the market is incorporated using the spatial econometrics method. The model specification process follows a systematic selection process which confirms the presence of spatial autocorrelations and performs several specification tests between four spatial model candidates.

The second essay investigates price competition in the geographical market dimension, where the longitude and latitude coordinates of universities are used to determine their locations. The prices set by a university are found to be positively influenced by prices, cost and demand variables of other competitors in the same geographical market region. Price competition in the geographical market is found to be integrated at the national level. 
The third essay examines price competition in the product market dimension. The Academic Ranking of World Universities (ARWU) rank is used to indicate the locations of universities along a prestige line. The specification process indicates positive spatial effects exist in price competition between universities that are located in a similar prestige range. Spatial effect is present in the demand and cost factors for published tuition but not net tuition. Spatial effect in published tuition competition is sensitive to different market size limitations, while it is persistently positive in net tuition competition in smaller product market range. 


\section{Acknowledgements}

This thesis would not be realized without the help of many. First, I would like to express the deepest appreciation to my supervisor, Professor Christopher Worswick, for his continuous guide and support. His mentorship was paramount in providing a valuable academic experience that made this arduous journey a thoughtful one.

I am thankful to my thesis committee members who have provided valuable comments and suggestions that made this thesis stronger: Associate Professor Marcel Voia from Carleton University, and Associate Professor Gamal Atallah from the University of Ottawa. I also wish to thank other faculty and staff from the department, including Marge Brooks for the numerous assistance, and my fellow classmates for the valuable friendship that keeps my passion to excel alive.

I would like to express my gratitude to International Islamic University Malaysia (IIUM) and the Government of Malaysia for the financial assistance during my study in Canada.

Finally, I would like to thank my wife, Aimi Fikry, for her love and understanding that keep me accompanied. My children: Maryam, Aiman and Isa, have made this journey more colorful and meaningful. I thank my parents, Ariffin Mohd Zain and Jamilah Hussain for their encouragement and allowing me to pursue my ambitions. I am grateful to my parents-in-law, Fickry Yaacob and Siti Rabiah Mohad, and all family members for their support. 


\section{Table of Contents}

$\begin{array}{ll}\text { Abstract } & \text { ii }\end{array}$

Acknowledgements $\quad$ iv

Table of Contents viii

List of Figures $\quad x$

List of Tables $\quad$ xvi

1 Introduction 1

2 International Student Demand for Higher Education in the U.S. 3

2.1 Introduction . . . . . . . . . . . . . . . . . 3

2.2 Literature Review . . . . . . . . . . . . . . . . . . . 7

2.3 Model . . . . . . . . . . . . . . . . . . . . . . . 11

2.4 Data . . . . . . . . . . . . . . . . . . 12

2.4 .1 Enrollment . . . . . . . . . . . . . . . . . . . . . 13

2.4 .2 Tuition and Fees $\ldots \ldots \ldots \ldots$

2.4 .3 Prestige and Quality . . . . . . . . . . . . . . . 16

2.4 .4 Other Factors . . . . . . . . . . . . . . . . . . . . . 19 


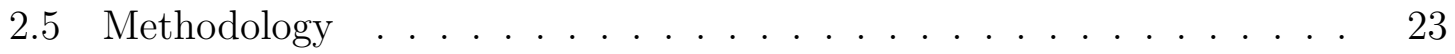

2.5.1 Model Selection Criteria . . . . . . . . . . . . . . . . . . . 24

2.5.2 Endogeneity of Published Tuition with International Students 25

2.5 .3 Dynamic Specification . . . . . . . . . . . . . . . 28

2.6 Results . . . . . . . . . . . . . . . . . . . . . . . . . . . 30

2.7 Conclusion . . . . . . . . . . . . . . . . . . . . . . . . . . . . . . . . . 53

3 Price Competition in the Geographical Market of U.S. Higher Education: A Spatial Regression Approach 56

3.1 Introduction . . . . . . . . . . . . . . . . 56

3.2 Literature Review . . . . . . . . . . . . . . . . . . . . . . 63

3.3 Data . . . . . . . . . . . . . . . . . . 66

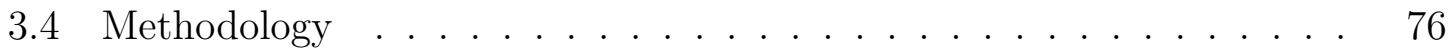

3.4.1 Endogeneity of Enrollment with Prices . . . . . . . . . 76

3.4.2 Test for Spatial Autocorrelation . . . . . . . . . . 78

3.4 .3 Model Specification Test . . . . . . . . . . . . . . . . . . 81

3.4.4 Method of Estimation . . . . . . . . . . . . . . 9 90

3.4.5 Interpretation of the Results . . . . . . . . . . . . 91

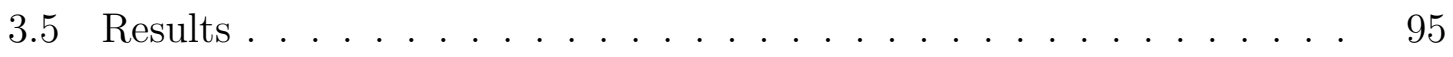

3.5.1 Spatial Correlation . . . . . . . . . . . . . . . . 95

3.5 .2 Model Specification . . . . . . . . . . . . . . . . . 100

3.5 .3 Regression Results . . . . . . . . . . . . . . . . 106

3.6 Conclusion . . . . . . . . . . . . . . . . . . . . . . . . . . . . . . . . . . . . 141

4 Price Competition in the Product Market of U.S. Higher Education: A Spatial Regression Approach 144

4.1 Introduction . . . . . . . . . . . . . . . . 144 
4.2 Literature Review . . . . . . . . . . . . . . . . . . . . . . . . . . . 148

4.3 Data . . . . . . . . . . . . . . . . . . . . 152

4.4 Methodology . . . . . . . . . . . . . . . . . . 153

4.4 .1 Test for Spatial Autocorrelation . . . . . . . . . . . . . . 154

4.4 .2 Model Specification Test . . . . . . . . . . . . . . . . . 156

4.4.3 Interpretation of the Results . . . . . . . . . . . . . 158

4.4 .4 Market Size Analysis . . . . . . . . . . . . . . . . . . . 159

4.5 Results . . . . . . . . . . . . . . . . . . . 160

4.5.1 Spatial Correlation . . . . . . . . . . . . . . 160

4.5.2 Model Specification . . . . . . . . . . . . . . . . . . . . . 164

4.5 .3 Regression Results . . . . . . . . . . . . . . . . . . 170

4.5.4 Market Size Comparison . . . . . . . . . . . . . . . 190

4.6 Conclusion . . . . . . . . . . . . . . . . . . . . . . . . . . . . . . . . . 191

5 Conclusion 194

$\begin{array}{ll}\text { Appendix A } & 197\end{array}$

A.1 List of Universities . . . . . . . . . . . . . . . . . . . 197

A.2 Endogeneity Test: Published Tuition and International Students . . . 201

A.3 Deviation Graphs . . . . . . . . . . . . . . . . . 203

A.4 Robustness Check Results . . . . . . . . . . . . . . . . 207

$\begin{array}{ll}\text { Appendix B } & 210\end{array}$

B.1 List of Variables . . . . . . . . . . . . . . . . . . . . . . 210

B.2 Endogeneity Test: Enrollment and Prices . . . . . . . . . . . 211

$\begin{array}{ll}\text { Appendix C } & 212\end{array}$

C.1 Moran Scatterplots: Geographical Market _. . . . . . . . . . . 212 
C.2 Spatial Regression without Potentially Endogenous Variables: Geographical Market . . . . . . . . . . . . . . . . . . . . 221

C.3 Time Fixed Effects: Geographical Market . . . . . . . . . . . . . . 224

$\begin{array}{ll}\text { Appendix D } & 227\end{array}$

D.1 Moran Scatterplots: Product Market . . . . . . . . . . . . 227

D.2 Spatial Regression without Potentially Endogenous Variables: Product Market . . . . . . . . . . . . . . . . . . . . 236

D.3 Time Fixed Effects: Product Market _. . . . . . . . . . . . . 239

D.4 Robustness Check: Specification Results . . . . . . . . . . . 242

D.5 Robustness Check: Regression Results . . . . . . . . . . . 246

$\begin{array}{ll}\text { Appendix E } & 279\end{array}$

$\begin{array}{ll}\text { Bibliography } & 295\end{array}$ 


\section{List of Figures}

2.1 Enrollment and tuition revenues (in $\$$ million) of postsecondary degreegranting institutions in the U.S. based on student residential status from 2005 to $2010 \ldots \ldots \ldots \ldots \ldots$

2.2 Average price elasticity of enrollments (linear specification) and ARWU rank for $2010 \ldots \ldots . \ldots . \ldots . \ldots . \ldots 44$

2.3 Average price elasticity of enrollments (dynamic specification) and ARWU rank for 2010 . . . . . . . . . . . . . . . 46

2.4 The relationship between deviations from mean published tuition growth and deviations from mean enrollments growth for selected years . . . 48

2.5 Average price elasticity of enrollments (fixed effects method) and ARWU rank for $2010 \ldots \ldots \ldots$. . . . . . . . . . . . . . . . . 51

2.6 Average price elasticity of enrollments (Hausman-Taylor method) and ARWU rank for 2010 . . . . . . . . . . . . . . . 52

3.1 Expenditures of Higher Education and GDP, 1986-2011 . . . . . . . . 59

3.2 Change in state appropriations per FTE Student, 2007-2012 . . . . . 61

3.3 Net tuition as a percent of public higher education revenue, 1987-2012 62

3.4 Moran scatterplot for published tuition in the geographical market for

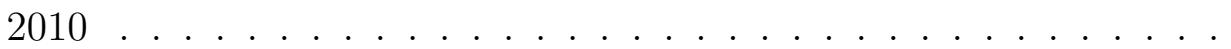


3.5 Moran scatterplot for net tuition in the geographical market for 2010

4.1 Average undergraduate tuition and fees in 4-year degree granting institutions in constant 2011-2012 dollars . . . . . . . . . . . . . . . . 145

4.2 Moran scatterplot for published tuition in the product market for 2010162

4.3 Moran scatterplot for net tuition in the product market for 2010 . . 163

A.1 The relationship between deviations from mean published tuition growth and deviations from mean enrollments growth . . . . . . . . . . 203

C.1 Moran scatterplots for published tuition in the geographical market . 212

C.2 Moran scatterplots for net tuition in the geographical market . . . . 217

D.1 Moran scatterplots for published tuition in the product market . . . 227

D.2 Moran scatterplots for net tuition in the product market . . . . . . . 232 


\section{List of Tables}

2.1 Sample distribution based on the Carnegie Commission Classification

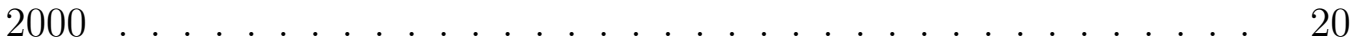

2.2 Geographic distribution of universities in the sample . . . . . . . . . 21

2.3 Descriptive statistics . . . . . . . . . . . . . . . . 23

2.4 Correlations among enrollments of new (first time, first year, full time, undergraduate) students . . . . . . . . . . . . . . . . . . 30

2.5 Correlations among variables . . . . . . . . . . . . . . . . 31

2.6 Panel-robust Hausman tests . . . . . . . . . . . . . . . . . . . . . . . 32

2.7 Relationship between enrollment of international students and price . 33

2.8 Panel-robust Hausman tests for nonlinear specifications . . . . . . . . 39

2.9 Nonlinear relationships between enrollment of international students and price. . . . . . . . . . . . . . . . . . . . . . 40

2.10 Augmented system GMM estimation for enrollment of international

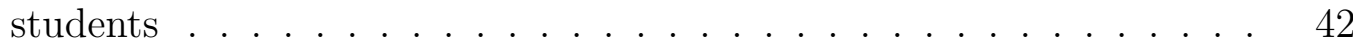

3.1 Sample distribution based on the Carnegie Commission Classification

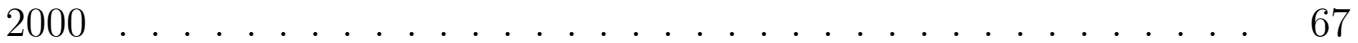

3.2 Descriptive statistics . . . . . . . . . . . . . . . . . 75

3.3 Descriptive statistics of monetary variables in raw values . . . . . . 75 
3.4 Spatial correlation statistics in the geographical market . . . . . . . 96

3.5 SARMA tests for spatial model specification . . . . . . . . . . . . 100

3.6 The LM specification tests for spatial lag and spatial error in the geographical market . . . . . . . . . . . . . . . . . 102

3.7 The LR specification tests for spatial autocorrelation in the geographical market . . . . . . . . . . . . . . . . . . . . . 103

3.8 Specification tests for spatial autocorrelation from SDM model in the geographical market . . . . . . . . . . . . . . . . 105

3.9 Price competition in the geographical market with no spatial effets (FE method) .......................... 107

3.10 Price competition in the geographical market with spatial effects (SDM specification) . . . . . . . . . . . . . . . . . 110

3.11 Marginal effects for published tuition in the geographical market . . . 112

3.12 Marginal effects for net tuition in the geographical market . . . . . . 117

3.13 Spatial regression for public universities in the geographical market . 120

3.14 Marginal effects for published tuition of public universities in the geographical market . . . . . . . . . . . . . . . . . . . . 122

3.15 Marginal effects for net tuition of public universities in the geographical market . . . . . . . . . . . . . . . . . 124

3.16 Spatial regression for private universities in the geographical market . 126

3.17 Marginal effects for published tuition of private universities in the geographical market . . . . . . . . . . . . . . . . . . . . . . . . 128

3.18 Marginal effects for net tuition of private universities in the geographical market . . . . . . . . . . . . . . . . . . . . . . 130

3.19 Spatial regression for the geographical market truncated at 400 miles 133 
3.20 Marginal effects for published tuition in the geographical market: 400 miles limit . . . . . . . . . . . . . . . . . 135

3.21 Marginal effects for net tuition in the geographical market: 400 miles

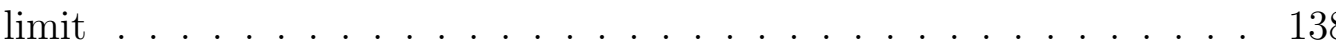

4.1 Spatial correlation statistics in the product market . . . . . . . . . 161

4.2 SARMA tests for spatial model specification . . . . . . . . . . . 164

4.3 The LM specification tests for spatial lag and spatial error in the product market . . . . . . . . . . . . . . . . . . . . 166

4.4 The LR specification tests for spatial autocorrelation in the product market . . . . . . . . . . . . . . . . 167

4.5 Specification tests for spatial autocorrelation from SDM model in the product market . . . . . . . . . . . . . . . . . . . . 169

4.6 Price competition in the product market . . . . . . . . . . . . 171

4.7 Marginal effects for published tuition in the product market . . . . . 173

4.8 Marginal effects for net tuition in the product market . . . . . . . . . 175

4.9 Price competition between public universities in the product market . 178

4.10 Marginal effects for published tuition of public universities in the product market . . . . . . . . . . . . . . . . . . . . . . 179

4.11 Marginal effects for net tuition of public universities in the product

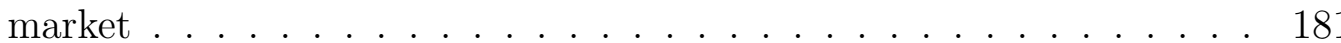

4.12 Price competition between private universities in the product market 184

4.13 Marginal effects for published tuition of private universities in the product market . . . . . . . . . . . . . . . . . . . . 186

4.14 Marginal effects for net tuition of private universities in the product

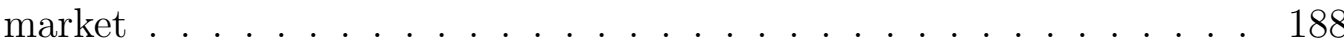


4.15 Product market size comparison . . . . . . . . . . . . . . . . . . . 190

A.1 2-step GMM estimation results and endogeneity tests . . . . . . . . . 201

A.2 Robustness check using fixed effects estimation . . . . . . . . . . . 207

A.3 Robustness check using Hausman-Taylor estimation . . . . . . . . . . 208

A.4 Robustness check using first differences estimation . . . . . . . . . . 209

B.1 List of variables used for spatial regression analysis in Chapter 3 and Chapter 4 . . . . . . . . . . . . . . . . . . 210

B.2 2-step GMM estimation results and endogeneity tests . . . . . . . . . 211

C.1 Spatial regression of the geographical market without potentially endogenous variables . . . . . . . . . . . . . . . . . 221

C.2 Marginal effects for published tuition of in the geographical market without potentially endogenous variables . . . . . . . . . . . . . 222

C.3 Marginal effects for net tuition of in the geographical market without potentially endogenous variables . . . . . . . . . . . . . . 223

C.4 Price competition in the geographical market with spatial and time

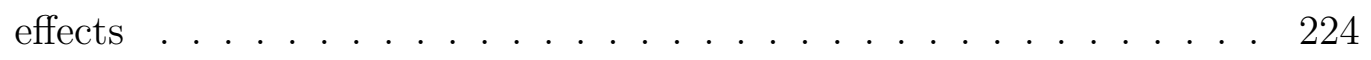

C.5 Marginal effects for published tuition in the geographical market with time effects . . . . . . . . . . . . . . . . 225

C.6 Marginal effects for net tuition in the geographical market with time

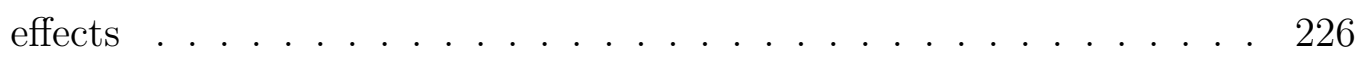

D.1 Spatial regression of the product market without potentially endogenous variables . . . . . . . . . . . . . . . . . 236

D.2 Marginal effects for published tuition of in the product market without potentially endogenous variables . . . . . . . . . . . . . . 237 
D.3 Marginal effects for net tuition of in the product market without potentially endogenous variables . . . . . . . . . . . . . . . . 238

D.4 Price competition in the product market with spatial and time effects 239

D.5 Marginal effects for published tuition in the product market with time

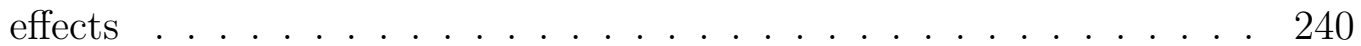

D.6 Marginal effects for net tuition in the product market with time effect 241

D.7 SARMA tests for spatial model specification . . . . . . . . . . . . . . 242

D.8 The LM specification tests for spatial lag and spatial error in the product market . . . . . . . . . . . . . . . . . . . . . . 243

D.9 The LR specification tests for spatial autocorrelation in the product market . . . . . . . . . . . . . . . . . . . . . 244

D.10 Specification tests for spatial autocorrelation from SDM model in the product market . . . . . . . . . . . . . . . . . . . . 245

D.11 Model specification decisions . . . . . . . . . . . . . . . . . 247

D.12 Spatial regressions for the product market in 2004 . . . . . . . . 255

D.13 Marginal effects for published tuition in the product market for 2004256

D.14 Marginal effects for net tuition in the product market for 2004 . . . 257

D.15 Spatial regressions for the product market in 2005 . . . . . . . . 258

D.16 Marginal effects for published tuition in the product market for $2005 \quad 259$

D.17 Marginal effects for net tuition in the product market for 2005 . . . . 260

D.18 Spatial regressions for the product market in 2006 . . . . . . . . . 261

D.19 Marginal effects for published tuition in the product market for 2006262

D.20 Marginal effects for net tuition in the product market for 2006 . . . . 263

D.21 Spatial regressions for the product market in 2007 . . . . . . . . . 264

D.22 Marginal effects for published tuition in the product market for $2007 \quad 265$

D.23 Marginal effects for net tuition in the product market for 2007 . . . . 266 
D.24 Spatial regressions for the product market in $2008 \ldots \ldots \ldots \ldots$

D.25 Marginal effects for published tuition in the product market for 2008268

D.26 Marginal effects for net tuition in the product market for 2008 . . . 269

D.27 Spatial regressions for the product market in $2009 \ldots \ldots \ldots$

D.28 Marginal effects for published tuition in the product market for 2009271

D.29 Marginal effects for net tuition in the product market for 2009 . . . . 272

D.30 Spatial regressions for the product market in 2010 . . . . . . . . . 273

D.31 Marginal effects for published tuition in the product market for 2010274

D.32 Marginal effects for net tuition in the product market for 2010 . . . 275

D.33 Spatial regressions for the product market in $2011 \ldots \ldots \ldots \ldots$

D.34 Marginal effects for published tuition in the product market for 2011277

D.35 Marginal effects for net tuition in the product market for 2011 . . . 278

E.1 List of abbreviations and variables used in the thesis . . . . . . 279 


\section{Chapter 1}

\section{Introduction}

This thesis is comprised of three essays in economics of higher education. These three essays are empirical works that share a common subject matter, which focuses on university behavior in the higher education market.

The first essay, presented in Chapter 2, analyzes university-level factors that influence the enrollment of international undergraduate students at U.S. universities. A panel of 116 universities from 2003 to 2011 is used in the analysis. The main objective of this essay is to explain the relationship between price and enrollment of international students. The sample is divided into male and female subsamples to allow for heterogeneity across gender. The issue of potential endogeneity between enrollment and tuition is addressed by comparing pooled OLS and 2-step GMM estimations. The model selection exercise involves panel-robust Hausman tests to determine the most suitable estimation method among three candidates: fixed effects (FE), random effects (RE), and Hausman-Taylor (HT). The model specification process considers four different specifications: linear, quadratic, multiplicative, and dynamic specification. The regression results obtained are then verified through several robustness checks. 
Chapters 3 and 4 attempt to integrate spatial econometrics techniques into the analysis of price competition between universities in two market dimensions: geographical and product respectively. The sample consists of 528 universities which span from 2004 to 2011. These two essays examine how the price and financial aid policies of a university are influenced by the proximity of competitors in the market. Universities that are located in the same geographical region or assigned in similar prestige levels are expected to display similar pricing strategies. The spatial effects are incorporated into the model through a spatial weighting matrix. The location of universities in the geographical market is determined by their longitude and latitude coordinates while the Academic Ranking of World Universities (ARWU) rank is used to indicate the location of universities in the product market. The model specification procedure follows a systematic and rigorous approach where the presence of spatial effects must be verified before a spatial model could be used. There are four spatial model candidates considered in the model selection exercise: spatial lagged dependent variable (SAR), spatial error model (SEM), spatial lagged dependent variable with spatial error (SARMA), and spatial lagged dependent variable and spatial lagged explanatory variables (SDM). The model selection process involves several tests which investigate the significance of different spatial specifications. The market size is then truncated into smaller limits to inspect the extent of local spatial effects and to assess the characteristics of price competition in smaller market dimension.

Chapter 5 provides an overall conclusion of the thesis. All appendices and references are located at the end of the thesis. 


\section{Chapter 2}

\section{International Student Demand for Higher Education in the U.S.}

\section{$2.1 \quad$ Introduction}

The U.S. higher education sector continues to be a significant contributor to its economy. In the academic year 2011-2012, the postsecondary degree-granting institutions in U.S. contributed $\$ 483$ billion $^{1}$ to the Gross Domestic Products (GDP) in 2011 (Snyder and Dillow 2013). The expenditure of 764,495 international students forms approximately $\$ 21.81$ billion from this amount, where $\$ 15.81$ billion is from tuition and fees (NAFSA 2013).

One of the main components of the internationalization of higher education is cross-border mobility of students. Currently the dominant trend of cross-border student mobility is from less developed and newly industrialized countries to developed countries, where the U.S. is the leading destination for international students in the

\footnotetext{
${ }^{1}$ This expenditure is estimated in January 2013 by the National Center for Education Statistics (NCES) based on data collected from the Integrated Postsecondary Education Data System (IPEDS).
} 
world. Although the global mobility of students is expected to grow and become more intensely competitive, the U.S. will likely remain the top destination for study because of its ability to integrate international students at a faster rate when compared with other competing countries and also due to the overwhelming size of its higher education system (Choudaha and Chang 2012).

There are various factors that influence an international student's decision to study at a foreign country. These factors can be viewed as the result from the interaction between push factors of the home country and pull factors of the host country. The push factors refer to various circumstances in the source country that instigate the student to embark on study outside the country. On the other hand, the pull factors are numerous conditions in the destination country that attract international students to migrate and study there (Mazzarol and Soutar 2002). Despite strong growth in student mobility, the roles of governments in both sending and receiving countries have changed from direct sponsors into regulators and facilitators while the demand and supply for international students are increasingly determined by market forces (Li and Bray 2007). As a result, mobility of students is now looked upon as trade rather than aid or cultural exchange.

Among the major pull factors that attract international students to the U.S. are the perceived high quality of the U.S. higher education, the appeal of American culture, and the job prospect in the U.S. labor market after graduation (Altbach 2006a). Although there is a high inflow of international students into the U.S. higher education market, institutions still need to compete for high quality and self-funded students from the pool of prospective international students.

A prospective international student weighs two levels of pull factors: among competing countries and among competing institutions. Once the international student has decided to study in the U.S., now the pull factors among various institutions 
shall determine the placement decision. Since most of the international students are self-funded and not eligible for various financial aids offered to the U.S. resident students, tuition fees and various institutional characteristics are expected to affect the enrollment of international students. Figure 2.1 shows the enrollment of students and tuition revenues of all postsecondary institutions in the U.S. based on student residential status. On average, the international student pays tuition approximately three times more than the U.S. resident students.

Figure 2.1: Enrollment and tuition revenues (in $\$$ million) of postsecondary degreegranting institutions in the U.S. based on student residential status from 2005 to 2010

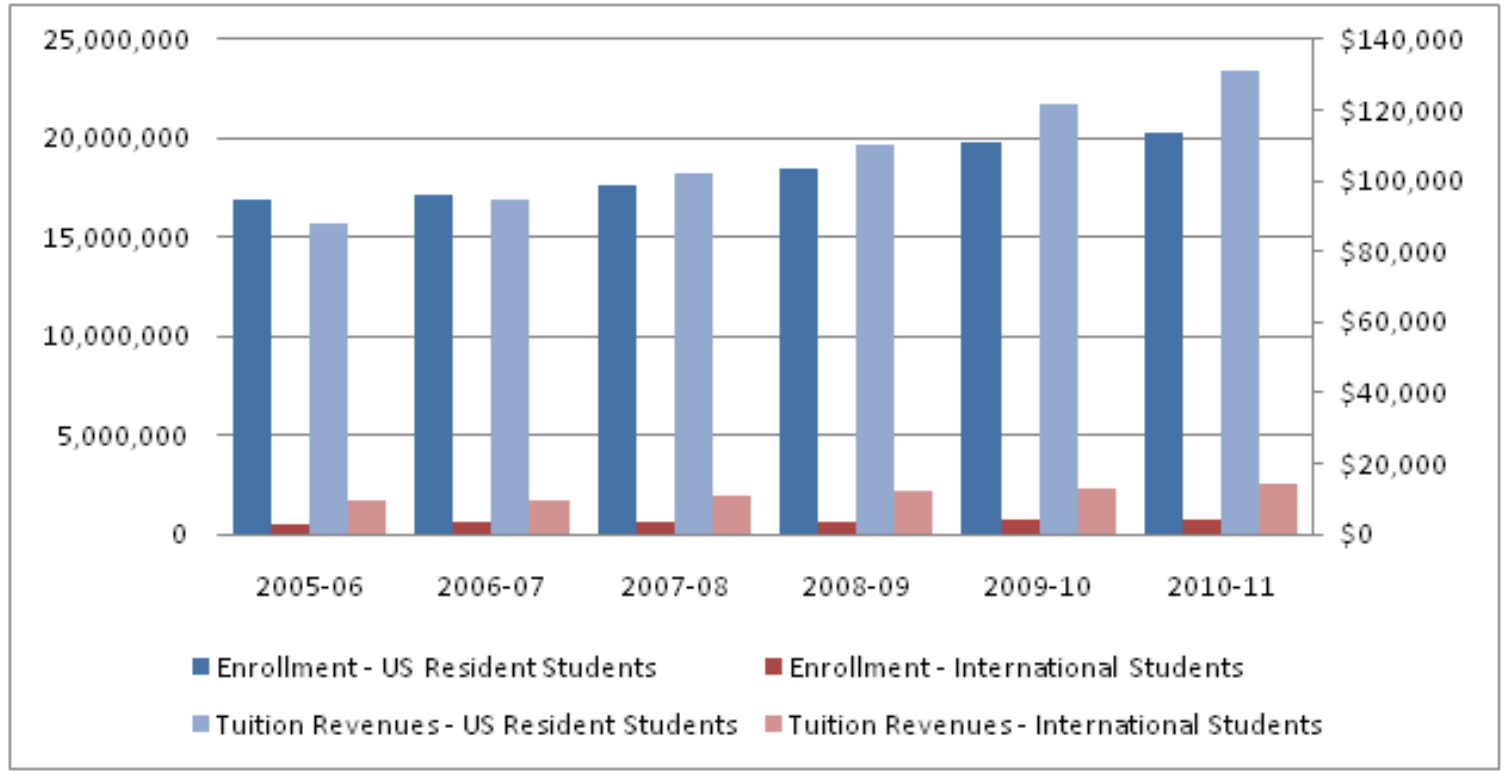

Note: Enrollment variables use the left axis while the tuition revenues use the right axis. The data for this graph is obtained from the annual Digest of Education Statistics reports by the National Center for Education Statistics (NCES) ${ }^{2}$ from 2005 to 2011; and the annual Economic Benefits of International Education to the U.S. Economy reports by NAFSA: Association of International Educators from 2005 to 2011.

Many universities in the U.S. are also facing fiscal challenges. The financial support from the federal and state governments to general operating expenses of the public education sector in the US fell from $\$ 87.4$ billion in 2011 to $\$ 81.2$ billion in 
2012 , while for the same time period the net tuition revenue increased from $\$ 54.7$ billion to $\$ 59.9$ billion. On the other hand, the educational appropriations per student fell to $\$ 5,906$ in 2012 despite stable enrollment growth, the lowest amount in 25 years since 1987 (State Higher Education Executive Officers 2013). As the financial support from state and local governments to public colleges and universities dwindled since the economic crisis in 2008, the share of tuition revenues to cover the expenditures of public institutions has increased. After the recession, coupled with cuts in government funding, many public universities across the country increased published tuition fees to compensate the decline in government support (Oliff et al. 2013). Therefore many institutions now depend on formal budgeting methods and allocation techniques to optimize their scarce resources. At the same time, understanding how various university-level characteristics affect international enrollment may allow universities' administrators and policymakers to formulate better strategies to achieve an optimal enrollment ratio among students of different residential status and a sound financial management.

Leslie and Brinkman (1987) suggest that studies of the determinants of enrollment of students are the second most researched area in higher education after studies on rate of return to education. They mentioned that the theory of demand, when applied in higher education, suggests that tuition and fees negatively affect enrollment, financial aids are positively related to enrollment, and tuition and fees charged by competitors positively affect enrollment.

This study uses U.S. data from the Integrated Postsecondary Education Database System (IPEDS) to verify the first two expectations. It is extremely difficult to investigate the last suggestion on the positive relation between tuition and fees charged by competitors and enrollment due to ambiguous submarket definition except for the very top schools. 


\subsection{Literature Review}

This study would contribute to existing literatures on factors affecting higher education choices among international students. While there are several micro- and macro-levels studies of international student mobility ${ }^{3}$, this analysis focuses on the university-level characteristics which seem to have been ignored in the economics of education literature.

There is a vast amount of literature available on student price response. Price affects student demand through two main channels; either through change in tuition and fees or through change in financial aids. One of the earliest attempts to construct price elasticity of education demand is by Funk (1972), where he used tuition and enrollment data of undergraduate students at U.S. private universities from 1959 through 1970 and found that education demand was inelastic. In that analysis, he used enrollment as the dependent variable and average tuition fees as the price variable. To separate the tuition effect from the non-tuition effects, he included time dummies in the linear regression to control for the non-tuition variables.

Jackson and Weathersby (1975) review seven empirical studies on the impact of price changes on individual demand for higher education. All seven papers in the review show that attendance cost negatively affects enrollment, although the size of the impact is very small. They find that a $\$ 100$ increase in tuition and fees is associated with between $0.05 \%$ and $1.46 \%$ decline in enrollment. Similarly, student financial aids significantly stimulate enrollment.

Leslie and Brinkman (1987) mention that there are about 30 empirical studies that analyzed the relationship between price and enrollments, where they provide a

\footnotetext{
${ }^{3}$ Micro-level studies look at various factors affecting individual student's decision to undertake studies at foreign countries, while studies on international student mobility at the aggregate or among countries are referred as macro-level. Li and Bray (2007) refer to study on institution characteristics as meso-level.
} 
thorough review on 25 of them that could be standardized into the student priceresponse coefficient $(\mathrm{SPRC})^{4}$. The data used in these studies span almost 50 years, from 1927 to 1976; and the sample ranges from enrollments at a specific institution to U.S. nationwide student enrollment data. As for price specification, 17 of the studies used tuition and two studies used financial aid. They find a negative relationship between tuition fees and enrollment. In 1988, Leslie and Brinkman (1988) review another 45 empirical studies that analyze the relationship between student financial aid and enrollments, where they found that financial aid positively encourage enrollment as well as retention rate among enrolled students.

St John (1990) finds that SPRC has decreased after the introduction of the Pell Grant program in 1974 to only $0.28 \%$. His sample includes college applicants to all 4-year and 2-year public and private institutions in U.S. from the high school batch of 1982, and he controlled for financial aid and family financial background. He also finds that an increase in financial aids is more effective in encouraging enrollment than a reduction in tuition fees.

Kane (1995) looks at the impact of tuition and aggregate enrollments in public colleges and universities in all 50 states in the U.S. from 1980 to 1992 while controlling for several state characteristics. He finds that tuition negatively affects enrollment, where the impact is more severe at community colleges. A \$ 1000 increase in tuition decreases enrollment at community colleges by $3.5 \%$, while the same increase in tuition at public universities reduces enrollment by only $1.4 \%$.

Heller (1997) performs a thorough review of previous studies on student price response and provides 46 key findings that explain the relationship between tuition, financial aid, students' socio-economic backgrounds, and enrollment. His findings are consistent with earlier studies where tuition fees and enrollment are negatively

\footnotetext{
${ }^{4}$ SPRC measures the percentage change in enrollment for a $\$ 100$ change in tuition.
} 
related. Based on all the studies that he reviewed, Heller suggests that the SPRC rate is between $0.5 \%$ and $1 \%$ across all types of institutions. Student financial aid is positively related to enrollment. Using the National Longitudinal Survey of Youth during the periods before and after the elimination of the Social Security Student Benefit Program in 1982, Dynarski (2003) finds that financial aid positively affects enrollment, where every $\$ 1000$ increase in benefits is expected to induce a $3.6 \%$ increase in enrollment.

There are several studies that analyzed the price effect on enrollment of students in institutes of higher education of other countries. In Canada, there are mixed results on the relationship between tuition and enrollment. Using data from universities across Canada between 1975 and 1993 while controlling for provincial differences and parental income level, Christofides et al. (2001) find that tuition is not a relevant determinant of enrollment. However Johnson and Rahman (2005) find that tuition negatively affects enrollment when provincial differences are controlled. Coelli (2009) looks at the impact of changes in tuition on enrollment of students based on family financial background in Canada after there was a major change in tuition structure across Canada in the 1990s and found that tuition increases correspond with lower enrollment. A more recent study on the impact of cost on university selection in Ontario from 1994 through 2005 by Dooley et al. (2012) finds no relationship between net cost and enrollment of high quality students. However these studies only look at the enrollment of Canadian students and not international students. From the United Kingdom, Soo and Elliott (2010) look at factors that affect the choice of universities by international undergraduate applicants. Using data from 2002 to 2007 of 97 universities, they find that tuition may affect the decision of some students but this relationship is suggested to be nonlinear. They also find that university ranking, as a measure of quality, positively affects applications of international students. 
Altbach (1991) looks into various factors that influence the decision to study overseas, where the foreign university's prestige level is listed as one of the pull factors. While the U.S. competes with other countries to attract international students, institutions in the U.S. compete among themselves for high quality and self-funded international students. A study by Mazzarol and Soutar (2002) from students in China, India, Indonesia and Taiwan listed the reputation of the institution as the most significant factor to motivate international students to enroll. Dreher and Poutvaara (2005) analyze the impact of student flows into the U.S. on the immigration pattern between 1971 and 2001. Using panel data of 78 countries, they find that the existing stock of international students significantly encourages migration from the same country of origin.

The NAFSA: Association of International Educators (NAFSA) uses data from Open Doors to provide its annual reports of international student contributions to the U.S. economy at the national and state levels. The Institute of International Education, through its publication Open Doors, provides comprehensive information on international students in the U.S. since the academic year 1954-55. While the NAFSA reports on the aggregate economic contribution of international students are useful for policymakers at the national and state levels to implement policies that attract international students, they do not provide information of the economic contribution of international students to each institution.

Although there have been long lists of studies on student price response, almost all of these studies look at an individual student facing enrollment decisions based on cost and benefit analysis under a utility maximization set up and rely on survey methods or experimental case study methodology. While these studies would be helpful to evaluate and formulate the effect of various price and financial aid policies on the level and composition of aggregate enrollments, they are not very useful to an individual 
institution that tries to optimally set its tuition and other characteristics that are within its own control. Furthermore, all of these studies look into the relationship between cost of education and the enrollment of home students. Compared to previous analyses, this study intends to investigate factors determining enrollments of international students at U.S. universities using university level characteristics based on non-experimental data.

\subsection{Model}

This paper shares some similarities with two other studies: Kane (1995) and Soo and Elliott (2010). Kane (1995) analyzes changes in tuition and enrollment in public colleges and universities in the U.S. while controlling for state-level characteristics such as state level of unemployment and state financial aid spending per capita, while Soo and Elliott (2010) look at the demand for U.K. higher education among international students. Compared with Funk (1972) that used time dummies to control for nontuition variables, Soo and Elliott (2010) included several university-level variables in their regression model.

The model specification of this paper is similar to Soo and Elliott (2010) where university-level characteristics are controlled, while the theoretical foundation of this work is influenced by the study on supply of enrollments in the economic model of university behavior developed by Garvin (1980). Garvin (1980) views university as a unitary actor that maximizes a well-defined utility function which is positively affected by prestige level, enrollment and quality level of students. In that model, enrollment of students is formalized as a function of several variables: number of faculty, change in tuition, control type ${ }^{5}$, previous prestige level and change in college-age population

\footnotetext{
${ }^{5}$ Control type refers to the status of the university as a public or private institution.
} 
in the state.

There are several other studies that assumed university as a utility-maximizing entity. Ehrenberg and Sherman (1984) assume that university derives utility from the quality level of enrolled students. The utility derived depends on different categories of enrolled students and it declines as more students from the same category are admitted.

Another study on the supply of enrollments in higher education is by Coates and Humphreys (2002), where university administrators act as bureaucrats who maximize their utility which depends on enrollment level, number and quality of faculty, other characteristics of the institution as well as the income level of the administrators. They analyzed the model in two different setups. In the first case, the administrators act as price-takers that could only manage enrollments while tuition is regulated by the authority. In the second case, the administrators act as price-setters. Enrollment of students is now a function of tuition, government appropriation, and operational costs of university such as faculty salary and maintenance cost.

\subsection{Data}

The sample used in this study consists of 116 universities from 2003 to $2011^{6}$.

The model specification for this study is largely influenced by the economic model of university behavior proposed by Garvin (1980) and the empirical model used by Soo and Elliott (2010). Enrollment at any specific university can be seen as a good that depends on its price, quality and other factors.

\footnotetext{
${ }^{6}$ The sample period starts at 2003 since the Academic Ranking of World Universities (ARWU) rank variable, used as a proxy for prestige and quality, was first published in 2003. Throughout the 2003-2011, there are 116 U.S. universities that are ranked consistently. For a complete list of universities included in the sample, see Appendix A.1 on page 197.
} 
The main equation to be estimated is taken from Soo and Elliott (2010) with modifications:

$$
Y_{i t}=\alpha_{i}+\gamma_{t}+\beta_{1} P_{i t}+\beta_{2} Q_{i t}+\beta_{3} X_{i t}+\beta_{4} Z_{i}+\epsilon_{i t}
$$

where $Y_{i t}$ is the number of international students enrollment, $\alpha_{i}$ is the university level effect, $\gamma_{t}$ is the time effect, $P_{i t}$ is the tuition and fees charged to international students, $Q_{i t}$ is a vector of the university's level of prestige and quality of education offered, $X_{i t}$ is a vector of time-varying variables, $Z_{i}$ is a vector of time-invariant variables, and $\epsilon_{i t}$ is an error term.

In order to estimate equation (2.1), four categories of variables are used. The selection of these variables is influenced mainly by Garvin's (1980) argument that universities compete in different submarkets that are confined to geography and quality, and Soo and Elliott's (2010) suggestion that price and popularity of university among enrolled students are important determinants of choice by prospective international students.

\subsubsection{Enrollment}

The official fall term number of enrollment of full time, first time, first-year, nonresident alien undergraduate students is used as the dependent variable. The U.S. Department of State defines a non-resident alien as any person who is not a U.S. citizen and holds a temporary visa without the right to stay permanently in the U.S. The non-resident alien students are not eligible for any government financial aid. To keep things simple, the term international student is used instead of non-resident alien student in this paper ${ }^{7}$. There are several reasons why this variable is used.

\footnotetext{
${ }^{7}$ The term 'home student' is used to refer to a U.S. resident student.
} 
The first time students better reflect the factors that influence the demand decision made by the first year students. These first time students take many institutional characteristics into consideration when applying and before finally choosing to enroll in a specific university. The institutional characteristics affect students' decisions in three stages: application, reply to admission offer, and enrollment. Any student may make many applications and may receive multiple admission offers, but the student can only be enrolled in one specific institution. Students will compare institutional characteristics several times in the process, and in the end the most important consideration is made at the enrollment decision. Therefore institutional characteristics have the most important impact at the enrollment stage.

The fall term is the official enrollment term in the U.S. and students who are enrolled in fall terms face the same application to enrollment process. Usually universities accept students' enrollment during other terms on special conditions. First time, first-year undergraduate students who follow the normal application procedures are enrolled in fall term. Therefore using the fall term enrollment figures in the analysis ensures the samples are derived from the same cohort. Other studies on international students that use fall term enrollment include the annual reports on economic benefit of international students prepared by NAFSA. There are also a few more reasons why enrollment figures are used as the dependent variable.

Jackson and Weathersby (1975) argue that it is best to use enrollment data to capture cost effects since application data may not reflect the true impact of cost. Potential students usually apply to more than one university, and the fees charged by those universities may be either more expensive or cheaper than the university in which students are enrolled.

However, application data may be able to reflect the actual enrollment demand by international students than enrollment data since the latter is subject to supply and 
capacity limits faced by universities. The data for international students in the IPEDS database is available at the enrollment level only. As for applications and admissions data, no distinction is made for international students. At these two levels, only total number of applications and total number of admissions are provided. Therefore the interpretation of the price effects estimates from this study should be regarded as conditional on the supply constraints of universities. The results should be interpreted as the impact of price on enrollment of new international students only and not as the absolute impact of price of education on demand. There are two dependent variables used in this study; the enrollment of first year, first time, full time, undergraduate male international students, MISTD; and its female counterpart, FISTD. The total enrollment is labelled as TISTD.

\subsubsection{Tuition and Fees}

The officially published tuition and required fees for international students are used as price variables, PTUITION. The information on published fees is available to applicants during the application period prior to the official enrollment in the fall semester.

Most U.S. public universities practice price discrimination based on students' residential status. At these institutions, there are three different tuition and fees structures: in-district, in-state, and out-of-state. Universities that practice price discrimination impose out-of-state tuition fees on international students and U.S. students who are not residents of the state where the university is located. Private universities usually charge the same fees to all students regardless of their residential status.

Many universities separate fees into two main components: tuition fees and re-

quired fees. Required fees are charges other than tuition where all students are 
required to pay except those who obtain special exceptions by universities' administrators. However, required fees exclude other non-university related expenses such as accommodation, transportation, entertainment, books and supplies. Very few universities charge single comprehensive fees that cover both tuition and required fees. To keep things simple, all tuition and fees that are related to international students are combined into one single tuition and fees variable since enrolled students need to pay both tuition and required fees. To keep the discussion simple, the published out-of-state tuition and fees shall be referred to as 'published tuition' in the remaining parts of this analysis.

All of the universities in the sample do not discriminate between in-district and in-state students ${ }^{8}$, while 77 universities (about $66.38 \%$ of the sample) in the sample are public universities that charge higher fees for out-of-state students than in-state students.

\subsubsection{Prestige and Quality}

To measure the quality of education provided at each university and its prestige level, two proxy variables are used: admission tests scores $(S A T A C T)$ of each university and its ranking.

The quality of education and academic reputation are two important elements that guide prospective students in the selection of postsecondary institutions. The academic standards of an institution have a large influence on the returns of education provided and thus affect the attendance value. Previous works such as Radner and Miller (1970), and Fuller et al. (1982) find that the quality of institution plays a significantly positive role in students' selection of universities.

\footnotetext{
${ }^{8}$ Usually community colleges discriminate between in-district students and out-of-district students, while public universities discriminate between in-state students and out-of-state students only.
} 
Admission tests scores relay to potential students information on the average academic level of current students at the university. The scores also give a broad picture of what is the expected level of academic effort required to complete the program. On the other hand, universities use admission tests scores to screen out applicants and determine the overall level of academic quality of accepted students. Universities administrators are able to use admission tests scores as a tool to maintain the overall quality of students with respect to their size and financial constraints.

For admission purposes, most universities consider a student's score in either the Scholastic Assessment Test (SAT) or the American College Testing (ACT). The use of admission tests scores is motivated by Spies (1973) and Kohn et al. (1976) where SAT scores are used as measure of quality of education offered by universities. Radner and Miller (1970), Fuller et al. (1982), and Savoca (1990) use the average SAT scores of enrolled students as a measure of institutional quality while individual SAT scores are used as a proxy of the student's ability. Ehrenberg and Sherman (1984) find that enrollment significantly depends on college quality measured by average freshmen SAT scores.

SAT and ACT have been competing with each other to be the leading admission test. Since both tests are accepted by universities, the ACT Composite 25th percentile score (ACTCM25) of students who gained admission into university is used as a proxy for quality of education of that university. The ACT composite test result is preferable to the SAT result since the former is the reported average from all three ACT components (mathematics, reading and writing) while there is no such report for SAT scores. There are few universities that provide SAT scores instead of ACT scores, but this issue is resolved by using the ACT-SAT concordance table designed by administrators of both tests to find comparable scores of both tests ${ }^{9}$.

${ }^{9}$ The ACT-SAT Concordance Tables and Guidelines are available at


To enhance the control for quality of education in the model, ranking is included as additional proxy for quality of education. Although ranking may not necessarily represent the actual level of education quality, its ordinal nature allows comparison of education quality between universities. Regardless of the critics on ranking methodology, Rauhvargers (2011) argues that the presence of ranking has caused universities to directly or indirectly improve their performance. Furthermore, ranking is the best available indicator of quality of education offered by universities. Altbach (2006) points out that it is less problematic to rank universities within a country compared to a world ranking due to several factors such as language barriers that affect the number of citations. Limitations on international mobility of students and varying education systems across countries would have no impact when ranking universities at the national level. Altbach (2011) further argues that despite serious questions raised on the validity of ranking methodologies, the published rankings nonetheless remain influential among stakeholders of higher education such as potential customers, academic decision makers and government officials. Bastedo and Bowman (2010) similarly argue that prestige is one of the most important factors in higher education organization performance evaluation, where rankings have become increasingly acceptable to all stakeholders in the sector and nearly impossible to be ignored.

Monks and Ehrenberg (1999) specifically analyze the impact of USNWR rankings on selective private institutions in the U.S. and find that changes in USNWR substantially influence the admission outcomes and pricing policies of universities. Universities respond to an increase in rank by decreasing the admission rates, increasing the average SAT scores, and providing less financial aid. Meredith (2004) later expands the analysis by including public colleges into the sample set and finds http://www.act.org/aap/concordance. Among previous studies that standardized different test scores are Radner and Miller (1970) and Volkwein and Sweitzer (2006). 
that admission outcomes are responsive to changes in rankings. Other studies such as Griffith and Rask (2007), and Bowman and Bastedo (2009) also find that improvement in USNWR rankings significantly increase admission.

Using ranking as measure of quality is motivated by Soo and Elliott (2010) where they used Times Higher Education rankings (THE) as a measure of quality of education for UK universities. Furthermore, Garvin (1980) argues that prestige is more important than the actual quality of an institution since prospective students refer to prestige when making enrollment decisions. According to him, prestige depends on the research output of faculty members, which is the main element in computation of university ranking. Although prestige and quality are closely related, there is a subtle difference between the two. Prestige reflects the perceptions of outsiders on the characteristics of universities, while quality is an objective measure of the same attributes (Garvin 1980).

The Academic Ranking of World Universities (ARWU) is used as a measure of prestige. ARWU is an annual ranking of universities around the world published by Shanghai Jiao Tong University since 2003. Since 2009, the publication of ARWU is managed by Shanghai Ranking Consultancy. This measure of prestige is expected to improve the control for quality in the estimation ${ }^{10}$. Table 2.1 presents the sample distribution based on the Carnegie Commission Classification 2000.

\subsubsection{Other Factors}

Several other factors are included in the model to control for university level effects that may affect the enrollment of international students. Besides quality of institution, Garvin (1980) also states that competition between universities is confined

\footnotetext{
${ }^{10}$ The original analysis of this study also used two other rank scores: the Quacquarelli-Symonds ranking (QS) and the U.S. News and World Reports ranking (USNWR).
} 
Table 2.1: Sample distribution based on the Carnegie Commission Classification 2000

\begin{tabular}{lc}
\hline \hline Carnegie Commission Classification 2000 & Universities \\
\hline Doctoral/Research Univ.: Extensive & 109 \\
Offer a wide range of baccalaureate programs and & \\
committed to graduate education through the doc- & \\
torate. Award 50 or more doctoral degrees per \\
year across at least 15 disciplines. \\
\hline $\begin{array}{l}\text { Doctoral/Research Univ.: Intensive } \\
\text { Offer a wide range of baccalaureate programs and }\end{array}$ \\
committed to graduate education through the doc- \\
torate. Award at least 10 doctoral degrees per \\
year across three or more disciplines, or at least \\
20 doctoral degrees per year overall. \\
\hline Total \\
\hline \hline
\end{tabular}

Note: The definition of each category is taken from IPEDS.

to geographical proximity of universities and prospective students. Universities that are more service-oriented within the same geographical submarket compete with each other to draw students from a limited pool defined by state or regional boundaries. These universities prefer larger size of enrollment more than higher quality of students. Similarly, students with lower academic quality prefer to attend local universities for various reasons such as to save cost of transportation and accommodation, and to keep hometown friendship.

Elite universities are more concerned with prestige and students' quality compared to enrollment size, and therefore these universities compete in the larger regional or nationwide market. At the same time, students with higher academic quality ignore geographical factors when applying to faraway universities with higher prestige. Therefore regional dummies are introduced to control for this submarket limit. There are eight geographic regions used in IPEDS, and Table 2.2 shows the distribution of geographic regions in the sample.

Universities that are known to be generous with financial aid to students are able to attract more potential students to consider applying to these universities. Jackson 
Table 2.2: Geographic distribution of universities in the sample

\begin{tabular}{lcc}
\hline \hline States & Region & Universities \\
\hline CT ME MA NH RI VT & New England & 15 \\
\hline DE DC MD NJ NY PA & Mid East & 23 \\
\hline IL IN MI OH WI & Great Lakes & 14 \\
\hline IA KS MN MO NE ND & Plains & 8 \\
SD & & \\
\hline AL AR FL GA KY LA & Southeast & 22 \\
MS NC SC TN VA WV & & \\
\hline AZ NM OK TX & Southwest & 9 \\
\hline CO ID MT UT WY & Rocky Mountains & 7 \\
\hline AK CA HI NV OR WA & Far West & 18 \\
\hline Total & & 116 \\
\hline \hline
\end{tabular}

The geographic classifications are taken from IPEDS.

and Weathersby (1975) find out that both low tuition and high grant aid increases enrollment significantly. Leslie and Brinkman (1987) when introducing theory of demand for higher education, explained that student aid can be regarded as either reducing net prices or increasing student money income. Financial aid affects enrollment from either changes in total aid amount or changes in number of recipients. Higher amount of financial aid offsets the effect of education cost while larger number of recipients means higher probability for a student to receive any amount of financial aid. In order to capture the effect of universities' financial aid, the average financial aid grant awarded by universities per enrolled student, AVAID, is included in Equation 2.11.

Financial aid grant offered by universities is used instead of federal or state aids since the former is under the purview of university's administrators. Compared to federal and state aids that are awarded based on students' financial needs and resi-

\footnotetext{
${ }^{11}$ The average amount of university's financial aid received per recipient is reported in IPEDS. To use this variable may overstate the effect of financial aid since not all students receive financial aid. Therefore the total amount of university's financial aid divided by total students enrolled is used instead.
} 
dential status, institutional aid is usually awarded based on academic merit that is closely related to university characteristics. The use of grant as an explanatory variable is motivated by Moore et al. (1991) findings which suggest that grants are the most effective form of student aid to influence enrollment to selective colleges while loan and work study offers have no significant effect on enrollment. Other more recent studies such as Dynarski (2003) also finds that financial aids have a significantly positive effect on enrollments.

To control for the overall popularity of the university among students, total number of undergraduate students from different residential categories enrolled in the previous academic year is used. This popularity measure is motivated by Soo and Elliott (2010). Total number of full time undergraduate home students from U.S. enrolled, THSTD, is used as measure of popularity of a university among U.S. students. Total male home students are labelled as $M H S T D$, while total female home students are labelled as FHSTD.

Since home students and international students may have differences in taste and preference, total number of full time international senior undergraduate students enrolled, SISTD ${ }^{12}$, is used to control for the popularity of a university among international students. Universities with higher international students' presence are more likely to attract a large number of international students. Many potential international students take into consideration the recommendations and advise from their friends who are already studying in the U.S. when choosing a university. It is important to note that first year students and senior students respond differently to changes in tuition. Continuing students, having already started their investment in education are less responsive to price changes (Leslie and Brinkman 1988). First-time freshmen are found to be more sensitive to changes in tuition at 4-year institutions

\footnotetext{
${ }^{12}$ Senior undergraduate students refer to students who are not in the first year level of study.
} 
compared to upperclassmen (Heller 1998) ${ }^{13}$. The inclusion of enrollment of home students and senior international students in the analysis also reflect the supply and capacity constraints faced by universities, which limits the space availability for new international students.

Table 2.3: Descriptive statistics

\begin{tabular}{lcrrrr}
\hline \hline Variable & Obs & \multicolumn{1}{c}{ Mean } & St. Dev. & \multicolumn{1}{c}{ Min } & \multicolumn{1}{c}{ Max } \\
\hline MISTD & 1044 & 63.51 & 76.64 & 0.00 & 890.00 \\
FISTD & 1044 & 51.55 & 59.28 & 0.00 & 574.00 \\
PTUITION (in thousand) & 1044 & 24.55 & 8.92 & 3.15 & 45.29 \\
AVAID (in thousand) & 1044 & 1.23 & 1.30 & 0.04 & 6.27 \\
ARWU & 1044 & 61.36 & 37.06 & 1.00 & 155.00 \\
SATACT & 1044 & 24.25 & 3.50 & 15.00 & 34.00 \\
SISTD & 1044 & 455.80 & 390.65 & 0.00 & 3102.00 \\
HMSTD & 1044 & 15402.28 & 8491.55 & 795.00 & 48679.00 \\
\hline \hline
\end{tabular}

The year dummy variables are included in the model to control for time-specific shocks such as changes in university enrollment environment and exchange rate fluctuations that affect the performance of all universities equally. Global events such as a fall in the value of dollar against other currencies or a strong economic performance among source countries would make it more affordable for international students to enroll in U.S. universities and this would translate into significantly positive year dummy. Table 2.3 reports descriptive statistics of the sample.

\subsection{Methodology}

The simplest way to estimate equation (2.1) is using ordinary least squares (OLS) by pooling all observations across universities and time. However OLS will ignore the panel feature of the data and produce invalid results if the unobserved university-

\footnotetext{
${ }^{13} \mathrm{An}$ endogeneity test will be implemented to check for the possibility of endogeneity between first time and senior international students.
} 
specific effects are correlated with the included explanatory variables (Kennedy 2003). Baltagi (2008) advises researchers not to simply stop at Hausman test results between fixed effects (FE) and random effects (RE), but to consider the Hausman and Taylor (1981) (HT) estimator as a possible alternative ${ }^{14}$. Following Soo and Elliott (2010), equation (2.1) for male and female students is estimated separately to investigate differences in preferences across gender. A dynamic specification using Arellano-Bond two-step system GMM is also considered to investigate the possibility that enrollment of new international students is affected by its past values.

\subsubsection{Model Selection Criteria}

The model selection method follows the procedure proposed by Baltagi et al. (2003), where Hausman (1978) specification tests are used to choose the best panel data estimator for this analysis. The first step is to conduct a Hausman test between the FE estimator and the RE estimator. If the test fails to reject the null hypothesis, then there are no systematic differences between the two estimators and the RE estimator is preferred. It can be safely assumed that the unobserved university level effects are not correlated with the explanatory variables. However if the test rejects the null hypothesis, then a second Hausman test is conducted between the FE estimator and the HT estimator.

For the second Hausman test, if the null hypothesis is not rejected, then the HT estimator is preferred to the FE estimator. If the test rejects the null hypothesis then the FE estimator is chosen over the HT estimator. Another feature of the HT

\footnotetext{
${ }^{14} \mathrm{HT}$ allows for some explanatory variables to be correlated with the unobserved individual effects and hence can be considered as a compromise between FE and RE that imposes a more strict restriction on correlation between unobserved individual effects and explanatory variables. FE assumes that all explanatory variables are potentially correlated with the unobserved individual effects whereas RE assumes that all explanatory variables are not correlated with the unobserved individual effects.
} 
estimator that makes it more attractive than the FE estimator is that through $\mathrm{HT}$ it is possible to estimate the effects of time-invariant variables such as the regional location of the university.

To control for within university correlation and heteroskedasticity in the error term, the standard errors in all estimations are clustered by university. As the error term is no longer independent and identically distributed (iid), the ordinary Hausman test is no longer valid. Cameron and Trivedi (2005) propose a consistent estimate of variance matrix for heteroskedastic error term by bootstrapping to produce a panelrobust Hausman test statistic as follows:

$$
H^{*}=\left(\tilde{\beta}_{1, R E}-\hat{\beta}_{1, F E}\right)^{\prime}\left[\hat{V}_{\text {Boot }}\left(\tilde{\beta}_{1, R E}-\hat{\beta}_{1, F E}\right)\right]^{-1}\left(\tilde{\beta}_{1, R E}-\hat{\beta}_{1, F E}\right)
$$

where

$$
\hat{V}_{\text {Boot }}\left(\tilde{\beta}_{1, R E}-\hat{\beta}_{1, F E}\right)=\frac{1}{B-1} \sum_{b=1}^{B}\left(\hat{\delta}_{b}-\overline{\hat{\delta}}\right)\left(\hat{\delta}_{b}-\overline{\hat{\delta}}\right)^{\prime}
$$

and

$$
\hat{\delta}=\tilde{\beta}_{1, R E}-\hat{\beta}_{1, F E}
$$

\subsubsection{Endogeneity of Published Tuition with International Students}

There is a possibility that published tuition may be endogenous to enrollment of international students. Previous studies such as Savoca (1990) and Soo and Elliott (2010) argue that the influence of price on enrollment should not be simply regarded as exogenous. While the in-state tuition of public universities is heavily regulated, their out-of-state tuition is not, and many universities potentially view international students as a vital part of their financial wellbeing (Choudaha and Chang 2012). Pri- 
vate universities that charge the same tuition structure to all students are also not bound to such price regulations. Hence university administration may use international students' demand conditions to adjust its out-of-state tuition. Following Soo and Elliott's (2010) suggestion to inspect for endogeneity of enrollment to published out-of-state tuition, a pooled Ordinary Least Squares (OLS) model and a Two Stage Least Squares (2SLS) model are estimated where published in-state tuition, admission rate and type of control ${ }^{15}$ are used as instruments for the published out-of-state tuition. The results of these two estimations will then be compared using Hausman (1978) specification test. The basic idea of the Hausman test between OLS and 2SLS is that if published tuition is exogenous, then there should not be a systematic difference between OLS and 2SLS.

This paragraph discusses the choice of instruments used in the endogeneity test. The published in-state tuition is the tuition charged on in-state students, and it is not directly related to international students ${ }^{16}$. Admission rate is also indirectly related to the enrollments of international students. A higher admission rate may not necessarily translates into higher enrollment since potential students usually send applications and receive admission offers from more than one university. Furthermore, the admission rate is a ratio of admission offers and total number of applications, where a university with very low admission rate is usually regarded as a university with very high quality level due to the huge number of applications by both home and international students. The status of a university as either a public or a private institution may be important to home students since they would be eligible for

\footnotetext{
${ }^{15}$ Type of control refers to the status of a university as either a public or private institution. The control type dummy equals one for public universities.

${ }^{16}$ There is a possibility of indirect effect from cross subsidization between in-state and out-of-state tuitions. Besides international students, U.S. students attending universities outside their states of residence are also required to pay out-of-state tuition. This should not invalidate the choice of in-state tuition as an instrument for out-of-state tuition.
} 
lower in-state tuition if they are enrolled at universities in their home state. However international students are required to pay the higher out-of-state tuition at public universities. Therefore there is no direct relationship between the status of a university and the enrollment of international students.

In order to get a more efficient result, a two-step Generalized Method of Moments (2SGMM) model is estimated with standard errors clustered by university. The standard errors are clustered by university to allow for correlation of errors within individual universities over time. Baum et al. (2003) suggest that for clustered regression, Generalized Method of Moments (GMM) estimate produces efficient and consistent coefficient estimates and diagnostic tests compared to standard instrumental variable (IV) estimates. Several identification tests are implemented using the 2SGMM model. Table A.1 in Appendix A.2 shows results from the 2SGMM estimates and several identification test statistics. The under-identification LM test shows that both male and female models in the sample are identified. The weak identification Wald test suggests that the published in-state tuition, admission rate and control type are strongly correlated with the published out-of-state tuition. However the Hansen $J$ tests of over-identification suggest that the chosen instruments are appropriate for the female model only.

The Hausman test compares 2SGMM estimates with OLS estimates. Since the standard errors are clustered by university, the Hausman test statistics are produced from the bootstrapping method as Cameron and Trivedi (2005) suggest. The result from the Hausman tests indicates that there is no systematic differences in the male model. However, the Hausman test statistic for the female model is large such that the null hypothesis of no systematic differences is rejected. These suggest that there is no endogeneity problem in the male model but it may be present in the female model. 
To further investigate the orthogonality of published tuition, the difference-inSargan-Hansen test or $C$-test for exogeneity suggested by Eichenbaum et al. (1988) is used. Baum et al. (2003) mention that unlike the Hausman chi-square statistic, the $C$ statistic is guaranteed to be nonnegative if both Hansen-Sargan statistics are derived using the same error variance estimated from the restricted IV regression. The $C$-test results presented at the bottom of Table 14 in Appendix 2 confirm the Hausman test results that published tuition could be treated as exogenous to enrollment at $5 \%$ level of significance for male and female models in the sample.

Since there is not enough evidence to treat published tuition as endogenous to enrollment, there is no need to use 2SLS to estimate equation (2.1) for both the male and female models in the sample.

\subsubsection{Dynamic Specification}

To investigate the possibility that enrollment of new international students is affected by previous enrollment, the following model is estimated:

$$
Y_{i t}=\alpha_{i}+\gamma_{t}+\phi Y_{i, t-1}+\beta_{1} P_{i t}+\beta_{2} Q_{i t}+\beta_{3} X_{i t}+\beta_{4} Z_{i}+\epsilon_{i t}
$$

where lagged enrollment is added as an explanatory variable.

Since the presence of lagged enrollment causes autocorrelation, equation (2.5) is transformed into:

$$
\Delta Y_{i t}=\Delta \gamma_{t}+\phi \Delta Y_{i, t-1}+\beta_{1} \Delta P_{i t}+\beta_{2} \Delta Q_{i t}+\beta_{3} \Delta X_{i t}+\Delta \epsilon_{i t}
$$

Equation (2.6) is then estimated using the augmented Arellano-Bond dynamic panel system GMM method as suggested by Roodman (2009). 
The augmented system GMM estimator uses equation (2.5) to produce a system of two equations: the first equation in differences and the second equation in levels. Additional instruments are obtained from the levels equation and this usually increases the efficiency of the estimation. To allow for heterokedasticity within each institution, two-step augmented system GMM is used with Windmeijer-corrected standard errors. If the first lag coefficient is significant, this process is repeated with additional lags to find the extent of past enrollments influence on current enrollment. Since the sample period is only from 2003 to 2011, the estimated coefficients from the dynamic specification represent only their short run effects on enrollment. The analysis on the long run effects of the explanatory variables in the dynamic model may be possible with longer data period. For example, the dynamic model could be used to estimate the impact of published tuition on future enrollment of international students in the long run. Firstly, from Equation 2.5:

$$
\left.\frac{\partial Y_{i t}}{\partial P_{i t}}\right|_{S R}=\beta_{1}
$$

and

$$
Y_{i, t+1}=\alpha_{i}+\gamma_{t+1}+\phi Y_{i, t}+\beta_{1} P_{i, t+1}+\beta_{2} Q_{i, t+1}+\beta_{3} X_{i, t+1}+\beta_{4} Z_{i}+\epsilon_{i, t+1}
$$

From Equation 2.8, the long run effect of published tuition on enrollment of new international students is:

$$
\left.\frac{\partial Y_{i, t+1}}{\partial P_{i t}}\right|_{L R}=\frac{\partial Y_{i, t+1}}{\partial Y_{i t}} \cdot \frac{\partial Y_{i t}}{\partial P_{i t}}=\phi \cdot \beta_{1}
$$




\subsection{Results}

Table 2.4 reports the correlations between the number of new international students and the new home students enrolled in the current academic year based on gender. All enrollment variables are positively correlated with each other. Male and female students of the same residential status are highly correlated. This suggests that students of the same origin take the same factors into consideration when deciding where to enroll. However the correlations across residential status for the same gender are relatively low. This signals that university-level factors may not have the same impact on international students and home students.

Table 2.4: Correlations among enrollments of new (first time, first year, full time, undergraduate) students

\begin{tabular}{lcccc}
\hline \hline & \multicolumn{2}{c}{ International } & \multicolumn{2}{c}{ Home } \\
& Male & Female & Male & Female \\
\hline International Male & 1.0000 & & & \\
International Female & 0.8923 & 1.0000 & & \\
Home Male & 0.3693 & 0.2452 & 1.0000 & \\
Home Female & 0.2679 & 0.2243 & 0.9208 & 1.0000 \\
\hline \hline
\end{tabular}

Table 2.5 shows correlation between the number of new international students enrolled and several explanatory variables used in the analysis. Surprisingly, published tuition is positively correlated with enrollment of new international students, which seems to contradict the usual prediction in demand theory. The published tuition is also positively correlated with senior international students.

The average university's financial aid is positively correlated with enrollment of new international students but still negatively correlated with enrollment of senior international students and home students. This is another contradicting finding since financial aid is expected to encourage enrollment of students.

The ranking variable, ARWU, is positively correlated with the enrollment of new 
Table 2.5: Correlations among variables

\begin{tabular}{lrrrrrr}
\hline \hline & TISTD & PTUITION & AVAID & ARWU & SATACT & SISTD \\
\hline PTUITION & 0.2714 & 1.0000 & & & & \\
AVAID & 0.0614 & 0.8095 & 1.0000 & & & \\
ARWU & -0.3094 & -0.4157 & -0.2404 & 1.0000 & & \\
SATACT & 0.1774 & 0.7038 & 0.7042 & -0.4810 & 1.0000 & \\
SISTD & 0.8444 & 0.0262 & -0.1380 & -0.2168 & -0.0029 & 1.0000 \\
THSTD & 0.2777 & -0.4553 & -0.6592 & -0.0380 & -0.4379 & 0.4723 \\
\hline \hline
\end{tabular}

and senior international students. At the same time, ARWU ranking is also positively correlated with the enrollment of home students ${ }^{17}$. This suggests that both international and home students prefer to enroll at universities with higher levels of prestige and quality. Besides rank, the 25th percentile score of ACT composite test is also used to proxy for quality of education offered by universities. The admission test score is positively correlated with enrollment of new international students. This suggests that new international students prefer to enroll at universities with higher required admission test score. Since admission test score is used to screen applicants, the correlation between admission test score and senior international students may not have a significant meaning. However the admission test score seem to be negatively correlated with the enrollment of home students. As expected, both ARWU rank and admission test score are positively correlated with published tuition. Higher test scores indicate higher quality of students' intake and contribute to the prestige of the universities among prospective students. Therefore universities with higher quality of students' intake are able to charge higher tuition and attract more international students. Another interesting result is that admission test score is positively correlated with ARWU rank. It is harder to get admission into universities with very high admission tests scores, and more prestigious universities are able to impose higher

\footnotetext{
${ }^{17}$ Note the order of the ranking variables, where a smaller number represents higher prestige and quality.
} 
admission tests scores for admission consideration.

Both total senior international students and total home students enrolled positively affect enrollment of new international students, where the former has a stronger correlation effect. This high correlation suggests that a large presence of international students' community attracts new international students through word of mouth effect and existence of social networks.

The panel-robust Hausman tests ${ }^{18}$ result between fixed effects (FE), random effects (RE) and Hausman-Taylor (HT) estimates is presented in Table 2.6. The first Hausman test compares FE and RE estimates, while the second Hausman test compares FE and HT estimates. At 5\% level of significance, these two Hausman tests result suggest that the FE method is preferred for the male model, while the RE method is preferred for the female model. Since FE is the preferred estimation method for Equation 2.1 for the male model, the time-invariant regional dummies are excluded from the estimation ${ }^{19}$.

Table 2.6: Panel-robust Hausman tests

\begin{tabular}{clrr}
\hline \hline & & Male & Female \\
\hline Test & Degrees of freedom & \multicolumn{2}{c}{14} \\
\hline FE vs RE & Hausman $\chi^{2}$ & 41.56 & 19.74 \\
& $p$-value & 0.00 & 0.14 \\
\hline \multirow{2}{*}{ FE vs HT } & Hausman $\chi^{2}$ & 900.95 & 951.38 \\
& $p$-value & 0.00 & 0.00 \\
\hline \hline
\end{tabular}

The results of regressions of Equation 2.1 are presented in Table 2.7. The regression estimation method used follows the panel-robust Hausman tests result obtained earlier. The standard errors are clustered by university to allow for heteroskedasticity

\footnotetext{
${ }^{18}$ The panel robust Hausman test statistics are computed based on Cameron and Trivedi (2005) suggestion since the standard errors of FE and RE estimates are clustered by university.

${ }^{19}$ Similar results are obtained when ARWU rank is replaced with QS rank and USNWR rank; where the FE method is preferred for all male models while the RE method is preferred for all female models.
} 
and correlation between error terms within university. All regressions include yearly dummies to control for macroeconomic shocks that affect all universities equally. The regional dummies are excluded from FE estimation due to the nature of FE estimation that disallows estimation of time-invariant variables.

Table 2.7: Relationship between enrollment of international students and price

\begin{tabular}{|c|c|c|c|c|c|}
\hline Variable & Male & Female & Variable & Male & Female \\
\hline PTUITION & $\begin{array}{l}-0.0058 \\
(0.0116)\end{array}$ & $\begin{array}{l}0.0275^{* * *} \\
(0.0061)\end{array}$ & SATACT & $\begin{array}{c}0.0133 \\
(0.0098)\end{array}$ & $\begin{array}{c}0.0144 \\
(0.0090)\end{array}$ \\
\hline AVAID & $\begin{array}{l}-0.1249^{* * *} \\
(0.0362)\end{array}$ & $\begin{array}{l}-0.0865^{* *} \\
(0.0359)\end{array}$ & $\begin{array}{l}\text { SISTD } \\
(\text { in } \log )\end{array}$ & $\begin{array}{c}0.7344^{* * *} \\
(0.0760)\end{array}$ & $\begin{array}{c}0.8853^{* * *} \\
(0.0398)\end{array}$ \\
\hline ARWU & $\begin{array}{c}0.0026 \\
(0.0025)\end{array}$ & $\begin{array}{l}-0.0020^{* *} \\
(0.0009)\end{array}$ & $\begin{array}{l}\text { THSTD } \\
(\text { in } \log )\end{array}$ & $\begin{array}{l}-0.4651 \\
(0.3663)\end{array}$ & $\begin{array}{l}-0.0859 \\
(0.0765)\end{array}$ \\
\hline Mid East & & $\begin{array}{l}-0.0867 \\
(0.0950)\end{array}$ & 2004 & $\begin{array}{c}0.0618 \\
(0.0529)\end{array}$ & $\begin{array}{c}0.0046 \\
(0.0553)\end{array}$ \\
\hline G Lakes & & $\begin{array}{l}-0.1592^{*} \\
(0.0957)\end{array}$ & 2005 & $\begin{array}{c}0.1365^{* * *} \\
(0.0498)\end{array}$ & $\begin{array}{c}0.0976^{*} \\
(0.0555)\end{array}$ \\
\hline Plains & & $\begin{array}{l}-0.2975^{* * *} \\
(0.1107)\end{array}$ & 2006 & $\begin{array}{c}0.2997^{* * *} \\
(0.0621)\end{array}$ & $\begin{array}{c}0.1470^{* *} \\
(0.0612)\end{array}$ \\
\hline Southeast & & $\begin{array}{l}-0.3143^{* * *} \\
(0.1068)\end{array}$ & 2007 & $\begin{array}{l}0.4239^{* * *} \\
(0.0819)\end{array}$ & $\begin{array}{l}0.2707^{\text {*** }} \\
(0.0636)\end{array}$ \\
\hline Southwest & & $\begin{array}{l}-0.3085^{* *} \\
(0.1535)\end{array}$ & 2008 & $\begin{array}{l}0.5086^{* * *} \\
(0.0934)\end{array}$ & $\begin{array}{l}0.2841^{\text {*** }} \\
(0.0694)\end{array}$ \\
\hline Rocky M & & $\begin{array}{l}-0.6101^{* * *} \\
(0.1216)\end{array}$ & 2009 & $\begin{array}{l}0.5927^{* * *} \\
(0.1117)\end{array}$ & $\begin{array}{c}0.3161^{\text {*** }} \\
(0.0750)\end{array}$ \\
\hline Far West & & $\begin{array}{l}-0.4072^{\text {*** }} \\
(0.0933)\end{array}$ & 2010 & $\begin{array}{c}0.6397^{* * *} \\
(0.1299)\end{array}$ & $\begin{array}{c}0.1961^{* *} \\
(0.0819)\end{array}$ \\
\hline Constant & $\begin{array}{c}3.2321 \\
(3.5005)\end{array}$ & $\begin{array}{l}-1.5766^{* *} \\
(0.7777)\end{array}$ & 2011 & $\begin{array}{c}0.7078^{* * *} \\
(0.1440)\end{array}$ & $\begin{array}{c}0.2132^{* *} \\
(0.0929)\end{array}$ \\
\hline$R^{2}-$ within & 0.5305 & 0.4582 & Obs & 1038 & 1036 \\
\hline$R^{2}$ - between & 0.5822 & 0.8930 & Method & $\mathrm{FE}$ & $\mathrm{RE}$ \\
\hline$R^{2}-$ overall & 0.5569 & 0.7743 & Univ & \multicolumn{2}{|c|}{116} \\
\hline
\end{tabular}

Dependent variable is ( $\log$ of ) enrollment of new international students Standard errors are clustered by university and shown in parentheses.

* Significant at $10 \% \quad * *$ Significant at $5 \% \quad * * *$ Significant at $1 \%$

Published tuition is significant and positively affects enrollment of international students in the RE estimated female model. In the FE estimated male model, as 
expected published tuition has a negative sign but it is not a significant determinant of enrollment. The different results between the male and the female models may have been caused by the different estimation methods used ${ }^{20}$.

There are several possible explanations for the positive effect of published tuition on enrollment of international students. It is possible that there are some other factors that influence both tuition and enrollments that are omitted from the regressions. Funk (1972) mentioned that it is important to separate the tuition effect from the nontuition effects to determine the price elasticity of education demand since change in non-tuition factors may shift the demand curve and offset the negative effects of price that would be expected from consumer choice theory. Another possible alternative explanation is that published tuition signals the unobservable quality level. Signaling theories suggest that price and quality are positively related, where a high price indicates the high quality of a product (Milgrom and Roberts 1986). In a market with price rivalry among competitors with huge differences of quality levels, signaling through price is sufficient to convey information about the unobserved quality to the consumers while at the same time advertising is not necessary (Fluet and Garella 2002). Given that there are big variations in rankings and admission test score as reported in Table 2.3, the quality gap among universities is huge. The use of price to signal quality to consumers is enhanced if there is no strong competition among sellers in the market (Adriani and Deidda 2011). Garvin (1980) pointed out that since universities compete in different submarkets limited by geography and quality levels, the competition between universities for international students at the national level is weakened by geographical location and ranking differences such that published tuition is regarded as a signal of quality. Therefore it is possible that the negative effects

\footnotetext{
${ }^{20}$ Similar results are observed for the QS and USNWR samples; where published tuition is not significant to male enrollment, and it is significant but positive to female enrollment.
} 
of price, as would be expected from consumer choice theory, have been completely cancelled out by the positive effects from signaling. A similar result has been observed in private liberal arts colleges (Breneman 1994) and among Asian-American first time students enrollment (Heller 1998). Looking at the coefficients' values, a $\$ 1000$ increase in published tuition would likely raise female enrollment around $2.75 \%$, and its price elasticity is estimated to be $0.68^{21}$.

Since published tuition is significant in the RE estimated female model but otherwise in the FE estimated male model, it is possible that the price effect of published tuition is sensitive to the estimation method used. A robustness check by comparing the coefficients for both models when the same estimation method is used suggests that different estimation methods affect the significance level of published tuition but not the sign of the coefficients ${ }^{22}$.

Another surprising finding is the negative effect of university's aid per student on enrollment of international students. University's aid is significantly negative in both models ${ }^{23}$. This seems to contradict earlier expectation on the positive effect of university's aid on students. Since most international students are not eligible for federal and state governments aids as these two are more need-based centric, financial aids offered by universities are more merit-based and therefore there is a bigger possibility for international students to receive this aid. However it is impossible to discern the specific amount of university's aid given to international students from the total amount of university's aid since IPEDS database provides aids variables

\footnotetext{
${ }^{21}$ Since the dependent variable, enrollment, is in logarithmic form while published tuition, as one of the explanatory variables, is in linear form, the price elasticity of enrollment is calculated by taking the estimated coefficient of pulished tuition and multiply it with average published tuition.

${ }^{22}$ The effects of different estimation methods are discussed in more details under robustness check analysis below.

${ }^{23}$ Since university's aid per student is significant in both models, a panel-robust Hausman test between OLS and 2SGMM and a $C$-test for endogeneity were performed. The results obtained suggest the absence of endogeneity in university's aid per student.
} 
with no indication of the residential status of the recipients ${ }^{24}$. Therefore it is possible that a larger portion of university's aid is also given to home students, which would encourage enrollment of home students compared to international students. With limited resources and supply constraints, higher enrollment of home students means that there is less space available for international students. Another possible explanation for the negative effect of university's aid on enrollment is that it is possible that universities send their quality signals via net tuition rather than through the stickier published tuition. Breneman (1994) found that institutions with declining academic quality levels would be less likely to send their signal by lowering their published tuition. Although changes in prestige have no impact on published tuition, Monks and Ehrenberg (1999) found that a drop in prestige level would induce universities to reduce their aid-adjusted tuition. Since financial aid is a more favorable channel to send signal of prestige level, students would be more sensitive towards any changes in financial aid than changes in published tuition.

Based on the estimated parameters' values, a $\$ 1000$ increase in average aid per student would likely cause enrollment of new international students to drop between approximately $8.65 \%$ and $12.49 \%$.

In the female model, the ARWU rank is significant and positively affects enrollment of new international students. The negative sign in front of the ranking coefficient is caused by the order of the ranking where a smaller number represents a higher prestige. Based on the estimated ranking coefficient, holding other factors constant, a 10-place improvement in ranking would lead to an increase in enrollment of international students by $2.0 \%$. The ARWU rank in the male model is not significant.

\footnotetext{
${ }^{24}$ IPEDS database provides various statistics of students' financial aids at the university level based on three categories of benefactors: Federal government, state government, and institution. However these statistics are not available for different categories of students. At the national level, it is possible to obtain the specific number of international students who received these aids.
} 
Again, this may be due to the different estimation method used.

Although admission test score, as a proxy of quality, is expected to attract enrollments, it is not significant in both models. One possible explanation for this result is that home students are more sensitive to admission test score compared to new international students. Furthermore, admission test score measures the quality of incoming students but not the overall quality level of the institution. On the other hand, rank score includes contributions of various members of the institution toward the prestige level.

It seems that new international students are more attracted to enroll at universities with greater presence of international students. The coefficients for senior international students are significantly positive in both models ${ }^{25}$. The positive effect between enrollment of new international students and enrollment of senior international students is expected as it reflects the possibility of recommendations from senior international students to prospective students through various communication channels. Furthermore, a bigger size of existing international students' population signals better ability of the university to provide various forms of assistance to international students and accommodate their needs. Senior international students are expected to help new international students to adapt to the new environment in the country. From the regressions results, a $1 \%$ increase in the number of senior international students raises enrollment of international students by between $0.73 \%$ and $0.89 \%$.

The popularity of the universities among home students is not a significant determinant of enrollment of new international students. The regressions results suggest that there is an inverse relation between enrollment of new international students and home students. The enrollment of home students is expected to be negatively

\footnotetext{
${ }^{25}$ To check for the possibility of endogeneity of senior international students to enrollment of new international students, another $C$-test of exogeneity is implemented. The result suggests that senior international students are exogenous to enrollment of new international students in both models.
} 
related to enrollment of international students due to limited resources and capacity constraints faced by universities. Moreover, this negative relationship suggests that international students and home students are substitute goods for placement in universities. However since the estimated coefficients of home students enrollment are not significant, these interpretations should be treated carefully.

Looking at the regional dummies, it seems that female new international students prefer to enroll at universities that are located in the New England region (which is the benchmark category), while the Rocky Mountains region is the least attractive region for them. The U.S. eastern regions are more attractive to female international students than the western regions. Since many of the regional dummies are significant, this indicates that most of the universities are located in different geographical submarkets as defined by Garvin (1980). Geographical differences affect the competition between universities for female new international students.

To further explore the relationship between enrollments and price, two other specifications of Equation 2.1 are considered. For the first case, squared published tuition is introduced as an additional explanatory variable. Interaction between published tuition and prestige and quality variables is used in the second case.

The panel-robust Hausman test results for nonlinear specifications are similar to the linear specification, where the FE estimation is preferred for the male model while the RE estimation is preferred for the female model ${ }^{26}$. Since the FE estimation is always preferred for male models while the RE estimation is always preferred for female models, this indicates that there is a systematic difference between male and female international students. The unobserved individual university effects seem to be correlated with university-level characteristics in the male models but otherwise

\footnotetext{
${ }^{26}$ Similar results are obtained from the panel-robust Hausman test results for nonlinear specifications of the QS and USNWR samples.
} 
in the female models. This issue will be addressed later when the price sensitivity between male and female international students are compared in Figure 2.4.

Table 2.8: Panel-robust Hausman tests for nonlinear specifications

\begin{tabular}{llrrrr}
\hline \hline & & \multicolumn{2}{c}{ Male } & \multicolumn{2}{c}{ Female } \\
& & Quadratic & Interaction & Quadratic & Interaction \\
\hline FE vs RE & Hausman $\chi^{2}$ & 33.80 & 37.90 & 19.63 & 20.32 \\
& $p$-value & 0.00 & 0.00 & 0.19 & 0.16 \\
\hline \multirow{2}{*}{ FE vs HT } & Hausman $\chi^{2}$ & 818.00 & 937.94 & 726.38 & 848.51 \\
& $p$-value & 0.00 & 0.00 & 0.00 & 0.00 \\
\hline \hline
\end{tabular}

Note: The Hausman statsitics above are panel-robust following Cameron and Trivedi (2005) suggestion due to clustered errors. The number of replications is 400.

Table 2.9 shows the regression results when the squared published tuition and the interaction term between published tuition and ARWU rank are added as explanatory variable. The estimation method for each model follows the results obtained from the panel-robust Hausman tests shown in Table 2.8. The male models are estimated using the FE method, while the female models are estimated using the RE method. The estimation results for quadratic specification are shown in columns 1 and 2 , while the results for interaction specification are shown in columns 3 and 4 .

From Table 2.9, both quadratic and interaction specifications failed to improve the relationship between enrollment and published tuition. The estimated coefficients for published tuition are not significant except for the female model with interaction specification, while all nonlinear terms of published tuition are not significant. Based on this result, a linear specification seems to perform better than a quadratic and an interaction specifications ${ }^{27}$.

It is possible that enrollment of international students is influenced by its past

\footnotetext{
${ }^{27}$ The quadratic specification is significant in the male model of the QS sample with a concave shaped published tuition. The threshold publised tuition is approximately $\$ 37,500$. The interaction specification is significant in the male model of the USNWR sample at $10 \%$ significance level.
} 
Table 2.9: Nonlinear relationships between enrollment of international students and price

\begin{tabular}{lcccc}
\hline \hline & \multicolumn{2}{c}{ Quadratic } & \multicolumn{2}{c}{ Interaction } \\
& $(1)$ & $(2)$ & $(3)$ & $(4)$ \\
Male & Female & Male & Female \\
& FE & RE & FE & RE \\
\hline PTUITION & 0.0152 & 0.0283 & -0.0029 & $0.0278^{* * *}$ \\
& $(0.0249)$ & $(0.0183)$ & $(0.0123)$ & $(0.0095)$ \\
PTUITION ${ }^{2}$ & -0.0004 & 0.0000 & & \\
& $(0.0004)$ & $(0.0004)$ & & \\
PTUITION*ARWU & & & -0.0001 & 0.0000 \\
& & & $(0.0001)$ & $(0.0001)$ \\
AVAID & $-0.0975^{* *}$ & $-0.0853^{* *}$ & $-0.1281^{* * *}$ & $-0.0868^{* *}$ \\
& $(0.0422)$ & $(0.0412)$ & $(0.0383)$ & $(0.0358)$ \\
ARWU & 0.0028 & $-0.0020^{* *}$ & 0.0042 & -0.0019 \\
& $(0.0025)$ & $(0.0009)$ & $(0.0042)$ & $(0.0027)$ \\
SATACT & 0.0149 & 0.0145 & 0.0135 & 0.0144 \\
& $(0.0098)$ & $(0.0090)$ & $(0.0098)$ & $(0.0090)$ \\
SISTD $($ in log $)$ & $0.7397^{* * *}$ & $0.8855^{* * *}$ & $0.7321^{* * *}$ & $0.8851^{* * *}$ \\
THSTD $($ in log $)$ & $(0.0761)$ & $(0.0401)$ & $(0.0779)$ & $(0.0404)$ \\
& -0.5110 & -0.0853 & -0.4350 & -0.0855 \\
Constant & $(0.3704)$ & $(0.0757)$ & $(0.3744)$ & $(0.0789)$ \\
& 3.3060 & $-1.5949^{* *}$ & 2.8870 & $-1.5865^{*}$ \\
& $(3.4965)$ & $(0.8020)$ & $(3.5834)$ & $(0.8506)$ \\
\hline Regional dummies & No & Yes & No & Yes \\
Year dummies & Yes & Yes & Yes & Yes \\
\hline$R^{2}$ & & & & \\
- within & 0.5315 & 0.4582 & 0.5310 & 0.4582 \\
- between & 0.6290 & 0.8930 & 0.5657 & 0.8929 \\
- overall & 0.5906 & 0.7743 & 0.5461 & 0.7742 \\
\hline Obs & 1038 & 1036 & 1038 & 1036 \\
Univ & 116 & 116 & 116 & 116 \\
\hline \hline
\end{tabular}

Dependent variable is (log of) enrollment of new international students Standard errors are clustered by university and shown in parentheses.

* Significant at $10 \% \quad * *$ Significant at $5 \% \quad{ }^{* * *}$ Significant at $1 \%$ 
values. To investigate this possibility, a dynamic specification with lagged enrollment introduced in Equation 2.1 is estimated. The augmented system GMM estimation result of Equation 2.5 is presented in Table 2.10. The results obtained in Table 2.10 indicate that enrollment is affected by its past values in both male and female models. Furthermore, autocorrelation is present in levels of the female model.

The two models are then re-estimated with two lags of enrollment. In this second estimation, male and female enrollments are no longer influenced by their two past values $^{28}$. Based on these results, it seems that both models would be better estimated with dynamic elements since lag enrollment is significant.

An issue with the dynamic specification is that lagged enrollments of international students may be collinear with senior international students. This relationship is very weak since the previous endogeneity test performed suggests that senior international students could be treated as exogenous to new enrollment. Furthermore, the dependent variables and their lagged values are separated based on gender while the senior international students variable is the aggregate number of senior international students. Finally, similar results are obtained when senior international student variable is excluded from the dynamic specification. Therefore it is safe to assume that the inclusion of lagged enrollments together with senior international students in the dynamic model specification may not affect the validity of the regression results.

Compared with the results from the linear estimation where published tuition is significantly positive in the female model only ${ }^{29}$, under the dynamic estimation now the published tuition is significantly positive in both models ${ }^{30}$. Looking at other vari-

\footnotetext{
${ }^{28}$ Similar observations obtained for the QS and USNWR samples.

${ }^{29}$ It is possible that under the linear specification, published tuition is significant in the female model only due to different estimation method used; female enrollment is estimated using the RE method while male enrollment is estimated using the FE method. However, when both models are estimated using the FE method, published tuition is not significant.

${ }^{30}$ Lagged enrollment is significant in the male model of the QS sample and the female model of the USNWR sample only.
} 
Table 2.10: Augmented system GMM estimation for enrollment of international students

\begin{tabular}{|c|c|c|}
\hline & Male & Female \\
\hline$E_{n r l}($ in log $)$ & $\begin{array}{l}0.2786^{* * *} \\
(0.0699)\end{array}$ & $\begin{array}{c}0.1253^{* *} \\
(0.0565)\end{array}$ \\
\hline PTUITION & $\begin{array}{l}0.0167^{* *} \\
(0.0071)\end{array}$ & $\begin{array}{l}0.0254^{* * *} \\
(0.0069)\end{array}$ \\
\hline AVAID & $\begin{array}{c}0.0183 \\
(0.0394)\end{array}$ & $\begin{array}{l}-0.0280 \\
(0.0392)\end{array}$ \\
\hline ARWU & $\begin{array}{l}-0.0017^{* *} \\
(0.0008)\end{array}$ & $\begin{array}{l}-0.0011 \\
(0.0009)\end{array}$ \\
\hline SATACT & $\begin{array}{c}0.0166 \\
(0.0120)\end{array}$ & $\begin{array}{c}0.0181 \\
(0.0114)\end{array}$ \\
\hline SISTD $($ in $\log )$ & $\begin{array}{l}0.7482^{* * *} \\
(0.1032)\end{array}$ & $\begin{array}{l}0.8587^{* * *} \\
(0.0840)\end{array}$ \\
\hline THSTD $($ in $\log )$ & $\begin{array}{c}0.0123 \\
(0.0816) \\
\end{array}$ & $\begin{array}{l}-0.0784 \\
(0.0893) \\
\end{array}$ \\
\hline Year dummies & Yes & Yes \\
\hline $\begin{array}{l}\text { Arellano-Bond } \mathrm{AR}(2) z \text {-score } \\
p \text {-value }\end{array}$ & $\begin{array}{l}0.33 \\
0.74\end{array}$ & $\begin{array}{l}2.42 \\
0.02\end{array}$ \\
\hline $\begin{array}{l}\text { Hansen overidentification } \chi^{2} \\
p \text {-value }\end{array}$ & $\begin{array}{r}102.61 \\
0.08\end{array}$ & $\begin{array}{r}103.91 \\
0.07\end{array}$ \\
\hline $\begin{array}{l}\text { Observation Count } \\
\text { Instrument Count } \\
\text { University Count } \\
\text { Period }\end{array}$ & $\begin{array}{c}918 \\
99\end{array}$ & $\begin{array}{cc} & 916 \\
& 99 \\
116 & \\
2004-11 & \end{array}$ \\
\hline
\end{tabular}

Dependent variable is (log of) enrollment of new international students

Windmeijer-corrected standard errors are shown in parentheses.

Number of instrument lags is limited to two.

* Significant at $10 \% \quad * *$ Significant at $5 \% \quad * * *$ Significant at $1 \%$ 
ables, university's aid per student is no longer significant under dynamic specification but enrollment of senior international students is still positively significant in both models.

The impact of published tuition under the dynamic specification seems smaller than the effect under the linear specification, especially for the female model ${ }^{31}$. A $\$ 1000$ increase in published tuition is expected to increase the enrollment of new international students between $1.67 \%$ and $2.54 \%$. The estimated price elasticity of enrollment is between 0.41 and 0.62 . As these values fall within the inelastic range, it seems that new international students are less sensitive to changes in published tuition.

The prestige and quality indicators have all the expected sign but not all of them are significant. An increase in prestige and quality seems to attract higher enrollment of new international students ${ }^{32}$. ARWU rank is significant in the male model but otherwise in the female model. A 10-place improvement in ARWU rank leads to an increase in male enrollment by approximately $1.7 \%$. The other quality proxy, the admission test score, is not significant in both models and this is similar to the earlier result obtained using the linear specification.

The popularity of the institution among senior international students is significantly positive in both models. This is similar with the linear specification results. However, under the dynamic specification, the size of the popularity impact is larger for male enrollment but smaller for female enrollment. A $1 \%$ increase in the enrollment of senior international students would lead to an increase in the enrollment of new international students between $0.75 \%$ and $0.86 \%$. The popularity of the institution among home students is not significant in both models.

\footnotetext{
${ }^{31}$ The coefficient of published tuition for the male model in the linear specification is not significant.

${ }^{32}$ Recall that ranking is ordered with the smaller numbers indicate higher prestige.
} 
Figure 2.2: Average price elasticity of enrollments (linear specification) and ARWU rank for 2010

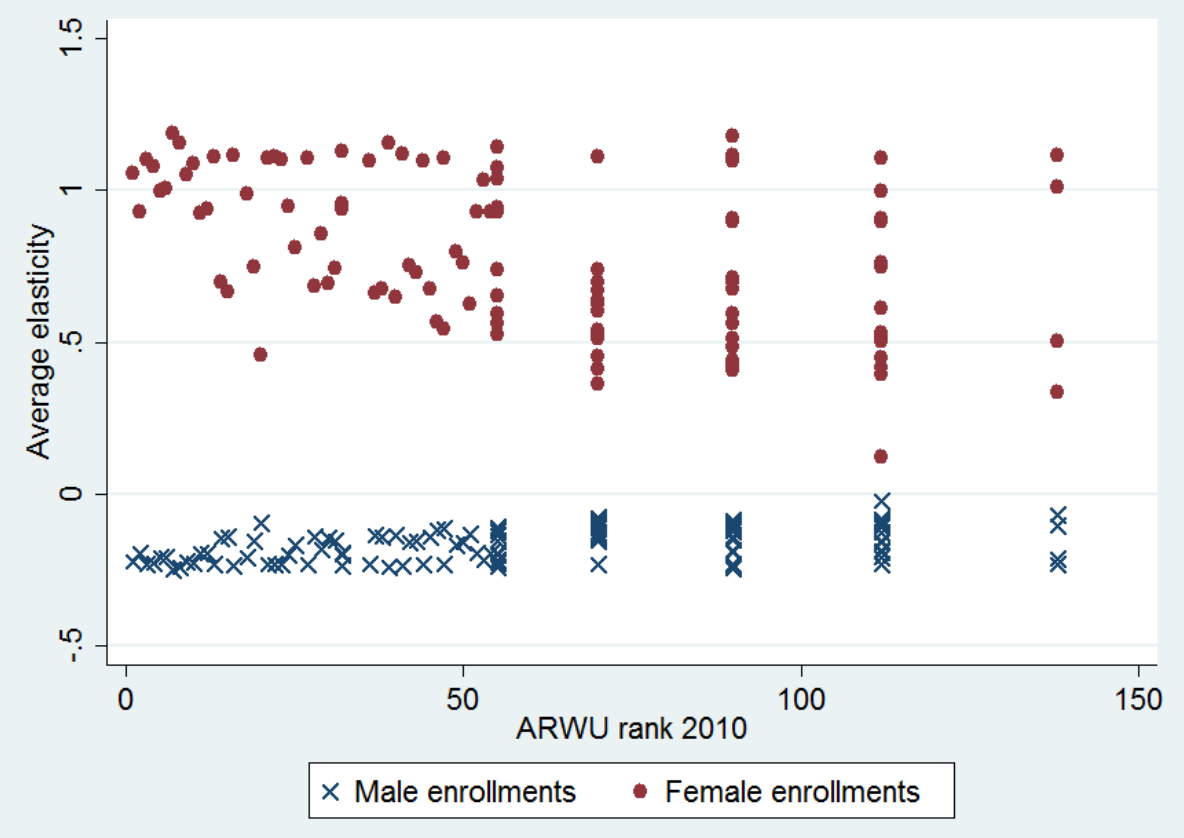

Since lagged enrollment at time $t-1$ is significant in both models, this is a strong evidence to suggest that the dynamic specification explains the relationship between price and enrollment better than the linear and nonlinear specifications. The other specifications in this study are static in nature and put a strong assumption that enrollment is not affected by its past values, while the dynamic specification allows for the effect of past enrollments to be controlled and isolated from the price and quality effects. However, since the dynamic specification disallows the estimation of time-invariant variables, the linear specification with RE method is used to refer to the impact of these time-invariant variables on enrollment.

Figure 2.2 provides additional information on the relationship between enrollments, published tuition, and ARWU rank scores. It shows the relationship between price elasticity of enrollments and ARWU rank score of each university, where higher 
prestige universities are ranked with smaller numbers for the year $2010^{33}$. The price elasticity of enrollments here is derived from the linear specification of Equation 2.1. Similar patterns are observed for other years. The male enrollment falls within the inelastic range ${ }^{34}$. Comparing the price elasticities of male and female enrollments, it seems that the price elasticity is sensitive to the different estimations used ${ }^{35}$. The price elasticity for male enrollments is less scattered; while its pattern is linear and not strongly influenced by differences in the ranking. The price elasticity of female enrollment for some institutions is above the unit elastic value. Enrollment of female internatioal students seems to be increasingly inelastic as ARWU rank scores drop to lower prestige level. This suggests that the demand for placement of international female students at higher prestige universities is more sensitive to changes in published tuition relative to male students. The female model has positive elasticity of enrollments due to the positive sign of the estimated coefficient of published tuition, where top ranking universities appear to have more elastic price of enrollments. This indicates that among top ranked universities, female international students perceive higher tuition as a signal of quality; while lower prestige universities would not lose enrollments with higher tuition. Female international students who enroll at higher prestige universities are more sensitive to changes in tuition. This result matches earlier expectation that the demand for placement at higher prestige universities is due to the positive effect of the prestige on enrollment that offsets the negative effect of price ${ }^{36}$.

\footnotetext{
${ }^{33}$ The price elasticity of enrollment is calculated by multiplying the coefficient of published tuition estimated from Equation 2.1 with published tuition of each university.

${ }^{34}$ The plotted average elasticities of male enrollments is scattered between zero and one in absolute value.

${ }^{35}$ Based on the previous panel-robust Hausman test results, the male model is estimated using the FE method while the female model is estimated using the RE method. Similar result is observed in the USNWR sample. However, different result is observed in the QS sample where both male and female models produce identical patterns of price elasticity of enrollments.

${ }^{36}$ To investigate the possibility that the different results observed between male and female en-
} 
Figure 2.3: Average price elasticity of enrollments (dynamic specification) and ARWU rank for 2010

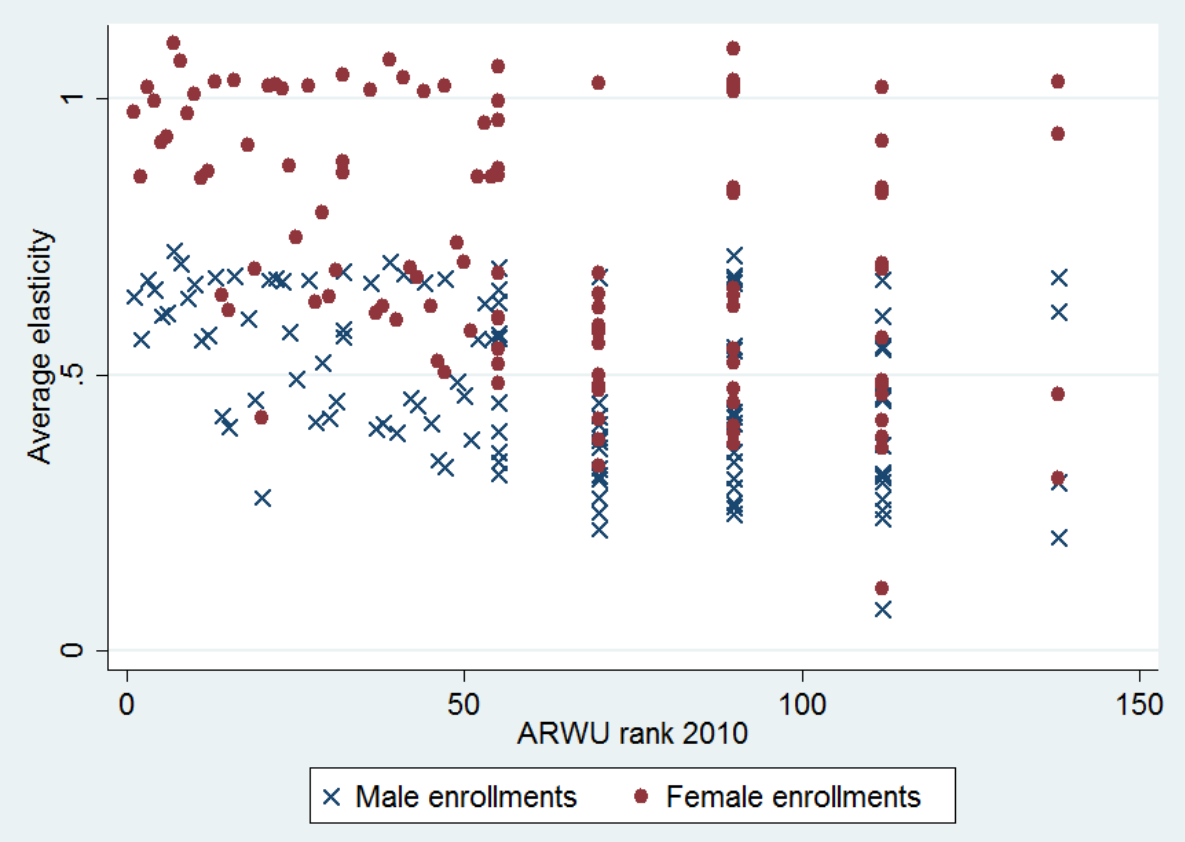

The dynamic specification of Equation 2.5 involves a two-step system GMM estimation method. The estimated price elasticity of enrollment under the dynamic specification and ARWU rank for the year 2010 is shown in Figure 2.3.

Similar patterns are observed for all other years. From the graph, the male and female price elasticity of enrollments displays identical patterns. There seems to be an inverse relationship between price elasticity of enrollment and ARWU rank, where top ranked universities are associated with relatively higher elasticity than lower ranked universities.

Figure 2.4 shows the relationship between deviations from changes in published tuition and deviations from changes in average enrollments for selected years ${ }^{37}$. Sim-

rollments are caused by the different estimation methods, both male and female enrollments will be estimated using the same estimation methods in the roubstness check later.

${ }^{37}$ Please refer to Figure A.1 in Appendix A.3 for graphs of all years. When analyzing the graphs, please be mindful of the different scales used on the axes. 
ilar patterns are observed for most of the years. For male enrollments, most of the deviations are scattered within the rectangle region of $(-1,4),(-1,0),(1,0)$, and $(1,4)$. The female enrollments display two distinct deviation patterns; scattered along the horizontal axis from 2004 to 2006, and scattered along a slightly tilted upward sloping line crossing the origin from 2007 onwards. The observations shown in Figure 2.4 are taken from two years that represent the two different patterns: 2006, and 2007. All other periods produce similar patterns with observations in 2006 and 2007.

Generally, universities which had the highest relative increase in published tuition also show the largest relative change in enrollments. It seems that universities that increase published tuition by a relatively bigger amount are still able to increase enrollments of international students. Female enrollments seem to be more sensitive to changes in published tuition than male enrollments since the enrollment deviation of male students is always near the vertical axis even when there is a large deviation in published tuition. Universities that increase published tuition relative to others are either able to increase enrollments of male students by a bigger amount than female students, or cause enrollments of male students to fall by a smaller amount compared with female students.

Prior to 2007, the deviation in published tuition is almost linearly related to deviation in female enrollments, where female enrollments appear to be scattered along the zero published tuition deviation. Starting in 2007, the female enrollments started to display an upward sloping deviation line. This indicates that universities that lower their published tuition tend to have fewer female enrollments, while universities that raise it are able to attract more female enrollments. The positive relationship between deviation in female enrollments and deviation in published tuition suggests that female students tend to view published tuition as a prestige and quality signal.

The previous panel-robust Hausman tests always suggest FE for male and RE for 
Figure 2.4: The relationship between deviations from mean published tuition growth and deviations from mean enrollments growth for selected years

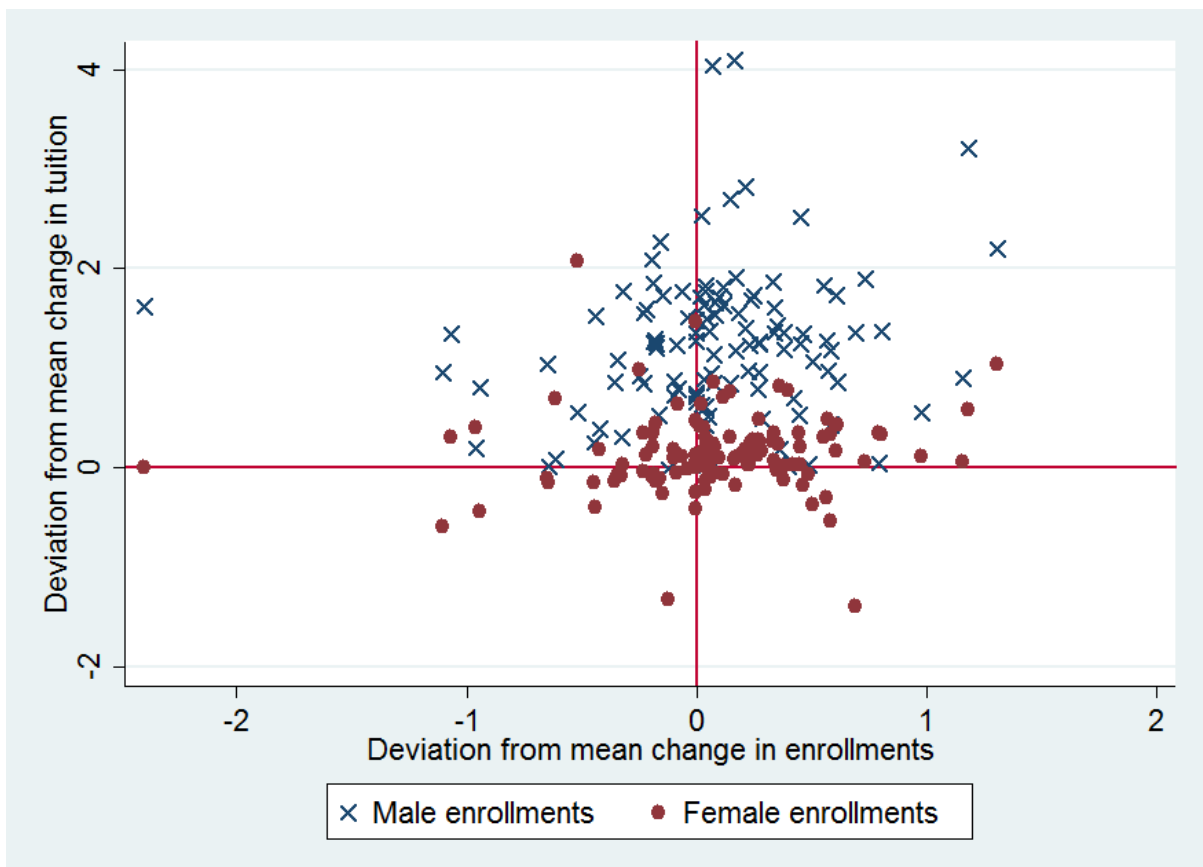

(a) 2006

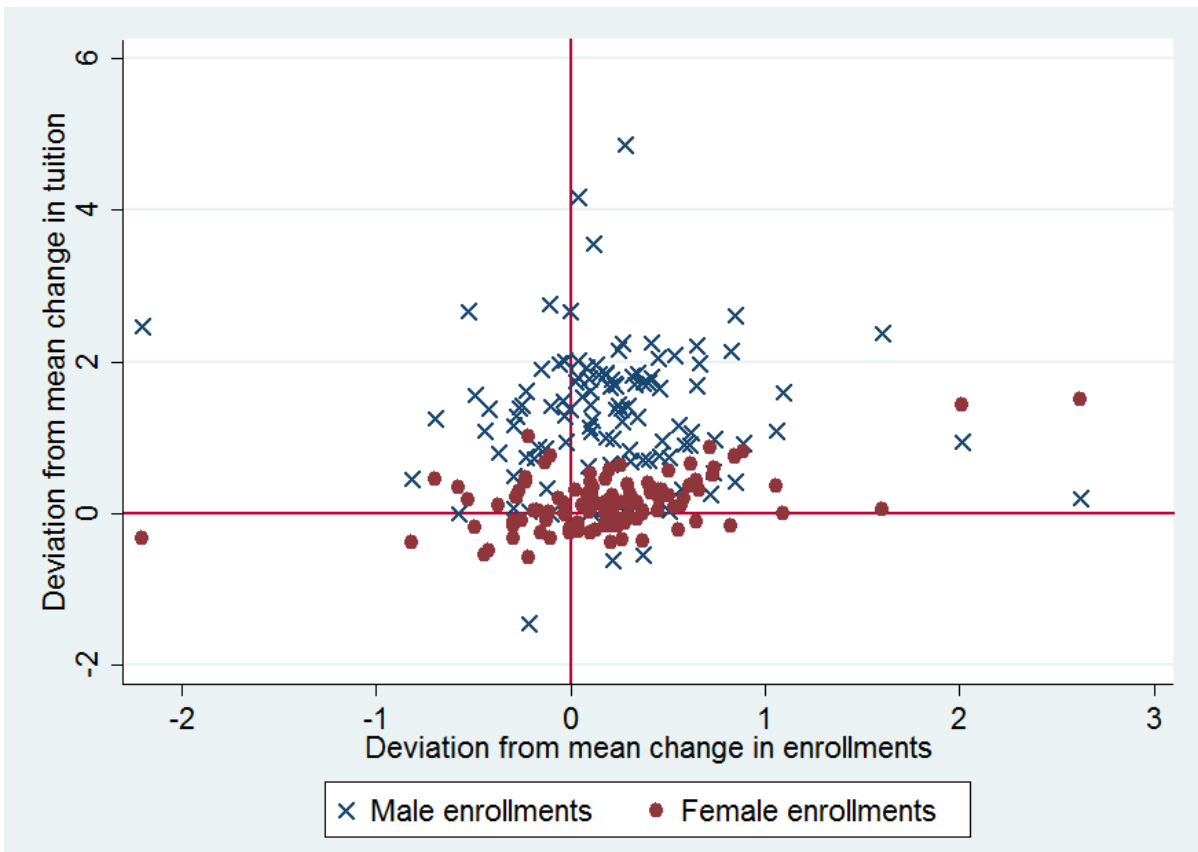

(b) 2007 
female international students, and at the same time the data indicates that female international students are more sensitive to price changes than their male counterpart. This difference could be attributed to the different treatment given to male and female international students who want to further their studies in the U.S. by their families, especially in a more traditional society. However since the data on the source country of international students is not available due to its sensitive nature, this interpretation could not be verified empirically.

Two robustness checks were performed on the results. First, Equation 2.1 is re-estimated using FE and HT methods on all samples. In the HT estimations, the regional dummies are included. The results obtained from the FE and HT estimations are then compared with the results obtained from the preferred estimation methods suggested by the panel-robust Hausman Test in Table 2.7 on page 33 and also the dynamic specification results presented in Table 2.10 on page 42 . These comparisons should be able to indicate whether different methods of estimations affect the results.

In the first robustness check, both male and female models are re-estimated using the FE method. Since the FE method is the preferred estimation method to estimate the male model, the FE estimation result of female model is the focus of discussion for robustness check. The results of the FE estimation are provided in Table A.2 in Appendix A.4. From the results, published tuition is still positive in the female model but not significant. At the same time, all prestige and quality variables are no longer significant. These results are surprising since both price and quality measures are not significant to demand. This suggests that international students are not sensitive to published tuition and prestige levels of universities within the U.S. Perhaps, having decided to go to the U.S., the price and prestige level differences among institutions within the country are no longer significant determinants.

As for other variables, the coefficients for university's aid per student remain signif- 
icantly negative to enrollment. The popularity of the institution among international students remains significantly positive to enrollment. As for popularity among home students, its estimated coefficient in the female model is still not significant.

Figure 2.5 shows the relationship between price elasticity of enrollment (estimated using FE method) and ARWU rank for $2010^{38}$. The price elasticity of enrollments for female international students is now inelastic ${ }^{39}$. Comparing the patterns between Figures 2.2 and 2.5, the price elasticity of female enrollments displays similar pattern and falls in the positive range. The patterns of price elasticity of enrollments between male and female international students are almost the opposite since the estimated published tuition coefficients for male and female international students are negative and positive respectively. The findings from the FE estimated price elasticity of enrollments show similar results with previous analysis when different estimation methods are used.

A comparison of the graph obtained using the FE method for male models and the RE method for female models in Figure 2.2 with the same graphs obtained using the FE methods for both male and female models in Figure 2.5 reveals that the price elasticity of enrollments for female students is now more concentrated within a smaller range. The price elasticity for female enrollments ranges between zero and 0.2 , which is small compared to the $0.00-1.50$ range obtained in Figure 2.2. A quick comparison between the elasticity graph obtained from dynamic specification in Figure 2.3 and the elasticity graph from the FE method here suggests for inelastic enrollment for both male and female international students, but the inelastic enrollment is more concentrated within a smaller range in the FE graph.

\footnotetext{
${ }^{38}$ Note that higher prestige universities are assigned with smaller rank numbers. Similar patterns are observed for other years.

${ }^{39}$ When the RE method is used to estimate female enrollment previously, several universities display elastic enrollment of female international students.
} 
Figure 2.5: Average price elasticity of enrollments (fixed effects method) and ARWU rank for 2010

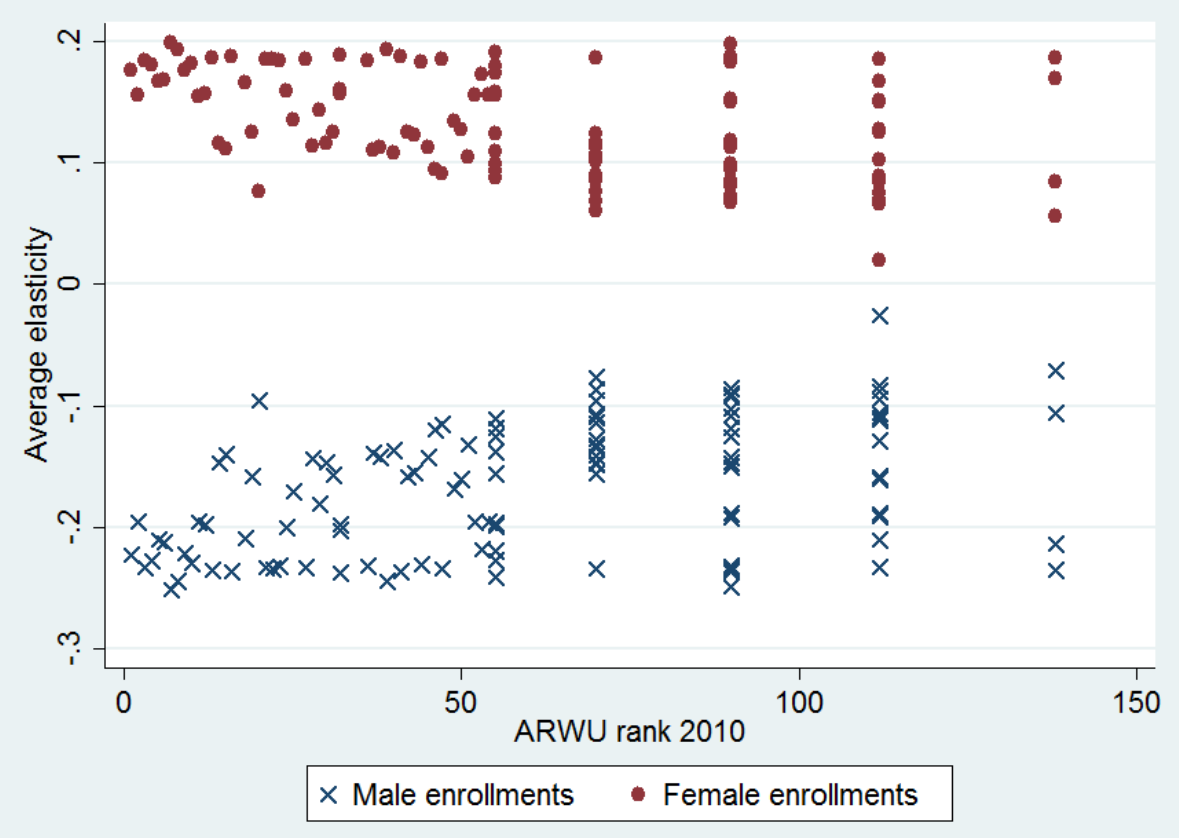

The HT estimation results of Equation 2.1 are shown in Table A.3 in Appendix A.4. In this robustness check, the discussions are on both male and female models since the HT estimation method is never preferred compared to FE and RE estimation methods. It seems that the HT estimations produce mixed results compared to the results obtained in Table 2.7 on page 33. Published tuition is now positive in both models but not significant. The aid coefficients are still negative but it is only significant in the male model. As for ARWU rank, its coefficient sign changed for the male model where it is now negative and significant. The negative ARWU rank coefficients in both male and female models indicate that an improvement in ARWU rank attracts higher enrollment of international students. This is similar to the results obtained in Tables 2.7 on page 33 and 2.10 on page 42 . The admission test score is now positive and significant in both male and female models. The results for senior international students remain the same. Population of home students is now 
Figure 2.6: Average price elasticity of enrollments (Hausman-Taylor method) and ARWU rank for 2010

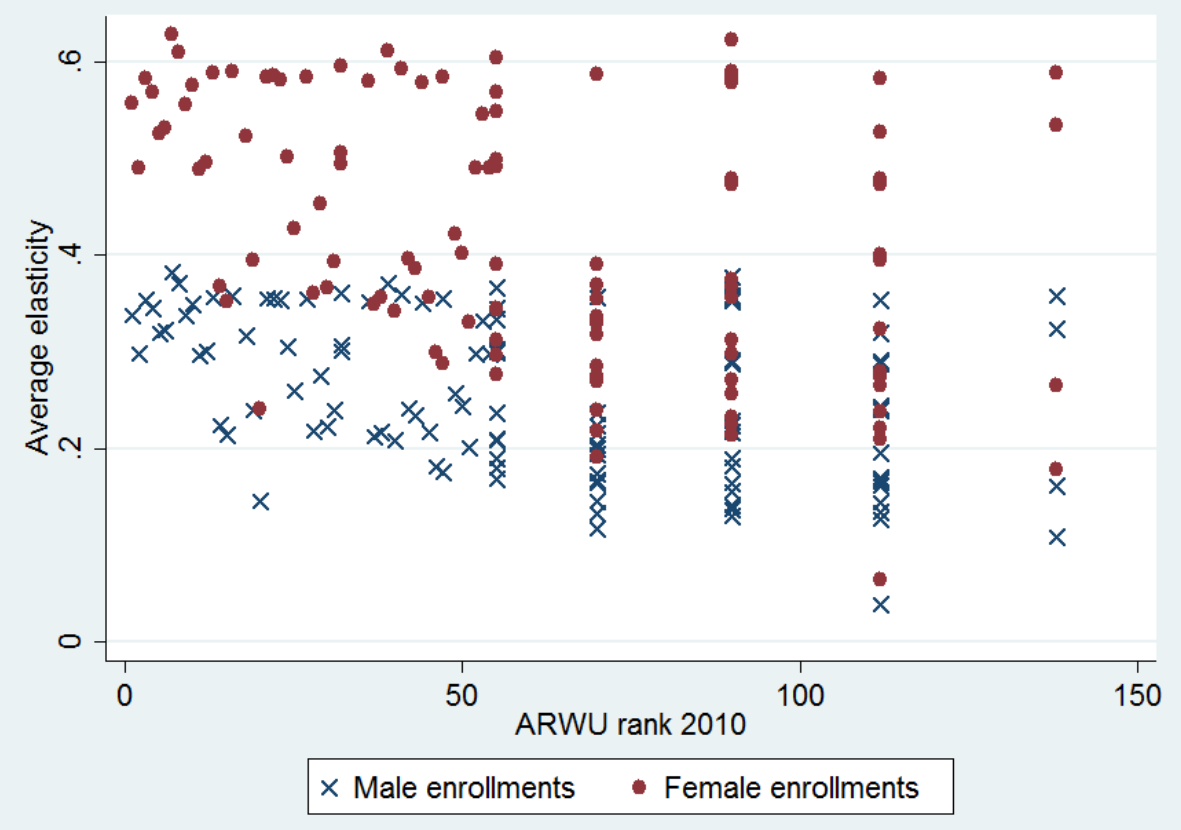

significant in the male model but remains insignificant in the female model. Since there are only few significant differences between the estimation methods used in Table 2.7, Table 2.10, and the HT estimation; it would be safe to assume that generally all three methods (linear, dynamic and HT estimations) yield similar results.

Figure 2.6 shows the relationship between average elasticity of enrollments estimated using the HT method and ARWU rank for the year 2010. The price elasticities of enrollments for both male and female international students are still in the inelastic range. The price elasticity for male enrollments is now positive and lower than the price elasticity for female enrollments. There is no big change in the price elasticity for female enrollments.

All these observations from comparing graphs in Figures 2.2, 2.3, 2.5, and 2.6 suggest that the price elasticity of enrollments is not influenced by different estimation methods. 
For the second robustness check, Equation 2.1 is re-estimated in first differences (FD), where the relationship now is between changes in enrollments and changes in the explanatory variables. The results are shown in Table A.4 in Appendix A.4. Based on the FD results, changes in published tuition are no longer significant to enrollment of international students except in the female model. Changes in aids are still negative and significant in both models. Prestige and quality changes are no longer significant to changes in enrollments. Popularity changes among senior international students and home students remain similar to the results obtained under the linear specification in Table 2.7. The third robustness check shows that published tuition seems to be sensitive to different specification between level and first difference although other explanatory variables seem to be fine and not affected by differences in specifications.

The results obtained from the robustness checks suggest that the estimation results obtained in Tables 2.7 and 2.10 are valid, and that most of the conclusions derived from the results hold. Comparing the results obtained in this paper with Soo and Elliott (2010), similarly published tuition positively affects the enrollment decision of new international students in the U.S. However, while Soo and Elliott (2010) found that nonlinear specification better describes the relationship between levels of tuitions and applications in the U.K., in the case of the U.S. a dynamic specification seems to perform better than the nonlinear specifications.

\subsection{Conclusion}

This essay explores the determinants of enrollment demands by international students at U.S. universities. The sample consists of 116 universities for the period 2003-2011. All university-level data are taken from the publicly available IPEDS database. The analysis considers the impact of publised tuition, average university's aid per student, 
university's characteristics reported in IPEDS and university's prestige published as ARWU rank scores on enrollment of international students. This study looks into which information and factors international students use in their enrollment decisions for U.S. universities.

The analysis shows that published tuition positively affects enrollments of international students. Since the prestige indicator is not always significant, this suggests that published tuition acts as a signal for prestige and quality of university. The positive effects from signaling for top prestige and high quality universities greatly offset the negative effects from increases in published tuition. There is only little evidence to support a nonlinear relationship between published tuition and enrollments of international students. University's financial aid is found to be negatively related to enrollments of international students in the linear specification but no longer significant in the dynamic specification. Since data on the recipient of the aid is unavailable, it is hard to suggest any constructive explanation of this unexpected relationship. As ARWU rank is not always significant while most of regional dummies are significant, this suggests that geographical differences are stronger than differences in prestige and quality in influencing female enrollments. However no similar conclusion could be derived for male enrollments since the fixed effects estimation used in the male model excludes time-invariant variables from the model. Female international students are found to be more sensitive to changes in prices than male international students. Enrollment of new international students is also affected by previous year's enrollment as shown in the dynamic specification results.

The results of this study would be helpful for administrators of universities to formulate the best tuition and aid policy to attract international students. While universities would be able to raise tuition without reducing enrollments, the increase should be accompanied with increase in prestige and quality. Rank is an important 
factor that administrators should always try to improve. New international students are found to have similar preferences to senior international students. These results could also help administrators to search for substitutability between home and international students. However there is not enough evidence to compare the preferences of international students and home students. 


\section{Chapter 3}

\section{Price Competition in the}

\section{Geographical Market of U.S.}

\section{Higher Education: A Spatial}

\section{Regression Approach}

\subsection{Introduction}

In May 1991, members of the Ivy League Overlap Group ${ }^{1}$ were charged by the U.S. Department of Justice to have colluded to restrain trade through price fixing, which violates Section 1 of the Sherman Antitrust Act. The schools were alleged to have engaged in information sharing of the financial background of common applicants, and agreed to award financial aid package to qualifying applicants based on need. The

${ }^{1}$ The Ivy League is a collegiate athletic conference comprising of eight private universities in Northeastern U.S.: Brown University, Columbia University, Cornell University, Dartmouth College, Harvard University, Princeton University, the University of Pennsylvania, and Yale University. The Ivy League Overlap Group consists of the eight members of the Ivy League and Massachussets Institute of Technology (MIT). 
financial aid given to each student equals to the difference between the comprehensive fee of the university (tuition, fees, room and board) and the contribution of the student and family. Although all parties agreed that price fixing did occur (Netz 1998), ultimately this case was settled out of court ${ }^{2}$. One interesting observation that could be derived from the case is that not only all members of the Ivy League Overlap Group are of the same prestige and quality levels, they are also located in the same geographical area, which is in the northeast of the U.S. These universities are also regarded to be in the same elite group with high prestige and quality. Since the Ivy League Overlap Group shares the same boundaries in two market dimensions, the competition between the universities is more intense. Given that price competition among the Ivy League Overlap Group was fixed through collusion, would a similar situation occur if there were no cooperation among the members? This study expects that while the actual price fixing is not possible without collusion, price competition between universities is still influenced by the pricing policies of other universities in the same market area. In other words, there is a positive correlation between prices of universities that share the same market dimensions; either the geographical market or the product market. The price policy of a university is strongly influenced by other universities that are located near to that university.

This study of interinstitutional competition in the geographical market dimension is influenced by the economic approach to the higher education market introduced by Garvin (1980), where the market for higher education could be divided into the geographical dimension and the product dimension ${ }^{3}$. Rothschild and White (1993) argue that the competition in the higher education market is limited within segments that are separated by geographical boundaries and quality differences. In addition

\footnotetext{
${ }^{2}$ For more information about this case, please refer to U.S. v. Brown University, et al., 1992.

${ }^{3}$ The product market dimension of higher education is analyzed in the next chapter.
} 
to geography and quality, Winston (1999) adds that the segmentation of the higher education market could also be attributed to the endowment size and ideological differences.

While the study of the behavior of profit-maximizing institutions and their market environments makes a substantial part of economic theory and analysis, recently there is a growing interest among economists in the analysis of non profit institutions and the market in which they operate, including universities and the higher education market. Higher education plays a prominent role in the U.S. economy. As shown in Figure 3.1, the expenditures on higher education constitute 3.2\% from total GDP from 2009 to 2011. This percentage has been increasing steadily from $2.4 \%$ since 1986 . Besides that, the higher education sector provides employment for large numbers of professionals and operational support staff.

Another unique feature of the higher education market in the U.S. is that there is an intense competition between different institutions, where a strong and diversified private sector competes together with various state and public university systems. The competitive feature that is inherent in the higher education market leads to the vitality of U.S. higher education (Rosovsky 1990). The market for higher education in the U.S. in the postwar period is characterized by interinstitutional competition that has become more intense as a result of expanding submarkets (Hoxby 1997). However, most of the studies that applied economic principles to university behavior focus on cost and allocation issues, while the marketplace context in which universities operate received less attention from economists (Rothschild and White 1993). This chapter is an attempt to fill up this gap by providing a thorough analysis of the price competition process that takes place in the market for higher education from the geographical market dimension.

In order to promote equal educational opportunities to students of various back- 
Figure 3.1: Expenditures of Higher Education and GDP, 1986-2011

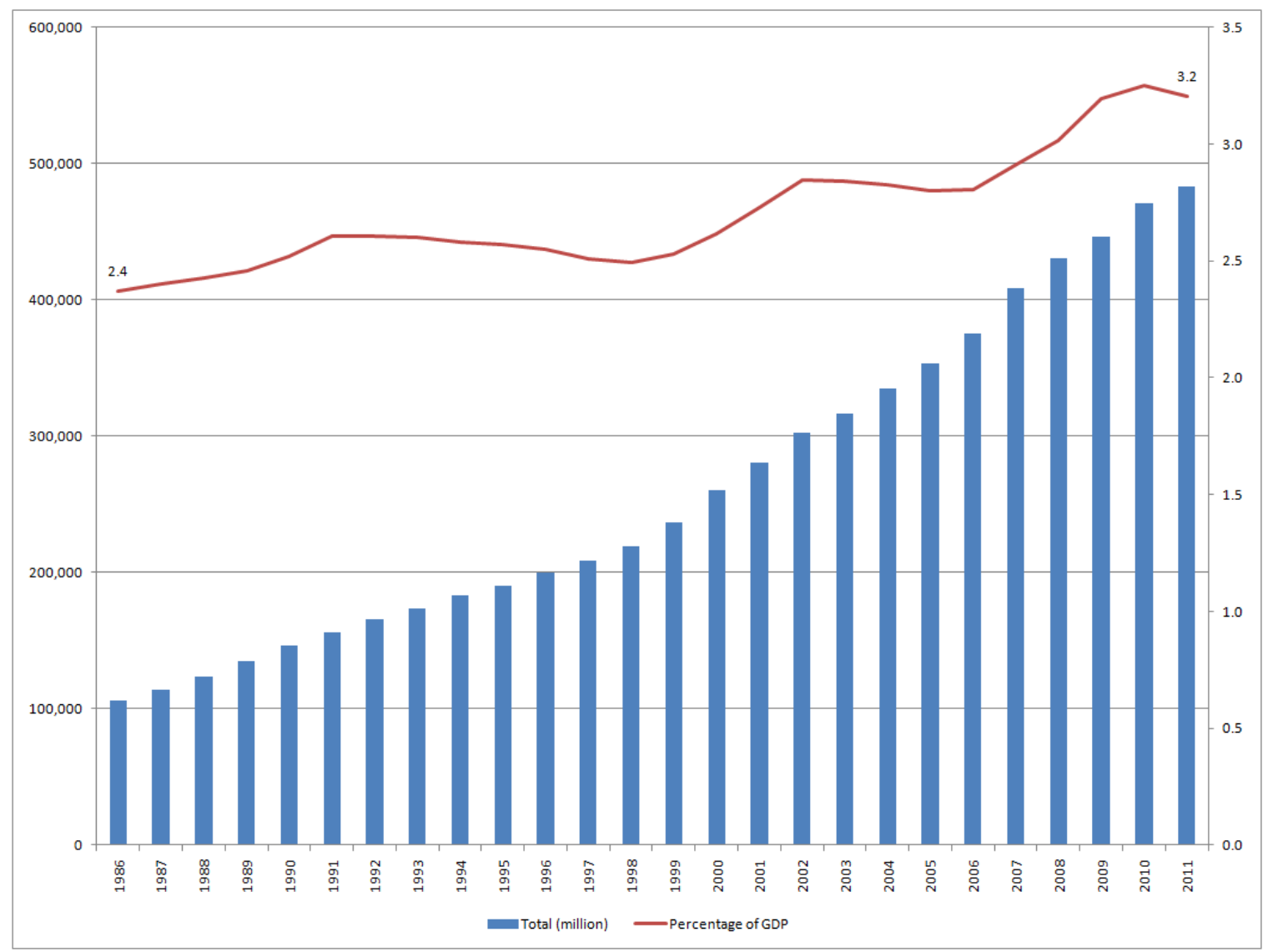

Source: U.S. Department of Commerce, Bureau of Economic Analysis, National Income and Product Accounts Tables 2013

grounds, the U.S. federal government started sharing the responsibility with states in providing subsidies to post-secondary students since the 1950s (McPherson and Schapiro 1999). Most institutions of higher education, public as well as private, receive large support from public funding, either directly or indirectly (Raines and Leathers 2003). The federal Pell Grants program is intended to help students with financial needs pay for their education. From this program, universities and colleges receive indirect support from the federal government in the form of payments from students who would otherwise be unable to enroll without these aids. On the other 
hand, state governments support the higher education sector by providing direct subsidies to public universities and colleges so that these institutions are able to offer low tuition and promote equal access to education.

However, recent decades have seen several changes in the financial support from the federal and states governments towards public higher education. Three national reports: The Second Newman Report: National Policy and Higher Education (1973) by the Newman Task Force on Higher Education; Higher Education: Who Pays? Who Benefits? Who Should Pay? (1973) by the Carnegie Foundation for the Advancement of Teaching; and The Management and Financing of Colleges (1973) by the Committee for Economic Development; suggested for a shift from a low-tuition policy to a need-based policy, where students and families should share the cost burden for higher education. Following this recommendation, the federal government is giving out more student loans and less grants (Hearn and Holdsworth 2004, Heller 2011), while the state appropriations for higher educations have been reduced substantially (St. John 2006). Due to the waning public support for higher education, universities are persuaded to be less dependent on public coffers and to look for other sources of revenue in order to maintain a healthy financial status. Since 1978, there have been a $40 \%$ decline in state appropriations for higher education (Weerts and Ronca 2006), while there is a large increase in tuition rates within the same period (Heller 2006). As shown in Figure 3.2, from 2007 to 2012, the average state appropriations per pulic full time equivalent student (FTE) has fallen by 23\% (State Higher Education Executive Officers 2013). From 2007 to 2012, only two states, Illinois and North Dakota, experienced an increase in state support for public institutions. Thirty states experienced a fall in state appropriation per student by more than $20 \%$.

With less financial support from federal and state governments, raising tuition may be the most attractive option available for universities. As shown in Figure 3.3, 
Figure 3.2: Change in state appropriations per FTE Student, 2007-2012

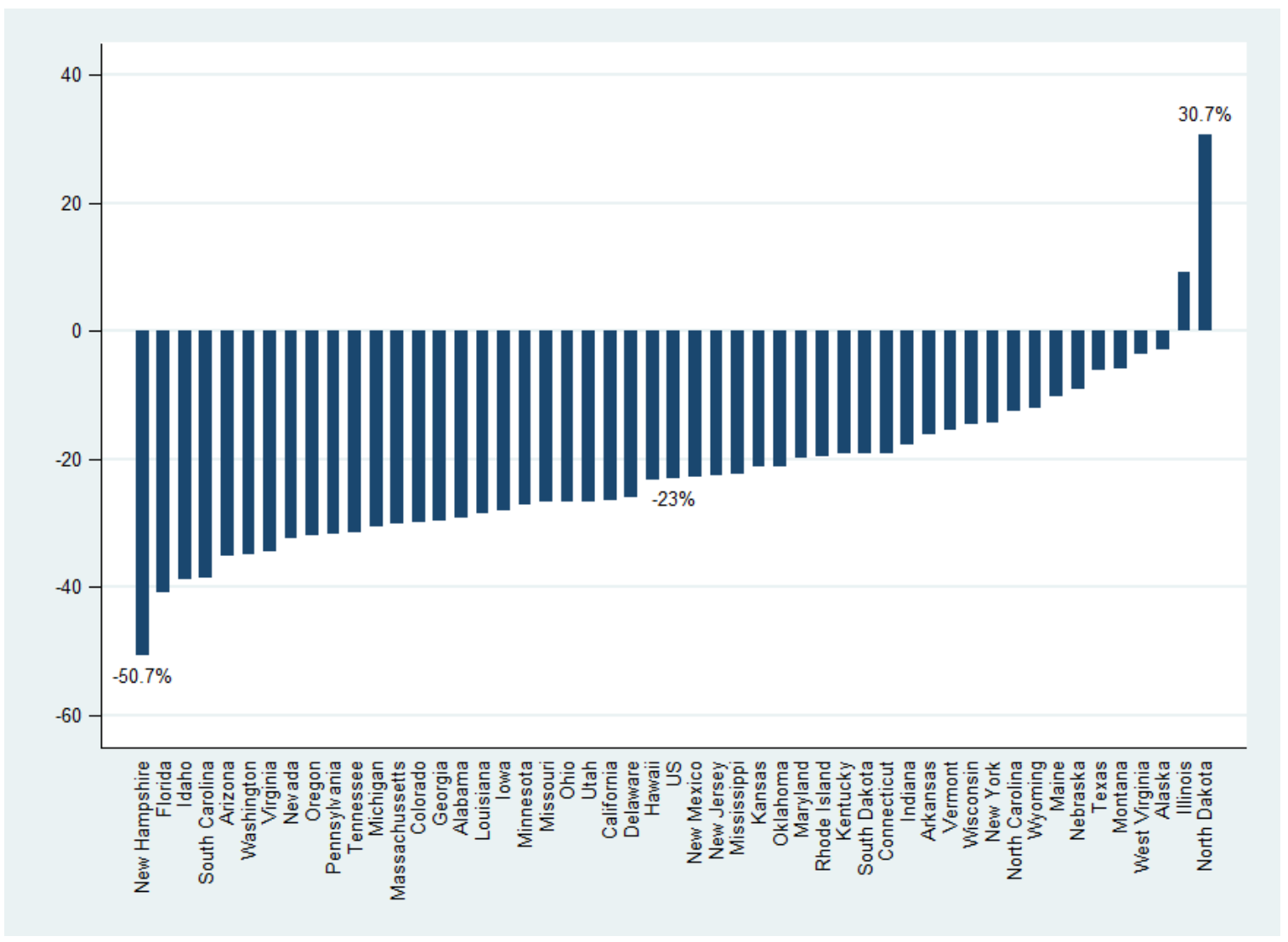

Source: State Higher Education Executive Officers (SHEEO) 2013

the share of net tuition revenue from the operational budget of public higher education has increased sharply since 2008 to 2012. From the graph, it seems that net tuition revenue increases rapidly during recessions. The burden of financing higher education is now transferred from taxpayers to students. In the current situation, it would be interesting to investigate how a university formulates its pricing policy given that it receives less funding from the governments and that the market has become more competitive.

This study contributes towards the existing literature on the behavioral analysis of non profit institutions. Specifically, this research investigates the price competition 
Figure 3.3: Net tuition as a percent of public higher education revenue, 1987-2012

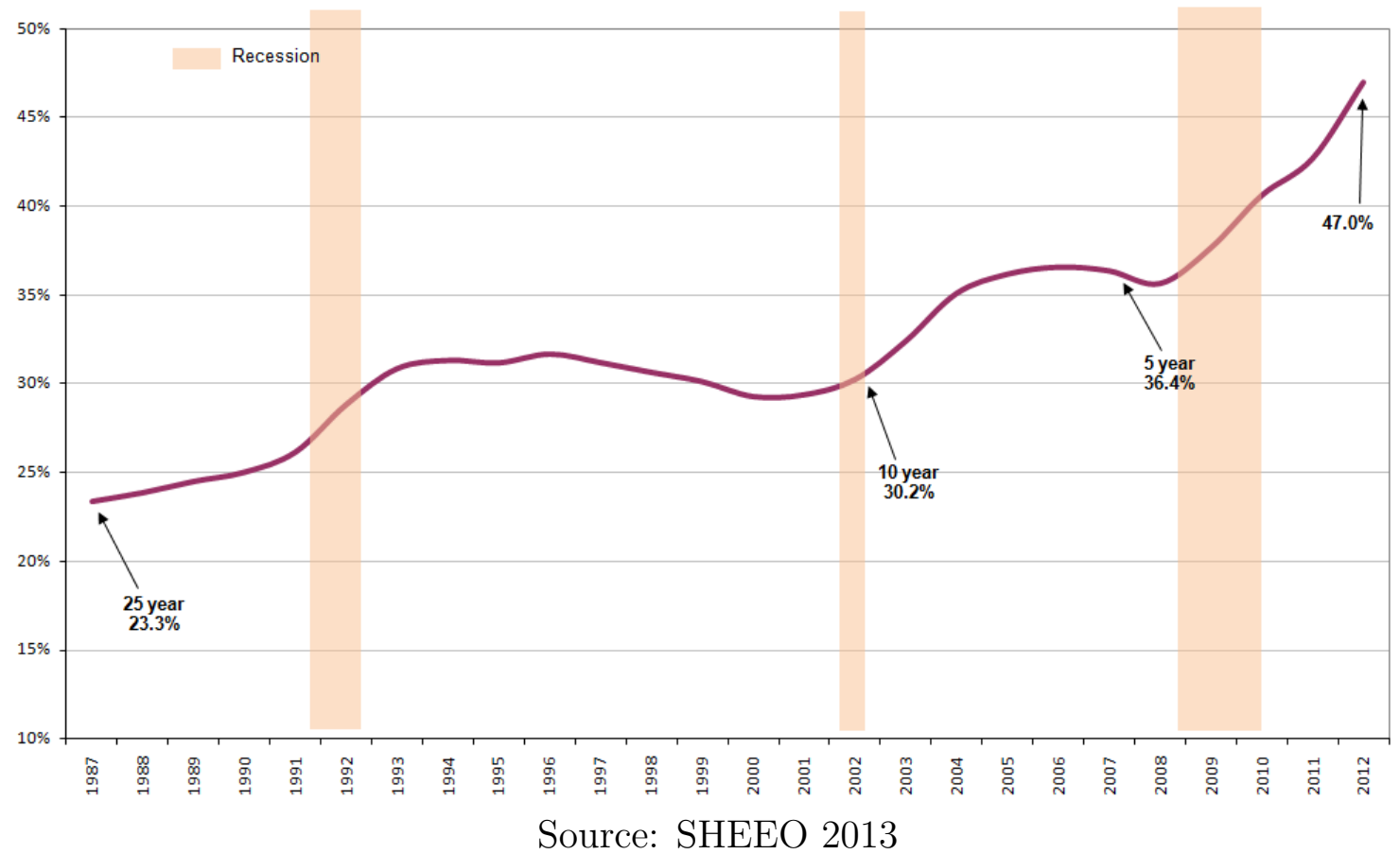

that takes place in the geographical market for higher education in the U.S. Although there are a number of private-for-profit institutions in the higher education market, most private universities are not for profit institutions ${ }^{4}$.

The present study integrates the theory of price competition and spatial regression techniques. The price competition between universities is believed to be influenced by the proximity of competitors in the geographical market space. To investigate this, the analysis introduces spatial proximity into empirical models of prices of higher education. Spatial regression models are used to identify the sign and magnitude of any spatial dependence between prices set by universities.

The organization of the paper is as follows. The next section discusses several

\footnotetext{
${ }^{4}$ After applying the condition of having at least $10 \%$ undergraduate students in a 4 -year baccaulaureate program, the sample used in this study consists of 528 public and not-for-profit private institutions only.
} 
other studies that are related to this research. The following section presents the data and variables used in this study. Section 3.4 discusses the methodology used in this analysis. The results are presented and discussed in Section 3.5.

\subsection{Literature Review}

This study contributes to existing literatures on market structure for non-profit organizations. Specifically, it applies spatial regression techniques to define price competition between universities in the geographical market. While spatial econometrics techniques are common in many geographical studies, recently there has been a rapid increase in their applications in various economics problems. However, spatial econometrics are relatively new and less developed compared to time-series econometrics (Pinkse and Slade 2010).

Rothschild and White (1993) believe that while most economic analysis of university behavior centred around cost measurements and allocation issues, there is a shortage in the analysis of the marketplace context of universities. Therefore this study attempts to contribute towards the market analysis of the higher education sector.

As mentioned earlier, following Garvin (1980), universities and colleges could be designated to different submarkets on the basis of their geographical location and the quality of their products. Although universities compete for undergraduate students, the market for higher education is less than perfectly competitive due to differences in geographical locations and academic reputations (Rothschild and White 1993). Furthermore, the institutional environment in which universities compete has more variations along different market dimensions compared to primary and secondary schools (Lowry 2004). Based on these arguments, competition in the higher education mar- 
ket is divided into two market dimensions: geographical market and product market. In almost all of the activities of a university, whether academic or non-academic in nature, the university is involved in a competitive market environment (Raines and Leathers 2003). This competition is further complicated since the students act as both consumers and inputs, and after graduation they are considered as outputs of the universities. At the same time, students also provide both monetary payments and quality inputs that influence the performance of other students, while universities provide both financial aids and educational services (Rothschild and White 1995). The interaction between students and universities determines the published tuition and the individual financial aid grant awards (Winston 1999).

Spatial econometrics are used extensively in the analysis of the geographical market dimension. Among the earliest economic studies that applied spatial econometrics technique is Ellison and Glaeser (1997), where the authors look into the geographic concentration of U.S. manufacturing industries in the Silicon Valley caused by industry-specific spillovers and natural advantages. Most of the manufacturing industries are found to be slightly localized, where the presence of manufacturing firms in the local market attracts other firms to establish their bases there. Brett and Pinkse (2000) use spatial econometrics models to study the interaction between municipal governments in British Columbia in determining tax rates and social services. They find little evidence that the tax rate in a municipality is influenced by the tax rate of other municipalities. Pinkse et al. (2002) analyze spatial price competition in the U.S. wholesale gasoline market. The price of gasoline between terminals is highly localized and strongly affected by the price of neighboring terminals. Kennan and Walker (2011) study the location choices for U.S. interstate migration based on income differentials. The magnitudes of migration flows is positively affected by changes in average state wage level. 
The geographical market for higher education is characterized by the coordinate of a university and its proximity to other universities. In this setting, a university chooses its location in the geographical market exogenously and then determines its prices. Since all of the universities and colleges in the sample were established a long time before the sample period started, the locations of universities and colleges could be treated as exogenous.

Most of the studies in the geographical market of higher education analyze geographical factors from the viewpoint of potential students. These studies looked at how the proximity of a university to students' homes affects their enrollment decision. Anderson et al. (1972) find that the enrollment of a student at a particular university is positively influenced by its geographical proximity through several ways: lower cost of attendance, change in preferences, and greater amount and better quality of information available to the potential student. This causes many undergraduate students to enroll at universities and colleges that are located within their state of residence or neighboring states. Hoxby (1997) finds that in 1949, around 93\% of undergraduate students in the U.S. were enrolled at institutions that were located in their home states. Since these universities draw their pool of applicants from a limited geographical area, the competition between them is defined loosely by the local boundaries. However the percentage of students attending institutions within states of residence has since fallen from $83 \%$ in 1963 (Harris 1972) to around 75\% in 1994 (Hoxby 1997). This suggests that there is an increasing growth in the integration of the geographical market for education where each university is now facing an increasingly larger market of potential students. Card (1995) analyzes the impact of geographical proximity of colleges on the return to education. The education level and income of a person in areas with a nearby college are found to be significantly higher than other persons, and these gains are concentrated among persons with poorly educated parents. 
A study by McMillen et al. (2007) is among the first attempts to analyze spatial price competition in the higher education sector. They find that the proximity of competitors positively affects price competition between universities in the geographical market. However, they do not follow any spatial model selection process and simply decided to use the spatial autoregressive (SAR) model among several potential spatial models. Furthermore, the sample used in their study consists of 929 private institutions only.

\subsection{Data}

The university-level data are drawn from the National Center for Educational Statistics (NCES) and its Integrated Postsecondary Education Database System (IPEDS). The U.S. county-level data are taken from the Small Area Income and Poverty Estimates (SAIPE) published by the Bureau of the Census, U.S. Department of Commerce.

The sample used in this study consists of 528 higher learning institutions in the U.S. from 2004 to $2011^{5}$. Using the 2000 Carnegie Classification, only universities where the bachelor's degree accounts for at least $10 \%$ of all undergraduate awards are selected into the sample. Table 3.1 shows the number of institutions in the sample based on the 2000 Carnegie Classification.

The published out-of-state tuition (PTUITION) is used as the dependent variable. Only public universities discriminate students based on residential status and charge lower tuition to in-state students. As these public institutions receive financial support from state governments, the in-state tuition is influenced by the welfare

\footnotetext{
${ }^{5}$ The sample period is from 2004 to 2011 due to data constraints. To keep the analysis simple, the higher learning institutions in the sample will be referred to as 'universities' throughout this study.
} 
Table 3.1: Sample distribution based on the Carnegie Commission Classification 2000

\begin{tabular}{lr}
\hline \hline 2000 Carnegie Classification & Total \\
\hline Doctoral/Research Universities: Extensive & 135 \\
Offer a wide range of baccalaureate programs and committed to graduate education & \\
through the doctorate. Award 50 or more doctoral degrees per year across at least & \\
15 disciplines. & 68 \\
\hline Doctoral/Research Universities: Intensive & \\
Offer a wide range of baccalaureate programs and committed to graduate education & \\
through the doctorate. Award at least 10 doctoral degrees per year across three or & \\
more disciplines, or at least 20 doctoral degrees per year overall. & 206 \\
\hline Masters Colleges and Universities I & \\
Offer a wide range of baccalaureate programs and committed to graduate education & \\
through the master's degree. Award at least 40 or more master's degrees per year & \\
across three or more disciplines. & \\
\hline Masters Colleges and Universities II & 72 \\
Offer a wide range of baccalaureate programs and committed to graduate education & \\
through the master's degree. Award 20 or more master's degree per year. & 26 \\
\hline Baccalaureate Colleges - Liberal Arts & \\
Primarily undergraduate colleges with major emphasize on baccalaureate programs. & \\
Award at least half of their baccalaureate degrees in liberal arts fields. & \\
\hline Baccalaureate Colleges - General & \\
Primarily undergraduate colleges with major emphasize on baccalaureate programs. & \\
Award less than half of their baccalaureate degrees in liberal arts fields. & \\
\hline Baccalaureate/Associate's Colleges & \\
Undergraduate colleges where the majority of conferrals are at subbaccalaureate level & \\
(associate's degrees and certificates), but bachelor's degrees account for at least ten & \\
percent of undergraduate awards. & \\
\hline Grand Total & \\
\hline \hline
\end{tabular}

Note: The definition of each category is taken from IPEDS.

goals and does not fully reflect the demand and cost factors in the market. Out-ofstate students are charged higher tuition by these public universities, while private universities usually charge the same tuition to all students ${ }^{6}$.

Universities are also known to use financial aid offers to attract students. Breneman (1994) finds that institutions with declining academic quality levels are less likely to send their signals by lowering their published tuition. Rather, these institutions would offer higher amounts of financial aid to compensate for the decline in

\footnotetext{
${ }^{6}$ All 210 private universities in the sample charge the same tuition to all students.
} 
quality. Although changes in prestige have no impact on published tuition, Monks and Ehrenberg (1999) find that a drop in prestige level would induce universities to reduce their net tuition. Since financial aid is a more favorable channel to send signal of prestige and quality levels, it is possible that a university would be more sensitive towards any changes in finanical aids offered by other universities than changes in their published tuition. Therefore the published tuition less the average institutional financial aid (NTUITION) is also used as a dependent variable.

Explanatory variables used in the study include the observed demand and cost factors, and local variants. The demand and cost variables used in this study are as follows: enrollment of undergraduate students (USTD), enrollment of graduate students $(G S T D)$, total endowment of the university (ENDOW), proportion of students receiving any financial assistance (PRAID), number of full time faculty staff (FACULTY), research spending ( RESEARCH), and teaching expenditure (TEACH). These variables are explained in the following paragraphs.

The first observed demand variable used is the enrollment of full time undergraduate students throughout the academic year. The enrollment of undergraduate students is directly associated with prices since the undergraduate students form the main student body at universities, and they are the ones that pay most of the tuition and fees collected by universities. As more undergraduate students are enrolled, universities need to provide adequate facilities to accommodate these additional students and maintain the universities' quality levels. This may translate into higher costs. However, at the same time, the burden of cost shared by each student may decrease since most of the facilities in universities are shared by students. A university is able to enroll more undergraduate students without the need to hire additional faculty members or expand the facilities on campus as long as the maximum capacity is not reached. In this situation, a university facing rising undergraduate enrollments may 
decide to charge lower prices. Based on Garvin (1980), the direction of a change in enrollment of undergraduate students on prices depends on the goal of the universities. An elite private university is usually more concerned with institutional prestige and student quality, and therefore is motivated to raise its prices when facing rising undergraduate enrollments. On the other hand, most of the large public universities are committed to a service philosophy which values enrollments more than prestige and quality. Furthermore, these public universities receive state funding that helps them meet their financial needs. Therefore public universties are expected to lower their prices when there is an increase in undergraduate enrollment.

The existence and extent of graduate programs contribute towards the prestige level of a university (Garvin 1980). The enrollment of graduate students enters the model separately from undergraduate enrollment due to their different behaviors and different ways of influencing the operational costs of universities. In both cases of teaching and research assistantships, graduate students are being paid lower than the costs of hiring additional faculty or research staff, and thus indirectly reduce the operational cost of the university. Furthermore, the costs associated with creating and expanding graduate programs are much lower than the benefits that they contribute to the university (Garvin 1980). Hence, it is expected that graduate enrollment would have a negative impact on prices. However since graduate enrollment indirectly affects prices, the influence may not be as strong as the effect of undergraduate enrollment on prices.

Endowment is included in the model to control for the size and financial ability of universities. Tobin (1974) suggests that endowment is the most important factor that a university should take into account when formulating its prices and quality level. The hierarchy in the market of higher education is determined initially by the amount of endowment since a large endowment gives university the ability to 
enhance its institutional quality and attract students with higher quality (Winston 1999). However, the effect of endowment on prices is ambiguous. A university with a larger endowment may reduce its prices by channeling some of the endowment as scholarships and financial aids to students. Monks and Ehrenberg (1999) find that universities tend to pass some portions of their increased endowment to their students through more generous financial aid packages, which translates to lower net tuition. Income from tuition and fees is usually the dominant source of revenue for universities with smaller endowment. A university with a small endowment is expected to charge higher prices compared to a well-endowed university. In this case, the relationship between endowment and prices is expected to be negative. A university with a large endowment is able to attract more students who are willing to pay higher prices in order for the university to preserve its financial health that indicates its quality long after they graduate (Hansmann 1990). Furthermore, a larger endowment is a signal that the university has a higher quality level; and a university may use its price to convey that signal. There is also a possibility of adverse effects from endowment, where a university with a large endowment may receive less donations from its alumni (Oster 2003). This could negatively affect public fundings and corporate givings as well. In this situation, a university may increase its price to compensate the reduction in other sources of revenue so that the university is able to sustain its endowment growth.

For a potential student, the proportion of students receiving aid reflects the probability that the student is able to receive financial aid once the student is enrolled. The ratio also indicates how generous a university is with its students. Besides quality level, financial aid is also an important factor that determines the college choice of a student. A university may use financial aid as a tool to attract enrollment of students. Furthermore, a university may also offer financial aid to attract high quality 
students. However, a university incurs higher cost when it awards more financial aid to students. In this scenario, the university is motivated to raise its price in order to meet the additional costs due to a larger number of students that receive financial aid. Based on this, the proportion of students receiving aid is expected to have a positive direct effect on prices. However, the feedback effect of the proportion of students receiving aid is expected to be negatively related to price. As other universities give financial aids to a greater number of students, an average university within their market boundary may lower its prices in order to attract enrollment of students. To do this, the university may either reduce its published tuition, or increase the average aid amount given to students so that its net tuition is now lower. While the total amount of financial aid disbursed to students may be viewed as potentially endogenous to prices, the proportion of students receiving aid is not since a higher proportion may not necessarily translates into a greater amount of financial aids ${ }^{7}$.

Garvin (1980) views faculty members as the main actors in universities that produce prestige through their research and publications. There is a positive relation between the prestige of a university and the number and quality of its faculty members. Faculty members with a higher quality level are expected to produce higher quality research and publications, while more research and publications could be produced with a larger number of faculty members that would add to the prestige level of the university. Several studies such as Radner et al. (1975) treat faculty as the main input in the production function of universities while student enrollment is used as a scale variable for institutional size. The faculty size and other variables that are measured in proportion to it, such as faculty publications and salaries, have also been used as indicators of prestige and quality levels (Volkwein and Sweitzer 2006).

\footnotetext{
${ }^{7}$ As mentioned earlier in this paragraph, the proportion of students receiving aid is included in the model to represent the probability that a student will receive financial aid after enrollment at a university, not the amount of aid received.
} 
Research spending and teaching expenditure form the main bulk of the operational cost of universities. These two types of expenditures represent the academic origin and main activities of universities. While universities of today have evolved and engaged in a growing number of non-academic activities, resesarch and teaching remain the most important activities for universities. Nerlove (1972) develops a production possibility frontier of a university in which the university jointly produces two goods; undergraduate education, and research and graduate education. In that model, the relationship between undergraduate education, and research and graduate education could either be complement or substitute in nature.

Furthermore, one of the ways for a university to improve its ranking is by producing more research and high quality students. To do this, the university needs to spend more on research and teaching, and hence there is a pressure to increase revenues in order to meet the financial requirements for more research and better teaching. As a university changes its research spending and teaching expenditure, it is expected that other universities that are located in the same geographical market and product market will also respond by changing their research spending and teaching expenditure; and this causes a feedback effect that influences their prices. However the direction of the feedback effect is ambiguous. A university may decide to increase or decrease its price when its neighbors raise their price due to higher research spending and teaching expenditure.

A positive feedback effect from research spending and teaching expenditure indicates that universities in the market tend to move in the same direction. In this case, an increase in research spending or teaching expenditure of other universities leads an average university to follow their steps and increase its prices. The change in the prices may be used to signal the new quality level of education offered at these universities, where greater amounts of research spending and teaching expenditure 
are associated with higher level of quality.

A negative feedback effect suggests that a university decides to move in the opposite direction from its neighboring universities. As other universities raise their research spending and teaching expenditure, a university may decide to charge lower prices in order to compensate for its relatively lower quality level. Furthermore, the university may want to increase its market share among prospective students who put greater weight on the cost of education than the quality level. Similarly, if other universities reduce their research and teaching expenditures, a university may raise its prices to send signals of its relatively higher quality level since it did not change its research spending and teaching expenditure.

Some readers may raise the issue of potential endogeneity between teaching expenditure and research spending with prices. This endogeneity issue might be more serious if total tuition revenue is used instead of published and net tuitions. However, since published and net tuitions are measures of prices per students while teaching expenditure and research spending are in aggregate values, the possiblity of endogenous relationship between them may be ignored ${ }^{8}$.

To control for local variants in the product market, two variables are used: the admission test scores $(S A T A C T)$ and the admission rate (ADMRATE). Both are among the most used variables to classify universities into different qualitative categories. The use of admission test scores as measures of educational quality of universities is motivated by Radner and Miller (1970), Spies (1973), Kohn et al. (1976), Fuller et al. (1982), Savoca (1990), and Clarke (2002). For this analysis, the ACT Composite 25th percentile score of students who gained admission is used as a proxy for quality of a

\footnotetext{
${ }^{8} \mathrm{~A}$ higher published and net tuitions may not necessarily translate into higher revenue if enrollment is small, while teaching expenditure and research spending could still be high even with low published and net tuitions if the university receives large funding from the government or other parties. Nevertheless, this issue will be discussed again in the results section.
} 
university.

The admission rate has been used as a measure of quality in previous studies such as Black and Smith (2006) ${ }^{9}$ and Volkwein and Sweitzer (2006). High admission test scores and low admission rates reflect a high prestige level, while low admission test scores and high admission rates reflect a low prestige level. A university that reduces its entrance requirements may bolster enrollments of lower qualified students but leads to a decline in the applications from better qualified students (Webster 2001). Since both admission test scores and admission rate represent prestige and quality levels, admission test scores are expected to positively affect prices while admission rate negatively affects prices.

Population density in the county $(P O P D E N)$ and median income level of the county $(M E D I N C)$ are used to control for local variants in the geographical market. Population density is measured in thousand of persons per square mile, where it is a ratio of total population (in thousand) in the county and the land size of the county. These measures of geographical variants represent the urbanization and cost of living effects to the prices of universities. The idea of including these measures is that geographical areas with booming population and increased income are better equipped with infrastructures and richer economic activities. Universities that are located in these areas are more inclined towards raising their tuitions (Bailey et al. 2004).

A dummy variable that equals one for public institutions $(P U B L I C)$ is added to control for the differences between public and private universities. Public universities receive public funding and charge lower tuition to in-state students ${ }^{10}$, while private

\footnotetext{
${ }^{9}$ Instead of admission rate, Black and Smith (2006) used the rejection rate as a quality indicator of a university.

${ }^{10}$ In-state student refers to a student who is a resident in the state where the university is located, while out-of-state student refers to a student who is not a resident in the state where the university is located.
} 
Table 3.2: Descriptive statistics

\begin{tabular}{lrlrr}
\hline \hline Variable & \multicolumn{1}{c}{ Mean } & Std Dev & \multicolumn{1}{c}{ Min } & \multicolumn{1}{c}{ Max } \\
\hline PTUITION (in log) & 9.8493 & 0.4376 & 8.0956 & 10.7208 \\
NTUITION (in log) & 9.3896 & 0.3847 & 6.3936 & 10.3420 \\
USTD (in thousand) & 10.2381 & 8.9905 & 0.5590 & 63.1010 \\
GSTD (in thousand) & 3.3817 & 3.6722 & 0.0000 & 24.6380 \\
ENDOW (in log) & 17.9385 & 2.1324 & 9.1736 & 24.3322 \\
PRAID & 0.8185 & 0.1399 & 0.2300 & 1.0000 \\
FACULTY (in thousand) & 0.5145 & 0.4630 & 0.0290 & 3.3560 \\
RESEARCH (in log) & 15.3172 & 2.6681 & 7.4360 & 20.9369 \\
TEACH (in log) & 17.9412 & 1.1306 & 14.9131 & 21.3560 \\
SATACT & 21.3239 & 3.6003 & 5.0000 & 34.0000 \\
ADMRATE & 0.6445 & 0.1961 & 0.0626 & 1.0000 \\
POPDEN (in thousand) & 2.6403 & 8.9913 & 0.0026 & 69.4430 \\
MEDINC (in log) & 10.7575 & 0.2295 & 9.9612 & 11.5813 \\
PUBLIC & 0.6023 & 0.4895 & 0.0000 & 1.0000 \\
\hline \hline
\end{tabular}

Number of observations for each variable is 4224 .

universities are less dependent on public subsidies and charge the same tuition to all students regardless of their residential status. For ease of reference, a list of variables used and their description are provided in Table B.1 in Appendix B.1.

Table 3.2 reports the descriptive statistics of the sample. In this analysis, all monetary variables (PTUITION, NTUITION, ENDOW, RESEARCH, TEACH, and $M E D I N C)$ are used in log formats. For the sake of comparison, Table 3.3 shows the descriptive statistics of these monetary variables in dollar values.

Table 3.3: Descriptive statistics of monetary variables in raw values

\begin{tabular}{lrrrr}
\hline \hline Variable & \multicolumn{1}{c}{ Mean } & Std Dev & \multicolumn{1}{c}{ Min } & \multicolumn{1}{c}{ Max } \\
\hline PTUITION (in \$) & 20787.61 & 8861.90 & 3280.00 & 45290.00 \\
NTUITION (in \$) & 12755.42 & 4231.34 & 598.00 & 31007.00 \\
ENDOW (in \$ million) & 472.00 & 1840.00 & 0.96 & 36900.00 \\
RESEARCH (in \$ million) & 61.30 & 143.00 & 0.00 & 1240.00 \\
TEACH (in \$ million) & 124.00 & 189.00 & 3.00 & 1880.00 \\
MEDINC (in \$) & 48264.10 & 11638.88 & 21189.00 & 107075.00 \\
\hline \hline
\end{tabular}




\subsection{Methodology}

All universities are assumed to behave as utility-maximizing entities and engage in a Bertrand game, where the price set by a university is partly influenced by the price adopted by other universities located in the same market, and partly upon demand and cost factors. The methodology employed in this paper follows Baller et al. (2001), Baltagi et al. (2007), and Elhorst (2010). Altogether there are four spatial model specifications considered in this study, which shall be discussed in the model specification test subsection later.

The methodology section is organized as follows. Firstly the endogeneity issue between enrollment of undergraduate students and prices is addressed. Next, the presence of spatial effects in the prices of universities is investigated using simple spatial autocorrelation statistics. Once the presence of spatial effects is confirmed, a hybrid model specification approach is employed to choose the most appropriate spatial models. The next section describes the estimation method used. The last subsection explains how the regression results are interpreted.

\subsubsection{Endogeneity of Enrollment with Prices}

There is a possibility that enrollment of undergraduate students may be endogenous to prices. Previous researches such as Savoca (1990) and Soo and Elliott (2010) suggest that the relationship between between enrollment of students and prices should not be simply treated as exogenous without any investigation. To address this issue, this study follows the suggestion for endogeneity test as proposed by Soo and Elliott (2010), where the results from a pooled ordinary least squares (OLS) regression and

a two stage least squares (2SLS) regression are compared using the Hausman (1978) specification test. The basic idea behind the Hausman test between OLS and 2SLS 
is that if enrollment of undergraduate students is exogenous to prices, then the two regression methods have no systematic differences.

In order to allow for correlation of errors within individual university over time, the standard errors are clustered by university. Since the standard errors are clustered by university, the two-step generalized method of moments (2SGMM) method is used instead of standard instrumental variable (IV) method for a more efficient and consistent coefficient estimates and diagnostic tests (Baum et al. 2003). There are two instrumental variables used for enrollment of undergraduate students: lagged enrollment of undergraduate students, and lagged proportion of students receiving any financial aid. These two variables are chosen as instruments due to the lack of other candidates from the data source. As noted by Kennedy (2003), predetermined variables such as the lagged values of explanatory variables could be used as instruments since they are correlated with the original explanatory variables that are potentially endogenous. Furthermore, these predetermined variables are not contemporaneously correlated with prices, which is a weaker restriction than strict exogeneity.

Several identification tests are performed to verify the suitability of the instruments used for the 2SGMM model. The results are presented in Table B.2 in Appendix B.2. The underidentification LM test shows that enrollment of undergraduate students is identified in both published tuition and net tuition models. The large $F$ statisitcs from the weak identification Wald test indicate that lagged enrollment of undergraduate students and lagged proportion of students receiving any financial aid are strongly correlated with enrollment of undergraduate students. However the Hansen $J$ test for overidentification indicates that the chosen instruments are appropriate in published tuition only.

The Hausman test is used to compare the pooled OLS estimates and the 2SGMM estimated. The Hausman test statistics are derived using a bootstrapping method 
suggested by Cameron and Trivedi (2005) since the standard errors are clustered by university. The results from the Hausman test indicate that there are no systematic differences between 2SGMM and pooled OLS estimates for published tuition and net tuition. This suggests that there is no endogeneity problem in the sample.

The difference-in-Sargen-Hansen test or $C$ test for exogeneity (Eichenbaum et al. 1988) is used to investigate further the orthogonality of enrollment of undergraduate students. Unlike the Hausman $\chi^{2}$ statistic, the $C$ statistic is nonnegative if both Hansen-Sargan statistics are derived using the same error variance estimated from the restricted IV regression (Baum et al. 2003). The $C$ test results presented at the bottom of Table B.2 in Appendix B.2 failed to reject the null hypothesis of endogeneity at $5 \%$ level of significance, which is similar to the Hausman test results obtained earlier. Based on these findings, there is no need to use instrumental variables in the analysis.

\subsubsection{Test for Spatial Autocorrelation}

Following Baller et al. (2001), the first step in a spatial analysis is to verify the presence of spatial autocorrelation in the data. If there is no evidence of spatial autocorrelation, then the price competition model could be estimated using ordinary least squares (OLS) or any other panel regression method. However if there is a lack of independence across spatial units, this could lead to model misspecification problems (Anselin 1988b).

Two statistical tests are used to examine the presence of spatial autocorrelation: Moran's I-statistic (Moran 1950) and Geary's C-statistic (Geary 1954). 
The Moran's I-statistic is calculated as follows:

$$
I=\frac{N \sum_{i=1}^{n} \sum_{j=1} w_{i j}\left(x_{i}-\bar{x}\right)\left(x_{j}-\bar{x}\right)}{\sum_{i=1}^{n} \sum_{j=1} w_{i j} \sum_{i=1}^{n}\left(x_{i}-\bar{x}\right)^{2}}
$$

where $N$ is the number of spatial units, $\bar{x}$ is the mean of the variable, $x_{i}$ is the value of the variable at a particular location, $x_{j}$ is the value of the variable at another location, and $w_{i j}$ is a weight index that measures the location of $i$ relative to $j$. The Moran's $I$-statistic varies between -1.0 and 1.0 which indicate negative and positive spatial autocorrelation respectively, and zero indicates spatial independence.

The Geary's $C$-statistic is constructed as follows:

$$
C=\frac{(N-1) \sum_{i=1}^{n} \sum_{j=1} w_{i j}\left(x_{i}-x_{j}\right)^{2}}{2 \sum_{i=1}^{n} \sum_{j=1} w_{i j}\left(x_{i}-\bar{x}\right)}
$$

The Geary's $C$-statistic varies from 0 to 2 , where 0 indicates a perfect positive spatial autocorrelation, 1 indicates spatial independence, and 2 indicates a perfect negative spatial autocorrelation.

The Moran's I-statistic is constructed by examining the differences between the variables of each spatial unit and its mean, and weight the differences based on their distance. The Geary's $C$-statistic uses the differences between the variables of each pair of spatial units instead, and weights the differences based on their distance. Therefore the Moran's I-statistic is more sensitive to global differences as it focuses on how similar or dissimilar each pair of observations is to the overall average, while the Geary's $C$-statistic is more sensitive to local differences as it focuses on how different observations of each pair are from each other. In both tests, the null hypothesis of spatial randomness is tested against the alternative of spatial autocorrelation, where the values of a variable of interest are systematically related to the spatial distance. 
To test for the presence of spatial autocorrelation in the geographical market dimension, the haversine distance measured from the longitude and latitude coordinates of the universities' locations are used as the spatial weight matrix. In this case, the matrix $W$ in equations (3.1) and (3.2) is treated as a geospatial weighting matrix. Since the location of universities in the geographical market is fixed (as the campuses do not move), the geospatial weighting matrix is also fixed. This allows for a panel regression method to be used to analyze the geographical market later. It is convenient to apply the haversine distance measurement when units are located on the surface of the earth and the locations of the units in the geographical market are represented by coordinate variables, in this case the longitude and latitude coordinates (Drukker et al. 2013). The weights assigned in matrix $W$ are inversely related to the distances between units, where smaller distances are assigned with larger weights. This specification assumes that all universities in the U.S. are located within the same geographical market, and the spatial effect is measured at the global level.

In order to investigate whether price determination is influenced by spatial effects, the elements in the spatial weight matrix represent the true distance between universities in each market dimension. The test for spatial autocorrelation is firstly performed where all universities are included in the market dimension. If the presence of spatial autocorrelation is confirmed, then the next step is to determine the model specification. However if there is no spatial autocorrelation detected, then the spatial weight matrix will be truncated into smaller market size, since putting all universities in the market size may be too large and hence leading to no spatial dependence between the universities. Other studies such as Ying (2003) use different distance bands to find the optimal distance in which the spatial autocorrelation is maximized.

For the geographical market, if the U.S. continent is too large to be considered as a market, then the market size will be reduced where only universities that are 
located within certain distance are considered to be in one market. As a first step, the 400 miles distance is chosen to limit the market size. The decision to use 400 miles as the cut-off point is motivated by McMillen et al. (2007), since the 400 miles distance resembles a one-day drive that makes universities located within this distance as possible substitutes. In this approach, universities that are located beyond 400 miles distance are assigned zeros in the spatial weight matrix $W$ :

$$
w_{i j}= \begin{cases}1 & \text { if } d_{i j}<400 \quad \text { and } i \neq j \\ 0 & \text { otherwise }\end{cases}
$$

where $d_{i j}$ is the haversine distance between universities $i$ and $j$ in miles. The elements in the spatial weighting matrix are then row-normalized. Since the geographical market size is limited to 400 miles, the spatial effect from this specification represents the local spatial effect. If there are no spatial effects, then the process is repeated with a smaller market size. The absence of spatial effects from smaller market size would indicate that price competition between universities is not affected by geographical distance.

\subsubsection{Model Specification Test}

If the presence of spatial autocorrelation is confirmed, the next step would be to determine the proper model specification among different approaches that have been used to model spatial dependence (Baller et al. 2001, Elhorst 2010). While Moran's $I$-statistic is probably the best known test for spatial autocorrelation, Anselin and Rey (1991) found that the Moran's I test does not discriminate between different spatial specifications.

The two most common specifications used to incorporate spatial effects in applied 
empirical works are either in the form of a spatially lagged dependent variable, or expressed as a spatial autoregressive process for the error term (Anselin et al. 2000). Another specification that is considered in this study is where spatial effects are incorporated in both the spatially lagged dependent variable and the spatially lagged explanatory variables. Altogether there are four competing model specifications that are considered in this study. In the first specification, spatial autocorrelation exists in the spatially lagged dependent variable only. The second specification extends the first model by adding spatial autocorrelation from the spatially lagged explanatory variables. The third specification assumes that spatial autocorrelation is present in the error term only. The final specification combines the first and third specifications, where spatial autocorrelation is present in both the spatially lagged dependent variable as well as the error term.

In the first specification, a spatially lagged value of the dependent variable is introduced as an additional regressor:

$$
y=\rho W y+X \beta+u
$$

In equation (3.4), $y$ is a vector of price charged by universities, $W y$ is a spatially lagged price variable for spatial weight matrix $W, \rho$ is a spatial autoregressive coefficient, $X$ is a matrix of explanatory variables with coefficients $\beta$, and $u$ is an error term. The spatial lag is a weighted average value for prices of other universities located in the same market, and the weight matrix $W$ is constructed as an inverse distance measure between two universities in market space. This specification is known as the spatial autoregressive (SAR) model. If a spatially lagged dependent variable is disregarded, this may cause biased and inconsistent estimates of $\beta$ coefficients. In the SAR specification, the error term is assumed to be normally distributed with 
constant variance.

Note that equation (3.4) resembles a reaction function derived from Bertrand competition between universities, where the price set by a university depends partly upon the prices set by other universities located in the same market and partly upon demand and cost factors. Hence the proper way to model the price competition between universities is to use the SAR model as chosen by McMillen et al. (2007) in the analysis of price competition among private colleges.

The SAR model in equation (3.4) can be extended to include spatially lagged explanatory variables from neighbors as additional regressors. This model is known as the spatial durbin model (SDM):

$$
y=\rho W_{1} y+X \beta+W_{2} X \theta+u
$$

In equation (3.5), $W_{1}$ is the spatial weighting matrix for the spatially lagged dependent variable while $W_{2}$ is the spatial weighting matrix for the spatially lagged explanatory variables. $\theta$ is a vector of coefficients for the spatially lagged explanatory variables that need to be estimated. In this study, both spatial weighting matrices for the lagged dependent variable and the lagged explanatory variables are the same, $W_{1}=W_{2}=W$. The error term $u$ is normally distributed with constant variance.

The third specification incorporates spatial dependence in the error term:

$$
\begin{aligned}
& y=X \beta+v \\
& v=\lambda W v+u
\end{aligned}
$$

where $\lambda$ is the parameter associated with the spatial moving average, and $u$ is a standard error term. This specification is known as the spatial error model (SEM). 
If spatial dependence in the error term is ignored, the estimates for variance of $\beta$ coefficients may be biased and cause misleading inference.

As noted by Baller et al. (2001), the SAR model indicates a diffusion process in which a change in one location predicts an increased probability of a similar change in neighboring locations; while the SEM model may suggest for omitted spatially correlated regressors that would cause inferential errors. In the case of price competition between universities, the SAR model shows how a university would change its price if other universities change their prices. The SEM model indicates how the price set by a university is affected by shocks in the prices of its neighbors. The SDM model improves the SAR model's neighbor effects where the price set by a university is also affected by changes in the control variables of neighboring universities that affect their prices, which later influence the price of the university. The SAR and SDM models are better alternatives to the SEM model to analyze the market definition for universities since the SAR and SDM specifications make it possible to control the impact of a change in price by other universities upon a price set by a university.

The model specification process used in this paper follows the hybrid spatial specification method suggested by Florax et al. (2003) with some modifications. The hybrid approach itself is a combination of the classical approach outlined by Anselin and Rey (1991) and the robust approach proposed by Bera and Yoon (1993). The model selection process is described in the following paragraphs.

For the model selection process, first consider a linear regression equation for $n=1, \ldots, N$ spatial units:

$$
y=X \beta+u
$$

where $y$ is an $N$ by 1 vector of observations of the dependent variable, $X$ is an $N$ by $k$ matrix of explanatory variables, $\beta$ is a $k$ by 1 vector of estimated coefficients, 
and $v$ is an $N$ by 1 vector of uncorrelated error terms with mean zero and constant variance.

The null hypothesis of spatial independence for all specification tests is based on a linear estimation of equation (3.7) obtained through the ordinary least squares (OLS) method. The results obtained from the OLS estimation is then used to investigate the presence of spatial dependence through means of misspecification tests. If the true data generating process is affected by spatial dependence, then the misspecification tests would indicate which type of spatial effects exists. The alternative hypothesis of spatial dependence is derived from different spatial regression equations, where the spatial effects are incorporated as a spatial lag, a spatial error, or both. The classical approach uses Lagrange multiplier (LM) test statistics derived from the OLS estimation under the null hypothesis of spatial independence, while the robust approach proposes robust versions of the tests. The hybrid approach simply suggests that both versions are used, where the robust test statistics are referred to if the classical tests fail to indicate the preferred model.

Equation (3.7) could be generalized to include spatial effects as follows:

$$
\begin{aligned}
& y=\rho W_{1} y+X \beta+v \\
& v=\lambda W_{2} v+u
\end{aligned}
$$

Equation (3.8) incorporates spatial dependence as a spatial lag and in the error term, and is known as the spatial autoregressive moving average (SARMA) model. In this study, the same spatial weighting matrix is used for both the spatial lag term and the spatial lag error term; $W_{1}=W_{2}=W$. The error term $u$ is normally distributed with mean zero and constant variance. According to Huang (1984), SARMA is the most general alternative of spatial dependence. A test on the absence of any spatial 
dependence involves testing the joint null hypothesis $H_{0}: \rho=\lambda=0$ in equation (3.8). The test for the joint spatial lag and spatial error is a Lagrange multiplier (LM) test taken from Anselin et al. (1996):

$$
L M_{\rho \lambda}=\frac{\left(e^{\prime} W y / s^{2}-e^{\prime} W e / s^{2}\right)^{2}}{N \tilde{J}_{\rho-\beta}-T_{1}}+\frac{\left(e^{\prime} W e / s^{2}\right)^{2}}{T_{1}}
$$

with

$$
N \tilde{J}_{\rho-\beta}=T_{1}+(W X \beta)^{\prime} M(W X \beta) / s^{2}
$$

where $e$ is an $N$ by 1 vector of regression residuals from equation (3.7), $s^{2}=e^{\prime} e / N$, $W X \beta$ is a spatial lag of the predicted values of equation (3.7), $M=I-X\left(X^{\prime} X\right)^{-1} X^{\prime}$ is the projection matrix, and $T_{1}=\operatorname{tr}\left(W^{\prime} W+W^{2}\right)$, with $\operatorname{tr}$ as the matrix trace operator. The $L M_{\rho \lambda}$ test statistic is distributed as a $\chi^{2}$ with two degrees of freedom. In this test, if the null hypothesis is rejected, then there is evidence of spatial dependence in the form of both spatial lag and spatial error. However, if the null hypothesis is not rejected, then there is not enough evidence of spatial effects ${ }^{11}$.

If the $L M_{\rho \lambda}$ test indicates the presence of general spatial effects, then other LM specification tests are considered to determine the most suitable model specification for price competition between universities.

The first test is the LM test for spatial lag dependence $\left(L M_{\rho}\right)$ as proposed by Anselin (1988):

$$
L M_{\rho}=\frac{\left(e^{\prime} W y / s^{2}\right)^{2}}{\left(N \tilde{J}_{\rho-\beta}\right)}
$$

The $L M_{\rho}$ test is distributed as $\chi^{2}$ with one degree of freedom. The null hypothesis of the $L M_{\rho}$ test is that the spatial lagged dependent variable has no spatial autocor-

\footnotetext{
${ }^{11}$ The $L M_{\rho \lambda}$ test is not included in the list of tests under the classical, robust, or hybrid approaches mentioned earlier. However since SARMA is the most general spatial form and it is possible that spatial effects exist in both spatial lag and spatial error, the $L M_{\rho \lambda}$ test should be performed.
} 
relation, $H_{0}: \rho=0$.

The second test is the LM test for spatial error $\left(L M_{\lambda}\right)$ as suggested by Burridge (1980):

$$
L M_{\lambda}=\frac{\left(e^{\prime} W e / s^{2}\right)^{2}}{T_{1}}
$$

The $L M_{\lambda}$ test is distributed as $\chi^{2}$ with one degree of freedom. The null hypothesis of the $L M_{\lambda}$ test is the absence of spatial autocorrelation in the error term, $H_{0}: \lambda=0$.

It is important to note that both $L M_{\rho}$ and $L M_{\lambda}$ tests assume that the spatial dependence of the other form is absent ${ }^{12}$. For example, the null hypothesis for $L M_{\rho}$ test, $H_{0}: \rho=0$, is conditional upon $\lambda=0$. Similarly, the null hypothesis for $L M_{\lambda}$ test, $H_{0}: \lambda=0$, is conditional upon $\rho=0$. If this assumption is violated, then the $L M_{\rho}$ and $L M_{\lambda}$ tests based on the OLS regression of equation (3.7) are no longer valid. To overcome this potential problem, Anselin et al. (1996) propose two tests that are robust to the presence of the other form of spatial dependence. The LM test for spatial lag that is robust to misspecification of a spatial error process $\left(L M_{\lambda}^{*}\right)$ is constructed as follows:

$$
L M_{\lambda}^{*}=\frac{\left(e^{\prime} W y / s^{2}-e^{\prime} W e / s^{2}\right)^{2}}{N \tilde{J}_{\rho-\beta}-T_{1}}
$$

The $L M_{\lambda}^{*}$ is distributed as $\chi^{2}$ with one degree of freedom. Similarly, the LM for spatial error that is robust to misspecification in the form of spatial lag term $\left(L M_{\lambda}^{*}\right)$ is constructed as follows:

$$
L M_{\lambda}^{*}=\frac{\left(e^{\prime} W e / s^{2}-T_{1}\left(N \tilde{J}_{\rho-\beta}\right)^{-1}\left(e^{\prime} W y / s^{2}\right)\right)^{2}}{T_{1}-T_{1}^{2}\left(N \tilde{J}_{\rho-\beta}\right)^{-1}}
$$

\footnotetext{
${ }^{12}$ The $L M_{\rho}$ and $L M_{\lambda}$ tests are listed in the classical specification approach mentioned earlier. Their robust versions, $L M_{\lambda}^{*}$ and $L M_{\lambda}^{*}$, are listed in the robust specification approach.
} 
The $L M_{\lambda}^{*}$ is distributed as $\chi^{2}$ with one degree of freedom. As suggested by Shehata (2012), the robust versions of the LM tests are used only when the null hypotheses in the classical versions of the test are rejected.

Altogether there are five LM specification tests mentioned above, where four of them $\left(L M_{\rho}, L M_{\lambda}, L M_{\rho}^{*}\right.$, and $\left.L M_{\lambda}^{*}\right)$ are from the hybrid approach. The results obtained from the various LM specification tests based on the OLS estimation of equation (3.7) are used to select the best spatial model among three spatial specifications: SARMA, SAR, and SEM ${ }^{13}$. Equation (3.7) is then estimated with spatial effects in the form suggested by these LM specification tests, either as in equation (3.4), equation (3.6), or equation (3.8).

Alternative to these LM specification tests are the likelihood ratio (LR) tests that could be used to investigate the presence of spatial effects in the model. There are three LR tests that correspond to the three types of spatial dependence discussed earlier. Since the SARMA specification is the most general specification that includes both types of spatial dependence, all three LR statistics are constructed from the SARMA specification as in equation (3.8). However, compared to the LM specification tests, there is additional cost to perform the LR specification tests since two estimations are needed for each LR test statistic. One of the estimations assumes spatial independence, while the other incorporates the spatial effects. To test for the joint hypothesis of no spatial autocorrelation in the spatially lagged dependent variable and the spatially lagged error term, $H_{0}: \rho=\lambda=0$, the $L R_{\rho \lambda}$ test is used. The $L R_{\rho \lambda}$ test statistic is distributed as a $\chi^{2}$ with two degrees of freedom. To test for the absence of spatial autocorrelation in spatially lagged dependent variable, $H_{0}: \rho=0$,

\footnotetext{
${ }^{13}$ There is another spatial specification that is considered in this paper, which is the Spatial Durbin Model (SDM). The SDM model is not included in the classical, robust, or hybrid specification approaches mentioned earlier. Therefore the specification test for SDM is different from the LM specification tests used for SARMA, SAR, and SEM models. The SDM specification test will be explained later.
} 
the $L R_{\rho}$ statistic is used. For the absence of spatial autocorrelation in the error term, $H_{0}: \lambda=0$, the $L R_{\lambda}$ test is performed on the results obtained from equation (3.8). Both the $L R_{\rho}$ and the $L R_{\lambda}$ are distributed as $\chi^{2}$ with one degree of freedom.

For the SDM model, different specifications are used to compare it with the previous three models. To check if SDM is better than SAR and SEM models, firstly it should be noted that the SAR and SEM models are actually restricted forms of the SDM specification ${ }^{14}$. Using the same spatial weighting matrix for the spatially lagged dependent variable and the explanatory variables, the SDM model is:

$$
y=\rho W y+X \beta+W X \theta+u
$$

If $\theta$ in equation (3.15) is zero, then this is actually a SAR model. Now, from the SEM model:

$$
\begin{aligned}
& y=X \beta+v \\
& v=\lambda W v+u
\end{aligned}
$$

the following equations are derived:

$$
\begin{aligned}
v(1-\lambda W) & =u \\
y(1-\lambda W) & =X \beta(1-\lambda W)+u \\
y & =\lambda W y+X \beta-\lambda W X \beta+u
\end{aligned}
$$

where equation (3.17) above is actually a constrained form of the SDM model if $\theta$ in

\footnotetext{
${ }^{14}$ The SDM specification is not considered in the classical, robust, or hybrid specification approaches mentioned earlier. Therefore all the specification tests used for SDM model are not derived from the OLS estimation in equation (3.7), rather the tests are derived from likelihood ratio $(L R)$ tests involving estimation of two different equations.
} 
equation (3.15) equals to $-\rho \beta$.

Based on these simple derivations, there are several tests that could be used from the SDM model. Firstly, to check if spatial autocorrelation is present in the spatially lagged dependent variable, the same LR-SAR test with null hypothesis $H_{0}: \rho=0$ is implemented.

To check for the absence of spatial autocorrelation in the spatially lagged explanatory variables, an LR test on the coefficients of the spatially lagged explanatory variables $\left(L R_{\theta}\right)$. The null hypothesis for the $L R_{\theta}$ test is $H_{0}: \theta=0$. The $L R_{\theta}$ test statistic is distributed as a $\chi^{2}$ with 12 degrees of freedom, which corresponds to the number of explanatory variables used in the model. If the $L R_{\theta}$ test fails to reject the null hypothesis, then the SAR specification should be chosen.

If the error term is affected by spatial autocorrelation, a nonlinear test $\left(N L_{\rho \beta}\right)$ is implemented with the null hypothesis $H_{0}: \theta=-\rho \beta$. The $N L_{\rho \beta}$ test was suggested by Burridge (1981). Similar to the $L R_{\theta}$ test, the $N L_{\rho \beta}$ test statistic is also distributed as a $\chi^{2}$ with 12 degrees of freedom. If the $N L_{\rho \beta}$ fails to reject the null hypothesis, then the SEM specification is favored. If both the $L R_{\theta}$ and the $L R_{\rho \beta}$ tests reject the null hypothesis, then the SDM specification should be chosen.

\subsubsection{Method of Estimation}

Once the spatial model specification is completed, the next step is to estimate the chosen model. Using the most general specification, the SARMA model, the likelihood function derived from equation (3.8) is as follows:

$$
\begin{aligned}
\log L= & -\frac{n}{2} \log \left(2 \pi \sigma^{2}\right)+\log |I-\rho W|+\log |I-\lambda W| \\
& -\frac{1}{2 \sigma^{2}}(y-\rho W y-X \beta)^{T}(I-\lambda W)^{T}(I-\lambda W)(y-\rho W y-X \beta)
\end{aligned}
$$


where $I$ is an $n \times n$ identity matrix. Depending on the chosen specification, $\rho$ and $\lambda$ could be zero. If the SAR model is chosen, then $\lambda$ is zero; and if the SEM model is chosen, then $\rho$ is zero. The likelihood function for the SDM model is derived from equation (3.5) as follows:

$$
\begin{aligned}
\log L= & -\frac{n}{2} \log \left(2 \pi \sigma^{2}\right)+\log |I-\rho W| \\
& -\frac{1}{2 \sigma^{2}}(y-\rho W y-X \beta-W X \theta)^{T}(y-\rho W y-X \beta-W X \theta)
\end{aligned}
$$

Equations (3.18) and (3.19) can be maximized to obtain efficient estimates of $\beta, \theta, \rho$, $\lambda$, and $\sigma^{2}$. Furthermore, this estimation can be simplified by using the fact that:

$$
\begin{aligned}
& |I-\rho W|=\prod_{j}\left(1-\rho \epsilon_{j}\right) \\
& |I-\lambda W|=\prod_{j}\left(1-\lambda \epsilon_{j}\right)
\end{aligned}
$$

where $\epsilon_{j}$ is the $j$ th eigenvalue of the spatial weighting matrix $W$. The maximum likelihood method is used to estimate the price competition model in the geographical market.

\subsubsection{Interpretation of the Results}

If the spatial effects are significant, then the interpretation of the coefficients estimated using the spatial regression method is different from a conventional least squares interpretation (LeSage and Pace 2014). In a spatial regression, the $r$-th coefficient, $\beta_{r}$, no longer represents the partial derivative of $y$ with respect to a change in the $r$-th explanatory variable from the matrix $X$, except for the SEM model. An examination of the data generating process for the spatial models shows that spatial regression models reflect non linear relationships between the dependent variable, $y$, and the 
right hand side variables. For non linear models, the interpretation of parameter estimates depends on the marginal effects of the variables, rather than the coefficients of the model.

For the SAR model, rearranging equation (3.4):

$$
y=\left(I_{n}-\rho W\right)^{-1}(X \beta+u)
$$

The partial derivative of $y$ with respect to the $r$-th variable in matrix $X$ in the SAR model is then:

$$
\frac{\partial y}{\partial x^{r}}=\left(I_{n}-\rho W\right)^{-1} I_{n} \beta_{r}
$$

It is clear from equation (3.23) that $\beta_{r}$ is no longer the partial change in $y$ as in the case of typical linear regression models. This is because a change in $x_{i r}$ now has two effects: one is a direct effect on the price of university $i, y_{i}$; and the other is an indirect effect where a change in $x_{j r}$ firstly affects the price of other universities in the market neighborhood, $y_{j}$, which in turn affects the price of university $i, y_{i}$ through the vector $W y$ in the model. In other words, a change in $x_{i r}$ would cause a feedback effect on $y_{i}$ through $y_{j}$.

An implication from the SAR model is that a change in the $r$-th variable for a single observation $i$ can potentially affect all price observations in vector $y$. With $n$ obervations, there is an $n \times n$ matrix of partial derivative responses for each of the $r$ explanatory variables in $y$ that could be considered (Won Kim et al. 2003, Kelejian et al. 2006). Therefore it is desirable to produce scalar summary measures of these varying impacts and make it easier to report the estimates of the marginal effects. The statistical significance of the marginal effects estimates could be verified if measures of dispersion of the estimates are available. 
Following the suggestion of LeSage and Pace (2009), the mean of the main diagonal elements of the $n \times n$ matrix in equation (3.23) is used as the scalar summary of the direct effect. This main diagonal element of this matrix show how changes in the $r$-th explanatory variable for university $i$ affect the price charged by university $i$, for all universities in the sample, $i=1, \ldots, n$. The mean of these $n$ elements is a scalar summary that represents how a change in the $r$-th explanatory variable in the typical or representative university affects the price of a typical university.

A similar problem exists when measuring the feedback effect on $y_{i}$ from a change in $y_{j}$ caused by a change in the $r$-th explanatory variable of university $j$. This indirect effect is represented by the off-diagonal elements of the $n \times n$ matrix in equation (3.23). To capture these effects, LeSage and Pace (2009) suggests that the mean of the sum of off-diagonal elements from each row is used to produce a scalar summary measure of the indirect effect. The estimates for direct and indirect effects of a SAR model are shown below:

$$
\begin{gathered}
M_{\text {direct }}=n^{-1} \operatorname{tr}(S(W)) \\
M_{\text {total }}=n^{-1} \iota^{\prime} S(W) \iota \\
M_{\text {indirect }}=M_{\text {total }}-M_{\text {direct }}
\end{gathered}
$$

where $S(W)=\left(I_{n}-\rho W\right)^{-1} I_{n} \beta_{r}$. The sum of direct and indirect effects is the total effect. There are two interpretations for the total effect as given by LeSage and Pace (2009). Firstly, it could be interpreted as the cumulative impact on the prices of all universities caused by a change in an explanatory variable of a university $j$. Secondly, it could be interpreted as the average total impact on the price of a typical university $i$ caused by a change in an explanatory variable that takes place in all universities. 
For the SDM model, from equation (3.5):

$$
y=\left(I_{n}-\rho W\right)^{-1}(X \beta+W X \theta+u)
$$

The partial derivative for the SDM model is:

$$
\frac{\partial y}{\partial x^{r}}=\left(I_{n}-\rho W\right)^{-1}\left(I_{n} \beta_{r}+W \theta\right)
$$

The interpretation for SDM estimates is similar to the interpretation for SAR model discussed earlier, the two scalar summary measures for the direct and indirect effects are constructed from the $n \times n$ matrix in equation (3.28).

For the SEM model, since the spatial dependence is present in the error term only, its partial derivatives could be derived directly from equation (3.6). The effect of a change in $x_{i r}$ on the price charged by university $i$ is:

$$
\frac{\partial y_{i}}{\partial x_{i}^{r}}=\beta_{r}
$$

From equation (3.29), the marginal effect of the own variable equals the estimated coefficients. In other words, the parameters of the SEM model represent the direct effect of changes in the explanatory variables on the dependent variable.

The effect of a change in $x_{i r}$ on the price of other universities, $y_{j}$, is:

$$
\frac{\partial y_{j}}{\partial x_{i}^{r}}=0
$$

From equation (3.30), the indirect effect in the SEM model is zero. Therefore there is no feedback effect in the SEM model. As the spatial error has no indirect effect, the interpretation for SARMA model, which combines spatial lag and spatial error 
elements, is similar to the interpretation for SAR model above.

In addition to the point estimates of the marginal effects, dispersion measures of the scalar summary statistics are needed in order to investigate the significance of the direct and indirect effects for the SAR and SDM models. LeSage and Pace (2014) propose that the measures of dispersion are derived by simulating values for the parameters from the estimated variance covariance matrix and plugging them into equations (3.23) and (3.28) to produce simulated summary effects estimates. The point estimates of the summary measures are taken from the median of the simulated summary estimates due to asymmetric distribution of the summary measures.

\subsection{Results}

In this section, firstly the presence of spatial autocorrelation is investigated by looking at the spatial correlation between the price variables and the location of universities in the geographical market dimension. Once the presence of spatial autocorrelation is confirmed, the following subsection discusses the model selection process using the hybrid spatial specification approach. The specification tests would suggest which model specification should be used to model price competition between universities. The next subsection then presents and discusses the regression results.

\subsubsection{Spatial Correlation}

To inspect for the presence of spatial autocorrelation in the geographical market dimension, two measures of spatial correlation are used: Moran's I-statistics and Geary's $C$-statistics. The longitude and latitude coordinates of universities are used to construct the spatial weighting matrix for the geographical market. The results are shown in Table 3.4. The Moran's $I$ statistics and the Geary's $C$ statistics each reject 
the null hypothesis of spatial independence in all years. This strongly suggests that published tuition and net tuition are affected by the presence of spatial autocorrelation in the geographical market.

Table 3.4: Spatial correlation statistics in the geographical market

\begin{tabular}{cllll}
\hline \hline & \multicolumn{4}{c}{ Geographical Market } \\
\cline { 2 - 5 } Year & \multicolumn{2}{c}{ Published Tuition } & \multicolumn{2}{c}{ Net Tuition } \\
\cline { 2 - 5 } 2004 & $0.140^{* * *}$ & $0.864^{* * *}$ & $0.080^{* * *}$ & $0.884^{* * *}$ \\
2005 & $0.130^{* * *}$ & $0.876^{* * *}$ & $0.069^{* * *}$ & $0.909^{* * *}$ \\
2006 & $0.126^{* * *}$ & $0.879^{* * *}$ & $0.051^{* * *}$ & $0.936^{* * *}$ \\
2007 & $0.118^{* * *}$ & $0.887^{* * *}$ & $0.065^{* * *}$ & $0.917^{* * *}$ \\
2008 & $0.110^{* * *}$ & $0.896^{* * *}$ & $0.048^{* * *}$ & $0.950^{* * *}$ \\
2009 & $0.116^{* * *}$ & $0.885^{* * *}$ & $0.036^{* * *}$ & $0.960^{* *}$ \\
2010 & $0.109^{* * *}$ & $0.894^{* * *}$ & $0.033^{* * *}$ & $0.958^{* *}$ \\
2011 & $0.106^{* * *}$ & $0.893^{* * *}$ & $0.024^{* *}$ & $0.959^{*}$ \\
\hline \hline
\end{tabular}

* Significant at $10 \%$ ** Significant at $5 \%$

*** Significant at $1 \%$

From Table 3.4, the Moran's I statistics for published tuition is between 0.106 and 0.140. As these values are positive and small, there is a moderate and positive correlation of changes in published tuition between universities. The Geary $C$ statistics for published tuition are less than but close to one, thus indicating a positive but weak spatial correlation. The range of Moran's I statistics for net tuition is much smaller and closer to zero, hence suggesting a weaker positive spatial correlation in net tuition. The Geary's $C$ statistics for net tuition also indicate a weaker spatial correlation compared to published tuition since the value of the statistics is closer to one.

Furthermore, the global spatial correlation in the geographical market for published tuition and net tuition seems to be weakening throughout the period of analysis. The Moran's I statistics are decreasing in values and approaching zero. The 
effect of local spatial correlation on net tuition is also weakening since its Geary's $C$ statistics are increasing in values and approaching one. However no similar trend is observed from the Geary's $C$ statistics for published tuition.

To illustrate the extent of spatial dependence in published tuition and net tuition in the U.S. higher education sector, the Moran scatterplot is used. The Moran scatterplot shows the relation between the dependent variable vector $y$ (in deviation from means form) and the average values of observations in the spatial lag vector $W y$. In the geographical market, the spatial weighting matrix $W$ is made of the inverse distance measures between universities based on their longitude and latitude coordinates. In this case, the nearer neighbors are given greater spatial weight while faraway neighbors are given smaller weight to influence published tuition and net tuition of a university.

The Moran scatterplot uses deviation from means on its axes with four Cartesian quadrants that center on zero values of the axes. The upper right quadrant, Quadrant I, reflects universities with price above the mean, and the average price of close neighboring universities are also above the mean. Quadrant II, the lower right quadrant, represents universities with price above the mean, but the average price of close neighboring universities below the mean. The lower left quadrant, Quadrant III, is made of universities that charge price below the mean, and the average price charged by close neighboring universities is also below the mean. Quadrant IV, the upper left quadrant, represents universities with price lower than the mean, but the average price of close neighboring universities is above the mean.

Figure 3.4 shows the Moran scatterplot of published tuition in 2010. Similar pattern is observed in all other years ${ }^{15}$. The figure suggests that there is a positive

\footnotetext{
${ }^{15}$ Please refer to Figure C.1 in Appendix C.1 for the Moran scatterplots of published tuition in all years.
} 
Figure 3.4: Moran scatterplot for published tuition in the geographical market for 2010

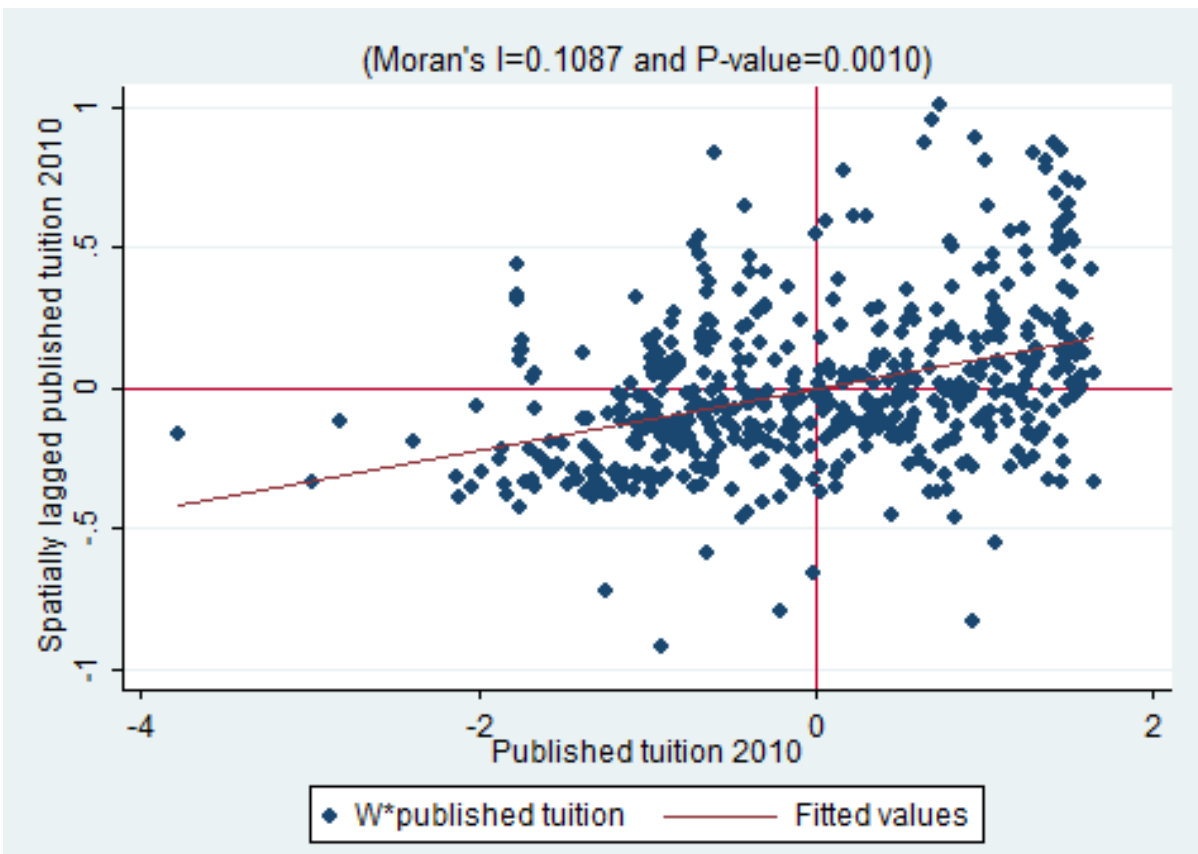

spatial correlation of published tuition between universities. From the scatterplot, there seems to be few outliers which consist of universities that charge published tuition much lower than the mean published tuition. This could be seen easily since the size of lengths of Quadrant III and Quadrant IV are longer.

The Moran scatterplot for net tuition in 2010 is shown in Figure 3.5. All other years display the same Moran scatterplot pattern ${ }^{16}$. Similar to published tuition, there is a positive spatial correlation of net tuition between universities in all years of the sample. However the positive spatial correlation seems to be weaker and approaching the horizontal axis towards the end of the sample years. Furthermore, the scatterplots for net tuition are more clustered towards the origin, while the scatterplots for published tuition are more spread out from the origins. The distribution of

\footnotetext{
${ }^{16}$ For the Moran scatterplots of net tuition in all other years, please refer to Figure C.2 in Appendix C.1.
} 
Figure 3.5: Moran scatterplot for net tuition in the geographical market for 2010

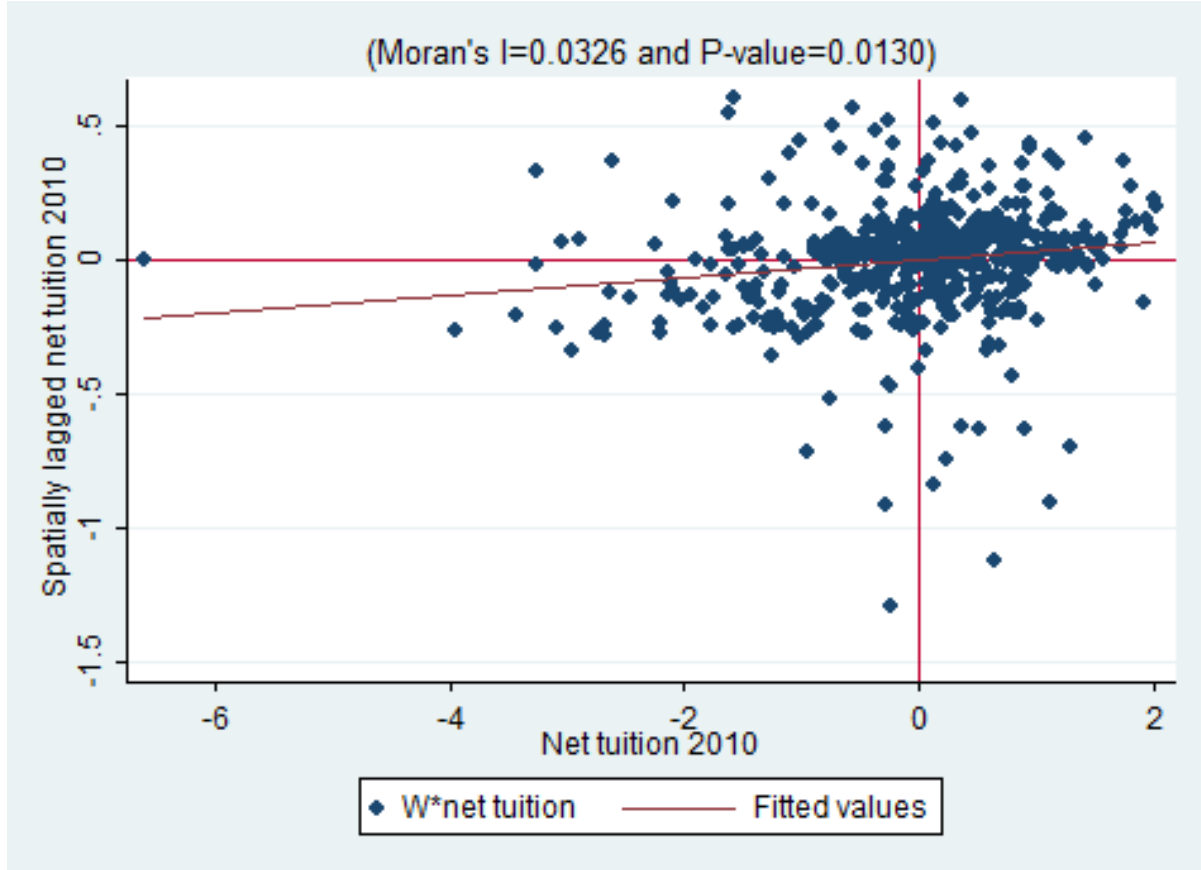

the Moran scatterplots is also affected by some outlier universities that charge lower net tuition than the mean net tuition. This is reflected by the widths of Quadrant III and Quadrant IV which are more than half of the graphs. In addition to that, the average net tuition charged by close neighbor universities is also lower than the mean net tuition from 2005 to 2010 since the heights of Quadrant II and Quadrant III in these years are more than half of the graphs.

The results from the Moran's I statistics and the Geary's $C$ statistics provide strong evidence of a significant spatial pattern in the geographical market dimension. The coefficients for spatial autocorrelation in the model is expected to be positive, although their size may be smaller with weaker significance level. Published tuition is expected to have stronger spatial dependence than net tuition. Since spatial correlation is significantly present, all subsequent analyses shall consider all universities 
in the sample a single market ${ }^{17}$.

\subsubsection{Model Specification}

Since the previous paragraphs confirmed the presence of spatial autocorrelation in the sample, the next step is to choose a spatial model through the hybrid specification approach described earlier. The model selection process starts with testing the spatial effects hypotheses on the SARMA model, which is the most general form of the spatial model. Both spatial lag and spatial error are included in the SARMA model. The null hypothesis for the $L M_{\rho \lambda}$ is that both the spatial lag and the spatial error are absent from the model. The results are shown in Table 3.5.

Table 3.5: SARMA tests for spatial model specification

\begin{tabular}{clc}
\hline \hline & \multicolumn{2}{c}{$L M_{\rho \lambda}$ Test: $H_{0}: \rho=\lambda=0$} \\
\cline { 2 - 3 } Year & \multicolumn{2}{c}{ Geographical Market } \\
\cline { 2 - 3 } 2004 & $85.1604^{* * *}$ & $18.6054^{* * *}$ \\
2005 & $73.1651^{* * *}$ & $14.8287^{* * *}$ \\
2006 & $66.9627^{* * *}$ & $10.2382^{* * *}$ \\
2007 & $53.8401^{* * *}$ & $13.6902^{* * *}$ \\
2008 & $42.0281^{* * *}$ & $9.9255^{* * *}$ \\
2009 & $41.6942^{* * *}$ & $9.8007^{* * *}$ \\
2010 & $34.5709^{* * *}$ & $8.9270^{* *}$ \\
2011 & $27.6063^{* * *}$ & $5.8811^{*}$ \\
\hline \hline
\end{tabular}

* Significant at $10 \% \quad * *$ Significant at $5 \%$

*** Significant at $1 \%$

The $L M_{\rho \lambda}$ test results indicate that spatial autocorrelation is strongly present in published tuition and net tuition in the geographical market since the null hypothesis of spatial independence is rejected in all years. The $L M_{\rho \lambda}$ statistics for net tuition seem to be decreasing towards the end of the sample period. Nevertheless, the null

\footnotetext{
${ }^{17}$ In the later part of the study, the market size is modified to analyze the spatial effects in a smaller or localized market.
} 
hypothesis of spatial independence is still rejected at 10\% significant level in 2011.

The results obtained from the $L M_{\rho \lambda}$ tests are identical with the results obtained from the spatial correlation analysis earlier. This suggest that the set of explanatory variables chosen to model price competition is able to incorporate spatial effects in the regressions for published tuition and net tuition in the geographical market.

Since the results from $L M_{\rho \lambda}$ tests suggest that spatial autocorrelation is present in the model, the next step is to check which type of spatial model better explains the geographical market. The null hypothesis of the $L M_{\rho \lambda}$ test equates both spatial lag and spatial error to zero. Since the $L M_{\rho \lambda}$ test rejects the null hypothesis, there is a need to clarify either both the spatial lag and the spatial error are not zero or only one of them is not zero.

Table 3.6 shows the specification test results for the geographical market. The null hypothesis in the $L M_{\rho}$ and $L M_{\rho}^{*}$ tests is that there is no spatial lag autocorrelation, while the null hypothesis for the $L M_{\lambda}$ and $L M_{\lambda}^{*}$ tests is that there is no spatial error autocorrelation.

For published tuition, the $L M_{\rho}$ and the $L M_{\lambda}$ statistics are significant in all years. Since both statistics are significant, the robust versions of the tests must be used as Shehata (2012) suggested. The robust $L M_{\rho}^{*}$ tests and the robust $L M_{\lambda}^{*}$ tests produce significant results in all years. These results suggest that the SARMA specification should be used to estimate published tuition in the geographical market.

When net tuition is used as the dependent variable, both $L M_{\rho}$ and the $L M_{\lambda}$ statistics are significant in all years. Similar with published tuition, the robust $L M_{\rho}^{*}$ tests for net tuition are significant in all years. However the robust $L M_{\lambda}^{*}$ tests are significant in 2007 only. Since panel regression is used to estimate net tuition in geographical market, the LM specification tests indicate that the SAR specification is the most suitable model. 
Table 3.6: The LM specification tests for spatial lag and spatial error in the geographical market

\begin{tabular}{|c|c|c|c|c|}
\hline \multirow[b]{2}{*}{ Year } & \multicolumn{4}{|c|}{ Geographical Market: Published Tuition } \\
\hline & $L M_{\rho}$ & $L M_{\rho}^{*}$ & $L M_{\lambda}$ & $L M_{\lambda}^{*}$ \\
\hline 2004 & $34.6379^{* * *}$ & $7.6580^{* * *}$ & $77.5024^{* * *}$ & $50.5225^{* * *}$ \\
\hline 2005 & $28.5134^{* * *}$ & $6.0693^{* *}$ & $67.0958^{* * *}$ & $44.6517^{* * *}$ \\
\hline 2006 & $28.7905^{* * *}$ & $7.2838^{* * *}$ & $59.6789^{* * *}$ & $38.1723^{* * *}$ \\
\hline 2007 & $23.6639^{* * *}$ & $5.7580^{* *}$ & $48.0821^{* * *}$ & $30.1761^{* * *}$ \\
\hline 2008 & $20.5748^{* * *}$ & $5.9066^{* *}$ & $36.1216^{* * *}$ & $21.4533^{* * *}$ \\
\hline 2009 & $20.2909^{* * *}$ & $6.0377^{* *}$ & $35.6565^{* * *}$ & $21.4033^{* * *}$ \\
\hline 2010 & $16.8879^{* * *}$ & $4.8491^{* *}$ & $29.7218^{* * *}$ & $17.6830^{* * *}$ \\
\hline \multirow[t]{2}{*}{2011} & $13.1751^{* * *}$ & $3.6416^{*}$ & $23.9648^{* * *}$ & $14.4312^{* * *}$ \\
\hline & \multicolumn{4}{|c|}{ "Geographical Market: Net Tuition } \\
\hline Year & $L M_{\rho}$ & $L M_{\rho}^{*}$ & $L M_{\lambda}$ & $L M_{\lambda}^{*}$ \\
\hline 2004 & $17.5011^{* * *}$ & $8.6582^{* * *}$ & $9.9472^{* * *}$ & 1.1044 \\
\hline 2005 & $13.2692^{* * *}$ & $5.5844^{* *}$ & $9.2443^{* * *}$ & 1.5595 \\
\hline 2006 & $9.7854^{* * *}$ & $5.2678^{* *}$ & $4.9704^{* *}$ & 0.4528 \\
\hline 2007 & $10.3250^{* * *}$ & $2.8702^{*}$ & $10.8200^{* * *}$ & $3.3652^{*}$ \\
\hline 2008 & $9.6171^{* * *}$ & $5.3875^{* *}$ & $4.5380^{* *}$ & 0.3084 \\
\hline 2009 & $9.5981^{* * *}$ & $4.9536^{* *}$ & $4.8471^{* *}$ & 0.2026 \\
\hline 2010 & $8.0337^{* * *}$ & $3.1884^{*}$ & $5.7386^{* *}$ & 0.8933 \\
\hline 2011 & $5.6931^{* *}$ & $2.9733^{*}$ & $2.9078^{*}$ & 0.1880 \\
\hline
\end{tabular}

${ }^{*}$ Significant at $10 \% \quad{ }^{* *}$ Significant at $5 \% \quad{ }^{* * *}$ Significant at $1 \%$

In the following paragraphs, the results obtained in the LM specification tests are to be compared with the LR specification tests. While the LM test results are obtained from the OLS estimation of equation (3.7), there is additional cost associated with the LR test since the test requires two estimations of the equation: with spatial effects and without spatial effects.

The results for the LR specification tests are presented in Table 3.7. The first column is the $L R_{\rho \lambda}$ statistics, which assumes that both $\rho$ and $\lambda$ are zero under the null hypothesis. The second column shows the $L R_{\rho}$ statistics, where the coefficient for the spatially lagged dependent variable is tested. The third column shows the $L R_{\lambda}$ test statistics, which investigate the presence of spatial dependence in the error 
term. This set of three columns are repeated twice, one for published tuition and another for net tuition.

Table 3.7: The LR specification tests for spatial autocorrelation in the geographical market

\begin{tabular}{cccc}
\hline \hline & \multicolumn{3}{c}{ Geographical Market } \\
\cline { 2 - 4 } Year & $L R_{\rho \lambda}$ Published Tuition \\
\cline { 2 - 4 } 2004 & $77.7826^{* * *}$ & $25.2124^{* * *}$ & $17.1963_{\lambda}{ }^{* * *}$ \\
2005 & $65.0525^{* * *}$ & $17.4533^{* * *}$ & $13.5938^{* * *}$ \\
2006 & $65.2801^{* * *}$ & $23.7109^{* * *}$ & $11.8282^{* * *}$ \\
2007 & $56.8954^{* * *}$ & $19.2873^{* * *}$ & $13.3393^{* * *}$ \\
2008 & $49.2005^{* * *}$ & $20.7528^{* * *}$ & $8.9359^{* * *}$ \\
2009 & $46.5370^{* * *}$ & $20.4943^{* * *}$ & $5.5715^{* *}$ \\
2010 & $39.0290^{* * *}$ & $15.8432^{* * *}$ & $4.4752^{* *}$ \\
2011 & $31.1853^{* * *}$ & $12.4347^{* * *}$ & $3.1060^{*}$ \\
\hline \hline & \multicolumn{3}{c}{ Net Tuition } \\
Year & $L R_{\rho \lambda}$ & $L R_{\rho}$ & $L R_{\lambda}$ \\
\hline 2004 & $29.1900^{* * *}$ & $21.1659^{* * *}$ & 1.2374 \\
2005 & $9.3385^{* * \dagger}$ & $0.0034^{\dagger}$ & $5.9176^{* * \dagger}$ \\
2006 & $4.9329^{* \dagger}$ & $0.0003^{\dagger}$ & $3.0947^{* \dagger}$ \\
2007 & $16.5785^{* * *}$ & $6.2253^{* *}$ & 0.0310 \\
2008 & $4.8093^{* \dagger}$ & $0.0005^{\dagger}$ & $3.1757^{* \dagger}$ \\
2009 & $4.9208^{* \dagger}$ & $0.0005^{\dagger}$ & $2.9127^{* \dagger}$ \\
2010 & $11.5307^{* * *}$ & 1.0533 & $6.6491^{* * *}$ \\
2011 & $5.1273^{*}$ & 0.5069 & 2.4851 \\
\hline \hline
\end{tabular}

* Significant at $10 \%$ ** Significant at $5 \%$

*** Significant at $1 \%$

$\dagger$ Convergence not achieved after 100 iterations

The LR specification test results for published tuition are similar with the LM specification test results obtained earlier. The $L R_{\rho \lambda}$ statistics are significant in all years, and at the same time both $L R_{\rho}$ and $L R_{\lambda}$ statistics are also significant in all years. This implies that spatial effects in published tuition are present in both types: the spatial lag and the spatial error. Therefore the SARMA specification should be used to model published tuition in the geographical market. The LR test results for 
net tuition do not lead to a very conclusive decision due to several factors. Firstly, the maximum likelihood estimation failed to reach convergence after 100 interations in four years: 2005, 2006, 2008, and 2009. Therefore the LR test results for these four years are not reliable. As for the remaining four years of the sample, different LR test results are observed. The $L R_{\rho \lambda}$ test remains significant in these four years. However in all those four years there is no year in which both $L R_{\rho}$ and $L R_{\lambda}$ are significant. The $L R_{\rho}$ is significant two years only; 2004 and 2007. The $L R_{\lambda}$ test is significant in one year only; 2010. Both $L R_{\rho}$ and $L R_{\lambda}$ are not significant in 2011. Furthermore, given that the $L R_{\rho \lambda}$ in 2011 is significant at $10 \%$ level only, this may indicate the absence of spatial effects in that year. Based on these LR test results for net tuition, the SAR model should be chosen for 2004 and 2007, and the SEM model should be chosen for 2010. However since panel regression is used to analyze the geographical market, there is a need to choose only one specification. Since the LR test specification for net tuition failed to lead to a conclusive result, the LM test results shall be used to decide the model specification. From the earler LM tests, the SAR model should be used to analyze net tuition.

Table 3.8 shows the SDM specification test results for the geographical market. As mentioned earlier in the Methodology Section, there are three tests involved. The first test, the $L R_{\rho}$ test, investigates if the spatially lagged dependent variable is significant or not. In the second test, the $L R_{\theta}$ test, checks the significance of spatially lagged explanatory variables. If the test fails to reject the null hypothesis, then the SAR specification is preferred over the SDM specification. The last test, the $N L_{\rho \beta}$ test, inspects if the coefficient of the spatially lagged explanatory variables equals to the negative value of the spatial coefficient of the dependent variable multiplied with the coefficient of the explanatory variable. If this is true, then the SEM specification is chosen over the SDM specification. These three tests are repeated twice; one for 
published tuition and another for net tuition.

Table 3.8: Specification tests for spatial autocorrelation from SDM model in the geographical market

\begin{tabular}{|c|c|c|c|}
\hline \multirow[b]{3}{*}{ Year } & \multirow{2}{*}{\multicolumn{3}{|c|}{$\begin{array}{c}\text { Geographical Market } \\
\text { Published Tuition }\end{array}$}} \\
\hline & & & \\
\hline & $L R_{\rho}$ & $L R_{\theta}$ & $N L_{\rho \beta}$ \\
\hline 2004 & $78.2477^{* * *}$ & $21.9722^{* *}$ & 17.81 \\
\hline 2005 & $52.5676^{* * *}$ & $21.0617^{* *}$ & 15.60 \\
\hline 2006 & $44.8128^{* * *}$ & $23.4460^{* *}$ & $20.17^{*}$ \\
\hline 2007 & $37.7649^{* * *}$ & $29.6469^{* * *}$ & $23.97^{* *}$ \\
\hline 2008 & $32.8568^{* * *}$ & $25.4294^{* *}$ & $23.69^{* *}$ \\
\hline 2009 & $26.1866^{* * *}$ & $31.0694^{* * *}$ & $29.89^{* * *}$ \\
\hline 2010 & $20.3559^{* * *}$ & $32.8189^{* * *}$ & $30.92^{* * *}$ \\
\hline \multirow[t]{2}{*}{2011} & $11.1913^{* * *}$ & $26.9589^{* * *}$ & $24.50^{* *}$ \\
\hline & \multicolumn{3}{|c|}{ Net Tuition } \\
\hline Year & $L R_{\rho}$ & $L R_{\theta}$ & $N L_{\rho \beta}$ \\
\hline 2004 & $4.1597^{* *}$ & $21.9480^{* *}$ & $25.42^{* *}$ \\
\hline 2005 & 1.8854 & $23.0559^{* *}$ & $24.72^{* *}$ \\
\hline 2006 & 2.4902 & $24.5487^{* *}$ & $25.78^{* *}$ \\
\hline 2007 & $6.2479^{* *}$ & $30.7706^{* * *}$ & $32.56^{* * *}$ \\
\hline 2008 & $3.7017^{*}$ & $38.6694^{* * *}$ & $40.03^{* * *}$ \\
\hline 2009 & $3.7535^{*}$ & $42.3651^{* * *}$ & $42.42^{* * *}$ \\
\hline 2010 & $4.9494^{* *}$ & $40.6034^{* * *}$ & $39.49^{* * *}$ \\
\hline 2011 & 0.8048 & $34.6153^{* * *}$ & $34.33^{* * *}$ \\
\hline
\end{tabular}

For published tuition in the geographical market, the null hypotheses of $L R_{\rho}$ and $L R_{\theta}$ are rejected in all years. The $N L_{\rho \beta}$ statistics are not significant in the first two years but then become significant in the remaining period. Since panel regression is used in the geographical market analysis, the SDM model seems to be better at explaining the spatial effects in published tuition. In other words, the spatial autocorrelation in published tuition is better explained with a spatial lagged dependent variable and spatial lagged explanatory variables, and it is safe to assume 
that the error term is free from any spatial effects.

The results from the SDM specification tests for net tuition are slightly different from the results obtained for published tuition. Now the $L R_{\theta}$ and $N L_{\rho \beta}$ statistics are significant in all years, while the $L R_{\rho}$ statistics are not significant in three years: 2005, 2006, and 2011. The previous LM tests suggest for the SAR model while the LR tests were inconclusive. From the SDM specification tests, since the $L R_{\theta}$ tests are significant in all years, the SDM model is preferred over the SAR model. Therefore, the SDM model is chosen to estimate the spatial effects in net tuition in the geographical market.

Since the locations of universities in the geographical market are fixed across time, there is only one spatial weighting matrix to be used in the analysis. This allows for panel estimations where the one spatial weighting matrix is used to control for spatial effects for observations from different years. Therefore only one model shall be used for each published tuition and net tuition in the geographical market, which in this case the SDM specification is chosen.

\subsubsection{Regression Results}

The previous specification tests indicate that the SDM model should be applied to model the spatial price competition in the geographical market. As the locations of universities in the geographical market are fixed, panel regressions are used. A panelrobust Hausman test is performed to determine whether fixed effects (FE) estimate or random effects (RE) estimate should be used. The results are shown at the bottom of Table 3.10 .

The Hausman test results indicate that there is a systematic difference between the estimated coefficients, therefore the FE method should be used to model spatial 
price competition in the geographical market. However as FE does not allow the estimation of time-invariant variables, the institution type variable ${ }^{18}$ is dropped.

Table 3.9: Price competition in the geographical market with no spatial effets (FE method)

\begin{tabular}{llc}
\hline \hline & Published Tuition & Net Tuition \\
\hline USTD & $-0.0096^{* * *}$ & -0.0021 \\
GSTD & $(0.0025)$ & $(0.0043)$ \\
& 0.0054 & $-0.0153^{*}$ \\
ENDOW & $(0.0038)$ & $(0.0083)$ \\
& 0.0007 & 0.0104 \\
PRAID & $(0.0045)$ & $(0.0063)$ \\
& $0.1060^{* *}$ & 0.0523 \\
FACULTY & $(0.0441)$ & $(0.0702)$ \\
& 0.0698 & 0.0727 \\
RESEARCH & $0.0158^{* * *}$ & $(0.0784)$ \\
TEACHING & $(0.0055)$ & $0.0201^{* * *}$ \\
SATACT & $0.5005^{* * *}$ & $0.0068)$ \\
& $(0.0218)$ & $(0.0306)$ \\
ADMRATE & -0.0006 & -0.0006 \\
POPDEN & $-0.0894^{* * *}$ & $(0.0024)$ \\
MEDINC & $(0.0284)$ & $-0.0979^{* *}$ \\
Constant & -0.0035 & $(0.0383)$ \\
& $(0.0074)$ & -0.0132 \\
Obs. & $\left(0.04912^{* * *}\right.$ & $(0.0169)$ \\
\hline \hline
\end{tabular}

Standard errors are clustered by universities and shown in parentheses.

${ }^{*} p<0.10,{ }^{* *} p<0.05,{ }^{* * *} p<0.01$

Table 3.9 shows the results from fixed effects (FE) estimate for published tuition and net tuition without spatial effects. In the following paragraphs, the results from Table 3.9 are discussed briefly, where the focus will be on the significance of the

\footnotetext{
${ }^{18}$ Institution type variable is a dummy variable that identifies a university as public or private.
} 
coefficients and the direction of the impact on price. These results are to be compared with the SDM estimation results, where the spatial effects are controlled in the model. When spatial effects are not controlled, many of the estimated coefficients are not significant. The enrollment of undergraduate students is significantly negative to published tuition, which indicate the typical negative relationship between price and quantity demanded in price theory. Similarly, the enrollment of graduate students is significantly negative to net tuition. Endowment is not significant to both published tuition and net tuition. Proportion of students receiving aid is significantly positive to published tuition but not significant in net tuition. As more students receive financial aid, a university incurs bigger cost and therefore is motivated to charge higher published tuition. Faculty size is not significant to both published tuition and net tuition. As expected, research and teaching expenditures are positively significant to both published tuition and net tuition. With greater amount of resources spent on research and teaching, a university needs to finance these expenses through higher price and at the same time may use the higher price to convey a signal to potential students that the university is investing a lot more in order to raise its prestige and quality level. The admission test score is not a significant determinant of both published tuition and net tuition. The admission rate is significantly negative to published tuition and net tuition. The negative relationship between admission rate and price is expected because if a university admits a larger number of students, each student then will have a smaller share of enrollment cost and therefore pay lower published tuition and net tuition. Population density of the county is not significant to both published tuition and net tuition. At the same time, the median income of the county's population is significantly positive to both published tuition and net tuition. This indicates that there is a positive relationship between higher cost of living and the price of a university. However, since the earlier specification tests show the presence of spatial 
correlation in the sample, the results from Table 3.9 are not reliable. Nevertheless, these results could be used to get a general idea on the relationship between these explanatory variables and the price variables. Furthermore, these results could be used to compare what happens to the model when spatial effects are included.

Table 3.10 shows the FE estimation results for the geographical market using the spatial Durbin model (SDM) specification, where the spatial effects are included as a spatially lagged dependent variable and as spatially lagged explanatory variables. Columns (1) and (3) in the table show the estimated coefficients of the ordinary explanatory variables, while columns (2) and (4) show the estimated coefficients of the spatially lagged explanatory variables ${ }^{19}$. From the results shown in Table 3.10, several of the estimated coefficients are significant. For published tuition, four main coefficients and four spatial lagged coefficients are significant. The undergraduate enrollment has a significant main coefficient while the graduate enrollment has a significant spatial lag coefficient. The remaining three variables have significant main coefficients and significant spatial lag coefficients: teaching expenditure, admission rate, and median income. Undergraduate enrollment, graduate enrollment, and admission rate negatively affect published tuition; while teaching expenditure, and median income positively affect it. The signs of these coefficients are similar with the FE regression results with no spatial effects in Table 3.9. However two variables are no longer significant to published tuition when spatial effects are incorporated: proportion of students receiving aid and research spending. When net tuition is used as the dependent variable, five main coefficients and one spatial lagged coefficient are significant. Enrollment of graduate students and admission rate are negative to net tuition; while research spending, teaching expenditure and median income are

\footnotetext{
${ }^{19}$ As mentioned earlier in Section 3.4, the SDM model incorporates the spatial effects in both the spatially lagged dependent variable as well as the spatially lagged explanatory variables.
} 
Table 3.10: Price competition in the geographical market with spatial effects (SDM specification)

\begin{tabular}{|c|c|c|c|c|}
\hline & \multicolumn{2}{|c|}{ Published Tuition } & \multicolumn{2}{|c|}{ Net Tuition } \\
\hline & $(1)$ & (2) & (3) & (4) \\
\hline & Main & Spatial Lag & Main & Spatial Lag \\
\hline \multirow[t]{2}{*}{ USTD } & $-0.0064^{* *}$ & -0.0014 & -0.0003 & -0.0264 \\
\hline & $(0.0030)$ & $(0.0101)$ & $(0.0044)$ & $(0.0175)$ \\
\hline \multirow[t]{2}{*}{ GSTD } & -0.0044 & $-0.0186^{* * *}$ & $-0.0181^{* * *}$ & -0.0007 \\
\hline & $(0.0042)$ & $(0.0051)$ & $(0.0084)$ & $(0.0125)$ \\
\hline \multirow[t]{2}{*}{ ENDOW } & -0.0008 & 0.0003 & 0.0086 & -0.0029 \\
\hline & $(0.0044)$ & $(0.0053)$ & $(0.0062)$ & $(0.0122)$ \\
\hline \multirow[t]{2}{*}{ PRAID } & 0.0649 & -0.0240 & 0.0503 & -0.1555 \\
\hline & $(0.0408)$ & $(0.0660)$ & $(0.0711)$ & $(0.3105)$ \\
\hline \multirow[t]{2}{*}{ FACULTY } & 0.0575 & -0.1268 & 0.0455 & 0.2299 \\
\hline & $(0.0490)$ & $(0.1358)$ & $(0.0796)$ & $(0.2727)$ \\
\hline \multirow[t]{2}{*}{ RESEARCH } & 0.0127 & 0.0149 & $0.0199^{* * *}$ & -0.0050 \\
\hline & $(0.0050)$ & $(0.0092)$ & $(0.0068)$ & $(0.0112)$ \\
\hline \multirow[t]{2}{*}{ TEACH } & $0.3402^{* * *}$ & $0.1350^{* * *}$ & $0.3722^{* * *}$ & 0.0558 \\
\hline & $(0.0253)$ & $(0.0467)$ & $(0.0378)$ & $(0.0970)$ \\
\hline \multirow{2}{*}{ SATACT } & -0.0007 & -0.0006 & 0.0000 & -0.0073 \\
\hline & $(0.0012)$ & $(0.0018)$ & $(0.0025)$ & $(0.0055)$ \\
\hline \multirow[t]{2}{*}{ ADMRATE } & $-0.0783^{* * *}$ & $-0.1360^{*}$ & $-0.0923^{* *}$ & 0.0316 \\
\hline & $(0.0264)$ & $(0.0726)$ & $(0.0381)$ & $(0.1242)$ \\
\hline \multirow[t]{2}{*}{ POPDEN } & 0.0005 & 0.0004 & 0.0080 & -0.0088 \\
\hline & $(0.0158)$ & $(0.0061)$ & $(0.0367)$ & $(0.0151)$ \\
\hline \multirow[t]{2}{*}{ MEDINC } & $0.4931^{* * *}$ & $-0.3797^{* * *}$ & $0.2867^{* * *}$ & $-0.2407^{* *}$ \\
\hline & $(0.0502)$ & $(0.0431)$ & $(0.0851)$ & $(0.0977)$ \\
\hline \multirow[t]{2}{*}{$\rho$} & \multicolumn{2}{|c|}{$0.3091^{* * *}$} & \multirow{2}{*}{\multicolumn{2}{|c|}{$\begin{array}{c}0.2788^{* * *} \\
(0.0054)\end{array}$}} \\
\hline & \multicolumn{2}{|c|}{$(0.0090)$} & & \\
\hline Observations & \multirow{2}{*}{\multicolumn{2}{|c|}{$\begin{array}{c}4224 \\
159.37^{* * *}\end{array}$}} & \multicolumn{2}{|c|}{4224} \\
\hline Hausman $\chi^{2}(23)$ & & & \multicolumn{2}{|c|}{$162.25^{* * *}$} \\
\hline
\end{tabular}

Standard errors are clustered by universities and shown in parentheses.

${ }^{*} p<0.1,{ }^{* *} p<0.05,{ }^{* * *} p<0.01$ 
positive to net tuition. Furthermore, the spatially lagged median income is also negatively significant to net tuition. This suggests that as the median income of a county increases, the net tuition of universities located in that county is also expected to increase while the net tuition of universities in other counties is expected to decrease. The sign of graduate enrollment, research spending, teaching expenditure, admission rate and median income remain similar to the fixed effects estimation with no spatial effects.

Another interesting result observed from Table 3.10 is that the estimated spatial lag coefficient, $\rho$, is significant in both published tuition and net tuition. For published tuition, the spatial lag coefficient is positive. After controlling for a list of demand and cost factors, the published tuition of a university seems to be moderately related to the published tuition of other universities. On the other hand, the size of the spatial lag coefficient for net tuition is smaller but still positively significant. This shows that the spatial effects in net tuition are relatively weaker than published tuition. This result is expected since the previous specification tests indicate that the spatial effects are stronger in published tuition than net tuition. Specifically, the spatial lag coefficient indicates that for every $10 \%$ increase in the weighted index of published tuition and net tuition of other universities, the published tuition and net tuition of an average university is expected to increase by $2.9899 \%$ and $2.6929 \%$, respectively. These percentage changes imply a $\$ 621.53$ increase in published tuition and a $\$ 343.49$ increase in net tuition for the average university ${ }^{20}$. Based on these calculations, the change in published tuition seems to be relatively moderate while smaller change takes place in net tuition.

As noted in Section 3.4 earlier, the SDM model coefficients cannot be interpreted

\footnotetext{
${ }^{20}$ These amounts are obtained when the percentage change calculated from the estimated coefficients is multiplied with the mean values of published tuition and net tuition.
} 
directly as partial derivatives as in a typical regression model. To assess the magnitude and direction of the impacts arising from changes in explanatory variables, the mean of the diagonal elements of the partial derivative matrix as shown in equation (3.28) is used to estimate the direct effects of these variables. To interpret their indirect effects, the mean row of each off-diagonal elements of the partial derivative matrix is used. These marginal effects for published tuition are shown in Table 3.11.

Table 3.11: Marginal effects for published tuition in the geographical market

\begin{tabular}{lccc}
\hline \hline & & Published Tuition & \\
& $(1)$ & $(2)$ & $(3)$ \\
& Direct Effects & Indirect Effects & Total Effects \\
\hline USTD & $-0.0066^{* * *}$ & -0.0098 & -0.0163 \\
GSTD & $(0.0026)$ & $(0.0205)$ & $(0.0209)$ \\
& -0.0045 & $-0.0422^{* * *}$ & $-0.0466^{* * *}$ \\
ENDOW & $(0.0047)$ & $(0.0152)$ & $(0.0170)$ \\
& -0.0006 & -0.0036 & -0.0042 \\
PRAID & $(0.0048)$ & $(0.0119)$ & $(0.0138)$ \\
& $0.0653^{*}$ & 0.0138 & 0.0790 \\
FACULTY & $(0.0397)$ & $(0.1411)$ & $(0.1523)$ \\
& 0.0649 & -0.2525 & -0.1877 \\
RESEARCH & $(0.0475)$ & $(0.2908)$ & $(0.3035)$ \\
& $0.0140^{* * *}$ & $0.0434^{*}$ & $0.0574^{* *}$ \\
TEACH & $(0.0051)$ & $(0.0244)$ & $(0.0259)$ \\
& $0.3424^{* * *}$ & $0.5115^{* * *}$ & $0.8540^{* * *}$ \\
SATACT & $(0.0279)$ & $(0.1220)$ & $(0.1250)$ \\
& -0.0007 & -0.0012 & -0.0020 \\
ADMRATE & $(0.0012)$ & $(0.0039)$ & $(0.0041)$ \\
POPDEN & $-0.0839^{* * *}$ & $-0.3471^{* *}$ & $-0.4310^{* *}$ \\
MEDINC & $(0.0264)$ & $(0.1692)$ & $(0.1765)$ \\
& -0.0003 & 0.0016 & 0.0013 \\
& $(0.0163)$ & $(0.0063)$ & $(0.0152)$ \\
\hline \hline Stand & $0.4923^{* * *}$ & $-0.4637^{* * *}$ & 0.0286 \\
& $(0.0521)$ & $(0.1009)$ & $(0.1099)$ \\
\hline
\end{tabular}

Standard errors are clustered by universities and shown in parentheses.

${ }^{*} p<0.1,{ }^{* *} p<0.05,{ }^{* * *} p<0.01$

From Table 3.11, there are three variables with significant marginal effects on 
published tuition: research spending, teaching expenditure, and admission rate.

Enrollment of undergraduate students exerts a negative direct impact on published tuition. The direct effect of a 100 increase in enrollment of undergraduate students leads to a $0.0658 \%$ decrease in published tuition. This indicates that an increase in undergraduate enrollment leads to a lower published tuition in own university, but no effect on published tuition of other universities. The inverse relationship between undergraduate enrollment and published tuition is attributable to the smaller share of education cost when the size of undergraduate enrollment is bigger. However, the total impact of a change in undergraduate enrollment on published tuition is not significant.

A change in graduate enrollment has no significant direct impact on published tuition, however its indirect and total effects are significantly negative. This indicates that there is a negative spillover of a change in the graduate enrollment of other universities on published tuition. A 100 increase in the enrollment of graduate students in a university leads to a $0.4132 \%$ decrease in published tuition of other universities. The total impact of graduate enrollment on published tuition is negative, where $91 \%$ of it is caused by the negative indirect effects. A 100 increase in graduate enrollment leads to a decrease in published tuition of all universities by $0.4553 \%$.

A change in endowment has no significant marginal effects on published tuition. All three types of its marginal effects are not significant.

The proportion of students receiving financial aid has a positive direct impact on published tuition. If the number of students receiving financial aid increases by $10 \%$, the published tuition of a university is expected to increase by $0.0067 \%$. A financial aid to the students could be granted by either the university itself or external institutions such as the Federal and state governments. The university incurs greater expenditure cost to fund bigger number of financial aids awarded by the university; 
hence it is more likely that the university will raise the published tuition. At the same time, as more students receive financial awards granted by external institutions such as federal and state governments, the university might be inclined to get those funds by increasing its published tuition. This may explained the positive direct impact of proportion of students receiving financial aid on published tuition. However, the indirect and total effects of proportion of students receiving financial aid are not significant.

The size of faculty members has no significant effect on published tuition.

Both research spending and teaching expenditure have significant positive marginal effects on published tuition. A change in research spending and teaching expenditure by a university positively affects its published tuition, and at the same time there is a positive spillover impact on published tuition of other universities in the market. As a university increases its spending on research and teaching, it incurs additional cost that translates into higher published tuition. A university that increases its research spending by $10 \%$ would likely raise its published tuition by $0.1403 \%$. At the same time, the positive spillover effects from this change would cause other universities to raise their published tuition by $0.4341 \%$. The total impact of a $10 \%$ increase in research spending is that the published tuition of all universities in the market increases on average by $0.5744 \%$, where more than $75 \%$ of the total impact is contributed by the spillover effects. Research spending is associated with the quality level of an institution, therefore a rise in research spending of a university may be viewed by other universities as a signal that the university intends to pursue higher quality level. Other universities would raise their research spending as well and this translates into higher published tuition in these universities, which later contributes to another increase in the published tuition of the university where the initial change in research expenditure happened. The second increase in published tuition caused 
by other universities changing their research spending (and hence their published tuition) is larger than the direct impact from changing its own research spending.

Teaching expenditure has significant marginal effects on published tuition. A change in the teaching expenditure of a university positively affects its published tuition, and at the same time there is a positive spillover impact on published tuition of other universities in the market. As a university increases its spending on teaching, it incurs additional cost that translates into higher published tuition. A 10\% increase in teaching expenditure of a university leads to a $3.4242 \%$ increase in its published tuition, while other universities in the market would be inclined to raise their published tuition by $5.1154 \%$. The total impact of a $10 \%$ increase in teaching expenditure is that the published tuition of all universities in the market is expected to increase on average by $8.5396 \%$. The indirect effect of teaching expenditure is greater than its direct effect; where about $60 \%$ of the total effect is contributed by the indirect effect. A university spends more money on teaching in order to provide better teaching environments for its students. Therefore it is expected that the students should pay a premium on these additional teaching improvements, and at the same time the university incurs higher operational cost to fund these improvements. If the positive effect of the improved teaching environment is greater than the negative effect of higher published tuition, then the university would be able to attract more enrollments. As a university increases its teaching expenditure, other neighboring universities would also be influenced to spend more money on teaching as to compete for students enrollments. In doing so, these neighboring universities would also raise their published tuition, which in turn provides a feedback effect that causes another increase in published tuition of the university where the initial change in teaching expenditure took place. Another interesting obervation is that the magnitude of the direct effect of teaching expenditure is greater than the direct 
effect of research spending. This indicates that a change in teaching expenditure has greater impact on published tuition than a similar change in research spending. This is expected since teaching is more related to the cost of education for each student compared to research.

The admission test scores have no significant marginal effects on published tuition. Regardless of the required scores needed to obtain admission, there is no significant impact on published tuition. Another indicator of quality level, the admission rate, has negative marginal impacts on published tuition. As more students are offered admission, published tuition is expected to decrease. If a university raises its admission rate by $10 \%$, its published tuition is expected to decrease by $0.0080 \%$. The feedback effect of this change is larger, where the published tuition of other universities in the market is expected to decrease by $0.0293 \%$. The total impact of a $10 \%$ increase in admission rate is that the published tuition in all universities is expected to decrease on average by $0.0350 \%$. When a university increases its admission rates, other neighboring universities are also inclined to offer more admissions and thus lowering their published tuition. The reduction in published tuition of neighboring universities would then decrease further the published tuition of the university where the change in admission rates first happened. From the results, neighboring universities are more sensitive to changes in admission rates of a university than the university itself since the indirect effect is more than three times greater than the direct effect.

The first measure of geographical variations, county's population density, has no marginal effects on published tuition. The second geographical variations measure, county's median income, has opposing direct and indirect effects. The direct effect of median income is positive to published tuition while its indirect effect is negative. If the median income of a county increases by $10 \%$, all universities that are located in that county are expected to raise their published tuition by $4.9232 \%$. Meanwhile, 
universities located in other counties are expected to reduce their published tuition by $4.6369 \%$. However, the total impact of median income is not significant to published tuition. This indicates that the opposing direct and indirect effects cancel out in the end.

Table 3.12: Marginal effects for net tuition in the geographical market

\begin{tabular}{lccc}
\hline \hline & & Net Tuition & \\
& $(1)$ & $(2)$ & $(3)$ \\
& Direct Effects & Indirect Effects & Total Effects \\
\hline USTD & 0.0024 & -0.0142 & -0.0118 \\
GSTD & $(0.0044)$ & $(0.0147)$ & $(0.0161)$ \\
& $-0.0170^{*}$ & -0.0042 & -0.0212 \\
ENDOW & $(0.0093)$ & $(0.0096)$ & $(0.0129)$ \\
PRAID & 0.0094 & -0.0002 & 0.0092 \\
& $(0.0069)$ & $(0.0088)$ & $(0.0118)$ \\
FACULTY & 0.0611 & -0.0107 & 0.0504 \\
RESEARCH & $(0.0759)$ & $(0.2298)$ & $(0.2459)$ \\
TEACH & 0.0356 & 0.1308 & 0.1664 \\
& $(0.0740)$ & $(0.2339)$ & $(0.2617)$ \\
SATACT & $\left(0.0211^{* * *}\right.$ & -0.0003 & $0.0208^{*}$ \\
& $0.3544^{* * *}$ & $(0.0082)$ & $(0.0109)$ \\
ADMRATE & $(0.0434)$ & 0.0791 & $0.4336^{* * *}$ \\
POPDEN & 0.0006 & $-0.1055)$ & $(0.1151)$ \\
MEDINC & $(0.0026)$ & $(0.0053)$ & -0.0027 \\
& $\left(0.0970^{* * *}\right.$ & -0.0130 & $-0.110063)$ \\
\hline Standard & $0.0066)$ & $(0.0812)$ & $(0.0857)$ \\
& $(0.0396)$ & -0.0025 & 0.0041 \\
& $0.3028^{* * *}$ & -0.0897 & $(0.0386)$ \\
& $(0.0919)$ & $(0.1103)$ & $(0.1204)$ \\
\hline
\end{tabular}

Standard errors are clustered by universities and shown in parentheses.

${ }^{*} p<0.1,{ }^{* *} p<0.05,{ }^{* * *} p<0.01$

The marginal effects for net tuition are shown in Table 3.12. For net tuition, there are five variables with significant direct effect and three variables with significant total effect. There is no variable with significant indirect effect. 
Enrollment of graduate students has a negative direct effect on net tuition. Compared to published tuition, it seems that net tuition is sensitive to changes in graduate enrollment while published tuition is sensitive to changes in undergraduate enrollment. If the graduate enrolment of a university increases by 100 students, the net tuition of that university is expected to decrease by $0.1686 \%$. However there is no significant spillover effect of changes in graduate enrollment on net tuition of other universities. This suggests that universities tend to increase their financial aid to students as more graduate students are enrolled.

Similar to the previous results for published tuition; endowment and faculty size have no significant marginal effects on net tuition. In addition to that, the proportion of students receiving aid is no longer significant.

Research spending and teaching expenditure have positive direct and total effects on net tuition, however their indirect effects are not significant. Similar to the results obtained for published tuition, the magnitude of research spending impact on net tuition is smaller than the size of teaching expenditure effect. A $10 \%$ increase in research spending leads to a $0.2110 \%$ increase in net tuition of the university. The total impact of a $10 \%$ increase in research spending is a $0.2078 \%$ reduction in net tuition of all universities. A university that raises its teaching expenditure by $10 \%$ is expected to increase its net tuition by $3.5443 \%$, which later leads other universities to increase their net tuition on average by $4.3357 \%$. Compared to published tuition, the total effect of teaching expenditure on net tuition is smaller. In other words, a change in teaching expenditure has a smaller impact on financial aid awarded by universities than published tuition.

The first measure of quality, admission test scores, has no marginal effect on net tuition. On the other hand, the second measure of quality, admission rate, has a negative direct effect on net tuition while its indirect and total effects are not 
significant. A $10 \%$ increase in the admission rate of a university will likely cause that university to reduce its net tuition by $0.9244 \%$.

Median income is the only measure of geographical variations with significant direct and total effects on net tuition. The other measure, population density, has no significant marginal effects. Median income has a positive direct and total effects on net tuition. This suggests that an increase in the median income of the county leads to a reduction in net tuition. In other words, a university tends to offer more financial aids to students as the society around its campus receives higher income.

To investigate the differences between public and private universities, the sample is divided into two subsamples based on the control of the institution. Since the FE method is used in the analysis for geographical market, it is not possible to include time-fixed variables such as the control-type dummy in the equation. Two subsamples are created: the first subsample consists of 318 public colleges and universities, and the second subsample is made of 210 private colleges and universities. The same steps explained in the methodology section are repeated on these two subsamples.

The spatial Durbin regression results for public universities are shown in Table 3.13. The first two columns are for published tuition, while the second two columns are for net tuition. Columns (1) and (3) show the estimated coefficients of the explanatory variables, while columns (2) and (4) show the estimated coefficients of the spatially lagged explanatory variables.

For both published and net tuition, the Hausman test results indicate that fixed effects estimation should be used. For published tuition, the results obtained in Table 3.13 are different from Table 3.10. Only the main coefficients of undergraduate enrollment and teaching expenditure remain significant. Admission rate and median income are no longer significant. At the same time, several other variables have become significant: faculty size, admission tests scores, and population density. The 
Table 3.13: Spatial regression for public universities in the geographical market

\begin{tabular}{|c|c|c|c|c|}
\hline & \multicolumn{2}{|c|}{ Published Tuition } & \multicolumn{2}{|c|}{ Net Tuition } \\
\hline & $(1)$ & $(2)$ & $(3)$ & $(4)$ \\
\hline & Main & Spatial Lag & Main & Spatial Lag \\
\hline \multirow[t]{2}{*}{ USTD } & $-0.0078^{* * *}$ & 0.0045 & $-0.0081^{* *}$ & 0.0036 \\
\hline & $(0.0025)$ & $(0.0152)$ & $(0.0038)$ & $(0.0253)$ \\
\hline \multirow[t]{2}{*}{ GSTD } & -0.0005 & 0.0027 & -0.0057 & -0.0133 \\
\hline & $(0.0048)$ & $(0.0398)$ & $(0.0069)$ & $(0.0521)$ \\
\hline \multirow[t]{2}{*}{ ENDOW } & -0.0045 & -0.0308 & -0.0019 & -0.0366 \\
\hline & $(0.0044)$ & $(0.0189)$ & $(0.0062)$ & $(0.0251)$ \\
\hline \multirow[t]{2}{*}{ PRAID } & -0.0384 & -0.0829 & -0.0927 & -0.2233 \\
\hline & $(0.0454)$ & $(0.2069)$ & $(0.0750)$ & $(0.4201)$ \\
\hline \multirow[t]{2}{*}{ FACULTY } & $0.1273^{* * *}$ & -0.0226 & $0.2053^{* * *}$ & 0.2883 \\
\hline & $(0.0442)$ & $(0.3439)$ & $(0.0612)$ & $(0.5293)$ \\
\hline \multirow[t]{2}{*}{ RESEARCH } & 0.007 & 0.0519 & 0.0089 & 0.0566 \\
\hline & $(0.0059)$ & $(0.0476)$ & $(0.0082)$ & $(0.0702)$ \\
\hline \multirow[t]{2}{*}{ TEACH } & $0.0615^{*}$ & 0.0199 & 0.0354 & 0.1828 \\
\hline & $(0.0319)$ & $(0.0907)$ & $(0.0622)$ & $(0.1608)$ \\
\hline \multirow[t]{2}{*}{ SATACT } & $-0.0046^{* *}$ & 0.0155 & $-0.0095^{* *}$ & 0.0043 \\
\hline & $(0.0022)$ & $(0.0097)$ & $(0.0040)$ & $(0.0254)$ \\
\hline \multirow[t]{2}{*}{ ADMRATE } & -0.0159 & -0.0844 & -0.0459 & -0.1336 \\
\hline & $(0.0295)$ & $(0.1533)$ & $(0.0458)$ & $(0.2396)$ \\
\hline \multirow[t]{2}{*}{ POPDEN } & $-0.0386^{* *}$ & $0.0916^{*}$ & $-0.0616^{*}$ & 0.0801 \\
\hline & $(0.0162)$ & $(0.0496)$ & $(0.0350)$ & $(0.0995)$ \\
\hline \multirow[t]{2}{*}{ MEDINC } & -0.0263 & 0.2202 & -0.1456 & 0.207 \\
\hline & $(0.0656)$ & $(0.1575)$ & $(0.1104)$ & $(0.2467)$ \\
\hline \multirow[t]{2}{*}{$\rho$} & \multicolumn{2}{|c|}{$0.8282^{* * *}$} & \multicolumn{2}{|c|}{$0.6920^{* * *}$} \\
\hline & \multicolumn{2}{|c|}{$(0.0479)$} & \multicolumn{2}{|c|}{$(0.0778)$} \\
\hline Observations & \multicolumn{2}{|c|}{2544} & \multicolumn{2}{|c|}{2544} \\
\hline Hausman $\chi^{2}(23)$ & \multicolumn{2}{|c|}{$52.50^{* * *}$} & \multicolumn{2}{|c|}{$45.30^{* * *}$} \\
\hline
\end{tabular}

Standard errors are clustered by universities and shown in parentheses.

${ }^{*} p<0.10,{ }^{* *} p<0.05,{ }^{* * *} p<0.01$ 
spatially lagged coefficient for population density is also significant at $10 \%$ level, while other spatially lagged coefficients remain insignificant.

Different results are also observed for net tuition in public universities when the sample is divided based on the type of the institution. Compared to Table 3.10, these variables are no longer significant: enrollment of graduate students, research spending, teaching expenditures, admission rate, and median income. However some of the variables are now significant to net tuition as seen in Table 3.13. Enrollment of undergraduate students is now significant, and it is negative to net tuition. The sign and size of the undergraduate enrollment coefficient for net tuition are very similar to published tuition. Faculty size is positively significant to net tuition, while admission test scores is negatively significant. Compared with published tuition, faculty size and admission test scores have the same direction of impact on net tuition but with larger magnitude. Population density is significantly negative to both published tuition and net tuition, although in the latter case the significance level is only at $10 \%$ while the spatial lag coefficient is not significant.

The coefficient for the spatially lagged dependent variable, $\rho$, is significant in both published tuition and net tuition. This is similar to the results obtained earlier in Table 3.10 on page 110 when the sample includes both public and private universities. Both published tuition and net tuition of a public university are positively affected by published tuition and net tuition of other public universities. However the size of $\rho$ in the public subsample is now larger. This suggests that the spatial effects are stronger among public universities. The spatial lag coefficients indicate that for every $10 \%$ increase in the weighted index of published tuition and net tuition of other public universities, the published tuition and net tuition of an average public university are expected to increase by $8.2135 \%$ and $6.8178 \%$ respectively.

The marginal effects for published tuition of public universities are shown in Table 
Table 3.14: Marginal effects for published tuition of public universities in the geographical market

\begin{tabular}{lccc}
\hline \hline & $(1)$ & Published Tuition & $(2)$ \\
& Direct Effects & Indirect Effects & Total Effects \\
\hline USTD & $-0.0079^{* * *}$ & -0.0175 & -0.0254 \\
& $(0.0022)$ & $(0.1057)$ & $(0.1065)$ \\
GSTD & 0 & 0.0274 & 0.0275 \\
& $(0.0062)$ & $(0.3024)$ & $(0.3059)$ \\
ENDOW & -0.0057 & -0.2683 & -0.274 \\
& $(0.0050)$ & $(0.2690)$ & $(0.2703)$ \\
PRAID & -0.0428 & -0.7254 & -0.7681 \\
& $(0.0440)$ & $(1.4892)$ & $(1.4916)$ \\
FACULTY & $0.1393^{* * *}$ & 0.6033 & 0.7426 \\
& $(0.0460)$ & $(2.2162)$ & $(2.2376)$ \\
RESEARCH & 0.0098 & 0.2898 & 0.2997 \\
& $(0.0066)$ & $(0.3191)$ & $(0.3223)$ \\
TEACH & $0.0624^{*}$ & 0.4866 & 0.549 \\
& $(0.0349)$ & $(0.5109)$ & $(0.5164)$ \\
SATACT & $-0.0043^{*}$ & 0.081 & 0.0767 \\
& $(0.0022)$ & $(0.0838)$ & $(0.0844)$ \\
ADMRATE & -0.0234 & -0.8772 & -0.9005 \\
& $(0.0292)$ & $(1.4462)$ & $(1.4535)$ \\
POPDEN & $-0.0364^{* *}$ & 0.384 & 0.3476 \\
& $(0.0149)$ & $(0.3441)$ & $(0.3374)$ \\
MEDINC & -0.012 & 1.4125 & 1.4005 \\
& $(0.0679)$ & $(1.2197)$ & $(1.2183)$ \\
\hline \hline
\end{tabular}

Standard errors are clustered by universities and shown in parentheses.

${ }^{*} p<0.1,{ }^{* *} p<0.05,{ }^{* * *} p<0.01$ 
3.14. There is no variable that has all three significant marginal effects. There are only five variables that have significant direct effects. Enrollment of undergraduate students negatively affects published tuition of public universities. For every 100 increase in undergraduate enrollment at a public university, the published tuition of that university is expected to decrease by $0.07870 \%$. Faculty size positively affects published tuition of public universities, where a 100 increase in the faculty size of a public university leads to an increase in its published tuition by $1.4947 \%$. Teaching expenditure has a significant positive direct impact on published tuition. For every $1 \%$ increase in teaching expenditure of a public university, its published tuition is expected to increase by $0.0624 \%$. Admission test score negatively affects own published tuition, where a 1 point increase in the admission test score of a public university leads to a $0.4291 \%$ decrease in its published tuition. Population density has a negative direct impact on published tuition, where if the population density around a public university increases by 1000 person per square miles, the published tuition of the university is expected to increase by $3.5745 \%$.

Table 3.15 presents the marginal effects for net tuition of public universities. Compared to the previous results obtained using the overall sample in Table 3.12, there are few changes observed in the results for public universities as shown in Table 3.15. In the public universities subsample, there is no variable that is significant in all three types of marginal effects; while enrollment of graduate students, research spending, teaching expenditure, and median income are no longer significant. There are four variables with significant direct effects to net tuition: undergraduate enrollment, faculty size, admission test scores, and population density. The direct impact of undergraduate enrollment to net tuition of public universities is similar to its impact to published tuition. If a public university increases its undergraduate enrollment by 100 students, that university is expected to lower its net tuition by $0.0827 \%$. Similarly, 
Table 3.15: Marginal effects for net tuition of public universities in the geographical market

\begin{tabular}{lccc}
\hline \hline & & Net Tuition & \\
& $(1)$ & $(2)$ & $(3)$ \\
& Direct Effects & Indirect Effects & Total Effects \\
\hline USTD & $-0.0083^{* *}$ & -0.0156 & -0.0238 \\
& $(0.0033)$ & $(0.0903)$ & $(0.0914)$ \\
GSTD & -0.0055 & -0.0467 & -0.0522 \\
& $(0.0081)$ & $(0.2064)$ & $(0.2098)$ \\
ENDOW & -0.0026 & -0.1623 & -0.1648 \\
& $(0.0068)$ & $(0.1298)$ & $(0.1310)$ \\
PRAID & -0.1009 & -1.1422 & -1.2431 \\
& $(0.0735)$ & $(1.6579)$ & $(1.6645)$ \\
FACULTY & $0.2268^{* * *}$ & 1.4635 & 1.6902 \\
& $(0.0612)$ & $(1.8237)$ & $(1.8487)$ \\
RESEARCH & 0.0115 & 0.1829 & 0.1943 \\
& $(0.0089)$ & $(0.2566)$ & $(0.2602)$ \\
TEACH & 0.0378 & 0.7831 & 0.8209 \\
& $(0.0677)$ & $(0.5381)$ & $(0.5444)$ \\
SATACT & $-0.0098^{* * *}$ & -0.017 & -0.0268 \\
& $(0.0037)$ & $(0.0931)$ & $(0.0935)$ \\
ADMRATE & -0.0541 & -0.6666 & -0.7207 \\
& $(0.0426)$ & $(0.9464)$ & $(0.9526)$ \\
POPDEN & $-0.0610^{* *}$ & 0.1315 & 0.0705 \\
& $(0.0334)$ & $(0.3212)$ & $(0.3023)$ \\
MEDINC & -0.1311 & 0.5078 & 0.3767 \\
& $(0.1101)$ & $(0.9427)$ & $(0.9325)$ \\
\hline \hline
\end{tabular}

Standard errors are clustered by universities and shown in parentheses.

${ }^{*} p<0.1,{ }^{* *} p<0.05,{ }^{* * *} p<0.01$ 
faculty size also has a significantly positive direct impact on net tuition. If a public university hires 100 more faculty members, that university is expected to raise its net tuition by $2.5458 \%$. The admission test scores negatively affect own net tuition. A public university that increases its admission test scores by 1 point is expected to lower its net tuition by $0.9752 \%$. From these results, it seems that net tuition of a public university is more sensitive to changes in faculty size and admission test scores compared to published tuition. The county's population density has a negative direct effect to published tuition. If a county's population density increases by 100 person per square miles, all universities located in that county are expected to reduce their published tuition by $0.5918 \%$.

Table 3.16 shows the spatial Durbin fixed effects regression for private universities in the geographical market. There are 210 private colleges and universities in the subsample. The Hausman test results indicate that fixed effects should be used to analyze both the published tuition and the net tuition.

For published tuition, none of the main coefficients of the explanatory variables is significant. There are six spatially lagged explanatory variables that have significant coefficients. The enrollment of undergraduate students in other private universities and the population density of other counties negatively affect published tuition of a private university. The other four variables: proportion of students receiving aid, faculty size, research spending, and teaching expenditure, positively affect published tuition.

The results for net tuition of private universities are also different from the previous results obtained from the overall sample. Comparing Tables 3.10 and 3.16, only the main coefficient for research spending remains significant. From the main coefficients estimation, research spending and population density positively affect net tuition. All other main coefficients are not significant. There are five spatially 
Table 3.16: Spatial regression for private universities in the geographical market

\begin{tabular}{|c|c|c|c|c|}
\hline & \multicolumn{2}{|c|}{ Published Tuition } & \multicolumn{2}{|c|}{ Net Tuition } \\
\hline & (1) & $(2)$ & $(3)$ & $(4)$ \\
\hline & Main & Spatial Lag & Main & Spatial Lag \\
\hline \multirow[t]{2}{*}{ USTD } & 0.0019 & $-0.0272^{* *}$ & 0.006 & $-0.1115^{* *}$ \\
\hline & $(0.0025)$ & $(0.0108)$ & $(0.0118)$ & $(0.0498)$ \\
\hline \multirow[t]{2}{*}{ GSTD } & -0.0029 & 0.0052 & -0.0162 & 0.0187 \\
\hline & $(0.0023)$ & $(0.0045)$ & $(0.0115)$ & $(0.0247)$ \\
\hline \multirow[t]{2}{*}{ ENDOW } & 0.0019 & -0.0037 & 0.0131 & 0.0386 \\
\hline & $(0.0039)$ & $(0.0056)$ & $(0.0105)$ & $(0.0364)$ \\
\hline \multirow[t]{2}{*}{ PRAID } & -0.0229 & $0.0871^{*}$ & -0.0266 & -0.2957 \\
\hline & $(0.0236)$ & $(0.0516)$ & $(0.1382)$ & $(0.4369)$ \\
\hline \multirow[t]{2}{*}{ FACULTY } & -0.088 & $0.2723^{* * *}$ & -0.3234 & 0.6822 \\
\hline & $(0.0565)$ & $(0.0911)$ & $(0.1996)$ & $(0.4942)$ \\
\hline \multirow[t]{2}{*}{ RESEARCH } & 0.0045 & $0.0147^{*}$ & $0.0197^{* *}$ & 0.0153 \\
\hline & $(0.0027)$ & $(0.0084)$ & $(0.0090)$ & $(0.0257)$ \\
\hline \multirow[t]{2}{*}{ TEACH } & -0.0013 & $0.1795^{* * *}$ & -0.0372 & $0.4660^{* *}$ \\
\hline & $(0.0171)$ & $(0.0441)$ & $(0.1020)$ & $(0.1960)$ \\
\hline \multirow[t]{2}{*}{ SATACT } & 0.0004 & -0.0002 & 0.0034 & $-0.0140^{* *}$ \\
\hline & $(0.0006)$ & $(0.0010)$ & $(0.0025)$ & $(0.0068)$ \\
\hline \multirow[t]{2}{*}{ ADMRATE } & -0.0216 & -0.0827 & -0.0868 & $-0.5375^{* * *}$ \\
\hline & $(0.0202)$ & $(0.0548)$ & $(0.0583)$ & $(0.1743)$ \\
\hline \multirow[t]{2}{*}{ POPDEN } & 0.0089 & $-0.0181^{* *}$ & $0.0691^{* *}$ & $-0.1279^{* *}$ \\
\hline & $(0.0057)$ & $(0.0085)$ & $(0.0346)$ & $(0.0604)$ \\
\hline \multirow[t]{2}{*}{ MEDINC } & 0.0102 & -0.0141 & -0.2208 & 0.3306 \\
\hline & $(0.0565)$ & $(0.0729)$ & $(0.1460)$ & $(0.2480)$ \\
\hline \multirow[t]{2}{*}{$\rho$} & \multicolumn{2}{|c|}{$0.7899^{* * *}$} & \multicolumn{2}{|c|}{-0.0117} \\
\hline & \multicolumn{2}{|c|}{$(0.0337)$} & \multicolumn{2}{|c|}{$(0.0429)$} \\
\hline Observations & \multicolumn{2}{|c|}{1680} & \multicolumn{2}{|c|}{1680} \\
\hline Hausman $\chi^{2}(23)$ & \multicolumn{2}{|c|}{$35.81^{* *}$} & \multicolumn{2}{|c|}{$74.33^{* * *}$} \\
\hline
\end{tabular}

Standard errors are clustered by universities and shown in parentheses.

${ }^{*} p<0.10,{ }^{* *} p<0.05,{ }^{* * *} p<0.01$ 
lagged explanatory variables with significant coefficients: undergraduate enrollment, teaching expenditure, admission tests score, admission rate, and population density. Teaching expnditure of other private universities positively affects net tuition of a private university, while the other variables seem to have negative effect on net tuition of a private university.

The estimated spatial lag coefficient for the dependent variables, $\rho$, is significantly positive for published tuition but not significant for net tuition. Since the value of $\rho$ is quite large, there is a strong positive spatial correlation between published tuition of private universities. For every $10 \%$ increase in the weighted index of published tuition of other universities, there will be a $7.8192 \%$ increase in published tuition of an average private university. However the spatial correlations between net tuition of private universities are not significant. This suggests that financial aid grants of a private universtiy are not affected by the financial aid grants of other private universities.

The marginal effects for published tuition of private universities are presented in Table 3.17. From the results, only research spending and admission rate have significant marginal effects of all three forms. Except for these two varaibles, no other variables have significant direct effects to published tuition. If a private university increases its research spending by $1 \%$, that university is expected to raise its published tuition by $0.0071 \%$. At the same time, there is a feedback effect from other private universities that responded by raising their published tuition as well, where this will increase the published tuition of that private university further by $0.0844 \%$. In total, it is expected that a $1 \%$ increase in research spending leads to a $0.0915 \%$ increase in published tuition of all private universities. Comparing the direct and indirect effects of research spending, it seems that the published tuition of a private university is more sensitive to changes in research spending of other private universities compared 
Table 3.17: Marginal effects for published tuition of private universities in the geographical market

\begin{tabular}{lccc}
\hline \hline & $(1)$ & $\begin{array}{c}\text { Published Tuition } \\
(2)\end{array}$ & $(3)$ \\
& Direct Effects & Indirect Effects & Total Effects \\
\hline USTD & -0.0014 & $-0.1259^{* *}$ & $-0.1273^{* *}$ \\
& $(0.0026)$ & $(0.0525)$ & $(0.0540)$ \\
GSTD & -0.0024 & 0.0129 & 0.0106 \\
& $(0.0031)$ & $(0.0287)$ & $(0.0312)$ \\
ENDOW & 0.0017 & -0.0149 & -0.0132 \\
& $(0.0045)$ & $(0.0249)$ & $(0.0269)$ \\
PRAID & -0.0135 & 0.3529 & 0.3394 \\
& $(0.0250)$ & $(0.2727)$ & $(0.2852)$ \\
FACULTY & -0.057 & $0.9398^{*}$ & 0.8828 \\
& $(0.0603)$ & $(0.5097)$ & $(0.5501)$ \\
RESEARCH & $0.0071^{* *}$ & $0.0844^{* *}$ & $0.0915^{* *}$ \\
& $(0.0033)$ & $(0.0428)$ & $(0.0448)$ \\
TEACH & 0.0195 & $0.8238^{* * *}$ & $0.8432^{* * *}$ \\
& $(0.0191)$ & $(0.1603)$ & $(0.1684)$ \\
SATACT & 0.0004 & 0.0004 & 0.0009 \\
& $(0.0006)$ & $(0.0044)$ & $(0.0044)$ \\
ADMRATE & $-0.0364^{*}$ & $-0.486^{*}$ & $-0.5224^{* *}$ \\
& $(0.0221)$ & $(0.2533)$ & $(0.2646)$ \\
POPDEN & 0.0076 & $-0.0543^{*}$ & -0.0468 \\
& $(0.0054)$ & $(0.0304)$ & $(0.0299)$ \\
MEDINC & 0.0089 & 0.0012 & 0.0101 \\
& $(0.0500)$ & $(0.2245)$ & $(0.2202)$ \\
\hline \hline
\end{tabular}

Standard errors are clustered by universities and shown in parentheses.

${ }^{*} p<0.1,{ }^{* *} p<0.05,{ }^{* * *} p<0.01$ 
to its own change in research spending. About $92 \%$ of the total effect of research spending to published tuition are contributed by the indirect effect. Admission rate has negative marginal effects to published tuition. A private university that increases its admission rate by $1 \%$ is expected to lower its published tuition by $0.0358 \%$. There is also a $0.3849 \%$ reduction in published tuition from the feedback effect of change in admission rate of other private universities. The total effect of a $1 \%$ increase in admission rate is a $0.4069 \%$ reduction in published tuition.

Besides research spending and admission rate, there are four other variables with significant indirect effects on published tuition. Two of them have positive indirect effects to published tuition: faculty size and teaching expenditure. Undergraduate enrollment and population density have negative indirect effects to published tuition. As for total effect, there are four variables with significant total effects to published tuition: undergraduate enrollment, research spending, teaching expenditure, and admission rate. If the enrollment of undergraduate students increases by 100 students, the published tuition in all private universities is expected to decrease on average by 1.1953\%. A 1\% increase in research spending and teaching expenditure is expected to cause the published tuition of all private universities to go up by $0.0915 \%$ and $0.8432 \%$ respectively. This indicates that teaching expenditure has greater influence on published tuition of private universities than research spending.

Overall, it seems that the published tuition of a private university is more influenced by changes that happen in other private universities than by its own changes. This is because for all variables with significant total effects, the indirect effects of these variables are greater than their direct effects.

For net tuition of private universities, its marginal effects estimation is presented in Table 3.18. Admission rate is the only variable that is significant in all three types of marginal effects on net tuition. A $1 \%$ increase in the admission rate of a 
Table 3.18: Marginal effects for net tuition of private universities in the geographical market

\begin{tabular}{lccc}
\hline \hline & $(1)$ & $\begin{array}{c}\text { Net Tuition } \\
(2)\end{array}$ & $(3)$ \\
& Direct Effects & Indirect Effects & Total Effects \\
\hline USTD & 0.0059 & $-0.1156^{* *}$ & $-0.1097^{* *}$ \\
& $(0.0100)$ & $(0.0483)$ & $(0.0500)$ \\
GSTD & -0.0153 & 0.0182 & 0.0028 \\
& $(0.0127)$ & $(0.0260)$ & $(0.0264)$ \\
ENDOW & 0.0137 & 0.0285 & 0.0422 \\
& $(0.0114)$ & $(0.0341)$ & $(0.0349)$ \\
PRAID & -0.0252 & -0.2446 & -0.2699 \\
& $(0.1336)$ & $(0.4225)$ & $(0.4800)$ \\
FACULTY & -0.2822 & 0.6784 & 0.3962 \\
& $(0.1842)$ & $(0.4919)$ & $(0.5506)$ \\
RESEARCH & $0.0213^{* *}$ & 0.0144 & 0.0356 \\
& $(0.0092)$ & $(0.0248)$ & $(0.0272)$ \\
TEACH & -0.0407 & $0.4506^{* *}$ & $0.4098^{* *}$ \\
& $(0.1046)$ & $(0.1920)$ & $(0.1673)$ \\
SATACT & 0.0034 & $-0.0142^{* *}$ & $-0.0108^{*}$ \\
& $(0.0024)$ & $(0.0063)$ & $(0.0057)$ \\
ADMRATE & $-0.0925^{*}$ & $-0.5341^{* * *}$ & $-0.6266^{* * *}$ \\
& $(0.0539)$ & $(0.1782)$ & $(0.1903)$ \\
POPDEN & $0.0689^{*}$ & $-0.1276^{* *}$ & -0.0587 \\
& $(0.0374)$ & $(0.0666)$ & $(0.0368)$ \\
MEDINC & -0.2246 & 0.384 & 0.1594 \\
& $(0.1392)$ & $(0.2620)$ & $(0.2108)$ \\
\hline \hline
\end{tabular}

Standard errors are clustered by universities and shown in parentheses.

${ }^{*} p<0.1,{ }^{* *} p<0.05,{ }^{* * *} p<0.01$ 
private university has a negative direct effect of $0.0884 \%$ on net tuition. At the same time, there is a negative feedback effect of about $0.4191 \%$ on net tuition of a private university from a $1 \%$ increase in admission rate of other private universities. In total, a $1 \%$ increase in admission rate of all private universities leads to a $0.4656 \%$ decrease in net tuition.

Research spending has a positive direct effect on net tuition, while its indirect and total effects are not significant. If a private university raises its research spending by $1 \%$, that university is expected to increase its net tuition by $0.0213 \%$. Population density is another variable with a postive direct effect to net tuition. Furthermore, its indirect effect is negative to net tuition. However the total effect of population density is not significant. The opposing direction of direct and indirect effects may cancel out each other. There are three variables with significant indirect and total effects to net tuition: undergraduate enrollment, teaching expenditure, and admission tests score. Undergraduate enrollment and admission tests score have negative indirect and total effects, while teaching expenditure has positive indirect and total effects. A 100 increase in undergraduate enrollment in private universities is expected to lower the net tuition of all private universities by $1.0390 \%$, which is almost similar to the results for published tuition earlier in Table 3.17. This suggests that private universities tend to reduce their prices when there is a increase in undergraduate enrollment. A $1 \%$ increase in teaching expenditure in private universities leads to a $0.4098 \%$ in the net tuition of all private universities. This amount is less than half of the total effect of teaching expenditure to published tuition. It seems that net tuition is less sensitive to changes in teaching expenditure compared to published tuition. If the admission tests score is raised by 1 point, all private universities are expected to reduce their net tuition by $1.0742 \%$. This suggests that private universities tend to increase their financial aid to students with higher admission tests score. 
In the following analysis, the 400 miles threshold distance is used to define a geographical market limit. As mentioned earlier, this approach is motivated by McMillen et al. (2007). In this approach, the elements of the spatial weighting matrix are no longer the inverse distances between universities in miles. The spatial weighting matrix is now a binary matrix, where its element equals one if the distance between two universities is less than 400 miles and zero otherwise. Each row of the spatial weighting matrix is then normalized such that the sum of the row equals one.

There is a small modification that is performed on the sample. In order to make the 400 miles distance radius feasible, only universities that are located in the 48 contiguous states are included in the sample. Three universities that are located in Alaska and Hawaii are excluded: Alaska Pacific University, University of Hawaii at Manoa, and Hawaii Pacific University. Since these universities are beyond the 400 miles radius of other universities in the sample and geographically not connected directly with other states, they are excluded from the sample. Now the sample contains 525 colleges and universities that are located in the contiguous states.

The spatial Durbin regression results for the 400 miles geographical market model are presented in Table 3.19. The panel robust Hausman test results shown at the bottom of Table 3.19 indicate that the FE estimate is preferred to the RE estimate.

For published tuition, there are two variables with significant main and spatial lag coefficients, and two variables with significant main coefficicent only. Enrollment of undergraduate students negatively affects published tuition, however the undergraduate enrollment of other universities seems to have no impact on published tuition of a university. The proportion of students receiving aid has significant main and spatial lag coefficients, but with opposite signs. The proportion of students receiving aid of a university seems to negatively affect its published tuition, while the proportion of students receiving aid in other universities seems to contribute positively to that 
Table 3.19: Spatial regression for the geographical market truncated at 400 miles

\begin{tabular}{|c|c|c|c|c|}
\hline & \multicolumn{2}{|c|}{ Published Tuition } & \multicolumn{2}{|c|}{ Net Tuition } \\
\hline & $(1)$ & $(2)$ & $(3)$ & $(4)$ \\
\hline & Main & Spatial Lag & Main & Spatial Lag \\
\hline \multirow[t]{2}{*}{ USTD } & $-0.0066^{* * *}$ & 0.0007 & -0.0004 & 0.0105 \\
\hline & $(0.0022)$ & $(0.0067)$ & $(0.0041)$ & $(0.0109)$ \\
\hline \multirow[t]{2}{*}{ GSTD } & -0.0027 & 0.015 & $-0.0193^{* *}$ & 0.008 \\
\hline & $(0.0029)$ & $(0.0111)$ & $(0.0082)$ & $(0.0221)$ \\
\hline \multirow[t]{2}{*}{ ENDOW } & -0.0055 & 0.0164 & 0.006 & $0.0339^{*}$ \\
\hline & $(0.0042)$ & $(0.0150)$ & $(0.0061)$ & $(0.0201)$ \\
\hline \multirow[t]{2}{*}{ PRAID } & $-0.0577^{*}$ & $0.4380^{* * *}$ & -0.0683 & $0.5771^{* * *}$ \\
\hline & $(0.0343)$ & $(0.1147)$ & $(0.0642)$ & $(0.2120)$ \\
\hline \multirow[t]{2}{*}{ FACULTY } & 0.0432 & 0.2614 & 0.0355 & $0.6986^{* *}$ \\
\hline & $(0.0403)$ & $(0.1739)$ & $(0.0781)$ & $(0.3389)$ \\
\hline \multirow[t]{2}{*}{ RESEARCH } & $0.0074^{*}$ & -0.017 & $0.0153^{* *}$ & -0.061 \\
\hline & $(0.0041)$ & $(0.0227)$ & $(0.0062)$ & $(0.0394)$ \\
\hline \multirow[t]{2}{*}{ TEACH } & $0.0502^{* * *}$ & $0.1970^{* * *}$ & $0.1585^{* * *}$ & 0.1251 \\
\hline & $(0.0182)$ & $(0.0497)$ & $(0.0452)$ & $(0.0889)$ \\
\hline \multirow[t]{2}{*}{ SATACT } & -0.0015 & 0.0056 & -0.0008 & 0.0007 \\
\hline & $(0.0011)$ & $(0.0041)$ & $(0.0025)$ & $(0.0106)$ \\
\hline \multirow[t]{2}{*}{ ADMRATE } & -0.0187 & -0.0302 & -0.0454 & -0.2076 \\
\hline & $(0.0227)$ & $(0.0845)$ & $(0.0384)$ & $(0.1703)$ \\
\hline \multirow[t]{2}{*}{ POPDEN } & -0.0094 & 0.0105 & -0.0149 & -0.0309 \\
\hline & $(0.0066)$ & $(0.0262)$ & $(0.0189)$ & $(0.0648)$ \\
\hline \multirow[t]{2}{*}{ MEDINC } & 0.0443 & -0.0092 & -0.0062 & -0.1676 \\
\hline & $(0.0465)$ & $(0.0762)$ & $(0.0970)$ & $(0.1602)$ \\
\hline \multirow[t]{2}{*}{$\rho$} & \multicolumn{2}{|c|}{$0.5325^{* * *}$} & \multicolumn{2}{|c|}{$0.2531^{* * *}$} \\
\hline & \multicolumn{2}{|c|}{$(0.0487)$} & \multicolumn{2}{|c|}{$(0.0452)$} \\
\hline Observations & \multicolumn{2}{|c|}{4200} & \multicolumn{2}{|c|}{4200} \\
\hline Hausman $\chi^{2}(23)$ & \multicolumn{2}{|c|}{$66.55^{* * *}$} & \multicolumn{2}{|c|}{$84.38^{* * *}$} \\
\hline
\end{tabular}

Standard errors are clustered by universities and shown in parentheses.

${ }^{*} p<0.10,{ }^{* *} p<0.05,{ }^{* * *} p<0.01$ 
university's published tuition. Research spending and teaching expenditure positively affect published tuition. While teaching expenditure of other universities also affects published tuition of a university positively, no similar result is observed for research spending. The influence of teaching expenditure of other universities on published tuition of a university seems larger than the impact of its own teaching expenditure. All other variables are not significant.

As for net tuition, there is no variable with significant main and spatial lag coefficients, while six variables have either significant main coefficient or significant spatial lag coefficient. Enrollment of graduate students seems to negatively affect net tuition, while the proportion of students receiving aids in other universities and faculty size of other universities positively affect net tuition. Research spending and teaching expenditure positively affect own net tuition. However unlike published tuition, both research spending and teaching expenditure of other universities seem to have no impact on net tuition of a university.

The estimated spatial lag coefficient of the dependent variable, $\rho$, is significant and positive for both published tuition and net tuition. Comparing the size of the coefficients, it seems that the spatial effects in published tuition are stronger by more than double the strength of spatial effects in net tuition. The spatial lag coefficients indicate that published tuition is $5.2063 \%$ higher at an average university for every $10 \%$ increase in the weighted index of published tuition of neighboring universities, while net tuition is only $2.4416 \%$ higher for similar comparison.

The marginal effects for published tuition in the 400 miles geographical market are presented in Table 3.20. Teaching expenditure is the only variable that is significant in all three types of marginal effects. If a university increases its teaching expenditure by $10 \%$, its published tuition is expected to increase by $0.5622 \%$. The indirect impact from a $10 \%$ increase in teaching expenditure of other universities is a $4.7347 \%$ increase 
Table 3.20: Marginal effects for published tuition in the geographical market: 400 miles limit

\begin{tabular}{lccc}
\hline \hline & $(1)$ & Published Tuition & $(2)$ \\
& Direct Effects & Indirect Effects & Total Effects \\
\hline USTD & $-0.0067^{* * *}$ & -0.0077 & -0.0144 \\
& $(0.0019)$ & $(0.0140)$ & $(0.0146)$ \\
GSTD & -0.002 & 0.0299 & 0.0279 \\
& $(0.0034)$ & $(0.0287)$ & $(0.0305)$ \\
ENDOW & -0.0049 & 0.0202 & 0.0153 \\
& $(0.0046)$ & $(0.0313)$ & $(0.0323)$ \\
PRAID & -0.0437 & $0.8939^{* * *}$ & $0.8502^{* * *}$ \\
& $(0.0335)$ & $(0.2056)$ & $(0.2068)$ \\
FACULTY & 0.0602 & 0.6003 & $0.6604^{*}$ \\
& $(0.0392)$ & $(0.3780)$ & $(0.3914)$ \\
RESEARCH & $0.0076^{*}$ & -0.0313 & -0.0237 \\
& $(0.0045)$ & $(0.0521)$ & $(0.0546)$ \\
TEACH & $0.0562^{* * *}$ & $0.4735^{* * *}$ & $0.5297^{* * *}$ \\
& $(0.0204)$ & $(0.0804)$ & $(0.0856)$ \\
SATACT & -0.0014 & 0.0109 & 0.0095 \\
& $(0.0010)$ & $(0.0090)$ & $(0.0089)$ \\
ADMRATE & -0.022 & -0.0862 & -0.1083 \\
& $(0.0217)$ & $(0.1943)$ & $(0.1972)$ \\
POPDEN & -0.0094 & 0.0168 & 0.0073 \\
& $(0.0065)$ & $(0.0530)$ & $(0.0512)$ \\
MEDINC & 0.0493 & 0.0584 & 0.1076 \\
& $(0.0481)$ & $(0.1471)$ & $(0.1367)$ \\
\hline \hline
\end{tabular}

Standard errors are clustered by universities and shown in parentheses.

${ }^{*} p<0.1,{ }^{* *} p<0.05,{ }^{* * *} p<0.01$ 
in published tuition. The total effect of a $10 \%$ increase in teaching expenditure leads to an increase in published tuition of all universities by $5.2969 \%$. The direct impact of teaching expenditure to published tuition is very small, where it constitutes about $10 \%$ of the total effect. Most of the influence of teaching expenditure on published tuition comes from the feedback effect. Enrollment of undergraduate students has a negative direct impact on published tuition, but its indirect and total effects are not significant. A 100 increase in undergraduate enrollment in a university leads to a $0.0668 \%$ decrease in its own published tuition. If a university spends $10 \%$ more in its research spending, it is expected that its published tuition will increase by $0.0761 \%$. The proportion of students receiving aids has no direct effects to published tuition, but its indirect and total effects are significant. If the proportion of students receiving aids increases by $1 \%$, the published tuition of all universities is expected to increase by $1.3401 \%$. Faculty size has no significant direct and indirect effects to published tuition but its total effect is significant at $10 \%$ level. If the faculty size increases by 100 staff, the published tuition of all universities is expected to increase on average by $9.3557 \%$.

To investigate the difference when the 400 miles distance limit is imposed, this paragraph discusses the comparison of the results obtained when no limit is imposed and when the geographical market is limited to 400 miles distance ${ }^{21}$. Similar significant results are observed for undergraduate enrollment, research spending, and teaching expenditure. The enrollment of undergraduate students has a negative direct impact on published tuition, and the magnitude of the impact is almost equal when the 400 miles distance limit is imposed. Research spending has a positive direct impact on published tuition but its magnitude has been reduced to almost half in

\footnotetext{
${ }^{21}$ The marginal effects for published tuition in the unlimited geographical market are shown in Table 3.11 on page 112 .
} 
the 400 miles distance model. Furthermore, the indirect and total effects of research spending are no longer significant in the 400 miles distance limit approach. Teaching expenditure is significant in all three types of marginal effects, where it positively affects published tuition. However the size of the direct, indirect and total effects of teaching expenditure in the 400 miles distance limit approach have become relatively smaller compared to the no limit model. This suggests that the spatial effects of teaching expenditure in a smaller geographical market are weaker, where a university is less sensitive to changes in teaching expenditure performed by other universities that are located within 400 miles distance. Proportion of students receiving aid has significant indirect effects and total effects to published tuition under the constrained market size model, while in the unconstrained market size approach it has a significant direct effect only to published tuition. At the same time, the marginal effects of graduate enrollment, admission rate and median income are no longer significant when the 400 miles distance limit is imposed.

The marginal effects for net tuition in the 400 miles geographical market are shown in Table 3.21. Teaching expenditure is the only variable with significant marginal effects of all three types. If a university raises its teaching expenditure by $1 \%$, that university is expected to increase its net tuition by $0.1576 \%$. The feedback effect from the same increase in teaching expenditure of other universities is about $0.2200 \%$ increase in net tuition. The total effect of a $1 \%$ increase in teaching expenditure is that the net tuition of all universities is expected to increase by $0.3775 \%$. The enrollment of graduate students has a negative direct impact on net tuition. If a university increases its intake of graduate students by 100, its net tuition is expected to decrease by $0.1843 \%$. Total endowment has a positive total effect to net tuition. As total endowment increases by $10 \%$, net tuition is expected to increase by $0.4813 \%$. The proportion of students receiving aid has a positive indirect and total effects to 
Table 3.21: Marginal effects for net tuition in the geographical market: 400 miles limit

\begin{tabular}{lccc}
\hline \hline & & Net Tuition & \\
& $(1)$ & $(2)$ & $(3)$ \\
& Direct Effects & Indirect Effects & Total Effects \\
\hline USTD & -0.0003 & 0.0122 & 0.0118 \\
& $(0.0035)$ & $(0.0144)$ & $(0.0151)$ \\
GSTD & $-0.0186^{* *}$ & 0.0063 & -0.0123 \\
& $(0.0092)$ & $(0.0358)$ & $(0.0403)$ \\
ENDOW & 0.0068 & 0.0414 & $0.0481^{*}$ \\
& $(0.0065)$ & $(0.0261)$ & $(0.0258)$ \\
PRAID & -0.062 & $0.7848^{* * *}$ & $0.7227^{* * *}$ \\
& $(0.0621)$ & $(0.2570)$ & $(0.2562)$ \\
FACULTY & 0.0589 & $0.9102^{* *}$ & $0.9691^{* *}$ \\
& $(0.0749)$ & $(0.4632)$ & $(0.4752)$ \\
RESEARCH & $0.0156^{* *}$ & -0.0782 & -0.0626 \\
& $(0.0065)$ & $(0.0602)$ & $(0.0624)$ \\
TEACH & $0.1576^{* * *}$ & $0.2200^{* *}$ & $0.3775^{* * *}$ \\
& $(0.0492)$ & $(0.1101)$ & $(0.1036)$ \\
SATACT & -0.0009 & 0.0023 & 0.0014 \\
& $(0.0024)$ & $(0.0145)$ & $(0.0138)$ \\
ADMRATE & -0.0519 & -0.2836 & -0.3355 \\
& $(0.0355)$ & $(0.2380)$ & $(0.2351)$ \\
POPDEN & -0.016 & -0.038 & -0.054 \\
& $(0.0191)$ & $(0.0846)$ & $(0.0757)$ \\
MEDINC & -0.0017 & -0.197 & -0.1987 \\
& $(0.0963)$ & $(0.2140)$ & $(0.1803)$ \\
\hline \hline
\end{tabular}

Standard errors are clustered by universities and shown in parentheses.

${ }^{*} p<0.1,{ }^{* *} p<0.05,{ }^{* * *} p<0.01$ 
net tuition, while its direct effect is not significant. Since the size of the indirect effect is large, this suggests that net tuition of a university is very sensitive to changes in net tuition of other universities within the 400 miles distance. Similarly, the indirect and total effects of faculty size to net tuition are also significant, positive and large. When a university hires more faculty members, other universities within the 400 miles distance respond by raising their net tuition, which in turn leads the university with more faculty members to increase its net tuition even more. Overall, a $1 \%$ increase in the proportion of students receiving aid and a 100 increase in faculty size leads to an increase in net tuition of all universities by $1.0600 \%$ and $16.3557 \%$ respectively. Research spending has a significant positive direct impact on net tuition, while its indirect and total effects are not significant. A university that increases its research spending by $10 \%$ is expected to raise its net tuition by $0.1563 \%$. This change will not significantly affect the net tuition of other universities within the 400 miles radius. The two measures of local variants, population density and median income have no significant marginal effects.

This paragraph discusses the comparison of marginal effects of net tuition when no distance limit and when the 400 miles distance is imposed ${ }^{22}$. Graduate enrollment has a negative direct effect in both approaches, however its size is now bigger under the 400 miles distance approach. Research spending still has a positive direct impact to net tuition in the 400 miles distance model but its total effect is no longer significant. Furthermore, the size of its direct impact has become smaller by more than $25 \%$. The indirect effect of teaching expenditure is now significant in the 400 miles distance model. At the same time, the direct and total effects of teaching expenditure in the 400 miles distance model has become smaller than the no distance limit model. This

\footnotetext{
${ }^{22}$ The marginal effects for net tuition in the unlimited geographical market are shown in Table 3.12 on page 117 .
} 
indicates that the spatial effects in net tuition in smaller market is weaker than in the larger nationwide market. The direct effect of admission rate and the total effect of median income are no longer significant in the 400 miles distance model.

Since proportion of students receiving aid, research spending and teaching expenditure are mostly significant in the previous analyses, some readers may raise the issue of potential endogeneity between the three variables with prices. However, as explained in the Data section earlier, these variables are assumed to be orthogonal to prices due to several reasons. Nevertheless, a spatial regression that excludes this set of three explanatory variables is estimated to investigate this endogeneity issue and the result is presented in Table C.1 in Appendix C.2. There are some changes on the size and significance level of some of the estimated coefficients but the direction remains the same for most of them. A number of variables that were not signficant in the original model are now significant: undergraduate enrollment (to net tuition), faculty size, admission test score, and population density; while few variables are no longer significant: graduate students enrollment, admission rate, and median income. Looking at the spatial effects, it seems that by excluding the three variables, the estimated $\rho$ for published and net tuitions are still positively significant but larger. The marginal effects of published tuition and net tuition are shown in Tables C.2 and C.3 respectively. Since the results obtained from the exclusion of these three variables are different than the original specification, it shows that the model is sensitive to the set of explanatory variables chosen. Therefore proportion of students receiving aid, research spending and teaching expenditure should be included in the model.

Some readers may be puzzled as to why time effects are excluded from the analysis. Since spatial analysis focuses on the space dimension, including time dimension in the analysis may complicate the analysis. This may be partly due to the huge increase in the number of coefficients that need to be estimated since the SDM mod- 
els estimate two coefficients for each explanatory variable; while in SAR, SARMA and SDM model, three marginal effects coefficients are estimated for each explanatory variable. This suspicion seems to be true since the year dummies inclusion works with the overall sample only, while in the other three subsamples (public, private, and truncated at 400 miles) the estimated failed to achieve convergence after 100 iterations. The regression result with year dummies is provided in Table C.4 in Appendix C.3. Comparing this result with the original model result in Table 3.10 on page 110, most the estimated coefficients in both models have similar size and direction, and they remain significance. The estimated spatial effects for published and net tuitions in both models are almost identical. The estimated marginal effects when time effects are included are shown in Tables C.5 and C.6 for published and net tuitions, respectively.

\subsection{Conclusion}

This study integrates economics principles and spatial econometrics technique in the analysis of the competitive behavior of universities in the geographical market dimension. The sample used in this study consists of a panel data of 528 universities in the U.S. from 2004 to 2011. The study found that the prices set by universities are influenced by the proximity of competitors located in the same market. The location of universities in the geographical market is determined by the longitude and latitude coordinates of the university's main campus.

The spatial econometrics method is used to incorporate spatial effects into the analysis. The model specification method follows a systematic approach, where the presence of spatial autocorrelation is verified before moving on to the model selection

process. There is a positive spatial autocorrelation in both published tuition and 
net nuition in the sample. However the spatial interdependence between prices of universities are found to be weakening towards the end of the sample period.

The hybrid model selection process is adopted to ensure that the most appropriate model is chosen among several spatial model candidates. Most of the specification tests from the hybrid approach suggest that spatial effect is present between the dependent variables and the explanatory variables but absent from the error term. In other words, the prices set by a university are influenced by changes in the prices and changes in the explanatory variables of other universities. However, the price of a university is not affected by a shock in prices of other universities.

The spatial effects in published tuition are stronger than net tuition. This suggests that universities tend to take the published tuition of other competitors into account when determining their published tuition, while their financial aid awards are less dependent on the financial aid policies of other competitors. The positive spatial coefficients indicate that the prices of universities tend to move in the same direction.

The spatial price interdependence is stronger among public universities than private universities. There is a very strong spatial effect in published tuition competition of public universities, and there is a considerable size of spatial effect in their net tuition competition. This shows that public universities located in the same geographical market tend to adjust their published tuition together. At the same time, state legislatures may also look at the published tuition of neighboring states when formulating the pricing policy of public universities in the state. Furthermore, outof-state students who are planning to enroll at a public university may consider all public universities located in the same geographical region as competitors. To attract these pool of applicants, public universities in the same geographical area may decide to implement similar pricing policy.

While the published tuition of private universities is also influenced by other pri- 
vate universities, there is no spatial effect in the net tuition competition of private universities. This indicates that the financial aid awards of private universities are not influenced by other nearby private universities in the area. Perhaps the financial aid policies of private universities are more influenced by the proximity of competitors in other market dimensions, such as the prestige and quality dimension. In this case, the financial aid policy of a private university is influenced by the financial aid policy of other private universities that share the same prestige and quality status. Furthermore, a prospective student may regard private universities of similar prestige and quality level as competitors.

When the geographical market is segmented into smaller regions, the spatial effect in published tuition decreases while the spatial effect in net tuition increases by a small amount. This suggests that as universities change their prices within a smaller market area, there is a smaller change in published tuition but almost the same change in net tuition compared to the same change at the national market. Since the mobility of students has increased rapidly and tremendous advance in transportation and communication technology, the geographical market for higher education in the U.S. is integrated at the national level. 


\section{Chapter 4}

\section{Price Competition in the Product Market of U.S. Higher Education: A Spatial Regression Approach}

\subsection{Introduction}

The market for higher education in the U.S. in the postwar period is characterized by interinstitutional competition that has become more intense as a result of expanding submarkets. At the same time, university's tuition in the U.S. has increased at a faster rate than inflation. This has prompted several critics to address higher education institutions, despite most of them being nonprofit organizations, as greedy and inefficient (Bennett 1987; Finn 1984). However, scholars have found mixed evidence that either supports or contradicts the notion (Gillen 2012). Nevertheless, since 1979, tuition and fees for undergraduate students in 4-year degree granting institutions have increased continuously as shown in Figure 4.1.

Between 1979 and 2011, tuition and fees have increased in real terms at an annual 
Figure 4.1: Average undergraduate tuition and fees in 4-year degree granting institutions in constant 2011-2012 dollars

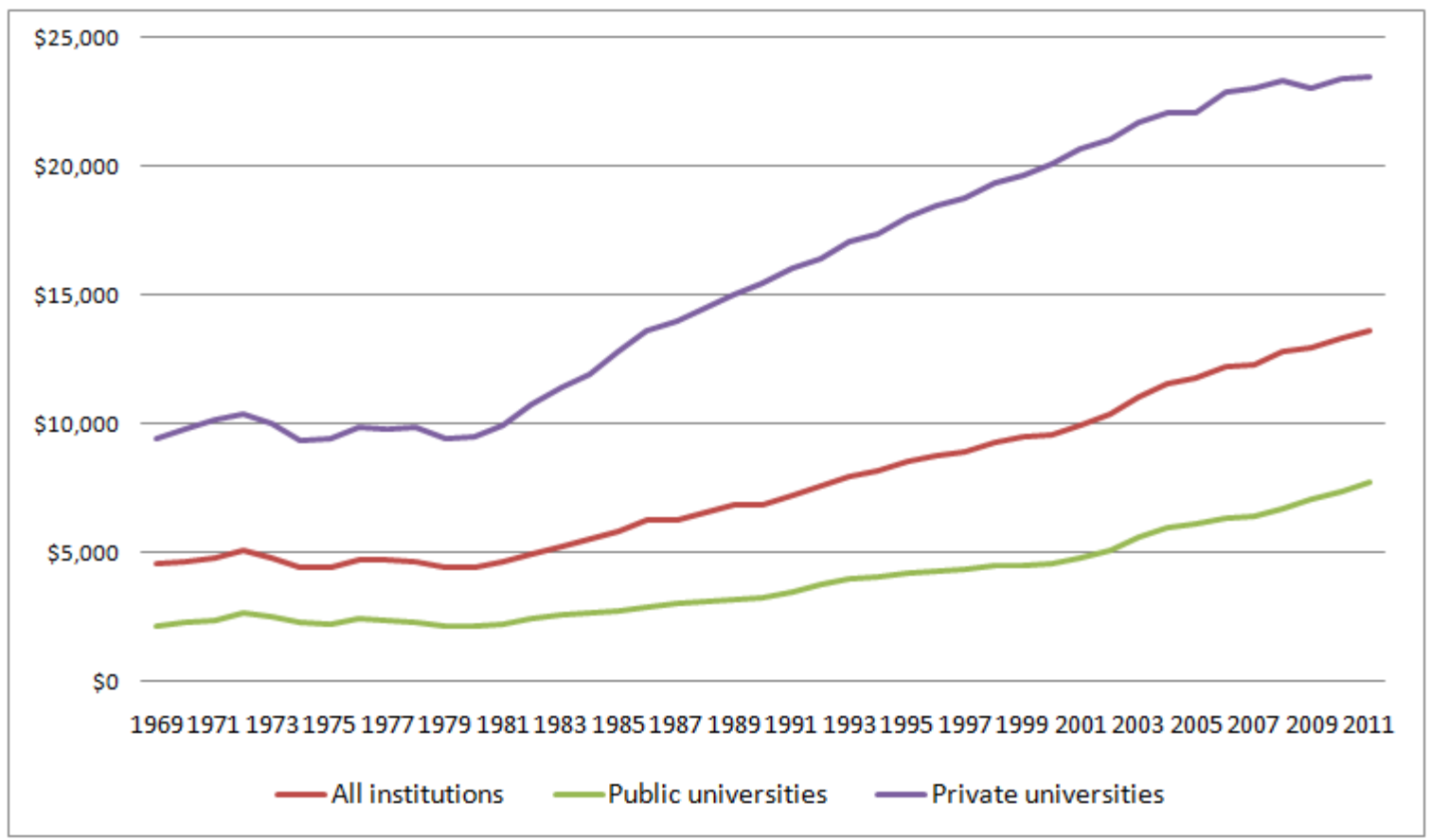

Source: U.S. Department of Education, National Center for Education Statistics, Integrated Postsecondary Education Data System, July 2012

average rate of $3.17 \%$ in public universities and $2.24 \%$ in private universities $^{1}$. At the same time, the federal funding for student aid grants has been declining (Hearn and Holdsworth 2004; Heller 2011), while the state appropriations for higher education have been reduced substantially (St. John 2006). These events have raised concerns on providing equal educational opportunities to students of various financial backgrounds.

In order to deal with these matters, a university has to plan its pricing policy and financial aid schemes while facing resource constraints like any other profit maximizing firm as well as competition from other universities in the market. For example, several

\footnotetext{
${ }^{1}$ These figures are for 4-year degree granting institutions only. Calculations are based on Figure 4.1 .
} 
selective private universities, known as the Ivy League Overlap Group, decided to compare and adjust the financial aid offers made to individual students so that these students would not make their choice solely based on the amount of financial aid offers. The U.S. Department of Justice investigated this practice and charged the universities involved as violating the Sherman Antitrust $\mathrm{Act}^{2}$. Eventually the case was settled out of court although all parties agreed that price fixing did occur (Netz 1998). An interesting observation from this case is that the Ivy League Overlap Group, besides being located in the same region area (which is the northeast of the U.S.), are also regarded to be in the same elite group with very high prestige and quality. Given that the Ivy League Overlap Group had colluded to influence its members' price competition, would similar events occur if there were no collusion between universities that are located in the same prestige and quality levels? This study expects that the price competition between universities is influenced by the proximity of competitors in the product market space.

This study of competition between universities in the product market dimension is influenced by the economic approach to the higher education market introduced by Garvin (1980), where the higher education market could be segmented into the geographical dimension and the product dimension. Other studies such as Rothschild and White (1993) argue that competition in the higher education market is limited within segments that are separated by geographical boundaries and quality differences, while Winston (1999) further add that the market for higher education could also be divided based on endowment size and ideological differences.

Since most universities are nonprofit organizations that rely on other revenues to supplement tuition, the application of economics principles to the behavior of universities analysis of their pricing and competitive behavior in the marketplace

\footnotetext{
${ }^{2}$ For more information about this case, please refer to U.S. v. Brown University, et al., 1992.
} 
is a topic of substantial interest. Although a large part of economic theory and analysis consists of the study of profit-maximizing firms' behavior and their market environments, recently the analysis of nonprofit institutions and the market in which they operate started to receive the attention of economists due to various reasons. These reasons have been mentioned in the introduction section for the geographical market of higher education of Chapter 3.

This study contributes towards the existing literature on the behavioral analysis of non profit institutions. Specifically, this research investigates the price competition that takes place in the market for higher education in the U.S. Although there are a number of private-for-profit institutions in the higher education market, most private universities are not for profit institutions ${ }^{3}$.

This analysis of price competition between universities contributes towards the literature of the behavioral study of non profit institutions ${ }^{4}$. Specifically, this study will analyze price competition in the product market for U.S. higher education using spatial regression method. This study attempts to fill the gap in the marketplace context analysis of universities addressed by Rothschild and White (1993).

This study uses spatial econometrics method beyond the geographical space, which is the traditional space dimension. The prestige and quality levels of universities are used to define the product market of higher education. In this case, the research contributes towards the practice of using spatial regression menthod in a nongeographic space defined by social factors.

The present study attempts to integrate the theory of price competition and spa-

\footnotetext{
${ }^{3}$ After applying the condition of having at least $10 \%$ undergraduate students in a 4 -year baccaulaureate program, the sample used in this study consists of 528 public and not-for-profit private institutions only.

${ }^{4}$ As mentioned previously, only universities and colleges that have at least $10 \%$ undergraduate students in a 4-year baccalaureate program are selected into the sample. After applying this filter, the sample consists of 528 public and not-for-profit private institutions only.
} 
tial regression techniques. Price competition between universities is believed to be influenced by the proximity of competitors of similar prestige and quality levels in the product market space. To investigate this, spatial proximity is applied into empirical models of prices of higher education. Spatial regression models are used to identify the size and direction of any spatial dependence between prices set by universities.

The paper is organized as follows. Section 4.2 discusses several other related works that have been done. The data and variables used in the analysis are presented in Section 4.3. Section 4.4 discusses the methodology used in this analysis. Section 4.5 presents and discusses the regression results.

\subsection{Literature Review}

While the analysis of the behavior of universities has been receiving the attention of economists recently, there is still a shortage in the study of the marketplace context in which universities operate (Rothschild and White 1993). Furthermore, the use of spatial econometrics in the non-geographical space dimension in research is still limited unlike studies related to the geographical space dimension. Nevertheless, there has been a rapid increase in the applications of spatial econometrics to various economic problems.

Spatial econometrics can also be used to analyze nongeographic dimensions, such as the product-characteristic space. Compared to the geographical space, the choices of location in the product-characteristic space may be subject to the endogeneity problem. In the product-characteristic market, the location of choices is subject to the profit-maximization objetive of the firm, and this leads to endogenous location ${ }^{5}$.

\footnotetext{
${ }^{5}$ The problem of endogeneity in the product market analysis of this study is solved by using a ranking score published by an external party of universities. Furthermore, all universities in the sample used are either public institutions or not-for-profit private institutions. Therefore the choice
} 
There are several studies that applied spatial econometrics technique in the productcharacteristic space. Pinkse and Slade (2004) analyze the effects of mergers in the U.K. brewing industry on price and brand competition. In their study, the brewing industry is characterized by the distance in quality between different brands produced by brewers. Another study by Lychagin et al. (2010) looks at the spillover effects of research and development productivity between firms in three spatial dimensions: geographic, technology, and product. They found that geographic and technological proximity leads to greater spillover effects than product market proximity.

The product market for higher education is characterized by the different levels of prestige and quality of education offered by universities. In this setting, education is viewed as a good with different prestige and quality attributes that depend on the performance of the universities. By using ranking, the prestige and quality of education of a university are easily identifiable by its potential customers and comparable among different universities.

However, academic quality is a difficult concept to quantify and hence the use of ranking as a measure of quality is questionable (Schmitz 1993, McGuire 1995, Marginson and Van der Wende 2007). In fact, there is no consensus on how academic quality should be measured (Stuart 1995). On the other hand, the prestige level of a university is measureable and it has significant effects on the behavior of administrators, faculty staff, students, and parents (Garvin 1980, Monks and Ehrenberg 1999a, Volkwein and Grunig 2005). While some studies treat quality and prestige as synonymous (Stuart 1995), there is a subtle distinction between the two (Gross and Grambsch 1973, Volkwein and Sweitzer). As Garvin (1980) points out, the prestige level of a university is more influential than the actual quality level of a university of locations in the product market by these universities is not subjected to profit maximization consideration. 
since prestige incorporates reputational elements that are ignored in quality calculations. Quality is a more objective measure of the characteristics of a university, while prestige is more subjective and reflects how those characteristics are perceived by external observers.

In the higher education industry, prestige is one of the most important factors that are used to evaluate the performance of a university (Garvin 1980; Bastedo and Bowman 2010). Ranking of universities involves reputational surveys on administrators and faculty combined with some data that have been selected. A number of studies found that although rankings affect the behavior of students and parents on college selection and choice, rankings have a more powerful influence on administrators, faculty and benefactors (Machung 1998; Hossler 2000; Ehrenberg 2003; Bastedo and Bowman 2010). At the same time, rankings proved to be very helpful for the evaluation of quality of universities (Machung 1998). While academic quality and prestige are only loosely related, rankings are actually a good indicator of the latter (Pike 2004; Rindova et al. 2005). Rankings of universities are more synonymous with organizational reputation than academic quality (Bowman and Bastedo 2009). Overall, it seems that ranking suits the need as an indicator of universities' prestige. Nevertheless, rankings do not only reflect the prestige of a university, but are very highly correlated with many academic quality indicators (Volkwein and Grunig 2005).

Although many administrators denounce ranking scores as being cosmetic, random, and lacking real measures of quality, they are swift to fill out questionnaires from ranking publishers and fast to tout a high ranking to prospective students (Monks and Ehrenberg 1999b, Meredith 2004). Published rankings of universities aggravate the competition between universities for top students since the applicant's behavior is strongly influenced by the rankings (Monks and Ehrenberg 1999a).

There have been no attempts to use the spatial regression method in the previous 
analysis of price competition between universities in the product market. While there are a number of studies that analyze the impact of changes in rankings on several admission variables, there are not many studies that look at the impact of rankings on prices. Bowman and Bastedo (2009) analyze the influence of rankings on several admission indicators such as the admission test scores, the percentage of top students enrolled, and the admission rate. Rank is used as an explanatory variable with several other control variables. Bastedo and Bowman (2010) investigate the impact of rankings on the financial resources of universities, including published tuition. Universities are grouped into several tiers based on their rankings. They found that a movement between the tier groups significantly affects published out-of-state tuition, where a decrease in prestige leads to lower published out-of-state tuition.

Another study by Monks and Ehrenberg (1999) investigates the impact of changes in rankings on the behavior of universities, including their pricing policies. A change in rank has no impact on published tuition but significantly affects net tuition. A change in rank has no impact on published tuition since the published tuition is regarded, in part, as a signal of academic quality; therefore, a university is reluctant to disclose its declining rank position through lower published tuition (Breneman 1994). However, the university may lower its net tuition by offering more generous financial aid packages to compensate its decline in rank. While the study empirically investigated the effects of ranking on prices, there is no spatial regression method involved. Rank is treated as an explanatory variable in that analysis, while in this study, rank is used to determine the location of universities in the product market. Through this process, each university has its own prestige level that is easily identifiable by its ranking score. The ranking scores are used to arrange universities along a prestige line. The differences in prestige define the interinstitutional competition in the product market. 


\subsection{Data}

The sample used in this analysis is the same as the one used in the analysis of price competition in the geographical market dimension in Chapter $3^{6}$. In addition to IPEDS and SAIPE data, the sample used in the product market analysis also consists of data from the Academic Ranking of World Universities (ARWU) published by Shanghai Jiaotong University.

There are two price variables that are used as the dependent variable in this study. The first one is the published tuition (PTUITION) charged to out-of-state students. The out-of-state tuition is chosen since the in-state tuition is subject to ceilings imposed by state legislatures. In this case, the in-state tuition may not really represent the real price that is subject to demand and supply movements in the market. Furthermore, only public universities discriminate tuitions based on students' residential status, while private universities charge the same tuition to all students. Therefore the published tuition charged to out-of-state students is used as the first dependent variable. The second price variable used is net tuition (NTUITION), which is published tuition less the average institutional aid. Financial aid offers are used as a tool to attract students. At the same time, universities also use financial aids as a signal of their quality level while published tuition is more sticky (Breneman 1994; Monks and Ehrenberg 1999a).

Explanatory variables used in the study include the observed demand and cost factors, and local variants. The demand and cost variables used in this study are as follows: enrollment of undergraduate students (USTD), enrollment of graduate students $(G S T D)$, total endowment of the university (ENDOW), proportion of students receiving any financial assistance $(P R A I D)$, number of full time faculty staff $(F A C$ -

\footnotetext{
${ }^{6}$ The sample consists of 528 universities from 2004 to 2011 . The sample distribution based on the 2000 Carnegie Classification is shown in Table 3.1 on page 67 in the previous chapter.
} 
$U L T Y)$, research spending (RESEARCH), and teaching expenditure (TEACH). To control for local variants in the product market, two variables are used: the admission test scores $(S A T A C T)$ and the admission rate $(A D M R A T E)$. These variables have been explained in the data section of Chapter 3. The descriptive statistics of the sample are presented in Table 3.2 on page 75 . For ease of reference, these variables are listed in Table B.1 in Appendix B.1.

\subsection{Methodology}

The methodology used in this paper follows Baller et al. (2001), Baltagi et al. (2007), and Elhorst (2010). There are four spatial model specifications considered in this study. Universities are assumed to be utility-maximizing entities competing in prices. The prices imposed by a university are influenced partly by proximity of competitors in the product market space and partly upon demand and cost factors. The methodology section starts with an investigation on the presence of spatial effects using simple spatial autocorrelation statistics. Once the presence of spatial effects is confirmed, a hybrid approach is used in the model specification tests to choose the most appropriate spatial model. The last subsection explains the interpretation of the estimated coefficients in the spatial model.

The model specification process and spatial regression interpretation have been explained in more details earlier in the Section 3.4 of Chapter 3 on geographical market dimension. The possiblility of endogeneity between enrollment of undergraduate students and prices have also been addressed there. 


\subsubsection{Test for Spatial Autocorrelation}

Before a spatial econometrics model could be used, firstly the presence of spatial autocorrelation in the data needs to be confirmed (Baller et al. 2001). There are two simple spatial autocorrelation statistics that are used to verify the presence of spatial autocorrelation in the data: Moran's $I$-statistic (Moran 1950) and Geary's $C$-statistic (Geary 1954). The Moran's I-statistic is defined earlier in equation (3.1) on page 79, while the Geary's $C$-statistic is given in equation (3.2) on 79 .

The product market is defined by a linear line on which universities are located according to their ARWU rank scores. Universities with higher prestige and quality are assigned with smaller rank scores, while larger rank scores represent lower prestige and quality. Since the ARWU rank scores are calculated by an external party ${ }^{7}$ based on past years data, the locations of universities along the product market line could be regarded as exogenous to current year's prices. The ARWU rank is chosen over other rankings since its ranking methodology is consistent throughout the years with no changes ${ }^{8}$. Furthermore, the ARWU rank scores put greater weight on the research contributions of faculty members, which is the main contributor for prestige and quality as argued by Garvin (1980).

The ARWU rank scores define a straight line used to measure the location of each university in the product market. The matrix $W$ in equations (3.4), (3.5), and (3.6) is now a measure of social distance between universities in the product market. Universities that are assigned the same rank by ARWU have zero distance between each other, and this causes a problem since each spatial unit in spatial estimation must have a unique location in the market dimension. To solve this problem, universities

\footnotetext{
${ }^{7}$ The ARWU rank scores are published by Shanghai Jiaotong University, which could be regarded as an external party to all U.S. universities that are being ranked.

${ }^{8}$ Other rankings are subject to continuous improvements in their calculation methods as claimed by their publishers every time a new rank is published.
} 
with the same location are differentiated by a factor of one thousandth. As for universities that are not assigned any rank by ARWU, they are grouped into one rank which is the next integer after the last ARWU rank ${ }^{9}$. For example, in 2004, a total of 140 universities in the sample were ranked by ARWU. The remaining 388 universities with no ARWU rank are ordered based on alphabetical order starting with 141.001. Since the ARWU ranking distance between universities is used as the spatial weighting matrix, all universities in the U.S. are assumed to be in the same product market. This specification allows for analysis on the global spatial effect.

However, since the location of a university in the product market varies from year to year, the social spatial weighting matrix is not fixed throughout the sample period. This is similar to Marginson (2006) where the hierarchy of higher education is subject to continual movement and flux, except for elite universities which seem to enjoy a relatively more stable position. In order to apply panel estimation methods, the location of universities in the product market needs to be modified such that it remains fixed throughout the analysis period. Therefore the ARWU rank from the year 2004, the initial year of the sample period, is used to determine the spatial weighting matrix in the product market. The ARWU rank published in 2004 used input values from the previous year and therefore it is safe to assume that it is exogenous to all values from 2004 onwards. Under this specification, universities assume that their locations in the product market from 2004 to 2011 are fixed by the 2004 ARWU rank scores. To check for the robustness of this approach, the results obtained will be compared with a cross-sectional analysis approach where the ARWU rank score from each year is used to create the spatial weighting matrix.

\footnotetext{
${ }^{9}$ This method follows Monks and Ehrenberg (1999) and Meredith (2004) where universities with no numerical rank are assigned with the last rank value of the year.
} 


\subsubsection{Model Specification Test}

If the Moran's I-statistic and the Geary's $C$-statistic verify the presence of spatial autocorrelation, then a spatial model should be used. However since there are several spatial models available, there is a need to choose the most appropriate spatial model based on a model specification approach (Baller et al. 2001; Elhorst 2010). Although Moran's I-statistic is perhaps the best detector for spatial autocorrelation, it does not specify which model specification should be used to capture those spatial autocorrelation (Anselin and Rey 1991).

There are four spatial models that are being considered to be used to estimate the price competition between universities in the product market. These four models have been introduced in lengthy detail in the Section 3.4 for the geographical market dimension in Chapter 3. The following paragraphs provide brief descriptions of the four models.

Basically, these models differ from each other based on how the spatial effect is introduced into the model. From the four models, there are three ways in which a spatial effect could be incorporated into the model. Firstly, the spatial effect could come from the dependent variable of other nearby individual units that are located within the same market region. In this case, a spatially lagged dependent variable is introduced into the model as an additional explanatory variable as shown in equation (3.4) on page 82. This approach is known as the spatial autoregressive (SAR) model. Secondly, in addition to the spatial effect caused by the dependent variable of other units, the spatial effect could also originate from the explanatory variables of other units in the market. In this specification, each explanatory variable in the equation has two estimated coefficients. The first coefficient is the ordinary coefficient that affects the dependent variable equally across the sample, while the second coefficient 
is a spatially lagged coefficient that measures the impact of changes in the explanatory variables of nearby units. This approach is known in the literature as the spatial Durbin model (SDM). The SDM equation is provided in equation (3.5) on page 83. In the third specification, the spatial effect is introduced via the error term. In this approach, the error term consists of two elements. The first element is influenced by the shocks in the dependent variable of other units located in the same market, while the second element is white noise. This model is known as the spatial error model (SEM), shown as equation (3.6) on page 83. The last specification combines the first model and the third model, where the spatial effect is assumed to be present in both the spatially lagged dependent variable and the error term. These two specifications are the most common spatial models used in the applied empirical works (Anselin et al. 2000), hence the combination of them produces the most general alternative of spatial dependence known as the spatial autoregressive moving average (SARMA) model in the literature (Huang 1984). The SARMA model is shown in equation (3.8) on page 85 .

To select the most appropriate spatial model, the hybrid spatial specification method is performed with some modifications. Florax et al. (2003) merge the classical approach suggested by Anselin and Rey (1991) and the robust approach outlined by Bera and Yoon (1993) to create the hybrid spatial specification method. The hybrid spatial model selection criteria is already explained thoroughly in the methodology section for the geographical market dimension in the previous chapter. Briefly, all of the specification tests involve testing the significance of spatial coefficients and test statistics derived from each of the four spatial models mentioned earlier. The null hypothesis in all these tests assumes the absence of spatial effect of the specific type associated with each of the four spatial models. If the test fails to reject the null hypothesis, then the model is unable to capture the spatial effect and other spatial 
models should be used instead. Most of the specification tests are decisive in nature, which means the result from the test points toward the more suitable model between two spatial models. The maximum likelihood method is used to estimate the chosen model.

\subsubsection{Interpretation of the Results}

The interpretation of the estimated coefficients from the SAR model, the SARMA model, and the SDM model is different from other least squares models (LeSage and Pace 2014). This is because the $r$-th coefficient, $\beta_{r}$, is no longer the partial derivative of $y$ with respect to a change in the $r$-th explanatory variable from the matrix $X$, except in the SEM model. There is a non linear relationship between the dependent variable $y$ and the variables on the right hand side of the spatial equation. The effects of the right hand side variables on the dependent variable in spatial models are interpreted using the marginal effects as proposed by LeSage and Pace (2009).

The marginal effects consist of two components: the direct effect and the indirect effect. The direct effect measures how a change in the $r$-th explanatory variable of university $i$ influences its own price $y_{i}$ directly. The indirect effect shows how a change in the $r$-th explanatory variable of university $j$ affects its price $y_{j}$, which in turn influences the price of university $i, y_{i}$, indirectly through the vector $W y$. This indirect channel of influence is also known as the feedback effect. Since the vector $W y$ is not used in the SEM specification, there is no indirect effect in the SEM model ${ }^{10}$. Hence the estimated coefficients in the SEM model could be used to interpret the partial effects of the explanatory variables on the dependent variable. The combination of direct and indirect effects is the total effect.

\footnotetext{
${ }^{10}$ Since the SARMA model consists of the SAR component and the SEM component, the interpretation of the SARMA model is complicated due to the SAR component.
} 
To verify the significance of the marginal effects, LeSage and Pace (2014) suggest for a dispersion measure derived from simulated variance covariance matrix of the spatial model. The technical details of the interpretation method used in this study have been explained in the methodology section of the geographical market dimension in the previous chapter.

\subsubsection{Market Size Analysis}

The spatial weighting matrix used in the product market will be truncated into smaller market size to investigate the extent of spatial effects in the product market. The objective of this approach is to check on the size and direction of spatial effects as the market size is limited into smaller area. This approach is used since universities in the top 10 rankings may not really be influenced by the prices set by universities in the above 100 ranks. In this case, instead of including all universities in the sample into a single product market, the product market is limited to universities that are located within smaller ranks difference. Under this specification, the matrix $W$ is defined as:

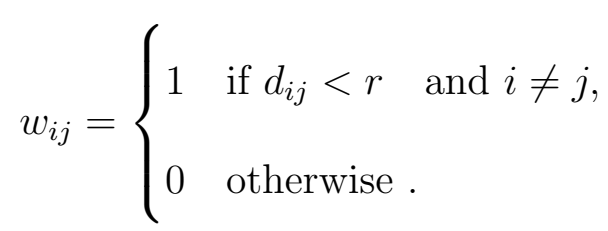

where $d_{i j}$ is the Euclidean distance between universities $i$ and $j$ in ARWU rank scores and $r$ is a threshold value that limits the product market size. Since the product market size is now limited to smaller rank differences, this specification focuses on the local spatial effect. As a starting point, the threshold value is set to 50 ranks based on Bowman and Bastedo (2009) findings, where changes within the top 50 ranks are found to have significant impact on student decisions. This step is repeated with smaller market size and a comparison of all estimated spatial coefficients will be 
performed.

\subsection{Results}

This section consists of two major parts. The first part implements the hybrid model specification approach explained earlier in the methodology section in several steps. Firstly, the presence of spatial autocorrelation is investigated by looking at the spatial correlation between the price variables and the location of universities in the product market dimension. Once the presence of spatial autocorrelation is confirmed, the following subsection discusses the model selection process using several spatial specification tests. The specification tests would suggest which model specification should be used to model the price competition between universities. In the second part of this section, the regression results from the chosen model are presented and discussed.

\subsubsection{Spatial Correlation}

To inspect for the presence of spatial autocorrelation in the product market dimension, two measures of spatial correlation are used: Moran's $I$-statistic and Geary's $C$ statistic. For spatial autocorrelation analysis, the ARWU rank scores from each year are used as the location indicator of universities in the product market. The results are shown in Table 4.1.

From Table 4.1, the null hypothesis of spatial independence is rejected by both the Moran's $I$ statistics and the Geary's $C$ statistics in all years. It seems that there is a strong spatial correlation between published tuition and net tuition of universities in the product market dimension.

In the product market, the Moran's I statistics and the Geary's $C$ statistics are sig- 
Table 4.1: Spatial correlation statistics in the product market

\begin{tabular}{ccccc}
\hline \hline & \multicolumn{4}{c}{ Product Market } \\
\cline { 2 - 5 } Year & \multicolumn{2}{c}{ Published Tuition } & \multicolumn{2}{c}{ Net Tuition } \\
\cline { 2 - 5 } & Moran's I & Geary's $C$ & Moran's $I$ & Geary's $C$ \\
\hline 2004 & $0.161^{* * *}$ & $0.821^{* * *}$ & $0.138^{* * *}$ & $0.827^{* * *}$ \\
2005 & $0.156^{* * *}$ & $0.832^{* * *}$ & $0.109^{* * *}$ & $0.887^{* * *}$ \\
2006 & $0.153^{* * *}$ & $0.840^{* * *}$ & $0.128^{* * *}$ & $0.866^{* * *}$ \\
2007 & $0.144^{* * *}$ & $0.849^{* * *}$ & $0.112^{* * *}$ & $0.892^{* * *}$ \\
2008 & $0.149^{* * *}$ & $0.844^{* * *}$ & $0.105^{* * *}$ & $0.881^{* * *}$ \\
2009 & $0.143^{* * *}$ & $0.845^{* * *}$ & $0.084^{* * *}$ & $0.879^{* * *}$ \\
2010 & $0.145^{* * *}$ & $0.844^{* * *}$ & $0.118^{* * *}$ & $0.856^{* * *}$ \\
2011 & $0.144^{* * *}$ & $0.846^{* * *}$ & $0.095^{* * *}$ & $0.881^{* * *}$ \\
\hline \hline * Significant at 10\% & ${ }^{* *}$ Significant at $5 \%{ }^{* * *}$ Significant at $1 \%$
\end{tabular}

nificant for both published tuition and net tuition in all years. This strongly suggests that published tuition and net tuition are affected by the presence of spatial autocorrelation in the product market. The range of Moran's I statistic for published tuition is between 0.144 and 0.161 , which is larger than those observed in the geographical market. This suggests that the positive spatial correlation between published tuition in the product market is stronger than the same correlation in the geographical market. The Geary's $C$ statistics for published tuition in the product market is smaller than their counterparts in the geographical market, which also suggests for stronger positive spatial correlation between published tuition in the product market. The Moran's $I$ statistics for net tuition in the product market are smaller than those for published tuition. In this case, the positive spatial effect for net tuition in the product market is weaker than the same effect for published tuition. The Geary $C$ statistics for net tuition are larger than those for published tuition for all years. This indicates that both global and local spatial correlations for net tuition in the product market are weaker compared to published tuition.

To illustrate the extent of spatial dependence in published tuition and net tuition 
Figure 4.2: Moran scatterplot for published tuition in the product market for 2010

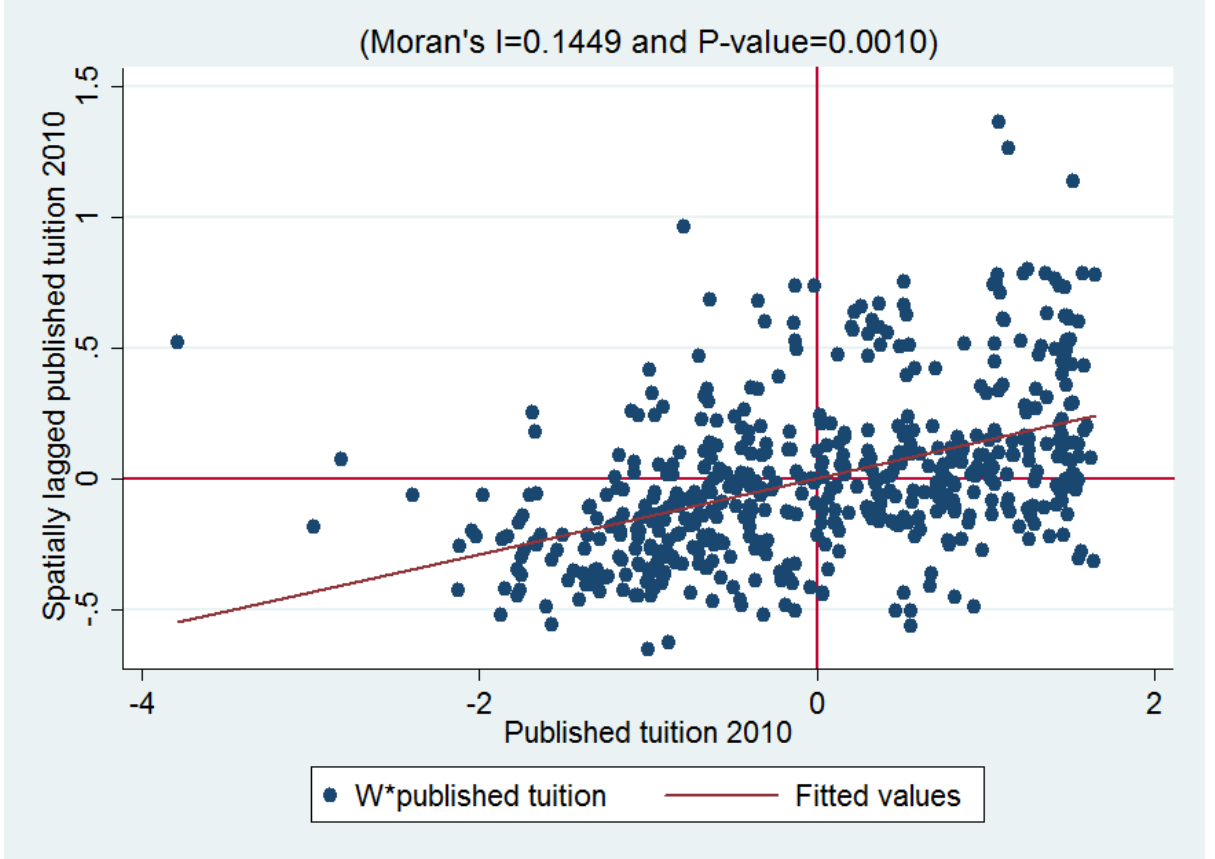

in the U.S. higher education sector, the Moran scatterplot is used. The Moran scatterplot shows the relation between the dependent variable vector $y$ (in deviation from means form) and the average values of observations in the spatial lag vector $W y$. The differences in ARWU rank scores are used for the spatial weighting matrix in the product market. The inverse distance is used in the spatial weighting matrix so that the nearer neighbors are given greater spatial weight while faraway neighbors are given smaller weight to influence published tuition and net tuition of a university ${ }^{11}$.

The Moran scatterplots for published tuition and net tuition in the product market are shown in Figure 4.2 and Figure 4.3 respectively. All other years display the same Moran scatterplot pattern ${ }^{12}$. There are positive spatial correlations in published tuition and net tuition in the product market. This indicates that universities are

\footnotetext{
${ }^{11}$ The interpretation of Moran scatterplot has been explained in Section 3.5 of Chapter 3 earlier.

${ }^{12}$ The Moran scatterplots of published tuition and net tuition in all other years are provided in Figures D.1 and D.2 in Appendix D.1 respectively.
} 
Figure 4.3: Moran scatterplot for net tuition in the product market for 2010

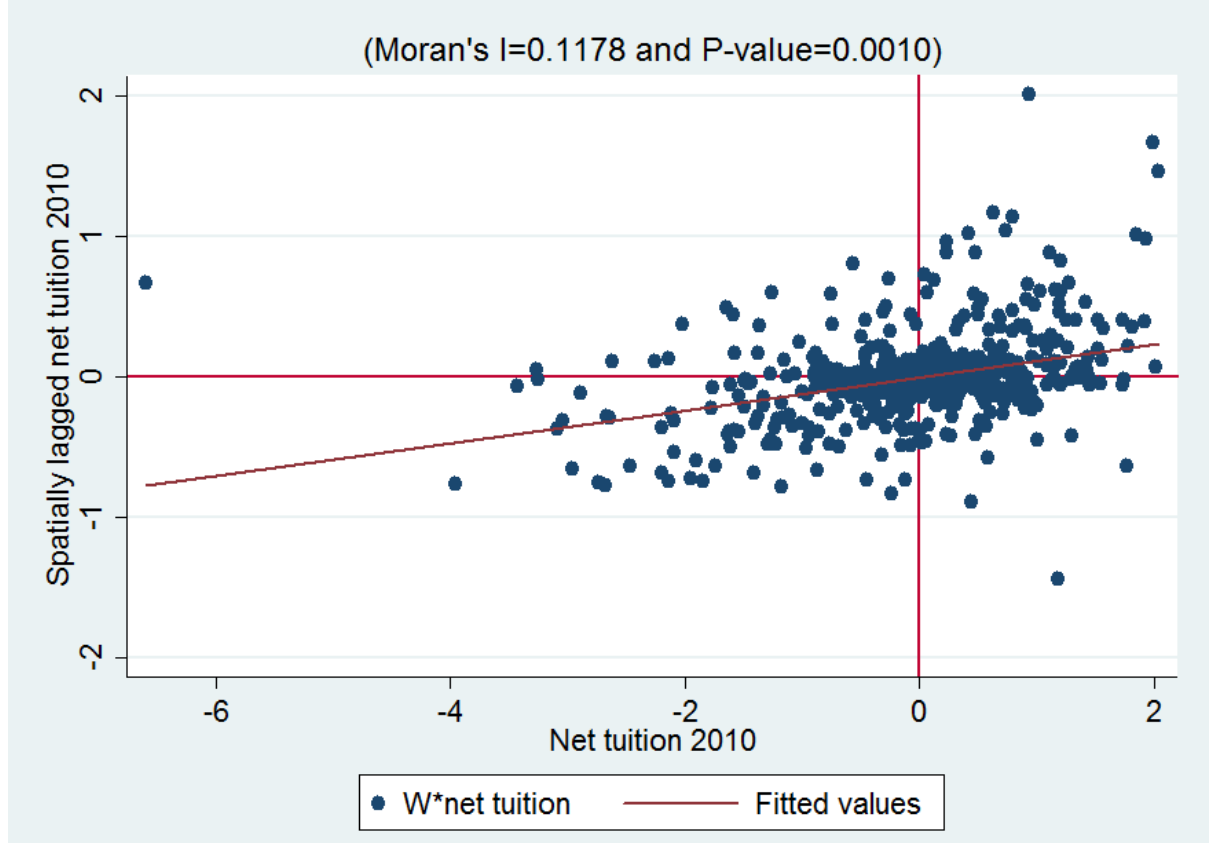

motivated to change their published tuition and net tuition in the same directions as their neighbors of the similar prestige and quality levels. The Moran scatterplots for published tuition are more dispersed while the Moran scatterplots for net tuition are more clustered towards the origin.

The results from the Moran's I statistics and the Geary's $C$ statistics provide strong evidence of a significant spatial pattern in the product market of higher education. Based on these results, it is expected that the coefficients for spatial autocorrelation in the model should have positive signs, although their size may be smaller with weaker significance level. At the same time, the spatial effects in published tuition are expected to be stronger than net tuition. Since spatial correlation is significantly present, all subsequent analyses shall consider all 528 universities in the sample as belonging in the same market. 


\subsubsection{Model Specification}

Now that the presence of spatial autocorrelation in the sample is confirmed, the next step is to determine the spatial model specification using the SARMA model, which is the most general form of spatial model specification. For model specification tests, the ARWU rank of 2004 is used as the spatial weighting matrix for all years ${ }^{13}$. The SARMA model includes both spatial lag and spatial error. The null hypothesis for the $L M_{\rho \lambda}$ is that both the spatial lag and the spatial error are absent from the model. The results are shown in Table 4.2.

Table 4.2: SARMA tests for spatial model specification

\begin{tabular}{lll}
\hline \hline & \multicolumn{2}{c}{$L M_{\rho \lambda}$ Test: $H_{0}: \rho=\lambda=0$} \\
\cline { 2 - 3 } Year & \multicolumn{2}{c}{ Product Market } \\
\cline { 2 - 3 } 2004 & Published Tuition & Net Tuition \\
2005 & $59.4480^{* * *}$ & $35.1498^{* * *}$ \\
2006 & $42.0601^{* * *}$ & $30.8182^{* * *}$ \\
2007 & $42.6295^{* * *}$ & $39.7207^{* * *}$ \\
2008 & $42.5809^{* * *}$ & $30.7366^{* * *}$ \\
2009 & $41.9809^{* * *}$ & $37.4295^{* * *}$ \\
2010 & $39.7040^{* * *}$ & $45.9548^{* * *}$ \\
2011 & $28.0999^{* * *}$ & $17.2675^{* * *}$ \\
\hline \hline * Significant at $10 \%$ & ${ }^{* *}$ Significant at $5 \%$ \\
*** Significant at 1\% &
\end{tabular}

From the $L M_{\rho \lambda}$ test results, the null hypothesis of spatial independence is rejected in all years at $1 \%$ significance level. There is a strong presence of spatial autocorrelation in both published tuition and net tuition in the product market. Similar results are observed when ARWU rank of each year is used to construct the spatial weighting matrix $^{14}$.

\footnotetext{
${ }^{13}$ The specification results obtained from using the 2004 ARWU rank will be compared with the specification results obtained from using ARWU rank of each year.

${ }^{14}$ Please refer to Table D.7 in Appendix D.4 for the $L M_{\rho \lambda}$ test results based on yearly ARWU rank.
} 
The results obtained from the $L M_{\rho \lambda}$ tests are identical with the results obtained from the spatial correlation analysis earlier. This suggests that the set of explanatory variables chosen to model the price competition is able to incorporate spatial effects in the regressions for published tuition and net tuition in the product market.

Since the results from the $L M_{\rho \lambda}$ tests indicate that spatial autocorrelation is strongly present in the model, the next step is to determine which type of spatial model better explains the product market. The null hypothesis of the $L M_{\rho \lambda}$ test equate both spatial lag and spatial error to zero. If this is rejected, then there is a need to investigate either both the spatial lag and the spatial error are not zero or only one of them is not zero.

The results from the LM specification tests for the product market are shown in Table 4.3. The null hypothesis in all specification tests is that the model has no spatial autocorrelation.

From Table 4.3, both $L M_{\rho}$ and $L M_{\lambda}$ tests for published tuition are significant in all years. However the robust $L M_{\rho}^{*}$ tests are not significant from 2009 to 2011; while the robust $L M_{\lambda}^{*}$ tests are significant in all years. Furthermore, the $L M_{\rho}^{*}$ test is significant at 5\% level for two years only (in 2006 and 2007), while for the remaining years the tests are significant at $10 \%$ level. On the other hand, the $L M_{\lambda}^{*}$ tests are significant at $1 \%$ level for all years. Looking at these results, the LM specification tests seem to prefer the SARMA specification over the SAR and SEM specifications for published tuition in the product market.

For net tuition, the $L M_{\rho}$ tests are significant in all years except 2009, while the $L M_{\lambda}$ tests are significant in all years. Moving on to the robust version of the tests, the $L M_{\rho}^{*}$ tests are not significant in all years; while the $L M_{\lambda}^{*}$ tests remain significant at $1 \%$ level in all years. Based on these results, the SEM specification should be used to estimate net tuition in the product market. 
Table 4.3: The LM specification tests for spatial lag and spatial error in the product market

\begin{tabular}{ccccc}
\hline \hline & \multicolumn{4}{c}{ Product Market: Published Tuition } \\
\cline { 2 - 5 } Year & $L M_{\rho}$ & $L M_{\rho}^{*}$ & $L M_{\lambda}$ & $L M_{\lambda}^{*}$ \\
\hline 2004 & $23.1923^{* * *}$ & $3.7410^{*}$ & $61.3470^{* * *}$ & $41.8957^{* * *}$ \\
2005 & $21.7193^{* * *}$ & $3.7429^{*}$ & $55.6994^{* * *}$ & $37.7230^{* * *}$ \\
2006 & $18.2427^{* * *}$ & $4.4677^{* *}$ & $37.5924^{* * *}$ & $23.8174^{* * *}$ \\
2007 & $18.1857^{* * *}$ & $3.9953^{* *}$ & $38.6341^{* * *}$ & $24.4437^{* * *}$ \\
2008 & $16.6910^{* * *}$ & $3.0652^{*}$ & $39.5156^{* * *}$ & $25.8899^{* * *}$ \\
2009 & $14.5881^{* * *}$ & 2.2872 & $39.6937^{* * *}$ & $27.3928^{* * *}$ \\
2010 & $14.5369^{* * *}$ & 2.4507 & $37.2533^{* * *}$ & $25.1672^{* * *}$ \\
2011 & $11.5284^{* * *}$ & 2.3837 & $25.7163^{* * *}$ & $16.5715^{* * *}$ \\
\hline \hline & \multicolumn{5}{c}{ Product Market: Net Tuition } \\
\cline { 2 - 5 } Year & $L M_{\rho}$ & $L M_{\rho}^{*}$ & $L M_{\lambda}$ & $L M_{\lambda}^{*}$ \\
\hline 2004 & $13.6911^{* * *}$ & 0.2575 & $34.88923^{* * *}$ & $21.4587^{* * *}$ \\
2005 & $10.9895^{* * *}$ & 0.0517 & $30.7665^{* * *}$ & $19.8287^{* * *}$ \\
2006 & $10.1384^{* * *}$ & 0.1130 & $39.6077^{* * *}$ & $29.5824^{* * *}$ \\
2007 & $7.9579^{* * *}$ & 0.1318 & $30.6048^{* * *}$ & $22.7787^{* * *}$ \\
2008 & $8.0846^{* * *}$ & 0.4991 & $36.9304^{* * *}$ & $29.3450^{* * *}$ \\
2009 & $4.9695^{* *}$ & 1.1398 & $24.8147^{* * *}$ & $20.9849^{* * *}$ \\
2010 & $4.8645^{* *}$ & $3.4063^{*}$ & $39.3372^{* * *}$ & $37.8790^{* * *}$ \\
2011 & $3.2369^{*}$ & 0.4962 & $16.7710^{* * *}$ & $14.0303^{* * *}$ \\
\hline * Significant at $10 \%$ & $* *$ & Significant at $5 \%$ & $* * *$ & Significant at $1 \%$
\end{tabular}

When the yearly ARWU rank is used to determine the locations of universities in the product market, similar results are observed ${ }^{15}$. The SARMA model and the SEM model are suggested for published tuition and net tuition respectively.

The results for the LR specification tests are presented in Table 4.4. Columns 1, 2 , and 3 of the table display the $L R_{\rho \lambda}, L R_{\rho}$, and $L R_{\lambda}$ respectively. The $L R_{\rho \lambda}$ test assumes both $\rho$ and $\lambda$ to be zero under the null hypothesis. The $L R_{\rho}$ test investigates the spatially lagged dependent variable coefficient. The $L R_{\lambda}$ test inspects the presence of spatial dependence in the error term.

\footnotetext{
${ }^{15}$ Please refer to Table D.8 in Appendix D.4 for the $L M_{\rho \lambda}$ test results based on yearly ARWU rank.
} 
Table 4.4: The LR specification tests for spatial autocorrelation in the product market

\begin{tabular}{cccc}
\hline \hline & \multicolumn{3}{c}{ Product Market } \\
\cline { 2 - 4 } Year & $L R_{\rho \lambda}$ Published Tuition \\
\cline { 2 - 4 } & $L R_{\rho}$ & $L R_{\lambda}$ \\
\hline 2004 & $64.4044^{* * *}$ & $20.1998^{* * *}$ & $12.6070^{* * *}$ \\
2005 & $62.0181^{* * *}$ & $21.1275^{* * *}$ & $12.6070^{* * *}$ \\
2006 & $50.1802^{* * *}$ & $21.7594^{* * *}$ & $4.7211^{* *}$ \\
2007 & $51.3462^{* * *}$ & $20.3404^{* * *}$ & $8.1929^{* * *}$ \\
2008 & $46.6956^{* * *}$ & $14.5283^{* * *}$ & $9.6123^{* * *}$ \\
2009 & $44.6665^{* * *}$ & $12.3959^{* * *}$ & $10.3960^{* * *}$ \\
2010 & $43.4133^{* * *}$ & $12.7197^{* * *}$ & $9.5333^{* * *}$ \\
2011 & $32.3012^{* * *}$ & $11.0857^{* * *}$ & $4.2392^{* *}$ \\
\hline \hline & \multicolumn{3}{c}{ Net Tuition } \\
Year & $L R_{\rho \lambda}$ & $L R_{\rho}$ & $L R_{\lambda}$ \\
\hline 2004 & $36.6711^{* * *}$ & $10.3805^{* * *}$ & 0.5919 \\
2005 & $32.1489^{* * *}$ & $8.0166^{* * *}$ & 1.1813 \\
2006 & $44.1877^{* * *}$ & $14.2562^{* * *}$ & 1.7400 \\
2007 & $32.6161^{* * *}$ & $7.7004^{* * *}$ & $2.7866^{*}$ \\
2008 & $37.8526^{* * *}$ & $8.3886^{* * *}$ & $4.8366^{* *}$ \\
2009 & $26.7222^{* * *}$ & $6.0709^{* *}$ & 2.0002 \\
2010 & $37.5945^{* * *}$ & $7.1268^{* * *}$ & $3.4684^{*}$ \\
2011 & $18.6387^{* * *}$ & $3.9100^{* *}$ & 1.2352 \\
\hline \hline
\end{tabular}

* Significant at 10\% ** Significant at 5\%

*** Significant at $1 \%$

The LR tests results obtained for published tuition is similar to the results of the previous LM specification tests. All three test statistics are significant in all years. Based on the LR tests results, the SARMA model is preferred over SAR and SEM specifications for published tuition. However, the LR tests results obtained for net tuition are different from the results of the previous LM specification tests. The $L R_{\rho \lambda}$ and the $L R_{\rho}$ statisitics are significant in all years, while the $L R_{\lambda}$ statistics are significant in three years only: 2007, 2008, and 2010. Furthermore, in 2007 and 2010, the $L R_{\lambda}$ statistics are significant at $10 \%$ level only. Based on the LR tests results, the SAR model should be used for net tuition. 
The LR tests results when yearly ARWU rank is used to determine the spatial weighting matrix suggest that the SAR model is used for published tuition, which is different than the results obtained when 2004 ARWU rank is used. This is because the $L R_{\lambda}$ statistics are not significant in all years except in 2004 only. For net tuition, the SAR model is suggested. The results obtained when the 2004 ARWU rank is replaced with the yearly ARWU $\operatorname{rank}^{16}$.

The SDM specifcation test results for the product market are presented in Table 4.5. The null hypothesis in the $L R_{\rho}$ test is that there is no spatial lag autocorrelation. For the $L R_{\theta}$ test, the null hypothesis is that the coefficients of all spatially lagged explanatory variables are zero, which means that the SAR specification is favored over the SDM specification. The null hypothesis for the $N L_{\rho \beta}$ test is that each coefficient of the spatially lagged explanatory variables equals to the negative value of the spatial coefficient multiplied with the coefficient of each explanatory variable. In this test, if the null hypothesis is not rejected, then the SEM model is preferred over the SDM model.

The SDM specification tests results suggest the SDM model published tuition. For published tuition, all three SDM specification tests are significant in all years except for 2011, where $L R_{\theta}$ is not significant. In this case, there is no significant difference between SDM model and SAR model since the estimated coefficients for all spatially lagged explanatory variables are not significant, therefore the SAR model should be chosen instead. However, since a panel estimation method will be used to analyze published tuition competition using the 2004 ARWU rank to determine the spatial weighting matrix, only one model specification could be chosen. Based on the SDM specification tests, the SDM model will be used to estimate published tuition

\footnotetext{
${ }^{16}$ Please refer to Table D.9 in Appendix D.4 for the LR specification test results when the spatial weighting matrix is determined by the yearly ARWU rank.
} 
Table 4.5: Specification tests for spatial autocorrelation from SDM model in the product market

\begin{tabular}{|c|c|c|c|}
\hline \multirow[b]{3}{*}{ Year } & \multicolumn{3}{|c|}{ Product Market } \\
\hline & \multicolumn{3}{|c|}{ Published Tuition } \\
\hline & $L R_{\rho}$ & $L R_{\theta}$ & $N L_{\rho \beta}$ \\
\hline 2004 & $50.3615^{* * *}$ & $19.4038^{*}$ & $19.88^{*}$ \\
\hline 2005 & $49.1355^{* * *}$ & $19.1039^{*}$ & $21.74^{* *}$ \\
\hline 2006 & $29.3283^{* * *}$ & $20.2036^{*}$ & $25.03^{* *}$ \\
\hline 2007 & $26.7612^{* * *}$ & $29.2361^{* * *}$ & $30.82^{* * *}$ \\
\hline 2008 & $24.4880^{* * *}$ & $29.6149^{* * *}$ & $28.16^{* * *}$ \\
\hline 2009 & $29.6960^{* * *}$ & $24.4543^{* *}$ & $22.12^{* *}$ \\
\hline 2010 & $24.4423^{* * *}$ & $29.3037^{* * *}$ & $27.04^{* * *}$ \\
\hline \multirow[t]{2}{*}{2011} & $16.9472^{* * *}$ & 18.3680 & $18.80^{*}$ \\
\hline & \multicolumn{3}{|c|}{ Net Tuition } \\
\hline Year & $L R_{\rho}$ & $L R_{\theta}$ & $N L_{\rho \beta}$ \\
\hline 2004 & $23.9228^{* * *}$ & 12.1980 & 16.65 \\
\hline 2005 & $22.8794^{* * *}$ & 11.9190 & 15.46 \\
\hline 2006 & $30.5851^{* * *}$ & 17.8009 & $23.56^{* *}$ \\
\hline 2007 & $21.1028^{* * *}$ & $21.9891^{* *}$ & $24.31^{* *}$ \\
\hline 2008 & $25.5685^{* * *}$ & $22.8569^{* *}$ & $24.40^{* *}$ \\
\hline 2009 & $16.9750^{* * *}$ & 17.6614 & $19.59^{*}$ \\
\hline 2010 & $24.0913^{* * *}$ & $21.5781^{* *}$ & $22.94^{* *}$ \\
\hline 2011 & $9.3457^{* * *}$ & 14.4719 & 15.48 \\
\hline
\end{tabular}

competition in the product market.

Different results are observed for net tuition, where only $L R_{\rho}$ is significant in all years. The $L R_{\theta}$ statistics are not significant in most years while the $N L_{\rho \beta}$ statistics are significant in all but three years: 2004, 2005, and 2011. This suggests that the SAR model should be used for net tuition.

When the 2004 ARWU rank is replaced with the yearly ARWU rank, the SDM specification tests suggest that the SDM model should be used for both published tuition and net tuition in most years. The only exceptions are for published tuition 
in 2005 and net tuition in 2004, where the SDM specification tests suggest for the SAR and SARMA models respectively ${ }^{17}$.

\subsubsection{Regression Results}

The product market analysis uses the ARWU rank in 2004 to determine the location of universities along a quality line in the product market. Based on the previous specification tests, the SDM specification is used to model spatial regression of published tuition while the SAR model is used for net tuition. The spatial regression results for the product market are shown in Table 4.6. The first two columns show the estimated coefficients for explanatory variables and spatially lagged explanatory variables from the SDM model for published tuition. Column (3) shows the estimated coefficients for explanatory variables from the SAR model for net tuition. The panel-robust Hausman test statistics for both published tuition and net tuition are significant as shown at the bottom of the table. Therefore the fixed effects (FE) method is used instead of the random effects (RE) method to estimate spatial price competition in the product market. However, the public-private type dummy is dropped since FE estimate disallow the estimation of time-invariant variables.

For published tuition, most of the estimated coefficients are not significant. The main coefficient for undergraduate enrollment is significantly negative but its spatially lagged coefficent is not significant. The negative effect of undergraduate enrollment indicates that universities tend to lower their published tuition as they enroll more undergraduate students, which suits the goal of service-oriented universities but not the goal of prestige-oriented universities. There seems to be a positive feedback effect of research spending although its main coefficient is not significant. This suggests

\footnotetext{
${ }^{17}$ The SDM specification tests results when yearly ARWU rank is used as the spatial weighting matrix are shown in Table D.10 in Appendix D.4.
} 
Table 4.6: Price competition in the product market

\begin{tabular}{|c|c|c|c|}
\hline & \multicolumn{2}{|c|}{ Published Tuition } & \multirow{3}{*}{$\begin{array}{c}\text { Net Tuition } \\
(3)\end{array}$} \\
\hline & $(1)$ & $(2)$ & \\
\hline & Main & Spatial Lag & \\
\hline \multirow[t]{2}{*}{ USTD } & $-0.0064^{* * *}$ & 0.0040 & -0.0010 \\
\hline & $(0.0024)$ & $(0.0082)$ & $(0.0039)$ \\
\hline \multirow[t]{2}{*}{ GSTD } & -0.0047 & 0.0032 & $-0.0173^{* *}$ \\
\hline & $(0.0031)$ & $(0.0073)$ & $(0.0078)$ \\
\hline \multirow[t]{2}{*}{ ENDOW } & -0.0044 & -0.0159 & 0.0064 \\
\hline & $(0.0039)$ & $(0.0147)$ & $(0.0055)$ \\
\hline \multirow[t]{2}{*}{ PRAID } & -0.0343 & -0.0046 & -0.0221 \\
\hline & $(0.0344)$ & $(0.1008)$ & $(0.0645)$ \\
\hline \multirow[t]{2}{*}{ FACULTY } & 0.0624 & -0.1060 & 0.0688 \\
\hline & $(0.0410)$ & $(0.1160)$ & $(0.0732)$ \\
\hline \multirow[t]{2}{*}{ RESEARCH } & 0.0061 & $0.0392^{*}$ & $0.0144^{* *}$ \\
\hline & $(0.0040)$ & $(0.0216)$ & $(0.0063)$ \\
\hline \multirow[t]{2}{*}{ TEACH } & $0.0432^{* *}$ & $0.1463^{* * *}$ & $0.1959^{* * *}$ \\
\hline & $(0.0187)$ & $(0.0514)$ & $(0.0329)$ \\
\hline \multirow[t]{2}{*}{ SATACT } & $-0.0019^{*}$ & 0.0065 & -0.0010 \\
\hline & $(0.0011)$ & $(0.0043)$ & $(0.0024)$ \\
\hline \multirow[t]{2}{*}{ ADMRATE } & -0.0194 & -0.0455 & -0.0572 \\
\hline & $(0.0209)$ & $(0.0932)$ & $(0.0351)$ \\
\hline \multirow[t]{2}{*}{ POPDEN } & -0.0001 & -0.0211 & -0.0088 \\
\hline & $(0.0063)$ & $(0.0295)$ & $(0.0156)$ \\
\hline \multirow[t]{2}{*}{ MEDINC } & -0.0116 & $0.1779^{* *}$ & -0.0215 \\
\hline & $(0.0440)$ & $(0.0773)$ & $(0.0642)$ \\
\hline \multirow[t]{2}{*}{$\rho$} & \multicolumn{2}{|c|}{$0.7156^{* * *}$} & $0.6423^{* * *}$ \\
\hline & \multicolumn{2}{|c|}{$(0.0390)$} & $(0.0410)$ \\
\hline Observations & \multicolumn{2}{|c|}{4224} & 4224 \\
\hline Universities & \multicolumn{2}{|c|}{528} & 528 \\
\hline Hausman $\chi^{2}$ & \multicolumn{2}{|c|}{$61.18^{* * *}$} & $65.75^{* * *}$ \\
\hline Est. method & \multicolumn{2}{|c|}{ SDM } & SAR \\
\hline
\end{tabular}

Asymptotic standard errors in parentheses

${ }^{*} p<0.1,{ }^{* *} p<0.05,{ }^{* * *} p<0.01$ 
that there is a positive impact of research spending of other universities on published tuition of a university. Teaching expenditure has significant main and spatially lagged coefficients. This suggests that teaching expenditure has positive direct and indirect effects on published tuition. The estimated main coefficient for admission test score is significantly negative but its spatially lagged coefficient is not. The last significant variable is the spatially lagged county's median income, which has a positive impact on published tuition. However its main coefficient is not significant.

The regression result for net tuition is obtained using the SAR model, hence there is only one estimated coefficient for each explanatory variable. From the list of all factors of demand, cost and local variants; only three variables are significant. Enrollment of graduate students has a negative effect on net tuition, while research spending and teaching expenditure have positive impact on net tuition.

The spatial lag coefficient for the dependent variable, $\rho$, is significantly positive for both published tuition and net tuition. The size of $\rho$ for published tuition is larger than net tuition. This shows that spatial effects in published tuition between universities of similar quality levels are relatively stronger than net tuition since the difference between the spatial lagged published tuition and net tuition is small. The spatial lag coefficients suggest that for every $10 \%$ in the weighted index of published tuition and net tuition of other universities, the published tuition and net tuition of an average university are expected to increase by $7.0584 \%$ and $6.3130 \%$ respectively.

As mentioned in Section 4.4 earlier, the interpretation of the explanatory variables impacts on prices cannot be done directly from the estimated coefficients of SDM and SAR models. Alternatively, the interpretation of the impacts of these variables depends on their estimated marginal effects.

Table 4.7 shows the marginal effects for published tuition. There are two variables that are significant in all three types of marginal effects: research spending and 
teaching expenditure. Two other variables have significant direct effect only: undergraduate enrollment and faculty size; while median income has significant indirect and total effects to published tuition.

Table 4.7: Marginal effects for published tuition in the product market

\begin{tabular}{lccc}
\hline \hline & & Published Tuition & \\
& & $(1)$ & $(3)$ \\
& Direct Effects & Indirect Effects & Total Effects \\
\hline USTD & $-0.0065^{* * *}$ & -0.0054 & -0.0119 \\
GSTD & $(0.0020)$ & $(0.0258)$ & $(0.0261)$ \\
& -0.0045 & -0.0002 & -0.0047 \\
ENDOW & $(0.0036)$ & $(0.0297)$ & $(0.0313)$ \\
PRAID & -0.0055 & -0.0818 & -0.0873 \\
& $(0.0043)$ & $(0.0572)$ & $(0.0580)$ \\
FACULTY & -0.0358 & -0.0791 & -0.1149 \\
& $(0.0341)$ & $(0.3325)$ & $(0.3400)$ \\
RESEARCH & $0.0666^{*}$ & -0.2263 & -0.1596 \\
TEACH & $(0.0404)$ & $(0.4094)$ & $(0.4262)$ \\
& $0.0092^{* *}$ & $0.1459^{*}$ & $0.1551^{*}$ \\
SATACT & $(0.0044)$ & $(0.0782)$ & $(0.0802)$ \\
& $0.0518^{* *}$ & $0.6275 * * *$ & $0.6793^{* * *}$ \\
ADMRATE & $(0.0204)$ & $(0.1308)$ & $(0.1299)$ \\
POPDEN & -0.0017 & 0.0191 & 0.0174 \\
MEDINC & $(0.0010)$ & $(0.0158)$ & $(0.0156)$ \\
& -0.0255 & -0.2494 & -0.2749 \\
& $(0.0214)$ & $(0.3381)$ & $(0.3461)$ \\
& -0.0015 & -0.0650 & -0.0665 \\
& $(0.0059)$ & $(0.0981)$ & $(0.0968)$ \\
& 0.0017 & $0.6418^{* *}$ & $0.6435^{* * *}$ \\
& $(0.0449)$ & $(0.2542)$ & $(0.2458)$ \\
\hline
\end{tabular}

Method of estimation is SDM. Number of obervations is 4224 .

Standard errors are clustered by universities and shown in parentheses.

${ }^{*} p<0.1,{ }^{* *} p<0.05,{ }^{* * *} p<0.01$

Enrollment of undergraduate students has a negative direct impact on published tuition. If a university enrolls 100 more undergraduate students, that university is expected to drop its published tuition by $0.0648 \%$. A university that hires 100 more faculty members, its published tuition is expected to increase by $0.6887 \%$. However 
there are no feedback effects associated with changes in undergraduate enrollment and faculty size. The two major components of a university's budget, research spending and teaching expenditure, have positive marginal effects on published tuition. Any change in either research spending or teaching expenditure of a university will also affect published tuition of other universities through the feedback effect. A $1 \%$ increase in research spending and teaching expenditure is expected to cause all universities to raise their published tuitions by $0.1551 \%$ and $0.6793 \%$ respectively. Most of these impacts originate from the feedback effect, where a university is more sensitive towards changes in research spending and teaching expenditure of its competitors than changes of its own. Furthermore, the magnitude of teaching expenditure effect is greater than research spending. This result is expected since universities tend to depend on external sources to fund researches while tuition revenues are used to finance teaching expenses. One of the measures of local variants, the county's median income, seems to have a positive impact on published tuition that originates from the feedback effect. In this situation, a university tends to raise its published tuition when the county's median income of its nearby competitors along the product line increases. In total, a $1 \%$ increase in median income leads to all universities to raise their publisehd tuitions by $0.6435 \%$.

The marginal effects for net tuition are displayed in Table 4.8. There are four variables that are significant in all three types of marginal effects: graduate enrollment, research spending, teaching expenditure, and admission rate.

Enrollment of graduate students have negative marginal effects on net tuition. It seems that the benefits of having more graduate students are greater than its associated costs. Universities may be able to cut down costs by employing graduate students as research and teaching assistants. A 100 increase in graduate enrollment leads to a $0.4610 \%$ drop in net tuition of all universities. Both research spending and 
Table 4.8: Marginal effects for net tuition in the product market

\begin{tabular}{lccc}
\hline \hline & & Net Tuition & \\
& $(1)$ & $(2)$ & $(3)$ \\
& Direct Effects & Indirect Effects & Total Effects \\
\hline USTD & -0.0011 & -0.0018 & -0.0029 \\
GSTD & $(0.0034)$ & $(0.0063)$ & $(0.0097)$ \\
& $-0.0172^{*}$ & $-0.0300^{*}$ & $-0.0472^{*}$ \\
ENDOW & $(0.0088)$ & $(0.0174)$ & $(0.0258)$ \\
PRAID & 0.0070 & 0.0122 & 0.0192 \\
& $(0.0061)$ & $(0.0110)$ & $(0.0170)$ \\
FACULTY & -0.0237 & -0.0441 & -0.0678 \\
& $(0.0644)$ & $(0.1156)$ & $(0.1796)$ \\
RESEARCH & 0.0856 & 0.1460 & 0.2316 \\
TEACH & $(0.0715)$ & $(0.1247)$ & $(0.1949)$ \\
& $0.0159^{* *}$ & $0.0274^{* *}$ & $0.0433^{* *}$ \\
SATACT & $(0.0066)$ & $(0.0125)$ & $(0.0187)$ \\
& $0.1989^{* * *}$ & $0.3368^{* * *}$ & $0.5357^{* * *}$ \\
ADMRATE & $(0.0360)$ & $(0.0575)$ & $(0.0822)$ \\
& -0.0011 & -0.0018 & -0.0030 \\
POPDEN & $(0.0024)$ & $(0.0040)$ & $(0.0063)$ \\
MEDINC & $-0.0623^{*}$ & $-0.1073^{*}$ & $-0.1696^{*}$ \\
& $(0.0340)$ & $(0.0619)$ & $(0.0945)$ \\
\hline \hline & -0.0098 & -0.0173 & -0.0271 \\
& $(0.0164)$ & $(0.0296)$ & $(0.0458)$ \\
& -0.0193 & -0.0365 & -0.0558 \\
& $(0.0665)$ & $(0.1163)$ & $(0.1820)$ \\
\hline
\end{tabular}

Method of estimation is SAR. Number of obervations is 4224 .

Standard errors are clustered by universities and shown in parentheses.

${ }^{*} p<0.1,{ }^{* *} p<0.05,{ }^{* * *} p<0.01$ 
teaching expenditure have positive marginal effects on net tuition, which is similar to the results obtained for published tuition earlier. A 1\% increase in reseach spending and teaching expenditure is expected to raise the net tuition of all universities by $0.0433 \%$ and $0.5357 \%$ respectively. Similar to published tuition, the marginal effects of research spending on net tuition are smaller than teaching expenditure, and most of the marginal effects originate from the indirect effect. One of the proxy variables for prestige and quality, admission rate, has negative marginal effects on net tuition. As universities admit more students, their net tuition decreases. This is true for service oriented universities that are able to achieve economies of scale and reduce their net tuition by offering more financial aids to students. If admission rate goes up by $1 \%$, all universities are expected to lower their net tuitions by $0.1560 \%$.

Since the FE method is used to estimate price competition in the product market, the control-type dummy variable that indicates the status of a university as either a public or private institution is excluded from the model. To compare the spatial effects in price competition between public and private universities, the sample is divided into two subsamples based on the control-type dummy variable. There are 318 public universities in the first subsample and 210 private universities in the second subsample.

Table 4.9 shows the price competition between public universities in the product market. The panel-robust Hausman tests shown at the bottom of the table indicate that both published tuition and net tuition should be estimated using the FE method.

The estimation results of published tuition in Table 4.9 are almost similar to the results obtained in Table 4.6 when the sample includes all universities. The main coefficient of enrollment of undergraduate students is still negative and its spatially lagged coefficient is not significant. The main coefficients of faculty size and research spending are now significant, while the spatially lagged coefficient of research spend- 
ing is no longer significant. Both main and spatially lagged coefficients of teaching expenditure are still significant. The results for the admission test score and median income remain the same.

There are more significant coefficients observed in the net tuition estimation results when the public subsample is used compared to the previous overall sample. Undergraduate enrollment is now significantly negative to net tuition, while graduate enrollment is no longer significant. Faculty size, admission test score, and population density are now significant; while research spending and teaching expenditure remain significant.

The estimated coefficient for the spatial lag dependent variable, $\rho$, is significantly positive in both published tuition and net tuition. This suggests that the spatial price competition between public universities is positive. Comparing the magnitude of the spatial effects, the size of $\rho$ of published tuition is still larger than net tuition. However, the difference between the two $\rho$ 's from the public universities subsample has become smaller compared to the all universities sample. While there is not much change in the spatial effects of published tuition, it seems that the spatial effects in the net tuition competition between public universities have increased. A $10 \%$ increase in the weighted index of published tuition and net tuition of other public universities leads to an increase in published tuition and net tuition of an average public university by $6.9319 \%$ and $6.7588 \%$ respectively.

Table 4.10 shows the marginal effects for published tuition of public universities. From the results, only teaching expnediture is significant in all three types of marginal effects. There are four variables with significant direct effect only: undergraduate enrollment, faculty size, research spending, and admission test score; while median income is the only variable with significant indirect and total effects to published tuition of public universities. 
Table 4.9: Price competition between public universities in the product market

\begin{tabular}{|c|c|c|c|}
\hline & \multicolumn{2}{|c|}{ Published Tuition } & \multirow{3}{*}{$\begin{array}{c}\text { Net Tuition } \\
(3)\end{array}$} \\
\hline & $(1)$ & $(2)$ & \\
\hline & Main & Spatial Lag & \\
\hline \multirow[t]{2}{*}{ USTD } & $-0.0080^{* * *}$ & 0.0028 & $-0.0088^{* *}$ \\
\hline & $(0.0025)$ & $(0.0093)$ & $(0.0037)$ \\
\hline \multirow[t]{2}{*}{ GSTD } & -0.0068 & 0.0172 & -0.0078 \\
\hline & $(0.0054)$ & $(0.0110)$ & $(0.0071)$ \\
\hline \multirow[t]{2}{*}{ ENDOW } & -0.0019 & -0.0080 & 0.0031 \\
\hline & $(0.0042)$ & $(0.0130)$ & $(0.0057)$ \\
\hline \multirow[t]{2}{*}{ PRAID } & -0.0250 & -0.0711 & -0.0706 \\
\hline & $(0.0447)$ & $(0.1179)$ & $(0.0722)$ \\
\hline \multirow[t]{2}{*}{ FACULTY } & $0.0912^{* *}$ & -0.0809 & $0.1682^{* * *}$ \\
\hline & $(0.0424)$ & $(0.1342)$ & $(0.0542)$ \\
\hline \multirow[t]{2}{*}{ RESEARCH } & $0.0096^{*}$ & 0.0033 & $0.0148^{*}$ \\
\hline & $(0.0054)$ & $(0.0238)$ & $(0.0083)$ \\
\hline \multirow[t]{2}{*}{ TEACH } & $0.0754^{* *}$ & $0.1060^{*}$ & $0.2000^{* * *}$ \\
\hline & $(0.0328)$ & $(0.0626)$ & $(0.0342)$ \\
\hline \multirow[t]{2}{*}{ SATACT } & $-0.0049^{* *}$ & 0.0143 & $-0.0092^{* *}$ \\
\hline & $(0.0020)$ & $(0.0098)$ & $(0.0037)$ \\
\hline \multirow[t]{2}{*}{ ADMRATE } & -0.0102 & -0.0786 & -0.0580 \\
\hline & $(0.0266)$ & $(0.1167)$ & $(0.0423)$ \\
\hline \multirow[t]{2}{*}{ POPDEN } & -0.0129 & -0.0240 & $-0.0383^{*}$ \\
\hline & $(0.0136)$ & $(0.0405)$ & $(0.0214)$ \\
\hline \multirow[t]{2}{*}{ MEDINC } & -0.0305 & $0.1840^{*}$ & -0.0364 \\
\hline & $(0.0620)$ & (0.1018) & $(0.0794)$ \\
\hline \multirow[t]{2}{*}{$\rho$} & \multicolumn{2}{|c|}{$0.7032^{* * *}$} & $0.6862^{* * *}$ \\
\hline & \multicolumn{2}{|c|}{$(0.0374)$} & $(0.0417)$ \\
\hline Observations & \multicolumn{2}{|c|}{2544} & 2544 \\
\hline Universities & \multicolumn{2}{|c|}{318} & 318 \\
\hline Hausman $\chi^{2}$ & \multicolumn{2}{|c|}{$37.94^{* *}$} & $30.89^{* * *}$ \\
\hline Est. method & \multicolumn{2}{|c|}{ SDM } & SAR \\
\hline
\end{tabular}

Asymptotic standard errors in parentheses

${ }^{*} p<0.1,{ }^{* *} p<0.05,{ }^{* * *} p<0.01$ 
Table 4.10: Marginal effects for published tuition of public universities in the product market

\begin{tabular}{lccc}
\hline \hline & $(1)$ & Published Tuition & $(2)$ \\
& Direct Effects & Indirect Effects & Total Effects \\
\hline USTD & $-0.0084^{* * *}$ & -0.0123 & -0.0207 \\
& $(0.0022)$ & $(0.0275)$ & $(0.0280)$ \\
GSTD & -0.0053 & 0.0423 & 0.0369 \\
& $(0.0063)$ & $(0.0405)$ & $(0.0434)$ \\
ENDOW & -0.0026 & -0.0411 & -0.0437 \\
& $(0.0044)$ & $(0.0435)$ & $(0.0440)$ \\
PRAID & -0.0312 & -0.2476 & -0.2788 \\
& $(0.0444)$ & $(0.3497)$ & $(0.3616)$ \\
FACULTY & $0.0976^{* *}$ & -0.0927 & 0.0049 \\
& $(0.0435)$ & $(0.4500)$ & $(0.4697)$ \\
RESEARCH & $0.0111^{*}$ & 0.0235 & 0.0347 \\
& $(0.0063)$ & $(0.0874)$ & $(0.0910)$ \\
TEACH & $0.0852^{* *}$ & $0.5413^{* * *}$ & $0.6265^{* * *}$ \\
& $(0.0352)$ & $(0.1509)$ & $(0.1476)$ \\
SATACT & $-0.0041^{* *}$ & 0.0383 & 0.0342 \\
& $(0.0020)$ & $(0.0323)$ & $(0.0326)$ \\
ADMRATE & -0.0207 & -0.3158 & -0.3365 \\
& $(0.0288)$ & $(0.3976)$ & $(0.4123)$ \\
POPDEN & -0.0155 & -0.0973 & -0.1127 \\
& $(0.0120)$ & $(0.1261)$ & $(0.1193)$ \\
MEDINC & -0.0119 & $0.5809^{* *}$ & $0.5689^{* *}$ \\
& $(0.0626)$ & $(0.2884)$ & $(0.2825)$ \\
\hline \hline
\end{tabular}

Method of estimation is SDM. Number of obervations is 2544 .

Standard errors are clustered by universities and shown in parentheses.

${ }^{*} p<0.1,{ }^{* *} p<0.05,{ }^{* * *} p<0.01$ 
Enrollment of undergraduate students has a negative direct impact on published tuition of public universities. This negative effect is expected since most of public universities are dedicated towards a service-oriented philosophy where an enrollment increase contributes greater utility than a similar prestige improvement. The magnitude of the negative direct effect of undergraduate enrollment on published tuition of public universities has become approximately $30 \%$ greater than its magnitude estimated from the overall sample previously. A public university that enrolls 100 more undergraduate students is expected to drop its published tuition by $0.0836 \%$. Compared to the previous overall sample result, both faculty size and research spending still have a positive direct effect on published tuition of public universities but their magnitudes are now larger. A public university that hires 100 more faculty members and spends $1 \%$ more in research is expected to increase its published tuition by $1.0252 \%$ and $0.0111 \%$ respectively. Teaching expenditure positively affects published tuition of public universities. Most of this positive impact is caused by other public universities of similar ranks changing their teaching expenditure, which is evident from the large size of its indirect effect. This indicates that public universities are sensitive to changes in teaching expenditure of their neighboring public universities along the product line. A $1 \%$ increase in teaching expenditure raises the published tuition of all public universities by $0.6265 \%$. Furthermore, the size of teaching expenditure total effect on published tuition of published universities is smaller compared to its size in the overall sample. As public universities receive financial support from various government agencies, a change in teaching expenditure may have smaller impact on their published tuition compared to private universities. The admission test score has a negative direct effect on published tuition. It seems that any public university that wants to raise its quality standard by increasing the admission test score will have to lower its published tuition. A public university that raises its admission test rate by 
1 point is expected to reduce its published tuition by $0.4092 \%$. Median income has positive indirect and total effects on published tuition of public universities. As the county's median income increases by $1 \%$, all public universities are expected to raise their published tuitions by $0.5689 \%$.

The marginal effects for net tuition of public universities are shown in Table Table 4.11. Altogether there are six variables with significant marginal effects to net tuition of public universities in the product market.

Table 4.11: Marginal effects for net tuition of public universities in the product market

\begin{tabular}{lccc}
\hline \hline & & Net Tuition & \\
& $(1)$ & $(2)$ & $(3)$ \\
& Direct Effects & Indirect Effects & Total Effects \\
\hline USTD & $-0.0093^{* * *}$ & $-0.0190^{* *}$ & $-0.0283^{* * *}$ \\
GSTD & $(0.0033)$ & $(0.0078)$ & $(0.0108)$ \\
& -0.0077 & -0.0161 & -0.0237 \\
ENDOW & $(0.0083)$ & $(0.0183)$ & $(0.0264)$ \\
PRAID & 0.0036 & 0.0077 & 0.0113 \\
& $(0.0064)$ & $(0.0136)$ & $(0.0199)$ \\
FACULTY & -0.0755 & -0.1593 & -0.2348 \\
& $(0.0747)$ & $(0.1634)$ & $(0.2369)$ \\
RESEARCH & $0.1879^{* * *}$ & $0.3862^{* * *}$ & $0.5741^{* * *}$ \\
TEACH & $(0.0537)$ & $(0.1322)$ & $(0.1799)$ \\
& $0.0170^{*}$ & $0.0349^{*}$ & $0.0519^{*}$ \\
SATACT & $(0.0089)$ & $(0.0202)$ & $(0.0287)$ \\
& $0.2066^{* * *}$ & $0.4158^{* * *}$ & $0.6224^{* * *}$ \\
ADMRATE & $(0.0377)$ & $(0.0708)$ & $(0.0945)$ \\
POPDEN & $-0.0098^{* * *}$ & $-0.0196^{* * *}$ & $-0.0295^{* * *}$ \\
MEDINC & $(0.0037)$ & $(0.0071)$ & $(0.0105)$ \\
& -0.0649 & -0.1302 & -0.1951 \\
& $(0.0421)$ & $(0.0856)$ & $(0.1259)$ \\
& $-0.0410^{*}$ & $-0.0847^{*}$ & $-0.1257^{*}$ \\
& $(0.0226)$ & $(0.0507)$ & $(0.0724)$ \\
& -0.0323 & -0.0689 & -0.1012 \\
& $(0.0850)$ & $(0.1788)$ & $(0.2628)$ \\
\hline
\end{tabular}

Method of estimation is SAR. Number of obervations is 2544 .

Standard errors are clustered by universities and shown in parentheses.

${ }^{*} p<0.1,{ }^{* *} p<0.05,{ }^{* * *} p<0.01$ 
Enrollment of undergraduate students, which has no significant marginal effects on net tuition in the overall sample, is now significantly negative to net tuition of public universities. More than half of its total effect is caused by its indirect effect. A 100 increase in undergraduate enrollments leads to a $0.2790 \%$ decrease in net tuition of all public universities. In this case, as public universities enroll more undergraduate students, bigger financial aids are disbursed to the students. As expected, faculty size, research spending, and teaching expenditure, have positive marginal effects on net tuition. Since these three variables are related to the operational cost of universities, any university that raise any of the three variables is expected to disburse lower financial aid and thus charge higher net tuition to its students. If faculty size increases by 100 staff, all public universities are expected to raise their net tuitions by 17.7553\%. A 1\% increase in research spending and teaching expenditure are expected to raise the net tuition of all public universities by $0.0519 \%$ and $0.6224 \%$ respectively. Similar to previous results, the impact of research spending on net tuition is smaller than teaching expenditure. A proxy variable for quality, the admission test score, has negative marginal effects to net tuition. Any higher admission test requirements imposed by public universities translate into larger financial aids given to students. If the admission test score increases by 1 point, the net tuition of all public universities is expected to decrease by $2.9069 \%$. A measure of geographical variants, population density, has negative marginal effects on net tuition of public universities. This suggests that public universities that are located in densely populated area tend to award more financial aids to students. If population density increases by 100 per square mile, the net tuition of all public universities is expected to drop by $1.1812 \%$.

The second subsample consists of 210 private universities. The estimation results of price competition between private universities in the product market are presented in Table 4.12. The panel-robust Hausman tests results at the bottom of the table 
indicate that FE method should be used to estimate both published tuition and net tuition.

The results for published tuition competition between private universities are different from the previous overall sample results shown in Table 4.6. Undergraduate enrollment is no longer significant. The spatially lagged coefficients of proportion of students receiving aid, admission test score, admission rate, and population density are now significant while the same coefficient of median income is no longer significant. The results for research spending remain the same. However, the main coefficients of teaching expenditure and admission test score are no longer significant. Since all main coefficients in published tuition estimation are not significant, this suggests that published tuition of private universities are more influenced by changes in other private universities through the feedback effect channel. Looking back at Table 4.9, the published tuition competition between public universities seems to be influenced more by the direct effect of its own changes since most of the estimated spatially lagged coefficients are not significant.

The results for net tuition competition between private universities as shown in Table 4.12 are almost the same with the overall sample results in Table 4.6. Only two things changed. Graduate enrollment is no longer significant while endowment is now significant to net tuition competition between private universities. Research spending and teaching expenditure remain as the only other coefficients that are significant to net tuition.

The spatial coefficients of the dependent variables, $\rho$, are significantly positive in both published tuition and net tuition. The spatial effects in published tuition competition between private universities remain larger than the spatial effects in net tuition competition. However, the difference between the two spatial effects has become bigger. This indicates that the published tuition of a private university is 
Table 4.12: Price competition between private universities in the product market

\begin{tabular}{|c|c|c|c|}
\hline & $\begin{array}{l}\text { Publish } \\
(1) \\
\text { Main }\end{array}$ & $\begin{array}{c}\text { ed Tuition } \\
(2) \\
\text { Spatial Lag }\end{array}$ & $\begin{array}{c}\text { Net Tuition } \\
(3)\end{array}$ \\
\hline USTD & $\begin{array}{l}-0.0002 \\
(0.0026)\end{array}$ & $\begin{array}{c}-0.0018 \\
(0.0121)\end{array}$ & $\begin{array}{c}0.0082 \\
(0.0120)\end{array}$ \\
\hline GSTD & $\begin{array}{l}-0.0020 \\
(0.0024)\end{array}$ & $\begin{array}{l}-0.0007 \\
(0.0039)\end{array}$ & $\begin{array}{l}-0.0097 \\
(0.0118)\end{array}$ \\
\hline ENDOW & $\begin{array}{c}0.0018 \\
(0.0040)\end{array}$ & $\begin{array}{c}0.0024 \\
(0.0087)\end{array}$ & $\begin{array}{l}0.0172^{* *} \\
(0.0087)\end{array}$ \\
\hline PRAID & $\begin{array}{l}-0.0209 \\
(0.0244)\end{array}$ & $\begin{array}{c}0.1951^{* * *} \\
(0.0748)\end{array}$ & $\begin{array}{c}0.0412 \\
(0.1295)\end{array}$ \\
\hline FACULTY & $\begin{array}{l}-0.0323 \\
(0.0644)\end{array}$ & $\begin{array}{l}-0.0522 \\
(0.0539)\end{array}$ & $\begin{array}{l}-0.2496 \\
(0.1954)\end{array}$ \\
\hline RESEARCH & $\begin{array}{c}0.0040 \\
(0.0029)\end{array}$ & $\begin{array}{l}0.0343^{* *} \\
(0.0139)\end{array}$ & $\begin{array}{l}0.0171^{* *} \\
(0.0084)\end{array}$ \\
\hline TEACH & $\begin{array}{c}0.0292 \\
(0.0180)\end{array}$ & $\begin{array}{l}0.1036^{*} \\
(0.0537)\end{array}$ & $\begin{array}{l}0.1206^{*} \\
(0.0716)\end{array}$ \\
\hline SATACT & $\begin{array}{l}-0.0004 \\
(0.0006)\end{array}$ & $\begin{array}{l}0.0027^{* *} \\
(0.0013)\end{array}$ & $\begin{array}{c}0.0021 \\
(0.0025)\end{array}$ \\
\hline ADMRATE & $\begin{array}{l}-0.0136 \\
(0.0197)\end{array}$ & $\begin{array}{c}-0.1264^{* *} \\
(0.0632)\end{array}$ & $\begin{array}{l}-0.0864 \\
(0.0624)\end{array}$ \\
\hline POPDEN & $\begin{array}{c}0.0065 \\
(0.0041)\end{array}$ & $\begin{array}{l}-0.0147^{*} \\
(0.0076)\end{array}$ & $\begin{array}{c}0.0258 \\
(0.0189)\end{array}$ \\
\hline MEDINC & $\begin{array}{c}0.0518 \\
(0.0409)\end{array}$ & $\begin{array}{l}-0.0453 \\
(0.0506)\end{array}$ & $\begin{array}{c}0.1556 \\
(0.1038)\end{array}$ \\
\hline$\rho$ & \multicolumn{2}{|c|}{$0.8092^{* * *}$} & $\begin{array}{c}0.5346^{* * *} \\
(0.0557)\end{array}$ \\
\hline Observations & \multicolumn{2}{|c|}{1680} & 1680 \\
\hline Universities & \multicolumn{2}{|c|}{210} & 210 \\
\hline Hausman $\chi^{2}$ & \multicolumn{2}{|c|}{$35.75^{* *}$} & $46.25^{* * *}$ \\
\hline Est. method & \multicolumn{2}{|c|}{ SDM } & SAR \\
\hline
\end{tabular}

Asymptotic standard errors in parentheses

${ }^{*} p<0.1,{ }^{* *} p<0.05,{ }^{* * *} p<0.01$ 
strongly affected by changes in published tuition of other private universities, while the same effect for net tuition is relatively weaker. Comparing the spatial effects observed between the private and public subsamples, it seems that private universities have greater tendency to react through published tuition than public universities. The opposite is true for net tuition; public universities tend to accommodate competition through net tuition more than private universities. The estimated values of $\rho$ of private universities suggest that for every $10 \%$ increase in the weighted index of published tuition and net tuition of other private universities, an average private university would increase its published tuition and net tuition by $8.0177 \%$ and $5.2273 \%$ respectively.

Table 4.13 shows the marginal effects for published tuition of private universities. There are three variables that are significant in all three types of marginal effects: research spending, teaching expenditure, and admission rate. Two variables have significant indirect and total effects only: proportion of students receiving aid and admission test score. Compared to public universities, it seems that enrollment of undergraduate students has no marginal effects on published tuition and also net tuition of private universities as shown later in Table 4.14.

The proportion of students receiving aid and admission test score have positive indirect and total effects on published tuition of private universities. As more students are given financial aids, private universities tend to raise their published tuition. A $10 \%$ increase in the proportion of students receiving aid leads to a $16.8669 \%$ increase in published tuition of all private universities. Almost 99\% of this increase happens through the feedback effect from other private universities. While admission test score negatively affects published tuition of public universities, its impact on published tuition of private universities is positive. As private universities raise their admission test scores, more high quality students are enrolled. The increase in the quality 
Table 4.13: Marginal effects for published tuition of private universities in the product market

\begin{tabular}{lccc}
\hline \hline & \multicolumn{3}{c}{ Published Tuition } \\
& $(1)$ & $(2)$ & $(3)$ \\
& Direct Effects & Indirect Effects & Total Effects \\
\hline USTD & -0.0007 & -0.0157 & -0.0165 \\
& $(0.0033)$ & $(0.0625)$ & $(0.0650)$ \\
GSTD & -0.0022 & -0.0128 & -0.0151 \\
& $(0.0030)$ & $(0.0221)$ & $(0.0240)$ \\
ENDOW & 0.0024 & 0.0122 & 0.0147 \\
& $(0.0044)$ & $(0.0426)$ & $(0.0437)$ \\
PRAID & 0.0111 & $0.9768^{* *}$ & $0.9879^{* *}$ \\
& $(0.0275)$ & $(0.4278)$ & $(0.4428)$ \\
FACULTY & -0.0386 & -0.4049 & -0.4435 \\
& $(0.0701)$ & $(0.3703)$ & $(0.4246)$ \\
RESEARCH & $0.0106^{* *}$ & $0.1887^{* *}$ & $0.1992^{* *}$ \\
& $(0.0044)$ & $(0.0749)$ & $(0.0783)$ \\
TEACH & $0.0492^{* *}$ & $0.6308^{* * *}$ & $0.6801^{* * *}$ \\
& $(0.0202)$ & $(0.2011)$ & $(0.2093)$ \\
SATACT & 0.0000 & $0.0123^{*}$ & $0.0123^{*}$ \\
& $(0.0006)$ & $(0.0069)$ & $(0.0070)$ \\
ADMRATE & $-0.0387^{*}$ & $-0.7269^{* *}$ & $-0.7656^{* *}$ \\
& $(0.0230)$ & $(0.3497)$ & $(0.3634)$ \\
POPDEN & 0.0045 & -0.0498 & -0.0453 \\
& $(0.0048)$ & $(0.0407)$ & $(0.0436)$ \\
MEDINC & 0.0514 & 0.0377 & 0.0892 \\
& $(0.0376)$ & $(0.2234)$ & $(0.2302)$ \\
\hline \hline
\end{tabular}

Method of estimation is SDM. Number of obervations is 1680 .

Standard errors are clustered by universities and shown in parentheses.

${ }^{*} p<0.1,{ }^{* *} p<0.05,{ }^{* * *} p<0.01$ 
level of students is accompanied by an increase in published tuition. This result is expected since most of private universities are more concerned with their prestige status and quality of students than enrollment size, while public universities assign greater utility value to enrollment size. Research spending and teaching expenditure have positive marginal effects on published tuition of private universities. Similar to public universities, the size of teaching expenditure effects are greater than research spending. The size of indirect and total effects of these two variables on published tuition of private universities are bigger than public universities. This suggests that private universities are more sensitive to changes in research spending and teaching expenditure of their competitors than public universities. A $1 \%$ increase in research spending and teaching expenditure leads to an increase in published tuition of all private universities by $0.1992 \%$ and $0.6801 \%$ respectively. Admission rate has negative marginal effects on published tuition. Any private university that raises its admission rate is expected to charge lower published tuition. About 95\% of the impact of admission rate on published tuition comes through the feedback effect. As admission rate increases by $1 \%$, all private universities are expected to lower their published tuitions by $0.5349 \%$.

The marginal effects for net tuition of private universities are presented in Table 4.14. There are only two variables with significant marginal effects: endowment and research spending. Endowment has positive marginal effects on net tuition of private universities. If endowment increases by $1 \%$, net tuition is expected to increase by $0.0382 \%$. This suggests that private universities tend not to give more financial aids to students eventhough their endowments have become larger. Research spending also has positive marginal effects on net tuition. A $1 \%$ increase in research spending leads to a $0.0396 \%$ increase in net tuition of all private universities.

Some readers may be concerned with the potential endogeneity between propor- 
Table 4.14: Marginal effects for net tuition of private universities in the product market

\begin{tabular}{lccc}
\hline \hline & & Net Tuition & \\
& $(1)$ & $(2)$ & $(3)$ \\
& Direct Effects & Indirect Effects & Total Effects \\
\hline USTD & 0.0083 & 0.0090 & 0.0172 \\
& $(0.0106)$ & $(0.0125)$ & $(0.0229)$ \\
GSTD & -0.0091 & -0.0099 & -0.0191 \\
& $(0.0135)$ & $(0.0153)$ & $(0.0286)$ \\
ENDOW & $0.0183^{*}$ & $0.0199^{*}$ & $0.0382^{*}$ \\
& $(0.0096)$ & $(0.0117)$ & $(0.0209)$ \\
PRAID & 0.0419 & 0.0403 & 0.0822 \\
& $(0.1286)$ & $(0.1438)$ & $(0.2714)$ \\
FACULTY & -0.2157 & -0.2385 & -0.4542 \\
& $(0.1865)$ & $(0.2128)$ & $(0.3957)$ \\
RESEARCH & $0.0191^{* *}$ & $0.0205^{*}$ & $0.0396^{* *}$ \\
& $(0.0089)$ & $(0.0106)$ & $(0.0190)$ \\
TEACH & 0.1216 & 0.1221 & 0.2437 \\
& $(0.0781)$ & $(0.0775)$ & $(0.1524)$ \\
SATACT & 0.0021 & 0.0023 & 0.0044 \\
& $(0.0025)$ & $(0.0027)$ & $(0.0052)$ \\
ADMRATE & -0.0949 & -0.1046 & -0.1994 \\
& $(0.0588)$ & $(0.0722)$ & $(0.1289)$ \\
POPDEN & 0.0257 & 0.0279 & 0.0535 \\
& $(0.0206)$ & $(0.0241)$ & $(0.0441)$ \\
MEDINC & 0.1597 & 0.1696 & 0.3293 \\
& $(0.1074)$ & $(0.1178)$ & $(0.2210)$ \\
\hline \hline
\end{tabular}

Method of estimation is SAR. Number of obervations is 1680 .

Standard errors are clustered by universities and shown in parentheses.

${ }^{*} p<0.1,{ }^{* *} p<0.05,{ }^{* * *} p<0.01$ 
tion of students receiving aids, research spending, and teaching expenditure with prices. To check on this, a spatial regression model without these three explanatory variables is estimated. The regression result is presented in Table D.1 in Appendix D.2. The result obtained is similar to the original model result shown in Table 4.6 on page 171. Only one variable that is no longer significant: graduate enrollment (net tuition), while a number of variables have become significant: endowment (published tuition), admission test score (net tuition), admission rate, and population density. However, the strength of spatial effects is much weaker when the three potentially endogenous variables are excluded since the values of $\rho$ for published and net tuitions are now smaller. The marginal effects from these smaller models on published and net tuitions are presented in Tables D.2 and D.3 respectively.

Another issue that some readers may raise is on the exclusion of time effects from the model. This issue has been addressed in the previous chapter on the geographical market dimension. The model estimation with year dummies work only with the overall sample, while for the other subsamples (public and private) the estimation failed to achieve convergence after 100 iterations. The estimation result with time effects on the overall sample is provided in Table D.4 in Appendix D.3, while the marginal effects on published and net tuitions are shown in Tables D.5 and D.6 respectively. The results obtained are similar, however the spatial effects seem to be relatively weaker when time effects are included.

To check the robustness of panel estimations using the ARWU 2004 rank, the results obtained are compared with the cross-sectional analysis results when price competition of each year is estimated separately using the ARWU rank of that specific year. The cross sectional results are provided in Appendix D.5. When the results from the cross-sectional analysis and the panel models are compared, they seem to have lots of similarities. The only obvious difference is the direction of research spending, 
where it has a negative impact on prices in the cross-sectional analysis but a positive effect on prices in the panel models analysis. Other than this, most of the other variables have the same sign and significance status in both results. This indicates that there is no major change in the locations of universities along the product line from 2004 to 2011. Therefore it is valid to use ARWU 2004 rank as the location indicator of all universities along the product line throughout that period.

\subsubsection{Market Size Comparison}

To investigate the extent of spatial effects in the product market, the product line is now segmented into smaller range, beginning with 50 rank differences. Under this specification, the price competition between universities is only affected by competitors that are ranked either 50 points above or below them. As mentioned in Section 4.4 earlier, the threshold rank is then changed to smaller values and all the spatial coefficients will be compared.

Table 4.15: Product market size comparison

\begin{tabular}{lll}
\hline \hline & PTUITION & NTUITION \\
\hline$\rho_{50}$ & $-1.4805^{* * *}$ & $0.7732^{* * *}$ \\
$\rho_{40}$ & $-0.4863^{* * *}$ & $0.7872^{* * *}$ \\
$\rho_{30}$ & -0.0028 & $0.7731^{* * *}$ \\
$\rho_{20}$ & $0.2854^{* * *}$ & $0.7373^{* * *}$ \\
$\rho_{10}$ & $0.2093^{* * *}$ & $0.6521^{* * *}$ \\
$\rho_{5}$ & $0.1728^{*}$ & $0.6020^{* * *}$ \\
\hline \hline${ }^{*} p<0.1,{ }^{* *} p<0.05,{ }^{* * *} p<0.01$
\end{tabular}

The calculated spatial coefficients for different market size are shown in Table 4.15. The spatial effects for published tuition are negative when the product market size is limited to 50 rank differences. The spatial effects are positive when the market size is limited to 20 rank differences and smaller. This suggests that spatial effects on 
published tuition are negative somewhere in between a very large market size and a very small market size. Based on the results obtained, it seems that the spatial effects in published tuition competition are sensitive to different market size limitations. Furthermore, spatial effects are weaker as the product market size becomes smaller.

For net tuition, the spatial effects for smaller product markets are all positive and are shrinking in magnitude as the market size becomes smaller. The greatest spatial effects in net tuition is observed when the market size is limited to 40 rank differences, which is near to 50 as suggested by Bowman and Bastedo (2009).

Some readers may be concerned with the inclusion of other non-ranked universities into a single group since these universities may not be competing in the same market. As mentioned earlier, this approach is motivated by Monks and Ehrenberg (1999) and Meredith (2004). Furthermore, dividing the sample into smaller subsamples may lead to failure to achieve convergence of the model estimation, which happens to the smaller subsamples when time effects are included in the model analysis earlier. Rather than dividing the sample into smaller subsamples, it is better to use the overall subsample and limit the strength of influence among universities to their nearest neighbors only. This is another reason why the market size comparison is performed here.

\subsection{Conclusion}

This study attempts to understand the behavior of universities in determining their prices in the product market dimension. Spatial econometrics specification is used to incorporate spatial effects in the empirical models of published tuition and net tuition. This study integrates the economics principles of price competition with spatial econometrics models. A hybrid model selection approach is adopted where 
the commonly used classical method and robust method in spatial econometrics are combined to choose the most appropriate spatial model.

This study also contributes towards the application of spatial econometrics outside the more common geographical space. The product market of higher education is defined by the prestige and quality levels of universities. The location of each university along a product line is determined by the ARWU rank scores. The price competition of universities in the product market is influenced by the proximity of competitors measured by the distance along the product line. Since the ARWU rank scores are determined by an external party to the universities using data from previous academic year, there is no endogeneity issue associated with the location of universities in the product market.

To allow for panel models estimation, the ARWU rank of 2004 is used to determine the location of universities in the product market from 2004 until 2011. This is because the position of universities in the ARWU rank may varies every year. This restriction seems valid since the results obtained from the ARWU 2004 rank are very similar to the results obtained from cross-sectional analysis using yearly ARWU ranks. This finding suggests that there is no major movements in the prestige and quality levels of universities within the 2004-2011 period.

Using a sample of 528 universities in the U.S., reduced form price models indicate that published tuition and net tuition are positively correlated in all years from 2004 to 2011. This suggests that all universities in the sample should be considered to be located within one large product market. The hybrid model specification approach suggests that for published tuition, spatial effects are also present in the explanatory variables, which consist of demand and cost factors and local variants. However there is no spatial effects in the explanatory variables for net tuition. The specification tests also suggest that spatial impact is absent from the error terms of published tuition 
and net tuition. The spatial effects in price competition of the product market are found to be significantly positive.

For public universities, the spatial effects in published tuition and net tuition are almost of the same magnitude. On the other hand, the published tuition competition between private universities is greatly affected by proximity of other private universities along the product market line. The spatial effects in the net tuition competition between private universities are much weaker than the net tuition between public universities, while the spatial effects in published tuition competition between private universities are stronger than the published tuition competition between public universities.

The product market size analysis suggests that the direction and magnitude of spatial effects in published tuition competition are sensitive to different product market size. On the other hand, the spatial effects in net tuition competition are persistently strong in smaller product market size. This indicates that universities tend to formulate their financial aids based on the financial aids policies of other universities with similar prestige and quality levels. 


\section{Chapter 5}

\section{Conclusion}

This thesis addressed two topics surrounding the economics of education: the impact of price on enrollment and the price competition between universities. Chapter 2 examined the demand for enrollment at U.S. universities by international students and its determinants. The relationship between enrollment of international students and price is best described by a dynamic model which incorporates the effect of previous year's enrollment into the model. The analysis found that published tuition positively affect enrollment of international students. This positive relationship is attributed to the role of published tuition as a signal for university's prestige and quality levels. The study also found that female international students are more sensitive to changes in published tuition compared to male international students.

Since international students come from various backgrounds, it would be interesting to study the relationship between university enrollments and the source country. This would enable universities to devise more effective strategies to attract interna-

tional students from different countries. However it is difficult to obtain profiles of international students at the university level due to their sensitive nature. The results from this study could also be improved by including published tuition charged 
by competitors in the analysis. This can be done if there are concrete delimitations of market boundaries among universities. This study can be easily extended to analyze the economic contribution of international students toward the financial performance of universities. The information can be used to complete a larger framework to estimate the price elasticity of education for different types of students and to develop a model of optimal tuition and aid policies for universities.

Chapter 3 investigated spatial effects in price competition between U.S. universities in the geographical market dimension. Each university is placed in the geographical market using its longitude and latitude coordinates. The distance between universities defines the extent of spatial effects a university may have on its competitors. A systematic model selection process was explained and applied to choose the most suitable spatial model among four spatial model candidates. Price competition in the geographical market is influenced by positive spatial effects, with stronger presence in published tuition competition than net tuition. Spatial effects also displayed stronger presence in the competition between public universities than private universities. However there is no evidence of spatial effects in the net tuition competition of private universities. As the geographical market is divided into smaller markets of closer distance, the spatial effects are weaker in published tuition but remain the same in net tuition competitions. Therefore the price competition between U.S. universities is no longer limited by any geographical borders other than the national border.

Finally, Chapter 4 analyzed the price competition between U.S. universities in the product market dimension. The ARWU rank scores are used to define a product market line that represents the prestige and quality levels of universities. This empirical analysis applied spatial regression outside the usual geographical space. The prestige and quality levels of universities from 2004 to 2011 are found to be persistent. Similar to geographical market, the spatial effects in price competition in the product market 
are positive. The spatial effects of price competition between public universities are different from private universities. Spatial effects have stronger influence in published tuition competition between private universities than net tuition competition, while its impact on published tuition and net tuition competitions between public universities are almost of similar size. Furthermore, as the product market is segmented into smaller ranges, spatial effects in published tuition competition are unstable and weaker but stronger and persistent in net tuition competition.

The spatial analysis of Chapters 3 and 4 could be improved by considering other more advanced spatial models. However, in order to include other spatial models as potential candidates, a more sophisticated spatial model selection process needs to be developed. Other parametric and nonparametric methods could also be applied to determine the spatial weighting matrices in the models beside the inverse distance method used in this thesis. For example, a contiguity matrix could be used to establish the extent of spatial effects between universities in the geographical market, while the $k$-nearest neighbor approach could be used to determine the spatial weighting matrix in the product market. Instead of comparing the spatial effects at different market size threshold, a more systematic approach could be used to determine the actual higher education market size in both the geographical and product market dimensions. However, this approach requires a rigorous theoretical framework that needs to be formulated in order to support the results. If this attempt is successful, its findings could be used alongside other common indicators to assess competition in the higher education market. The results from both the geographical market and the product market may be integrated by creating a spatial weighting matrix that could measure the location of universities in both dimensions simultaneously. 


\section{Appendix A}

\section{A.1 List of Universities}

List of universities in Chapter 2 analysis

Arizona State University

Columbia University

Boston College

Cornell University

Boston University

Dartmouth College

Brandeis University

Drexel University

Brigham Young University

Duke University

Brown University

Emory University

California Institute of Technology

Florida State University

Carnegie Mellon University

George Mason University

Case Western Reserve University

George Washington University

Clemson University

Georgetown University

Colorado State University-Fort Collins

Georgia Institute of Technology 


\begin{tabular}{|c|c|}
\hline Harvard University & Rensselaer Polytechnic Institute \\
\hline Indiana University-Bloomington & Rice University \\
\hline Iowa State University & Rutgers University-New Brunswick \\
\hline Johns Hopkins University & Saint Louis University \\
\hline Louisiana State University and & San Diego State University \\
\hline A\&M College & Stanford University \\
\hline Massachusetts Institute of Technology & Stony Brook University \\
\hline Michigan State University & SUNY at Albany \\
\hline Montana State University & Syracuse University \\
\hline New York University & Temple University \\
\hline North Carolina State University & Texas A\&M University-College Station \\
\hline at Raleigh & Texas Tech University \\
\hline Northeastern University & The University of Montana \\
\hline Northwestern University & The University of Tennessee \\
\hline Ohio State University & The University of Texas at Austin \\
\hline Oregon State University & Tufts University \\
\hline Pennsylvania State University & University at Buffalo \\
\hline Princeton University & University of Alabama at Birmingham \\
\hline Purdue University & University of Arizona \\
\hline
\end{tabular}




\begin{tabular}{|c|c|}
\hline University of California-Berkeley & University of Illinois \\
\hline University of California-Davis & at Urbana-Champaign \\
\hline University of California-Irvine & University of Iowa \\
\hline University of California-Los Angeles & University of Kansas \\
\hline University of California-Riverside & University of Kentucky \\
\hline University of California-San Diego & University of Maryland-College Park \\
\hline University of California-Santa Barbara & University of Massachusetts Amherst \\
\hline University of California-Santa Cruz & University of Miami \\
\hline University of Central Florida & University of Michigan-Ann Arbor \\
\hline University of Chicago & University of Minnesota-Twin Cities \\
\hline University of Cincinnati & University of Missouri-Columbia \\
\hline University of Colorado Boulder & University of Nebraska-Lincoln \\
\hline University of Connecticut & University of Nevada-Reno \\
\hline University of Denver & University of New Hampshire \\
\hline University of Florida & University of New Mexico \\
\hline University of Georgia & $\begin{array}{l}\text { University of North Carolina } \\
\text { at Chapel Hill }\end{array}$ \\
\hline University of Hawaii at Manoa & University of Notre Dame \\
\hline University of Houston & University of Oklahoma Norman \\
\hline University of Illinois at Chicago & Campus \\
\hline
\end{tabular}




$\begin{array}{ll}\text { University of Oregon } & \text { University of Washington-Seattle } \\ \text { University of Pennsylvania } & \text { University of Wisconsin-Madison } \\ \text { University of Pittsburgh-Pittsburgh } & \text { University of Wyoming } \\ \text { Campus } & \text { Vanderbilt University } \\ \text { University of Rhode Island } & \text { Virginia Commonwealth University } \\ \text { University of Rochester } & \text { Virginia Polytechnic Institute and } \\ \text { University of South Carolina-Columbia } & \text { State University } \\ \text { University of South Florida } & \\ \text { University of Southern California } & \text { Washington State University } \\ \text { University of Utah } & \text { Washington University in St Louis } \\ \text { University of Vermont } & \text { Yashiva University } \\ & \end{array}$




\section{A.2 Endogeneity Test: Published Tuition and In- ternational Students}

Table A.1: 2-step GMM estimation results and endogeneity tests

\begin{tabular}{|c|c|c|c|c|c|}
\hline Variable & Male & Female & Variable & Male & Female \\
\hline \multirow[t]{2}{*}{ PTUITION } & $0.0317^{* * *}$ & $0.0439^{* * *}$ & SATACT & 0.0152 & 0.0047 \\
\hline & $(0.0084)$ & $(0.0082)$ & & $(0.0138)$ & $(0.0113)$ \\
\hline \multirow[t]{2}{*}{ AVAID } & -0.0272 & $-0.1505^{* * *}$ & SISTD & $0.9233^{* * *}$ & $0.9334^{* * *}$ \\
\hline & $(0.0444)$ & $(0.0521)$ & $($ in $\log )$ & $(0.0405)$ & $(0.0404)$ \\
\hline \multirow[t]{2}{*}{ ARWU } & $-0.0028^{* * *}$ & $-0.0014^{*}$ & THSTD & -0.0090 & $-0.1292^{*}$ \\
\hline & $(0.0009)$ & $(0.0008)$ & $($ in $\log )$ & $(0.0836)$ & $(0.0743)$ \\
\hline \multirow[t]{2}{*}{ Mid East } & 0.0379 & -0.0704 & 2004 & -0.0401 & 0.0029 \\
\hline & $(0.0771)$ & $(0.0915)$ & & $(0.0438)$ & $(0.0533)$ \\
\hline \multirow[t]{2}{*}{ G Lakes } & 0.0839 & $-0.1606^{*}$ & 2005 & 0.0004 & 0.0751 \\
\hline & $(0.0871)$ & $(0.0904)$ & & $(0.0432)$ & $(0.0539)$ \\
\hline \multirow[t]{2}{*}{ Plains } & -0.1181 & $-0.2340^{* *}$ & 2006 & $0.0827^{*}$ & $0.1091^{*}$ \\
\hline & $(0.1100)$ & $(0.1052)$ & & $(0.0480)$ & $(0.0619)$ \\
\hline \multirow[t]{2}{*}{ Southeast } & -0.0511 & $-0.2605^{* * *}$ & 2007 & $0.1290^{* *}$ & $0.2202^{* * *}$ \\
\hline & $(0.0941)$ & $(0.0975)$ & & $(0.0559)$ & $(0.0617)$ \\
\hline \multirow[t]{2}{*}{ Southwest } & 0.1379 & -0.2260 & 2008 & $0.1219^{* *}$ & $0.2102^{* * *}$ \\
\hline & $(0.1240)$ & $(0.1522)$ & & $(0.0614)$ & $(0.0723)$ \\
\hline \multirow[t]{2}{*}{ Rocky M } & -0.1426 & $-0.5131^{* * *}$ & 2009 & $0.1101^{* *}$ & $0.2217^{* * *}$ \\
\hline & $(0.1141)$ & $(0.1209)$ & & $(0.0689)$ & $(0.0769)$ \\
\hline \multirow[t]{2}{*}{ Far West } & $-0.3670^{* * *}$ & $-0.4154^{* * *}$ & 2010 & 0.0405 & 0.0820 \\
\hline & $(0.0921)$ & $(0.0878)$ & & $(0.0727)$ & $(0.0830)$ \\
\hline \multirow[t]{2}{*}{ Constant } & $-2.5657^{* * *}$ & $-1.5341^{* *}$ & 2011 & 0.0439 & 0.0700 \\
\hline & $(0.8568)$ & $(0.7032)$ & & $(0.0870)$ & $(0.0975)$ \\
\hline
\end{tabular}

Dependent variable is ( $\log$ of ) enrollment of new international students

Standard errors are clustered by university and shown in parentheses.

* Significant at $10 \% \quad * *$ Significant at $5 \% \quad * * *$ Significant at $1 \%$ 
Table A.1: (continued) 2-step GMM estimation results and endogeneity tests

\begin{tabular}{lcc}
\hline \hline Test & Male & Female \\
\hline Underidentification $\chi^{2}$ & 33.172 & 33.173 \\
$p$-value & 0.0000 & 0.0000 \\
Weak identification $F$ & 68.252 & 69.107 \\
Overidentification $J$ & 9.889 & 0.440 \\
$p$-value & 0.0071 & 0.8024 \\
Hausman $\chi^{2}$ & 0.03 & 4.36 \\
$p$-value & 0.8551 & 0.0369 \\
Endogeneity $C$ & 0.0870 & 1.6290 \\
$p$-value & 0.7680 & 0.2018 \\
\hline \hline
\end{tabular}




\section{A.3 Deviation Graphs}

Figure A.1: The relationship between deviations from mean published tuition growth and deviations from mean enrollments growth

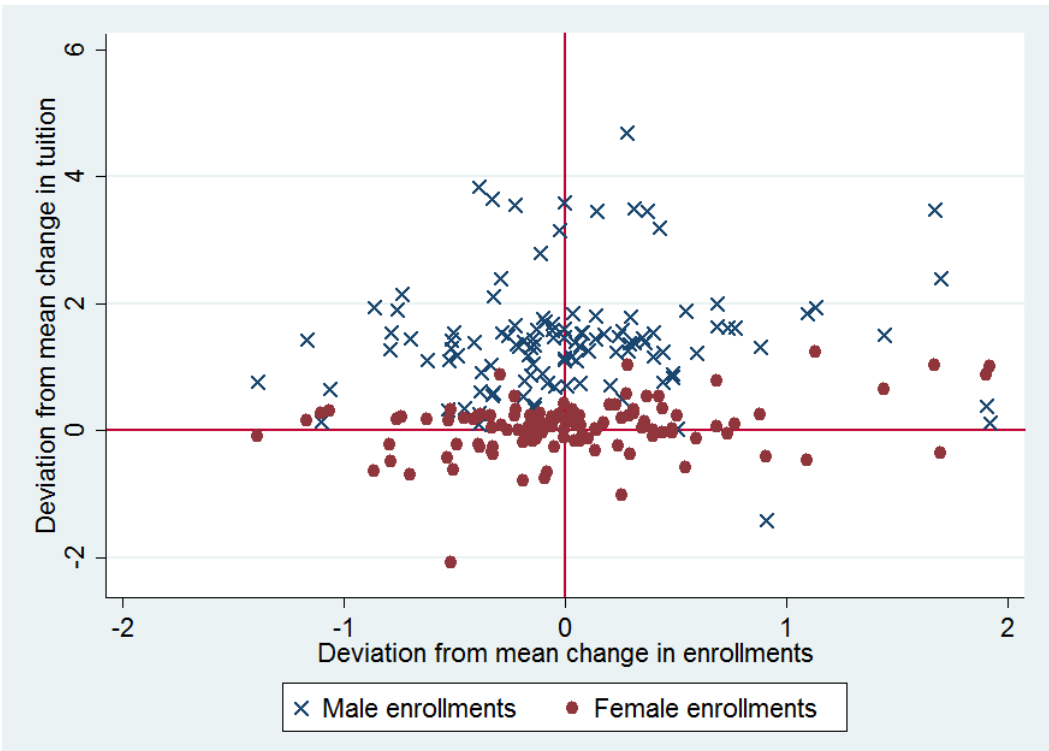

(a) 2004

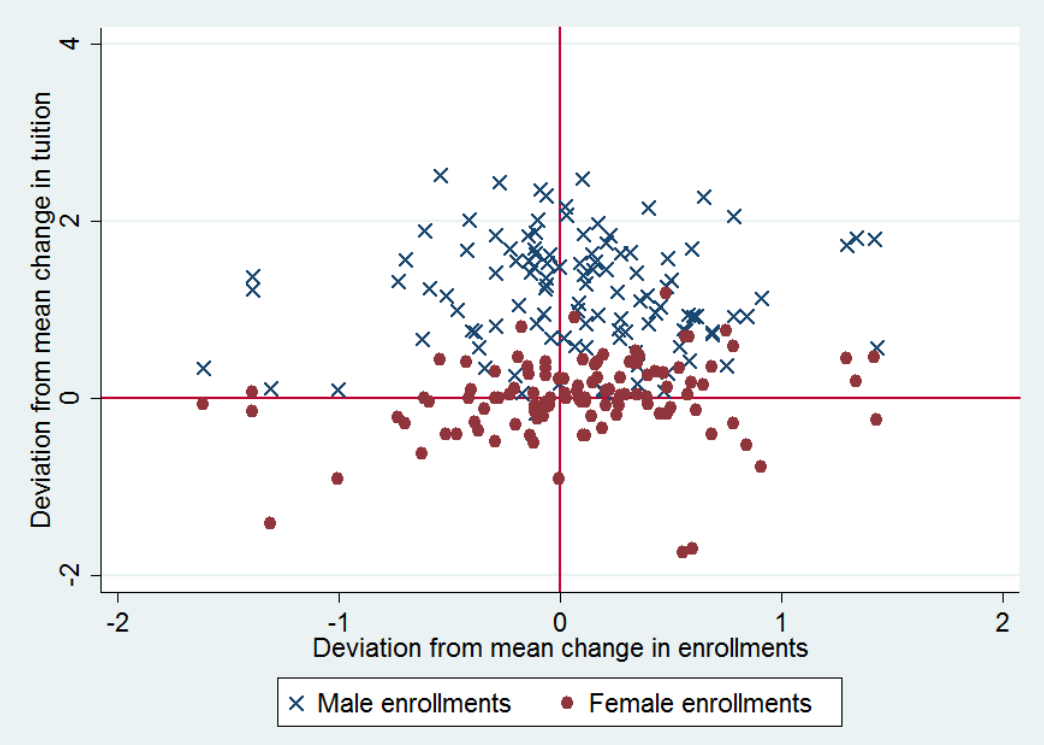

(b) 2005 
Figure A.1: (continued) The relationship between deviations from mean published tuition growth and deviations from mean enrollments growth

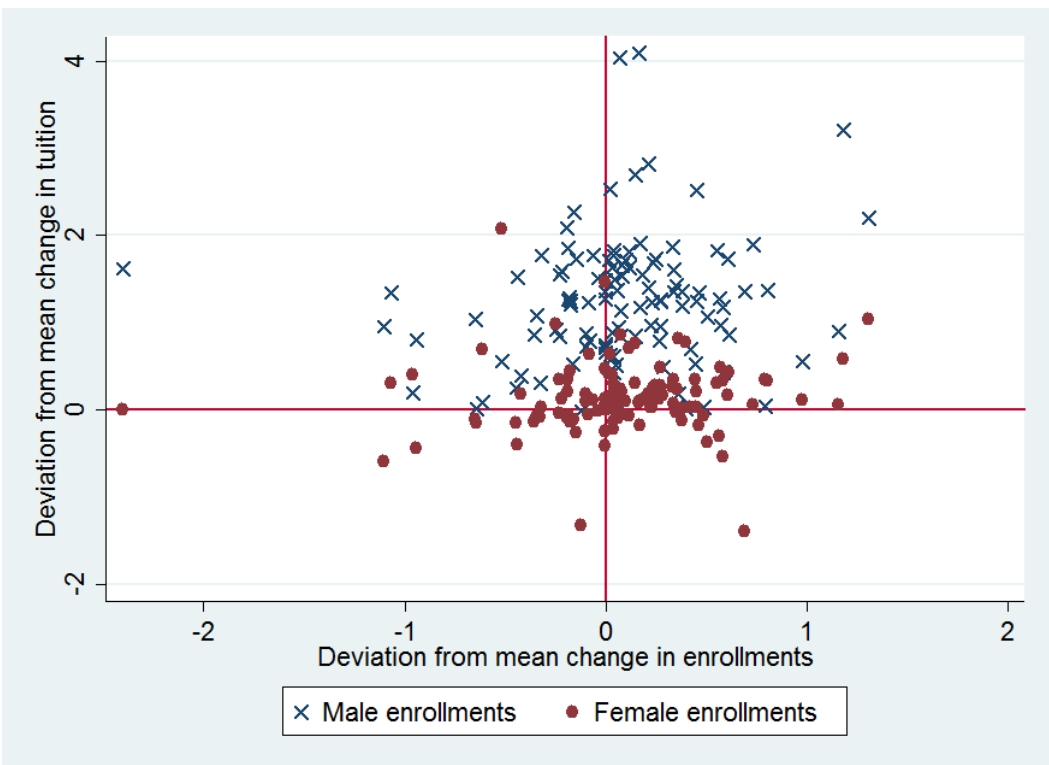

(c) 2006

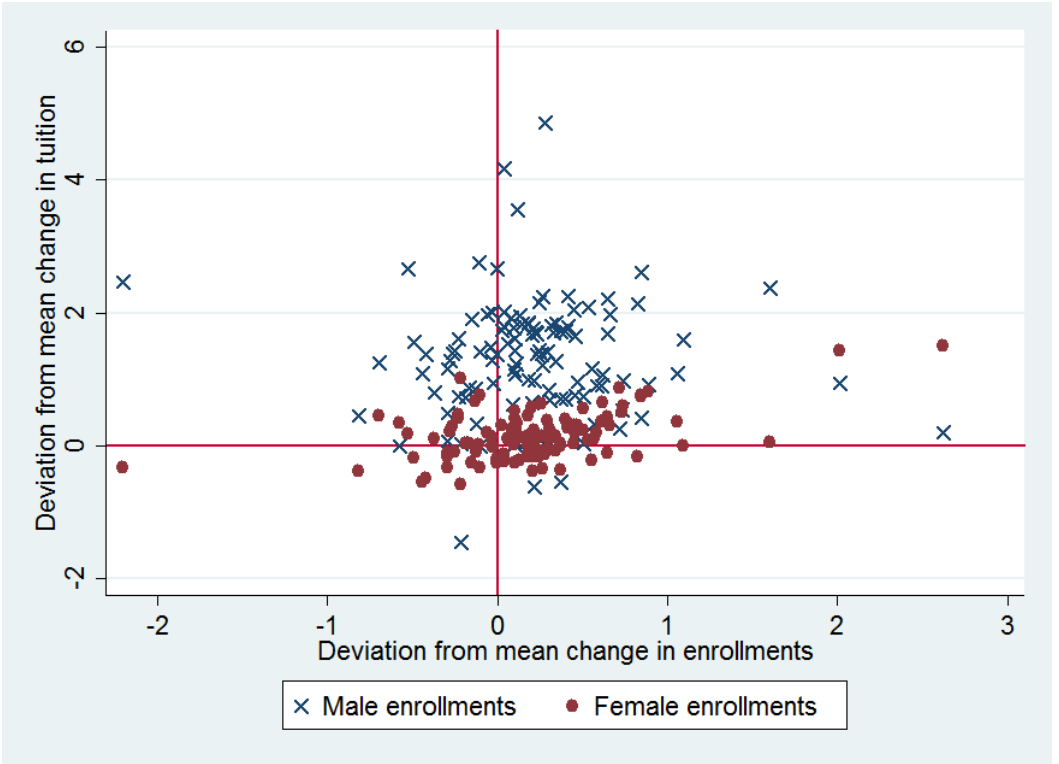

(d) 2007 
Figure A.1: (continued) The relationship between deviations from mean published tuition growth and deviations from mean enrollments growth

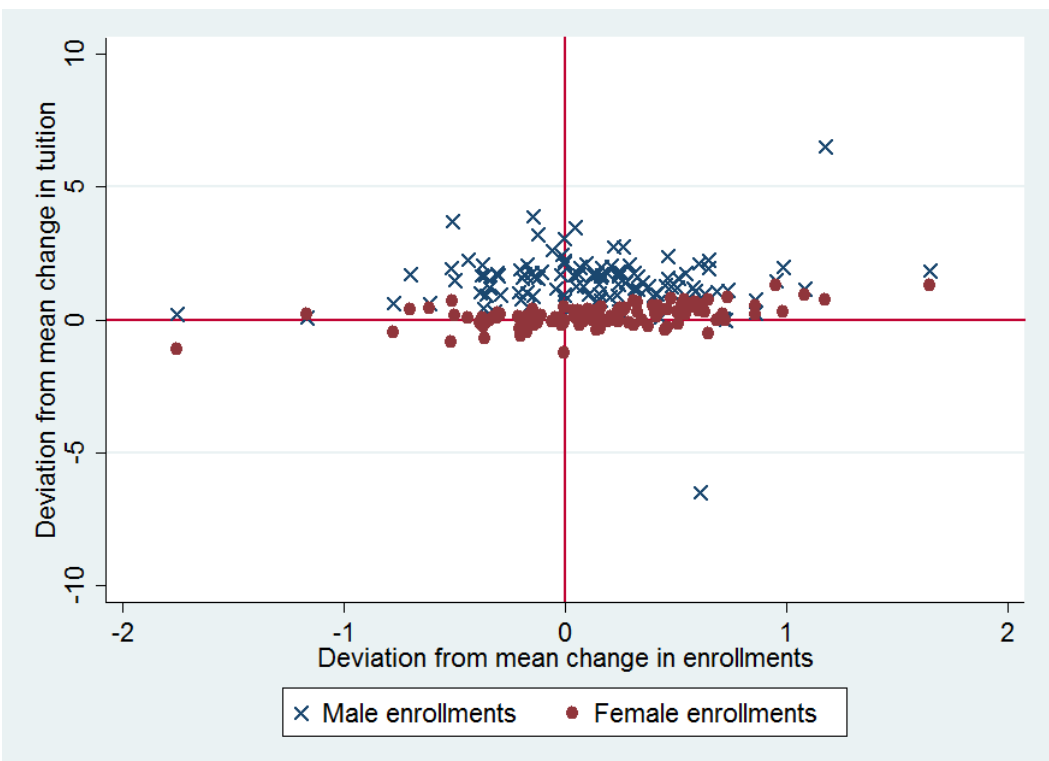

(e) 2008

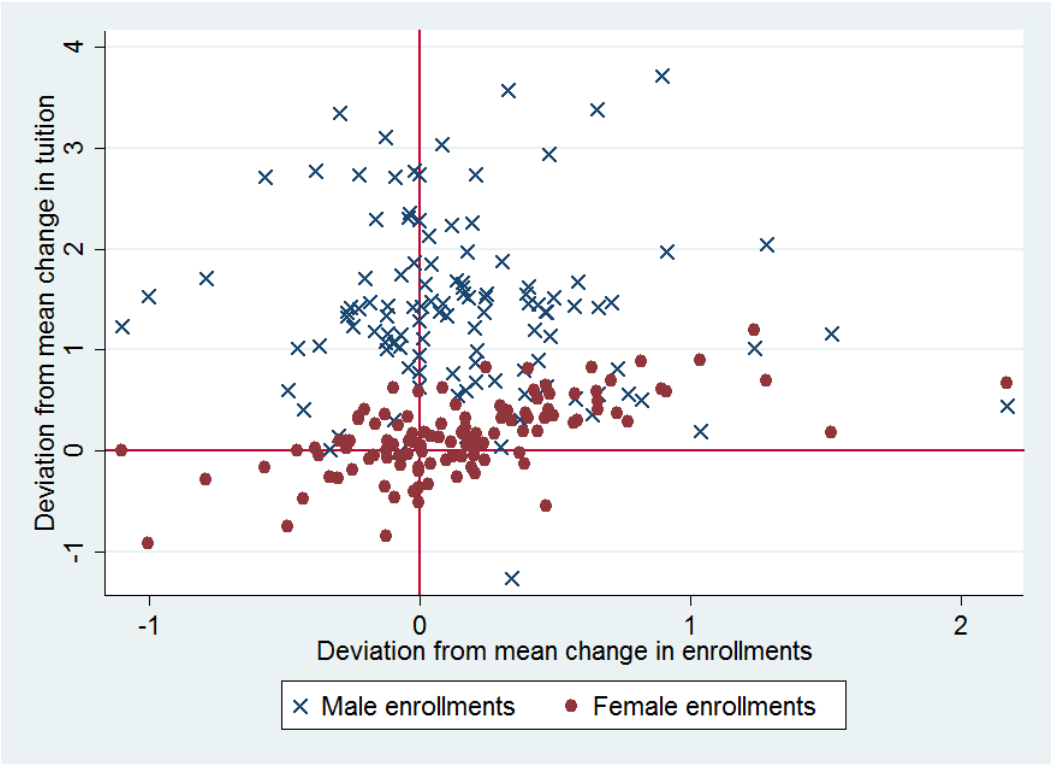

(f) 2009 
Figure A.1: (continued) The relationship between deviations from mean published tuition growth and deviations from mean enrollments growth

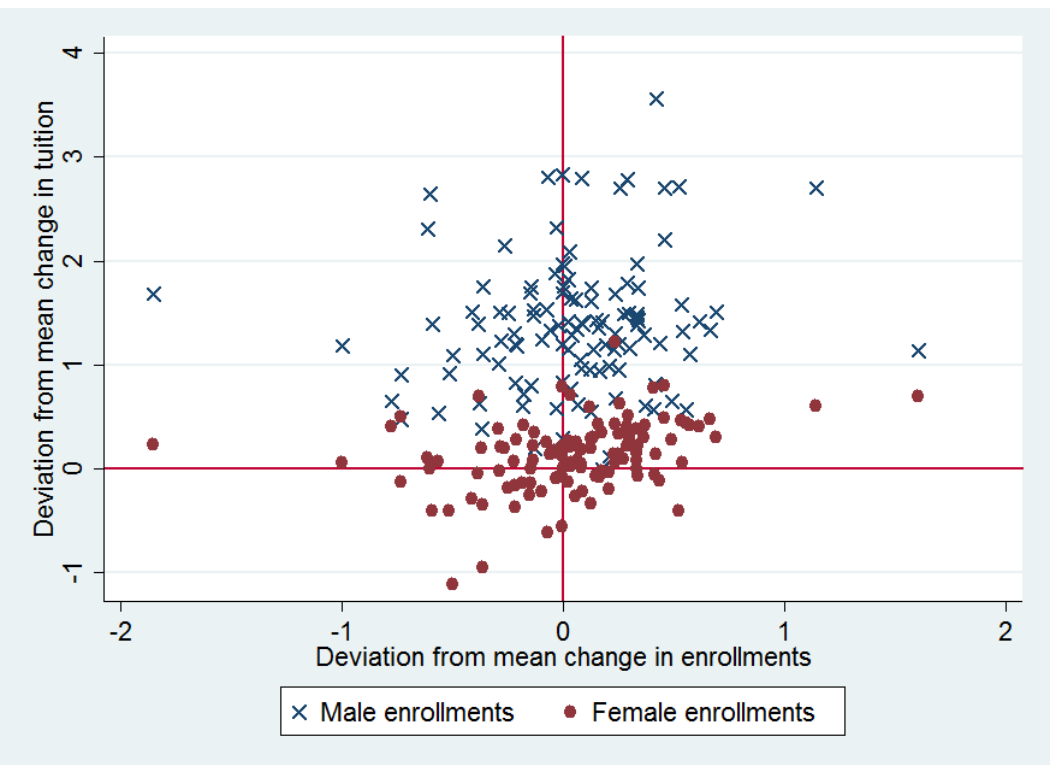

(g) 2010

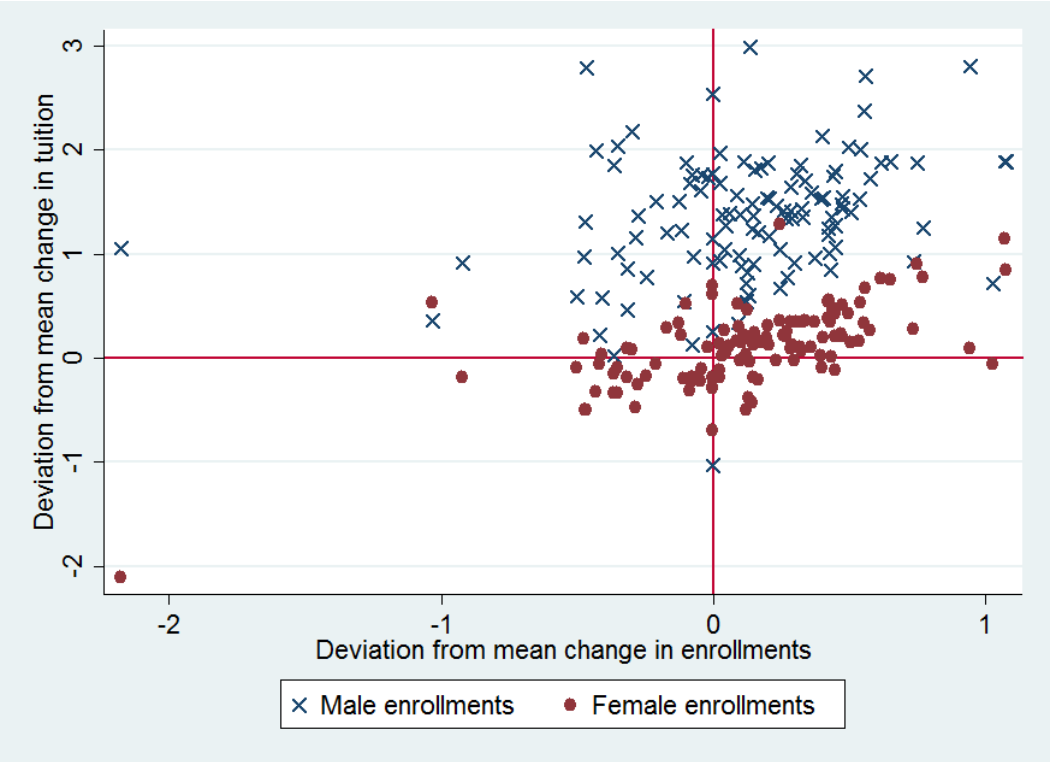

(h) 2011 


\section{A.4 Robustness Check Results}

Table A.2: Robustness check using fixed effects estimation

\begin{tabular}{lcc|lcc}
\hline \hline Variable & Male & Female & Variable & Male & Female \\
\hline PTUITION & -0.0058 & 0.0046 & SATACT & 0.0133 & 0.0102 \\
& $(0.0116)$ & $(0.0130)$ & & $(0.0098)$ & $(0.0095)$ \\
AVAID & $-0.1249^{* * *}$ & $-0.0837^{*}$ & SISTD & $0.7344^{* * *}$ & $0.7607^{* * *}$ \\
& $(0.0362)$ & $(0.0451)$ & $($ in log $)$ & $(0.0760)$ & $(0.0869)$ \\
ARWU & 0.0026 & -0.0010 & THSTD & -0.4651 & -0.5066 \\
& $(0.0025)$ & $(0.0026)$ & $($ in log $)$ & $(0.3663)$ & $(0.4360)$ \\
2004 & 0.0618 & 0.0472 & 2008 & $0.5086^{* * *}$ & $0.4873^{* * *}$ \\
& $(0.0529)$ & $(0.0571)$ & & $(0.0934)$ & $(0.1109)$ \\
2005 & $0.1365^{* * *}$ & $0.1715^{* * *}$ & 2009 & $0.5927^{* * *}$ & $0.5722^{* * *}$ \\
& $(0.0489)$ & $(0.0627)$ & & $(0.1117)$ & $(0.1293)$ \\
2006 & $0.2997^{* * *}$ & $0.2519^{* * *}$ & 2010 & $0.6397^{* * *}$ & $0.5091^{* * *}$ \\
& $(0.0621)$ & $(0.0790)$ & & $(0.1299)$ & $(0.1539)$ \\
2007 & $0.4239^{* * *}$ & $0.4175^{* * *}$ & 2011 & $0.7078^{* * *}$ & $0.5687^{* * *}$ \\
& $(0.0819)$ & $(0.0939)$ & & $(0.1440)$ & $(0.1756)$ \\
Constant & 3.2321 & 3.1953 & & & \\
& $(3.5005)$ & $(4.1871)$ & & & \\
\hline$R^{2}-$ within & 0.5305 & 0.4648 & & & \\
$R^{2}-$ between & 0.5822 & 0.7110 & & & \\
$R^{2}-$ overall & 0.5569 & 0.6346 & & & \\
\hline \hline
\end{tabular}

Dependent variable is ( $\log$ of ) enrollment of new international students Standard errors are clustered by university and shown in parentheses.

* Significant at $10 \% \quad{ }^{* *}$ Significant at $5 \% \quad{ }^{* * *}$ Significant at $1 \%$ 
Table A.3: Robustness check using Hausman-Taylor estimation

\begin{tabular}{lll|lcc}
\hline \hline Variable & Male & Female & Variable & Male & Female \\
\hline PTUITION & 0.0088 & 0.0145 & SATACT & $0.0229^{* *}$ & $0.0179^{*}$ \\
& $(0.0101)$ & $(0.0104)$ & & $(0.0088)$ & $(0.0093)$ \\
AVAID & $-0.0903^{* *}$ & -0.0598 & SISTD & $0.8337^{* * *}$ & $0.8547^{* * *}$ \\
& $(0.0354)$ & $(0.0413)$ & $($ in log $)$ & $(0.0539)$ & $(0.0511)$ \\
ARWU & $-0.0026^{*}$ & $-0.0024^{* *}$ & THSTD & $-0.1829^{* *}$ & -0.1035 \\
& $(0.0013)$ & $(0.0011)$ & $($ in log $)$ & $(0.0916)$ & $(0.0937)$ \\
Mid East & 0.0577 & -0.0919 & 2004 & 0.0221 & 0.0196 \\
& $(0.1051)$ & $(0.1014)$ & & $(0.0493)$ & $(0.0557)$ \\
G Lakes & 0.1601 & -0.1562 & 2005 & $0.0775^{*}$ & $0.1270^{* *}$ \\
& $(0.1357)$ & $(0.1041)$ & & $(0.0457)$ & $(0.0576)$ \\
Plains & $-0.2327^{*}$ & $-0.3531^{* * *}$ & 2006 & $0.2184^{* * *}$ & $0.1902^{* * *}$ \\
& $(0.1303)$ & $(0.1233)$ & & $(0.0571)$ & $(0.0676)$ \\
Southeast & -0.1978 & $-0.3692^{* * *}$ & 2007 & $0.3088^{* * *}$ & $0.3286^{* * *}$ \\
& $(0.1305)$ & $(0.1191)$ & & $(0.0744)$ & $(0.0755)$ \\
Southwest & -0.0294 & $-0.3858^{* *}$ & 2008 & $0.3509^{* * *}$ & $0.3615^{* * *}$ \\
& $(0.1460)$ & $(0.1638)$ & & $(0.0829)$ & $(0.0845)$ \\
Rocky M & $-0.4880^{* * *}$ & $-0.7198^{* * *}$ & 2009 & $0.3907^{* * *}$ & $0.4104^{* * *}$ \\
& $(0.1754)$ & $(0.1461)$ & & $(0.0974)$ & $(0.0942)$ \\
Far West & $-0.3990^{* * *}$ & $-0.4173^{* * *}$ & 2010 & $0.3916^{* * *}$ & $0.3092^{* * *}$ \\
& $(0.1374)$ & $(0.1080)$ & & $(0.1093)$ & $(0.1084)$ \\
Constant & -0.0769 & -1.0437 & 2011 & $0.4332^{* * *}$ & $0.3479^{* * *}$ \\
& $(0.9967)$ & $(0.9845)$ & & $(0.1202)$ & $(0.1245)$ \\
\hline \hline
\end{tabular}

Dependent variable is (log of ) enrollment of new international students

Standard errors are clustered by university and shown in parentheses.

* Significant at $10 \% \quad{ }^{* *}$ Significant at $5 \% \quad{ }^{* * *}$ Significant at $1 \%$ 
Table A.4: Robustness check using first differences estimation

\begin{tabular}{lcc}
\hline \hline Variable & Male & Female \\
\hline$\Delta$ PTUITION & 0.0192 & $0.0681^{* *}$ \\
$\Delta$ AVAID & $(0.0224)$ & $(0.0302)$ \\
& $-0.0632^{*}$ & $-0.1415^{* *}$ \\
$\Delta$ ARWU & $(0.0358)$ & $(0.0663)$ \\
& -0.0002 & 0.0012 \\
$\Delta$ SATACT & $(0.0050)$ & $(0.0065)$ \\
& 0.0048 & -0.0076 \\
$\Delta$ SISTD $($ in $\log )$ & $(0.0107)$ & $(0.0109)$ \\
& $0.3735^{* * *}$ & $0.4100^{* *}$ \\
$\Delta$ THSTD $($ in $\log )$ & $(0.1070)$ & $(0.1724)$ \\
& -0.3140 & $-0.9461^{*}$ \\
Constant & $(0.4571)$ & $(0.5418)$ \\
& $0.0651^{* *}$ & 0.0180 \\
$R^{2}$ & $(0.0326)$ & $(0.0468)$ \\
- within & \multicolumn{2}{c}{} \\
- between & 0.4728 & 0.3935 \\
- overall & 0.0124 & 0.5962 \\
Obs & 0.5906 & 0.1689 \\
Univ & \multicolumn{2}{c}{116} \\
\hline \hline
\end{tabular}

Dependent variable is change in (log of) enrollment of new international students Bootstrapped standard errors are shown in parentheses.

* Significant at $10 \% \quad{ }^{* *}$ Significant at $5 \% \quad{ }^{* * *}$ Significant at $1 \%$ 


\section{Appendix B}

\section{B.1 List of Variables}

Table B.1: List of variables used for spatial regression analysis in Chapter 3 and Chapter 4

\begin{tabular}{cl}
\hline \hline Variable & Description \\
\hline PTUITION & (Log of) published out-of-state tuition and fees \\
NTUITION & (Log of) published out-of-state tuition and fees minus aver- \\
& age institutional financial aid per student \\
USTD & Enrollment of undergraduate students (in thousand) \\
GSTD & Enrollment of graduate students (in thousand) \\
ENDOW & (Log of) total endowment \\
PRAID & Proportion of students receiving any financial assistance \\
FACULTY & Number of full time faculty staff (in thousand) \\
RESEARCH & (Log of) research spending \\
TEACH & (Log of) teaching expenditure \\
SATACT & Admission test scores, calculated using the 25th percentile \\
& $\begin{array}{l}\text { scores the comprehensive ACT test (and its equivalent in } \\
\text { the SAT test) of accepted applicants }\end{array}$ \\
ADMRATE & $\begin{array}{l}\text { Admission rate, calculated as the ratio between number of } \\
\text { applicants and number of admission offers }\end{array}$ \\
POPDEN & County's population density (in thousand) per square mile, \\
& calculated as the ratio between total county's population \\
& and county's area size \\
(Log of ) median county's income \\
AEDINC dummy variable that equals one for public university and \\
PUBLIC & zero for private university \\
\hline \hline
\end{tabular}




\section{B.2 Endogeneity Test: Enrollment and Prices}

Table B.2: 2-step GMM estimation results and endogeneity tests

\begin{tabular}{lcc|lcc}
\hline \hline Variable & PTUITION & \multicolumn{1}{l}{ NTUITION } & \multicolumn{1}{l}{ Variable } & \multicolumn{1}{l}{ PTUITION } & NTUITION \\
\hline USTD & -0.0084 & 0.0020 & GSTD & 0.0116 & 0.0032 \\
& $(0.0053)$ & $(0.0076)$ & & $(0.0089)$ & $(0.0124)$ \\
ENDOW & $0.0427^{* * *}$ & 0.0127 & PRAID & $0.1366^{* *}$ & $0.2858^{* * *}$ \\
& $(0.0101)$ & $(0.0136)$ & & $(0.0536)$ & $(0.0873)$ \\
FACULTY & 0.0409 & 0.1034 & RESEARCH & -0.0063 & $-0.0258^{* * *}$ \\
& $(0.0609)$ & $(0.0886)$ & & $(0.0065)$ & $(0.0083)$ \\
TEACH & $0.0479^{*}$ & $0.0710^{* *}$ & SATACT & $0.0270^{* * *}$ & $0.0196^{* * *}$ \\
& $(0.0247)$ & $(0.0360)$ & & $(0.0043)$ & $(0.0061)$ \\
ADMRATE & 0.0569 & $-0.4417^{* * *}$ & POPDEN & $-0.0030^{* *}$ & -0.0039 \\
& $(0.0548)$ & $(0.0825)$ & & $(0.0015)$ & $(0.00249)$ \\
MEDINC & $0.1875^{* * *}$ & $0.1711^{* * *}$ & PUBLIC & $-0.4137^{* * *}$ & $-0.1787^{* *}$ \\
& $(0.0428)$ & $(0.0616)$ & & $(0.0628)$ & $(0.0871)$ \\
Constant & $5.8710^{* * *}$ & $5.5507^{* * *}$ & & & \\
& $(0.5871)$ & $(0.8545)$ & & & \\
\hline \hline
\end{tabular}

Dependent variable is ( $\log$ of ) published tuition and net tuition

Standard errors are clustered by university and shown in parentheses.

* Significant at $10 \% \quad * *$ Significant at $5 \% \quad{ }^{* * *}$ Significant at $1 \%$

\begin{tabular}{lcc}
\hline \hline Test & PTUITION & NTUITION \\
\hline Underidentification $\chi^{2}$ & 62.3320 & 62.3320 \\
$p$-value & 0.0000 & 0.0000 \\
Weak identification $F$ & 9295.0940 & 9295.0940 \\
Overidentification $J$ & 0.5220 & 8.2690 \\
$p$-value & 0.4699 & 0.0040 \\
Hausman $\chi^{2}$ & 0.31 & 1.60 \\
$p$-value & 0.5750 & 0.2055 \\
Endogeneity $C$ & 3.6917 & 0.0209 \\
$p$-value & 0.0547 & 0.8851 \\
\hline \hline
\end{tabular}




\section{Appendix $\mathrm{C}$}

\section{C.1 Moran Scatterplots: Geographical Market}

Figure C.1: Moran scatterplots for published tuition in the geographical market

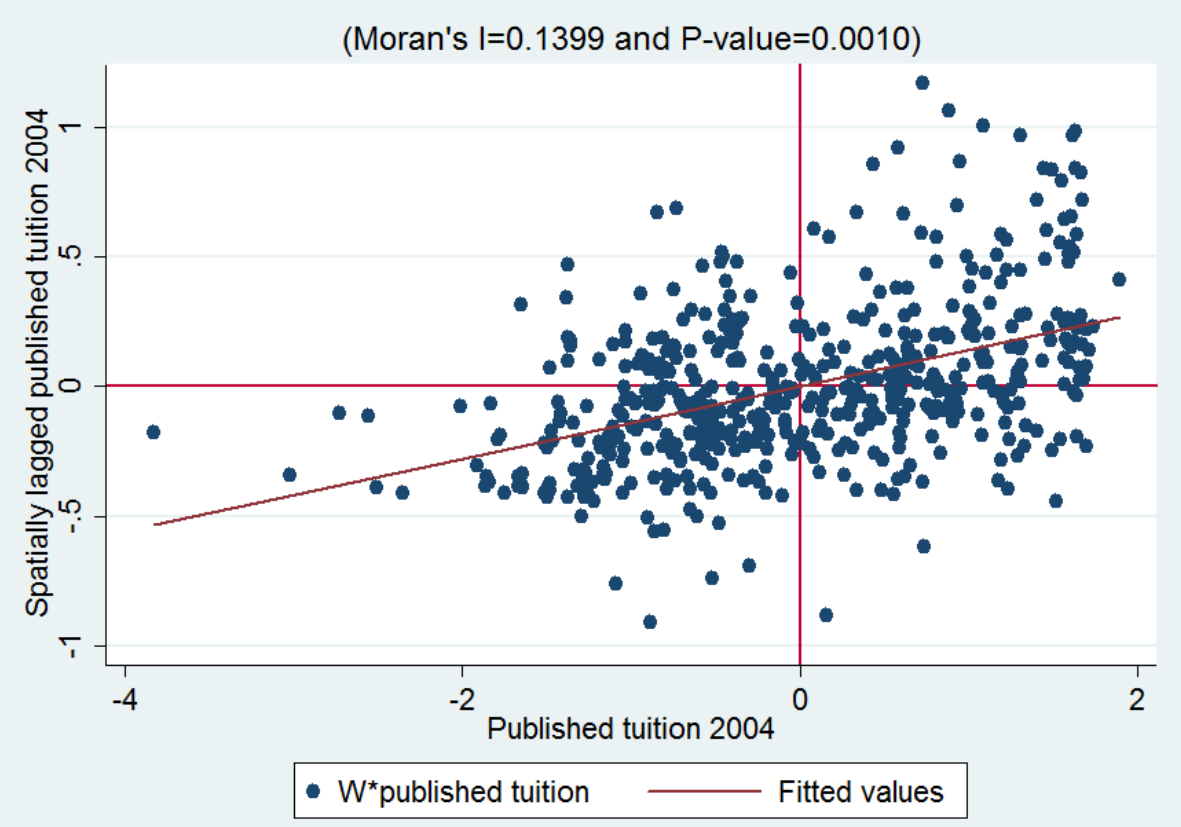

(a) 2004 
Figure C.1: (continued) Moran scatterplots for published tuition in the geographical market

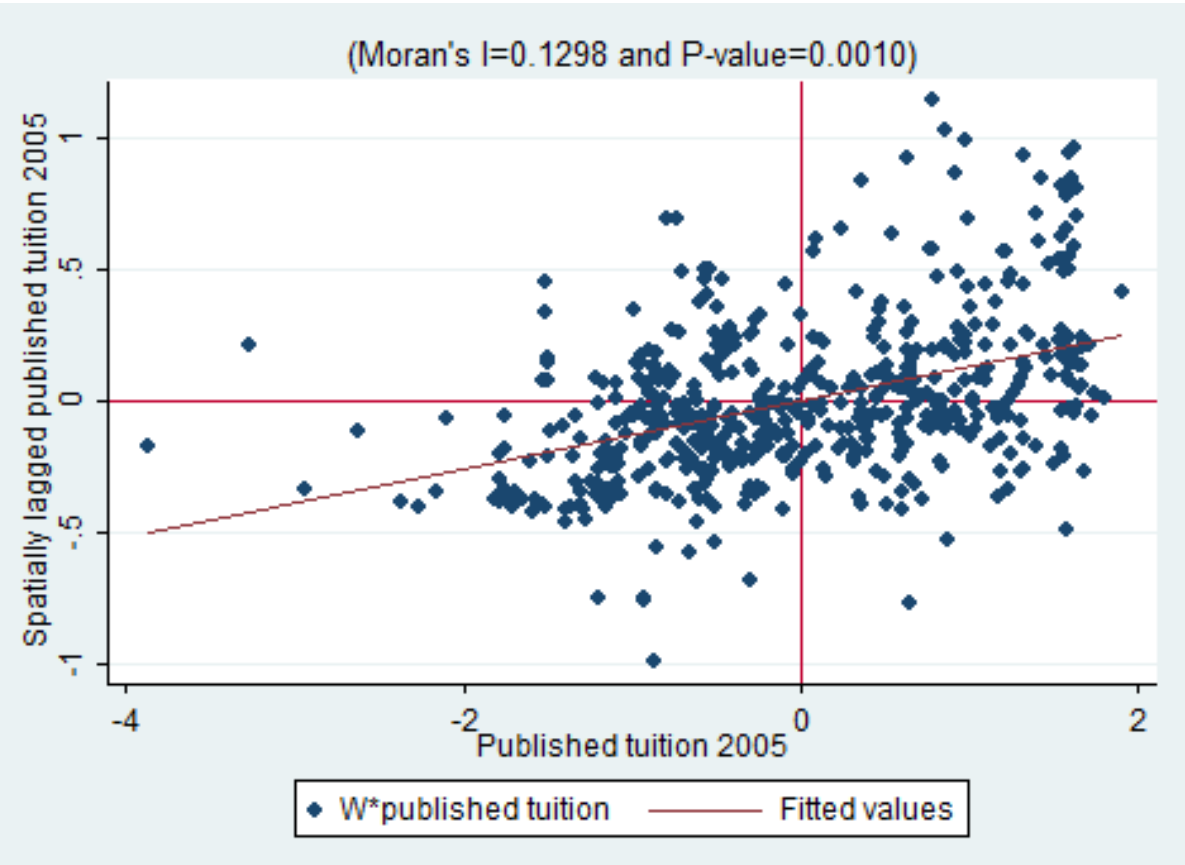

(b) 2005

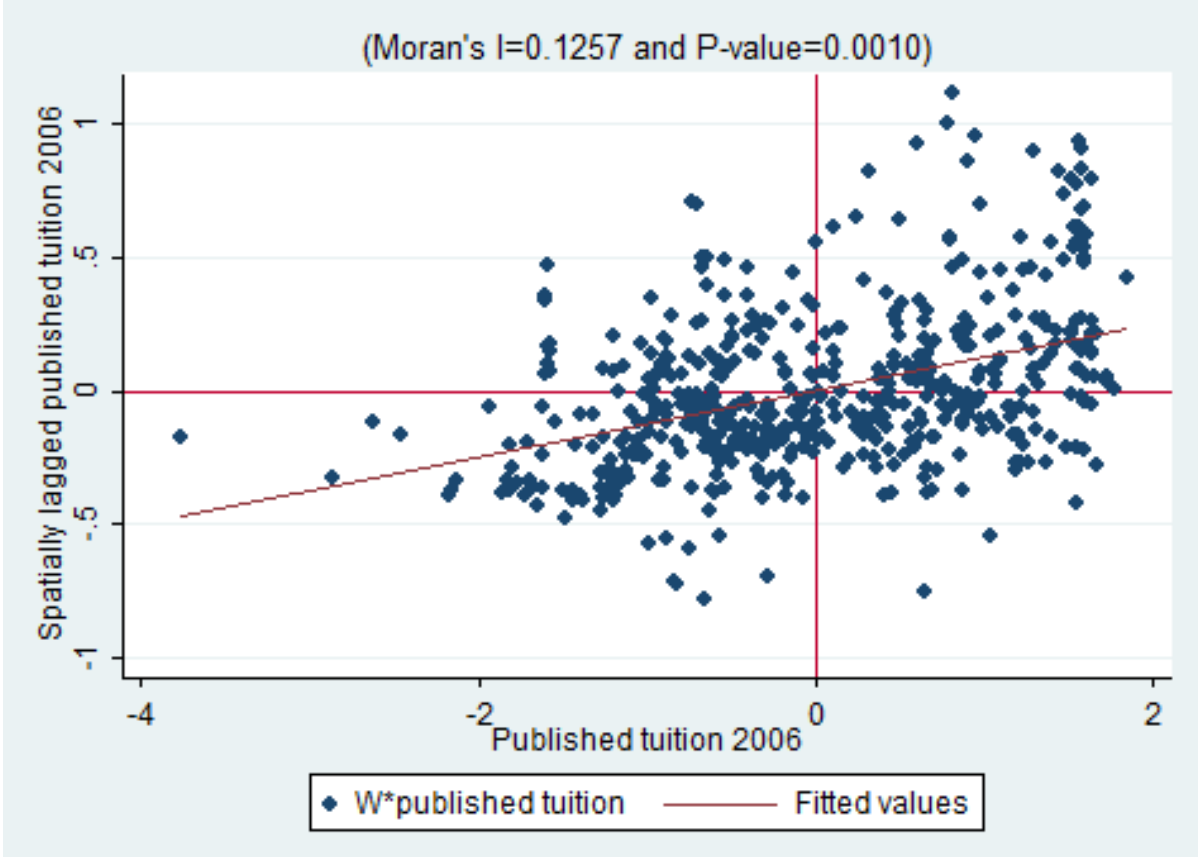

(c) 2006 
Figure C.1: (continued) Moran scatterplots for published tuition in the geographical market

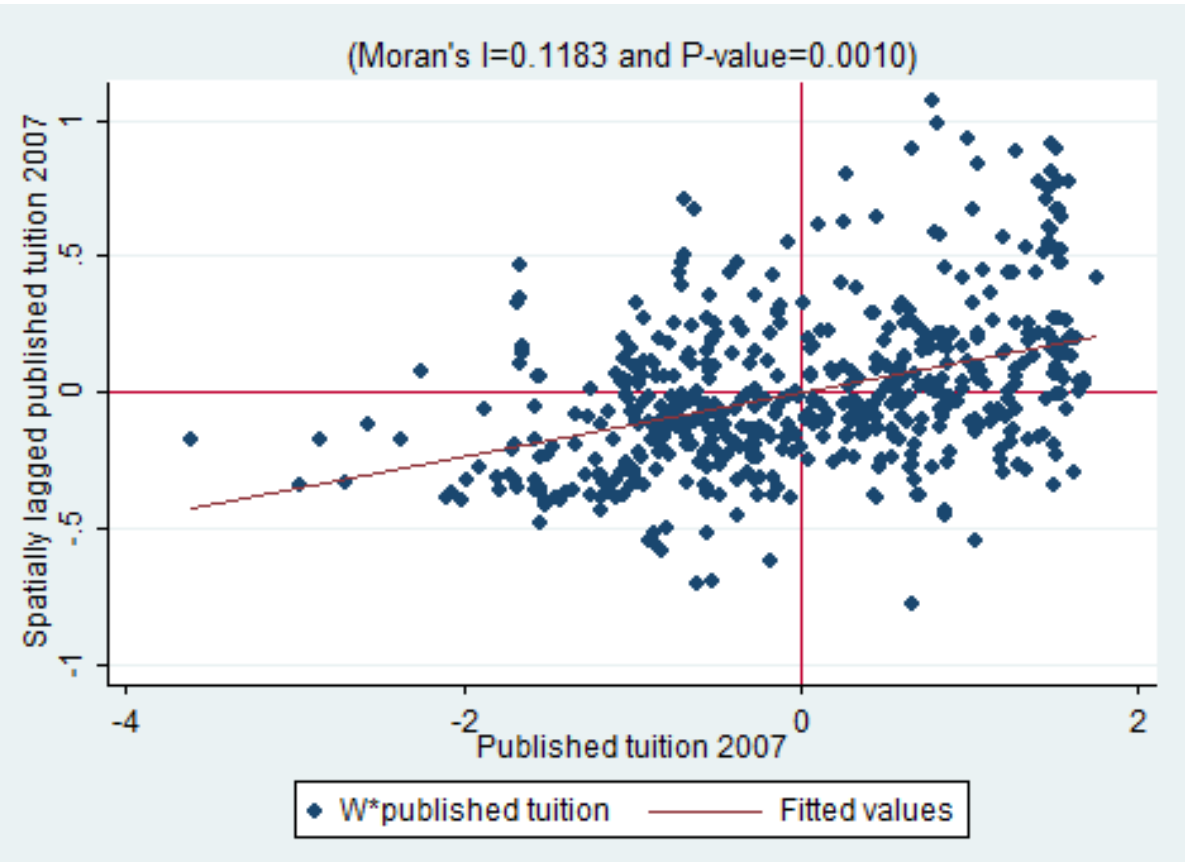

(d) 2007

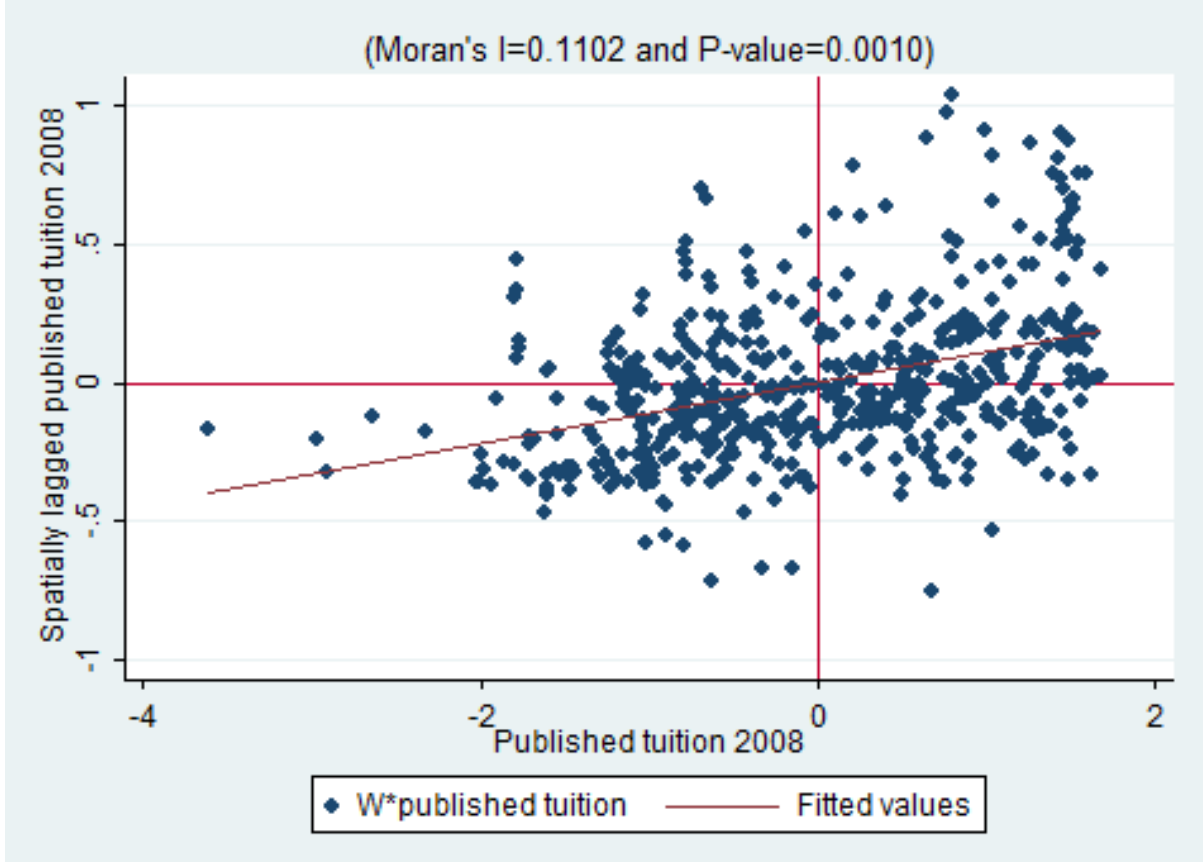

(e) 2008 
Figure C.1: (continued) Moran scatterplots for published tuition in the geographical market

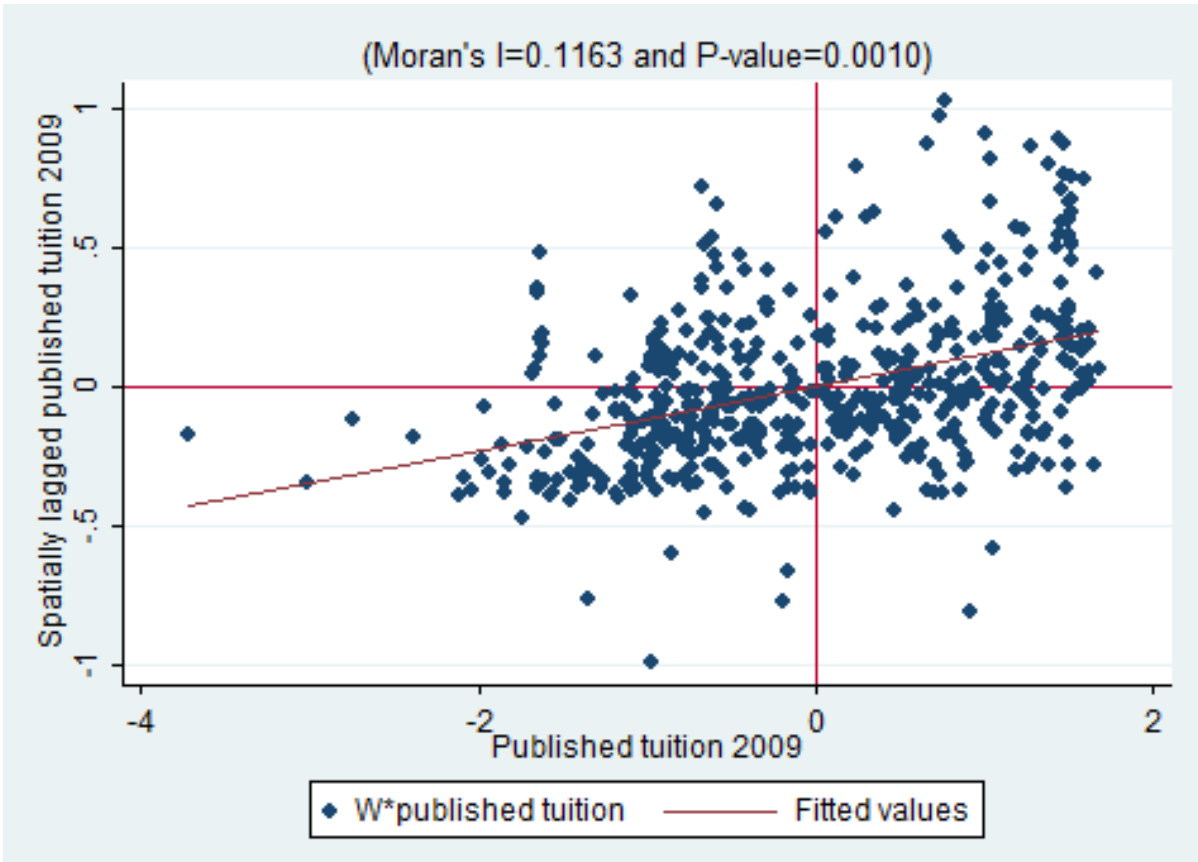

(f) 2009

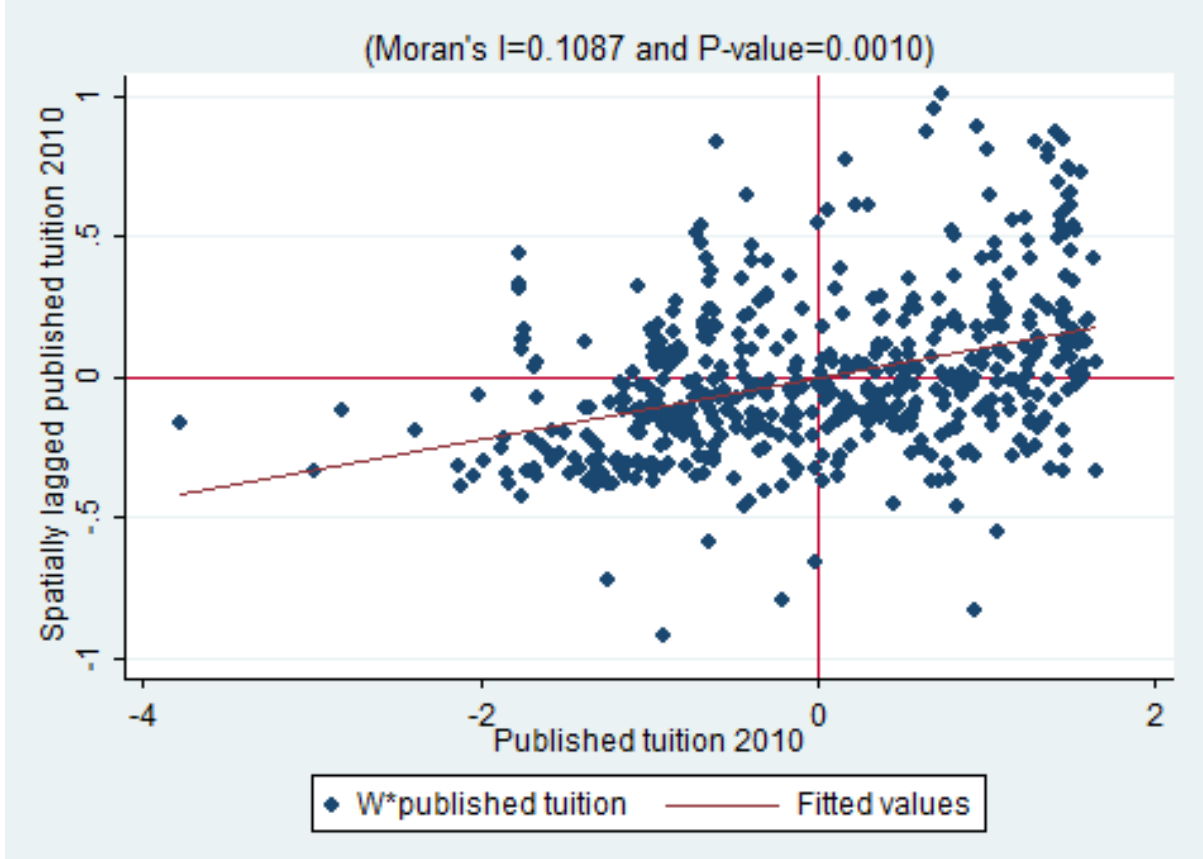

(g) 2010 
Figure C.1: (continued)Moran scatterplots for published tuition in the geographical market

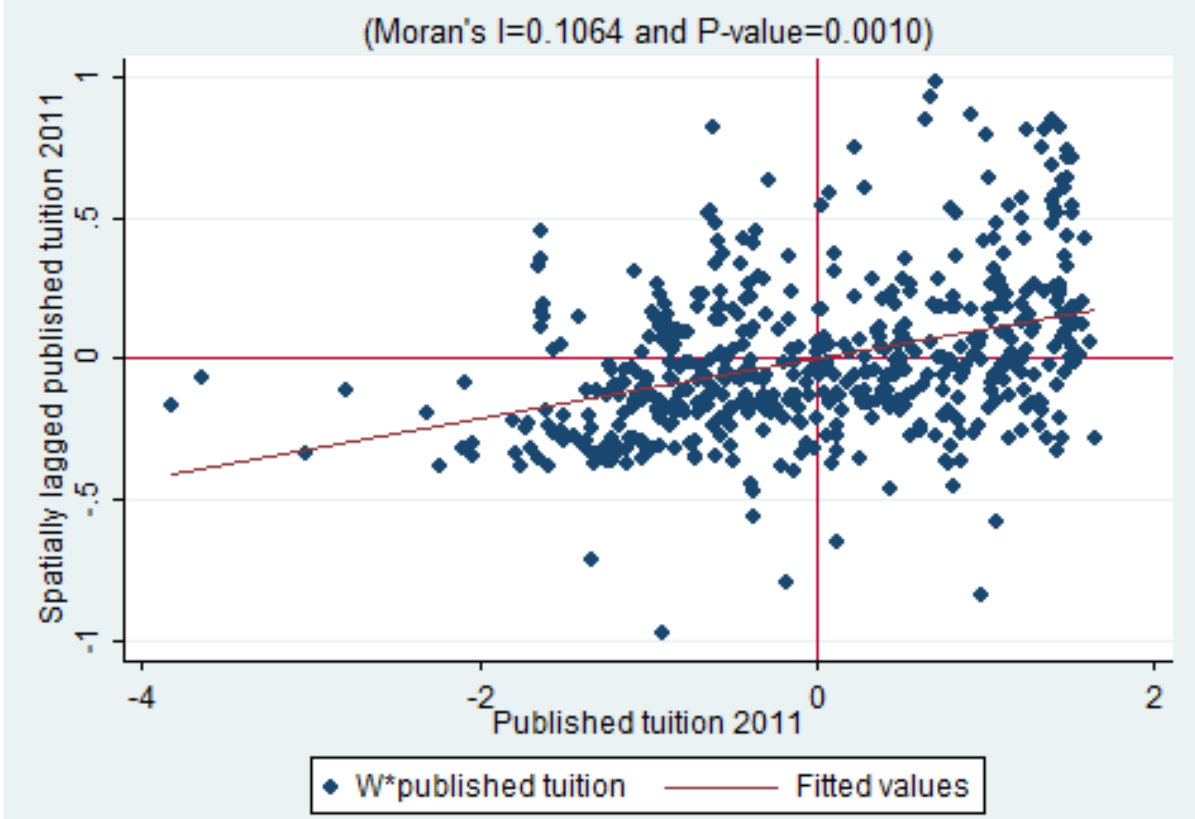

(h) 2011 
Figure C.2: Moran scatterplots for net tuition in the geographical market

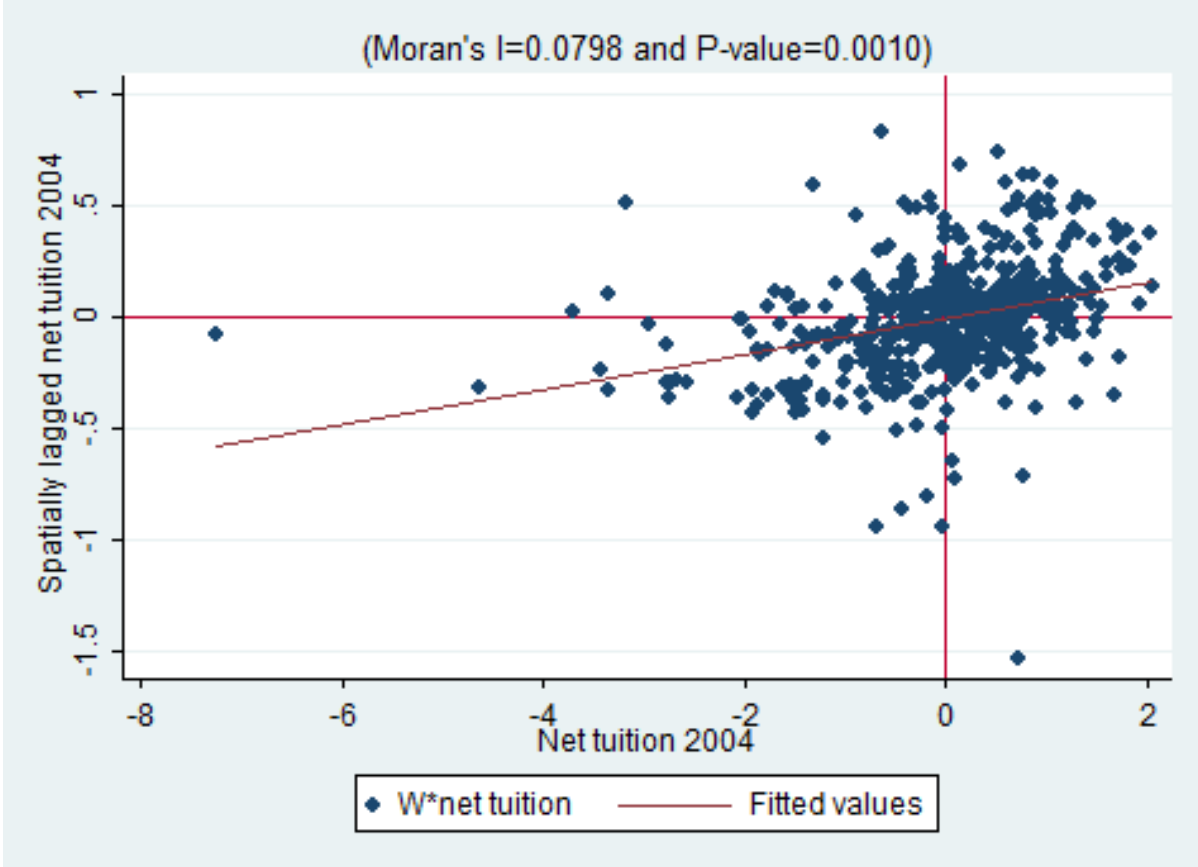

(a) 2004

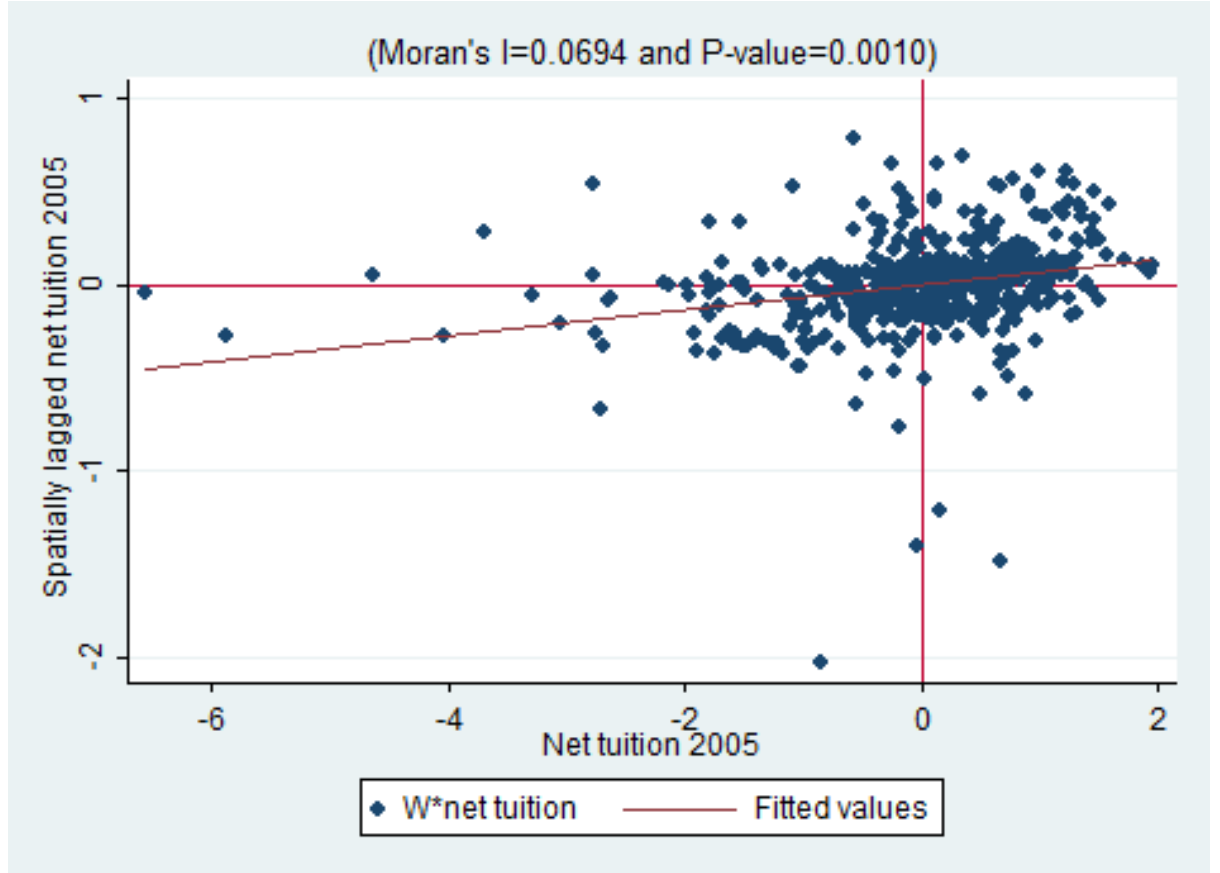

(b) 2005 
Figure C.2: (continued) Moran scatterplots for net tuition in the geographical market

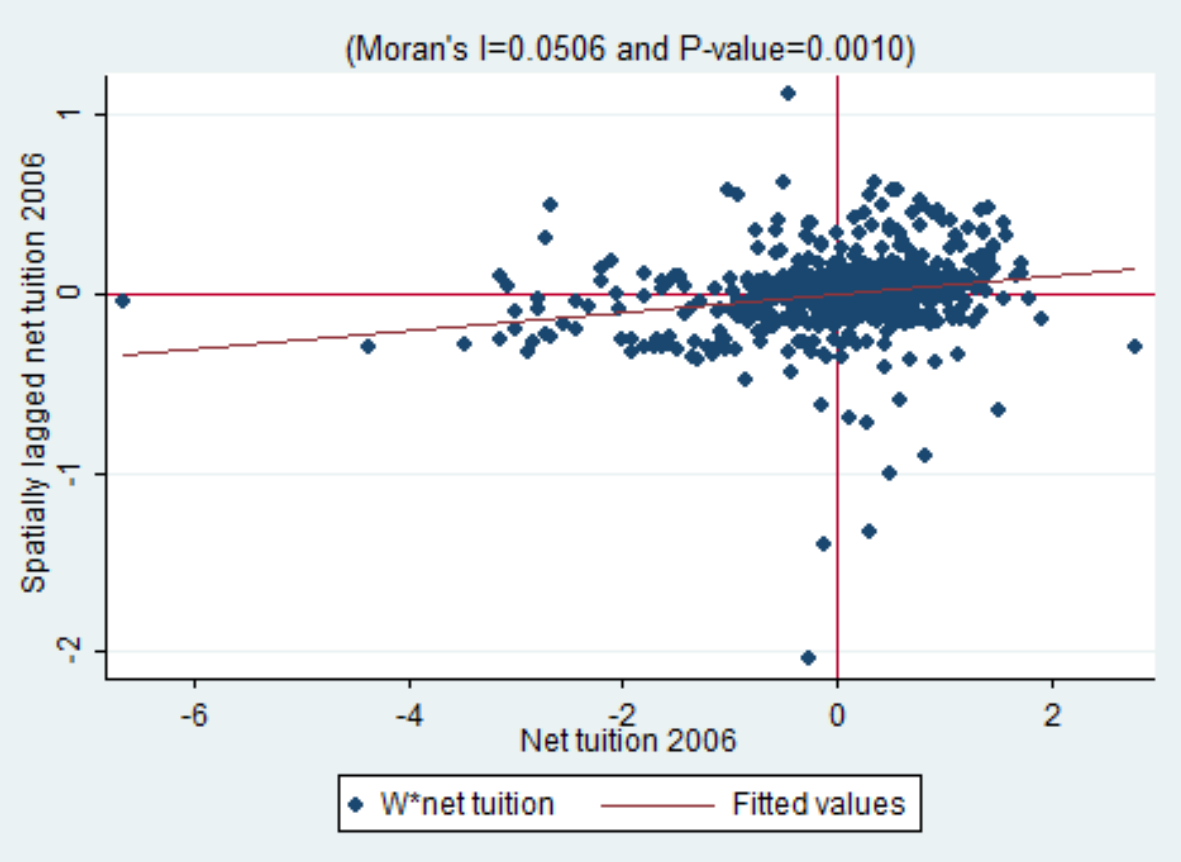

(c) 2006

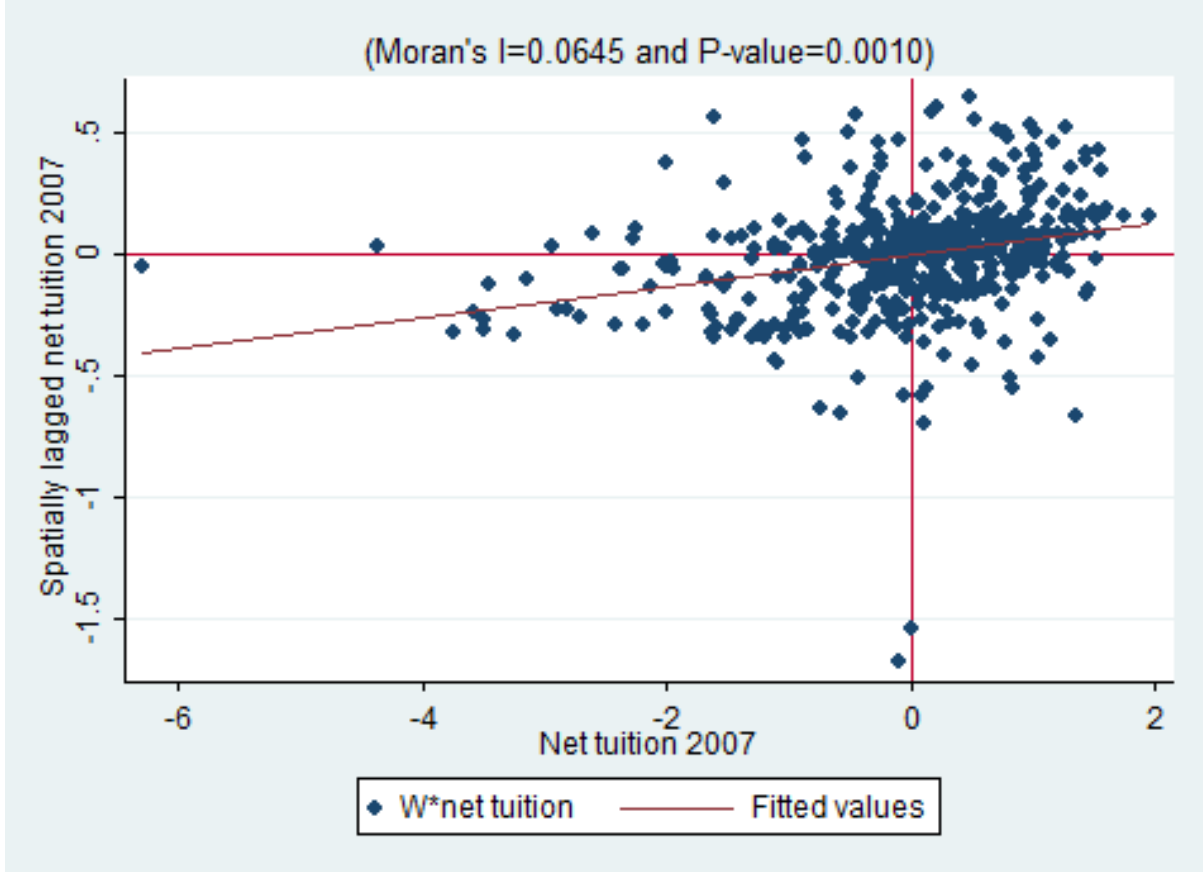

(d) 2007 
Figure C.2: (continued) Moran scatterplots for net tuition in the geographical market

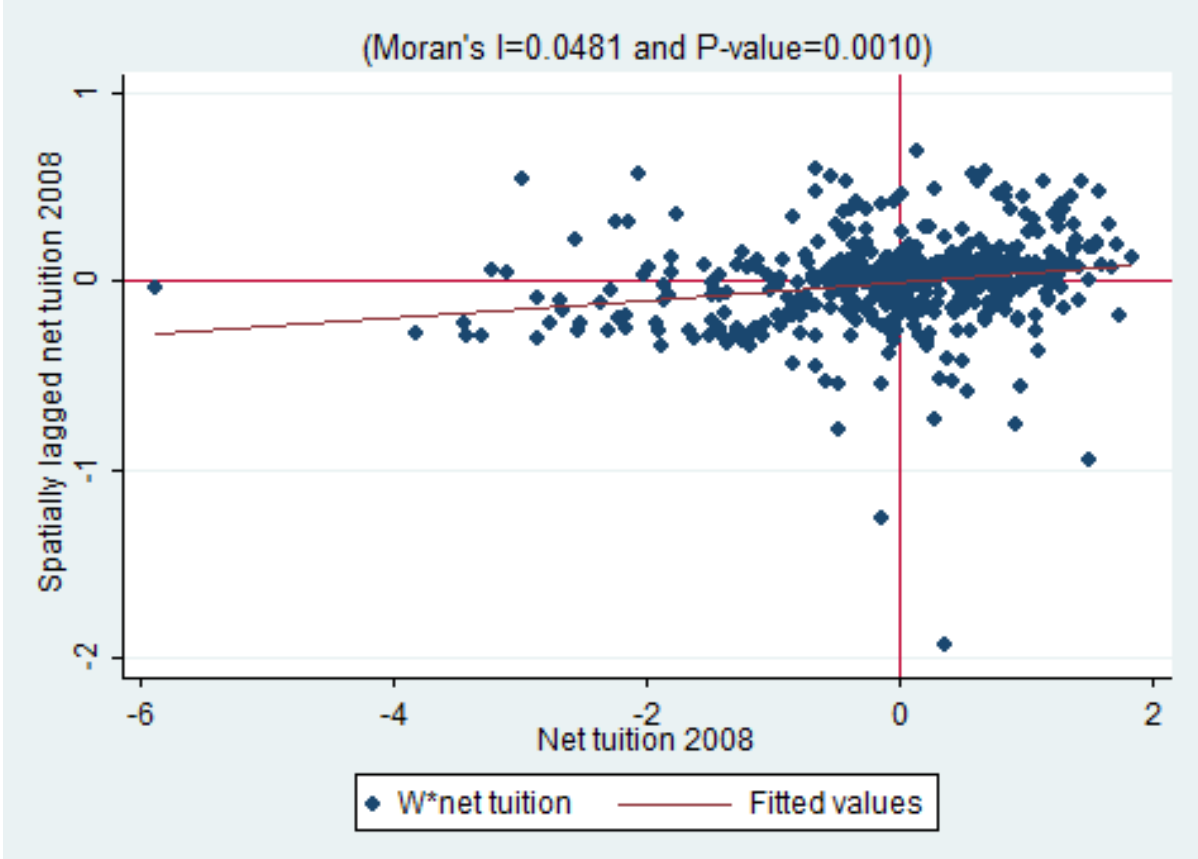

(e) 2008

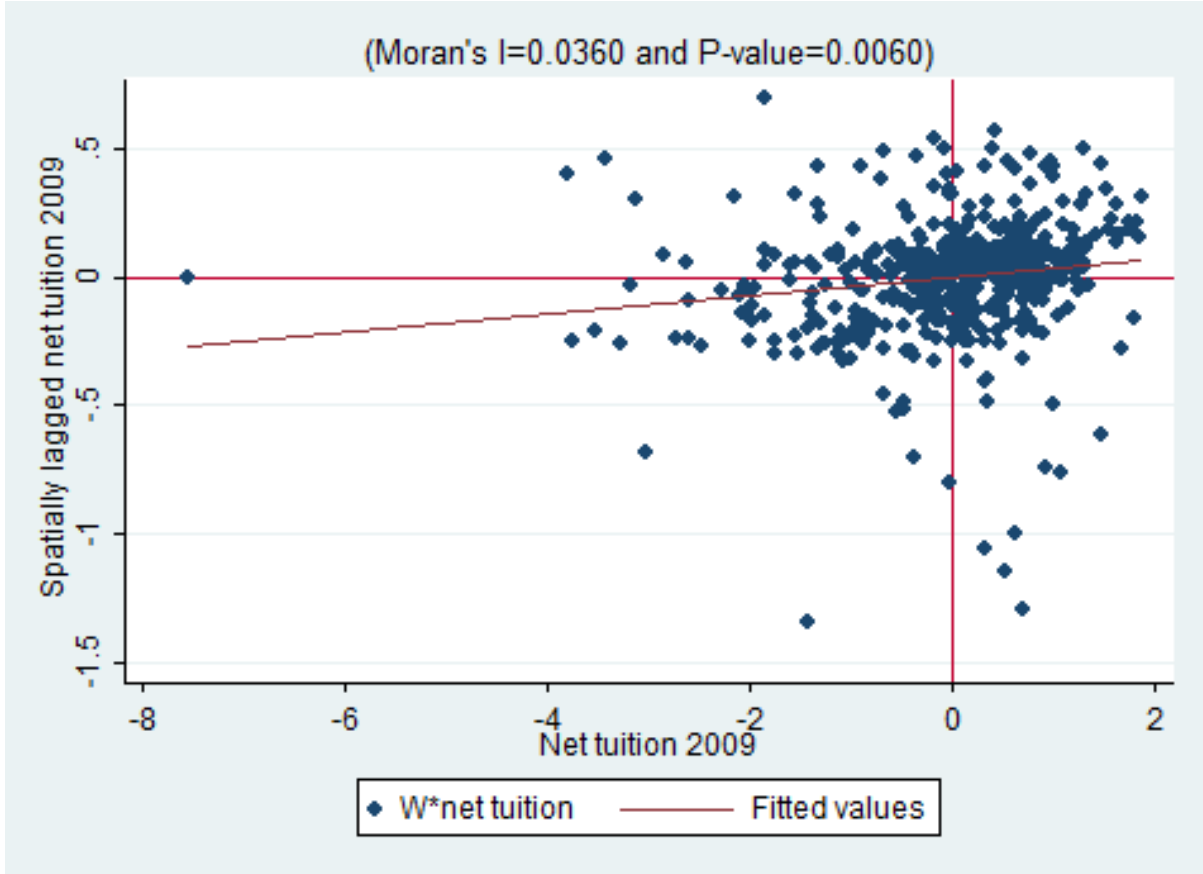

(f) 2009 
Figure C.2: (continued) Moran scatterplots for net tuition in the geographical market

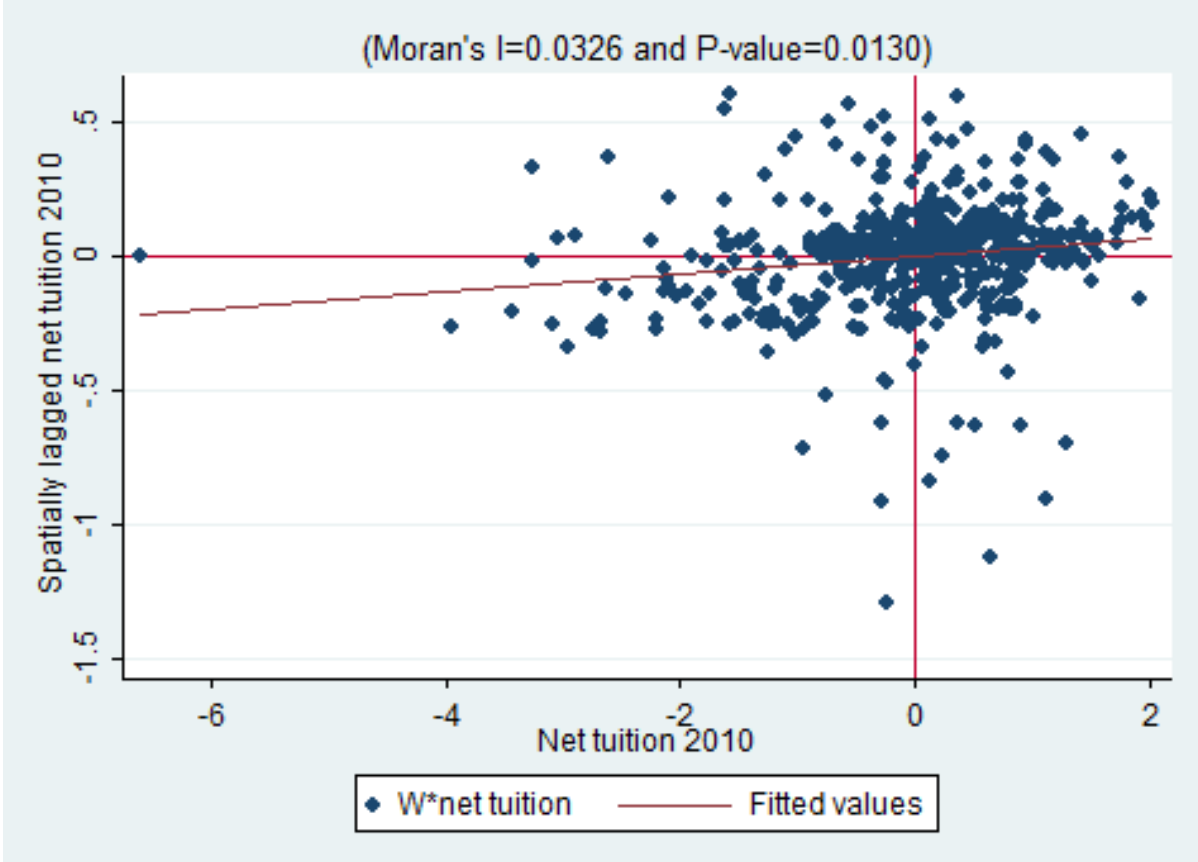

(g) 2010

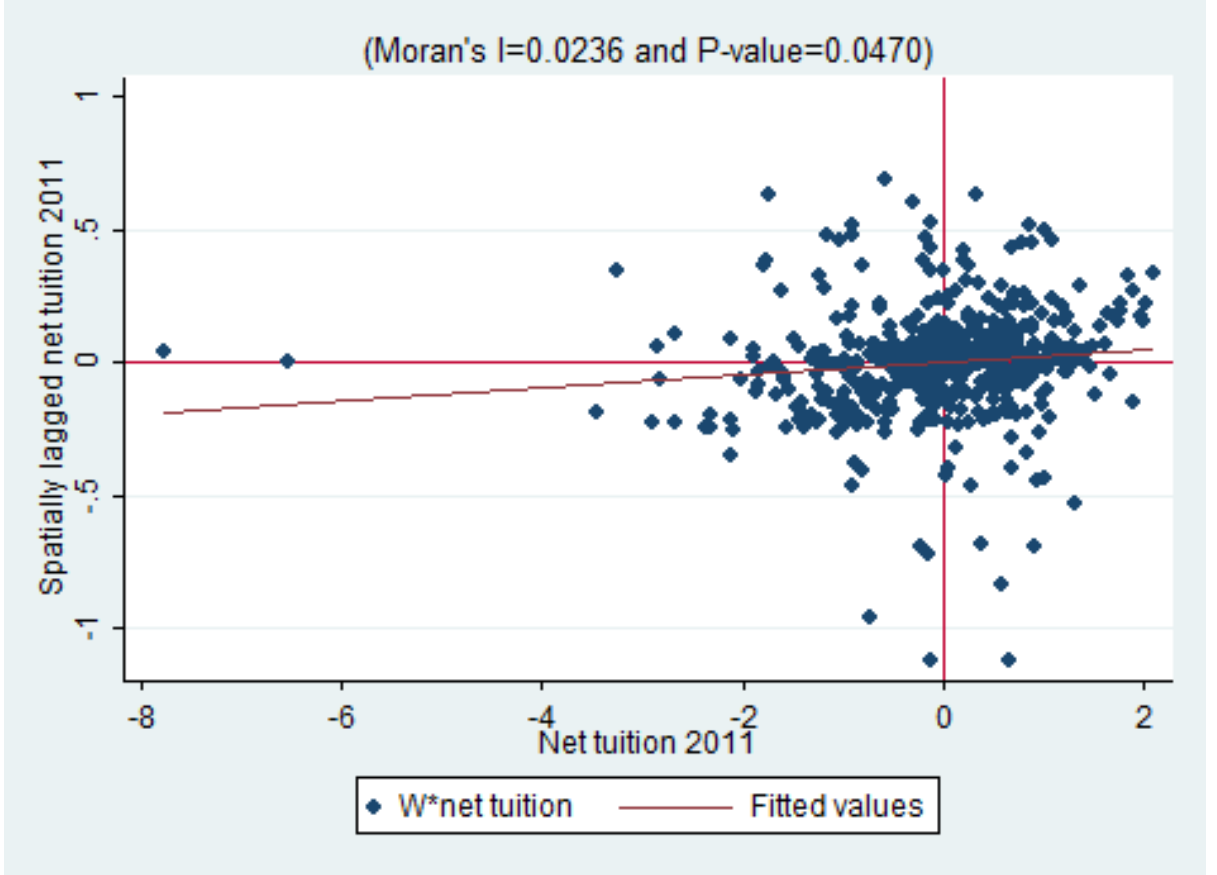

(h) 2011 


\section{C.2 Spatial Regression without Potentially Endoge- nous Variables: Geographical Market}

In this section, a spatial regression model for price competition in the geographical market is estimated with three potentially endogenous variables excluded: proportion of students receiving aid (PRAID), research spending (RESEARCH), and teaching expenditure $(T E A C H)$.

Table C.1: Spatial regression of the geographical market without potentially endogenous variables

\begin{tabular}{lcccc}
\hline \hline & \multicolumn{2}{c}{ Published Tuition } & \multicolumn{2}{c}{ Net Tuition } \\
& $(1)$ & $(2)$ & $(3)$ & $(4)$ \\
& Main & Spatial Lag & Main & Spatial Lag \\
\hline USTD & $-0.0084^{* * *}$ & 0.0062 & $-0.0098^{* *}$ & $0.0197^{*}$ \\
& $(0.0027)$ & $(0.0078)$ & $(0.0041)$ & $(0.0110)$ \\
GSTD & -0.0018 & -0.0019 & -0.0055 & -0.0015 \\
& $(0.0047)$ & $(0.0112)$ & $(0.0072)$ & $(0.0160)$ \\
ENDOW & -0.001 & -0.0012 & 0 & -0.0024 \\
& $(0.0044)$ & $(0.0147)$ & $(0.0068)$ & $(0.0192)$ \\
FACULTY & $0.1005^{* *}$ & 0.1605 & $0.1743^{* * *}$ & 0.2583 \\
& $(0.0453)$ & $(0.1472)$ & $(0.0615)$ & $(0.2187)$ \\
SATACT & $-0.004^{*}$ & $0.0253^{* * *}$ & $-0.0079^{* *}$ & $0.0348^{* * *}$ \\
& $(0.0021)$ & $(0.0089)$ & $(0.0039)$ & $(0.0132)$ \\
ADMRATE & -0.0216 & 0.1078 & -0.057 & 0.123 \\
& $(0.0297)$ & $(0.0992)$ & $(0.0466)$ & $(0.1479)$ \\
POPDEN & $0.0007^{* * *}$ & -0.0008 & $0.0033^{* * *}$ & -0.0016 \\
& $(0.0002)$ & $(0.0012)$ & $(0.0009)$ & $(0.0022)$ \\
MEDINC & -0.0042 & 0.0073 & -0.0052 & 0.0079 \\
& $(0.0043)$ & $(0.0053)$ & $(0.0061)$ & $(0.0079)$ \\
$\rho$ & \multicolumn{2}{c}{$0.5539^{* * *}$} & \multicolumn{2}{c}{$0.3785^{* * *}$} \\
& \multicolumn{2}{c}{$(0.0481)$} & \multicolumn{2}{c}{ SDM } \\
\hline Est. method & \multicolumn{2}{c}{ SDM } & \multicolumn{2}{c}{ SD } \\
\hline \hline
\end{tabular}

Standard errors are clustered by universities and shown in parentheses

${ }^{*} p<0.10,{ }^{* *} p<0.05,{ }^{* * *} p<0.01$ 
Table C.2: Marginal effects for published tuition of in the geographical market without potentially endogenous variables

\begin{tabular}{lccc}
\hline \hline & & Net Tuition & $(2)$ \\
& Direct Effects & Indirect Effects & $(3)$ \\
& $-0.0084^{* * *}$ & 0.0009 & -0.0076 \\
USTD & $(0.0023)$ & $(0.0169)$ & $(0.0178)$ \\
& -0.0016 & -0.0039 & -0.0054 \\
GSTD & $(0.0056)$ & $(0.0302)$ & $(0.0337)$ \\
& -0.001 & -0.0116 & -0.0127 \\
ENDOW & $(0.0048)$ & $(0.0322)$ & $(0.0327)$ \\
& $0.1195^{* * *}$ & 0.4502 & 0.5697 \\
FACULTY & $(0.0436)$ & $(0.3366)$ & $(0.3519)$ \\
& -0.0029 & $0.0529^{* * *}$ & $0.0501^{* *}$ \\
SATACT & $(0.0021)$ & $(0.0200)$ & $(0.0206)$ \\
& -0.0189 & 0.22 & 0.2011 \\
ADMRATE & $(0.0285)$ & $(0.2030)$ & $(0.2082)$ \\
& $0.0007^{* * *}$ & -0.001 & -0.0003 \\
POPDEN & $(0.0002)$ & $(0.0024)$ & $(0.0024)$ \\
& -0.0039 & 0.0125 & 0.0086 \\
MEDINC & $(0.0039)$ & $(0.0083)$ & $(0.0070)$ \\
&
\end{tabular}

Standard errors are clustered by universities and shown in parentheses.

${ }^{*} p<0.1,{ }^{* *} p<0.05,{ }^{* * *} p<0.01$ 
Table C.3: Marginal effects for net tuition of in the geographical market without potentially endogenous variables

\begin{tabular}{lccc}
\hline \hline & & Net Tuition & $(2)$ \\
& Direct Effects & Indirect Effects & Total Effects \\
\hline USTD & $-0.0094^{* * *}$ & 0.0232 & 0.0137 \\
GSTD & $(0.0036)$ & $(0.0169)$ & $(0.0179)$ \\
& -0.005 & -0.004 & -0.009 \\
ENDOW & $(0.0082)$ & $(0.0288)$ & $(0.0330)$ \\
& 0.0002 & -0.0103 & -0.0101 \\
FACULTY & $(0.0072)$ & $(0.0296)$ & $(0.0288)$ \\
& $0.1945^{* * *}$ & 0.4814 & $0.6758^{*}$ \\
SATACT & $(0.0579)$ & $(0.3474)$ & $(0.3584)$ \\
& $-0.0071^{*}$ & $0.0525^{* *}$ & $0.0454^{* *}$ \\
ADMRATE & $(0.0038)$ & $(0.0220)$ & $(0.0230)$ \\
& -0.0577 & 0.1799 & 0.1222 \\
POPDEN & $(0.0437)$ & $(0.2251)$ & $(0.2279)$ \\
& $0.0033^{* * *}$ & -0.0006 & 0.0027 \\
MEDINC & $(0.0009)$ & $(0.0031)$ & $(0.0031)$ \\
& -0.0049 & 0.011 & 0.006 \\
& $(0.0055)$ & $(0.0102)$ & $(0.0083)$ \\
\hline \hline
\end{tabular}

Standard errors are clustered by universities and shown in parentheses.

${ }^{*} p<0.1,{ }^{* *} p<0.05,{ }^{* * *} p<0.01$ 


\section{C.3 Time Fixed Effects: Geographical Market}

Table C.4: Price competition in the geographical market with spatial and time effects

\begin{tabular}{|c|c|c|c|c|}
\hline & \multicolumn{2}{|c|}{ Published Tuition } & \multicolumn{2}{|c|}{ Net Tuition } \\
\hline & $(1)$ & $(2)$ & $(3)$ & $(4)$ \\
\hline & Main & Spatial Lag & Main & Spatial Lag \\
\hline \multirow[t]{2}{*}{ USTD } & $-0.0061^{* * *}$ & -0.0044 & 0.0000 & -0.0325 \\
\hline & $(0.0024)$ & $(0.0070)$ & $(0.0040)$ & $(0.0159)$ \\
\hline \multirow[t]{2}{*}{ GSTD } & -0.0020 & $0.0053^{*}$ & $-0.0187^{* *}$ & 0.0136 \\
\hline & $(0.0033)$ & $(0.0028)$ & $(0.0073)$ & $(0.0183)$ \\
\hline \multirow[t]{2}{*}{ ENDOW } & $-0.0081^{*}$ & 0.0011 & 0.0023 & -0.0061 \\
\hline & $(0.0048)$ & $(0.0034)$ & $(0.0064)$ & $(0.0142)$ \\
\hline \multirow[t]{2}{*}{ PRAID } & -0.0439 & -0.0251 & -0.0386 & -0.2821 \\
\hline & $(0.0351)$ & $(0.0543)$ & $(0.0676)$ & $(0.2692)$ \\
\hline \multirow[t]{2}{*}{ FACULTY } & $0.0697^{*}$ & 0.0717 & 0.0546 & 0.3859 \\
\hline & $(0.0424)$ & $(0.0685)$ & $(0.0757)$ & $(0.2786)$ \\
\hline \multirow[t]{2}{*}{ RESEARCH } & $0.0073^{*}$ & 0.0122 & $0.0152^{* *}$ & -0.0099 \\
\hline & $(0.0042)$ & $(0.0078)$ & $(0.0065)$ & $(0.0150)$ \\
\hline \multirow[t]{2}{*}{ TEACH } & $0.0411^{* *}$ & -0.0360 & $0.1253^{* * *}$ & -0.1842 \\
\hline & $(0.0191)$ & $(0.0370)$ & $(0.0460)$ & $(0.1863)$ \\
\hline \multirow[t]{2}{*}{ SATACT } & -0.0013 & 0.0026 & -0.0005 & -0.0045 \\
\hline & $(0.0011)$ & $(0.0017)$ & $(0.0027)$ & $(0.0061)$ \\
\hline \multirow[t]{2}{*}{ ADMRATE } & -0.0194 & $-0.0440^{*}$ & -0.0375 & 0.1387 \\
\hline & $(0.0228)$ & $(0.0383)$ & $(0.0381)$ & $(0.1184)$ \\
\hline \multirow[t]{2}{*}{ POPDEN } & -0.0005 & -0.0063 & 0.0120 & -0.0220 \\
\hline & $(0.0108)$ & $(0.0050)$ & $(0.0351)$ & $(0.0186)$ \\
\hline \multirow[t]{2}{*}{ MEDINC } & 0.0087 & 0.0048 & -0.1018 & 0.1260 \\
\hline & $(0.0494)$ & $(0.0579)$ & $(0.0914)$ & $(0.1747)$ \\
\hline \multirow[t]{2}{*}{$\rho$} & \multicolumn{2}{|c|}{$0.3066^{* * *}$} & \multicolumn{2}{|c|}{$0.2764^{* * *}$} \\
\hline & \multicolumn{2}{|c|}{$(0.0021)$} & \multicolumn{2}{|c|}{$(0.0046)$} \\
\hline Year dummies & \multicolumn{2}{|c|}{ Yes } & \multicolumn{2}{|c|}{ Yes } \\
\hline
\end{tabular}

Standard errors are clustered by universities and shown in parentheses.

${ }^{*} p<0.1,{ }^{* *} p<0.05,{ }^{* * *} p<0.01$ 
Table C.5: Marginal effects for published tuition in the geographical market with time effects

\begin{tabular}{lccc}
\hline \hline & \multicolumn{3}{c}{ Published Tuition } \\
& $(1)$ & $(2)$ & $(3)$ \\
& Direct Effects & Indirect Effects & Total Effects \\
\hline USTD & $-0.0062^{* * *}$ & -0.0101 & -0.0163 \\
GSTD & $(0.0020)$ & $(0.0122)$ & $(0.0124)$ \\
& -0.0017 & -0.0088 & 0.0070 \\
ENDOW & $(0.0037)$ & $(0.0063)$ & $(0.0091)$ \\
& -0.0078 & -0.0032 & -0.0111 \\
PRAID & $(0.0052)$ & $(0.0076)$ & $(0.0112)$ \\
& -0.0439 & -0.0573 & -0.1012 \\
FACULTY & $(0.0344)$ & $(0.1009)$ & $(0.1144)$ \\
& $0.0789^{*}$ & 0.1916 & 0.2705 \\
RESEARCH & $(0.0405)$ & $(0.1541)$ & $(0.1731)$ \\
& $0.0082^{*}$ & $0.0299^{*}$ & $0.0381^{* *}$ \\
TEACH & $(0.0042)$ & $(0.0164)$ & $(0.0174)$ \\
& $0.0394^{*}$ & -0.0522 & -0.0128 \\
SATACT & $(0.0213)$ & $(0.0675)$ & $(0.0733)$ \\
& -0.0014 & 0.0039 & -0.0025 \\
ADMRATE & $(0.0011)$ & $(0.0034)$ & $(0.0037)$ \\
& -0.0219 & -0.1005 & -0.1223 \\
POPDEN & $(0.0220)$ & $(0.0741)$ & $(0.0822)$ \\
& -0.0008 & $-0.0127^{* *}$ & -0.0135 \\
MEDINC & $(0.0106)$ & $(0.0057)$ & $(0.0107)$ \\
& 0.0134 & -0.0014 & 0.0121 \\
& $(0.0520)$ & $(0.1010)$ & $(0.1060)$ \\
\hline \hline
\end{tabular}

Standard errors are clustered by universities and shown in parentheses.

${ }^{*} p<0.1,{ }^{* *} p<0.05,{ }^{* * *} p<0.01$ 
Table C.6: Marginal effects for net tuition in the geographical market with time effects

\begin{tabular}{lccc}
\hline \hline & $(1)$ & $\begin{array}{c}\text { Net Tuition } \\
(2)\end{array}$ & $(3)$ \\
& Direct Effects & Indirect Effects & Total Effects \\
\hline USTD & 0.001 & -0.0248 & -0.0238 \\
& $(0.0036)$ & $(0.0335)$ & $(0.0340)$ \\
GSTD & $-0.0187^{* *}$ & -0.0152 & -0.0339 \\
& $(0.0091)$ & $(0.0336)$ & $(0.0346)$ \\
ENDOW & 0.0043 & 0.0028 & 0.0071 \\
& $(0.0071)$ & $(0.0337)$ & $(0.0347)$ \\
PRAID & -0.0298 & 0.1469 & 0.1171 \\
& $(0.0651)$ & $(0.5136)$ & $(0.5266)$ \\
FACULTY & 0.0793 & 0.2765 & 0.3558 \\
& $(0.0728)$ & $(0.6301)$ & $(0.6548)$ \\
RESEARCH & $0.0160^{* *}$ & -0.0015 & 0.0145 \\
& $(0.0065)$ & $(0.0384)$ & $(0.0393)$ \\
TEACH & $0.1396^{* * *}$ & $0.5276^{* * *}$ & $0.6672^{* * *}$ \\
& $(0.0509)$ & $(0.1760)$ & $(0.1794)$ \\
SATACT & -0.0007 & -0.011 & -0.0117 \\
& $(0.0024)$ & $(0.0120)$ & $(0.0117)$ \\
ADMRATE & -0.0529 & 0.0004 & -0.0525 \\
& $(0.0353)$ & $(0.3251)$ & $(0.3322)$ \\
POPDEN & 0.0015 & 0 & 0.0015 \\
& $(0.0012)$ & $(0.0026)$ & $(0.0017)$ \\
MEDINC & $-0.0087^{*}$ & 0.0064 & -0.0024 \\
& $(0.0052)$ & $(0.0097)$ & $(0.0070)$ \\
\hline \hline
\end{tabular}

Standard errors are clustered by universities and shown in parentheses.

${ }^{*} p<0.1,{ }^{* *} p<0.05,{ }^{* * *} p<0.01$ 


\section{Appendix D}

\section{D.1 Moran Scatterplots: Product Market}

Figure D.1: Moran scatterplots for published tuition in the product market

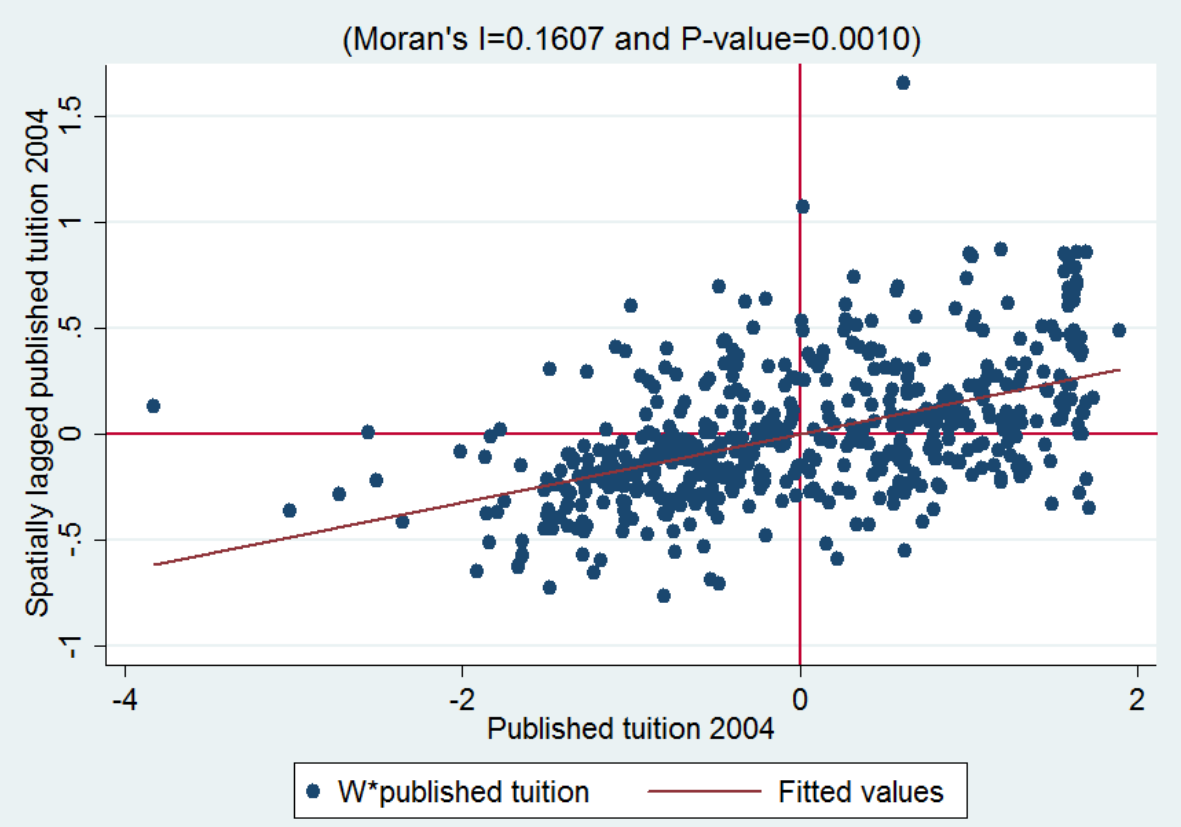

(a) 2004 
Figure D.1: (continued) Moran scatterplots for published tuition in the product market

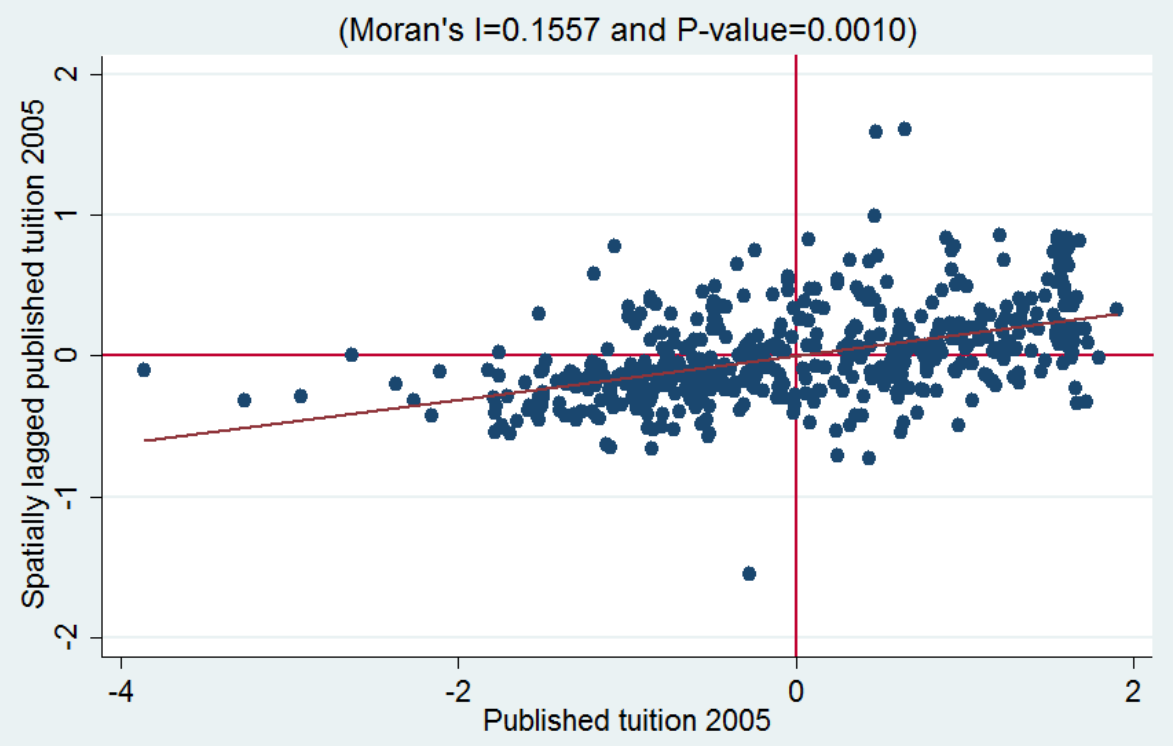

- $\mathrm{W}^{\star}$ published tuition $\longrightarrow$ Fitted values

(b) 2005

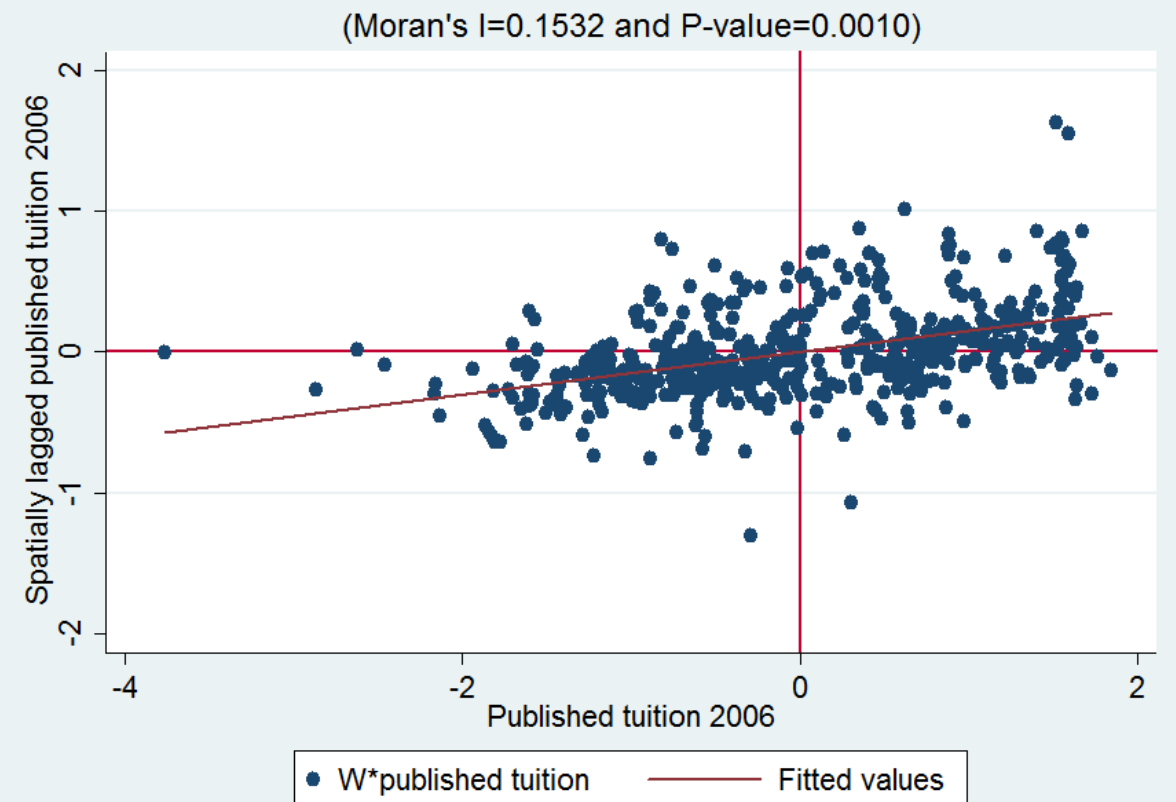

(c) 2006 
Figure D.1: (continued) Moran scatterplots for published tuition in the product market

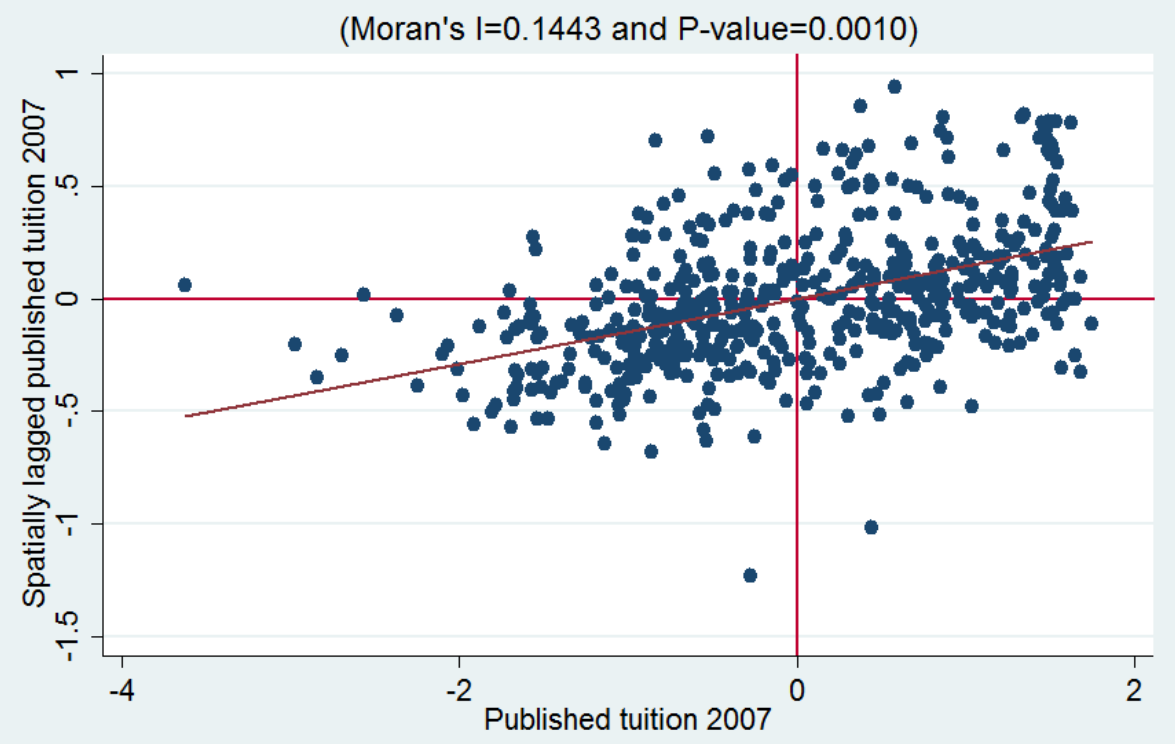

- $\mathrm{W}^{\star}$ published tuition $\longrightarrow$ Fitted values

(d) 2007

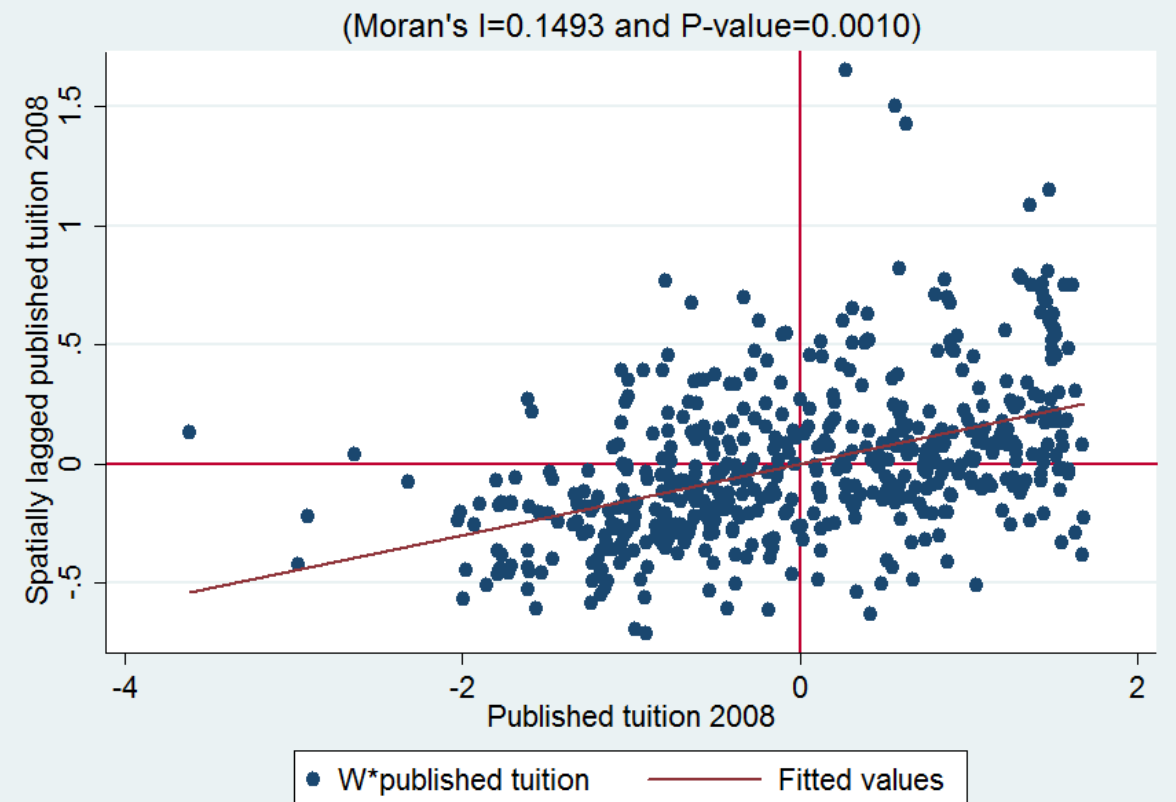

(e) 2008 
Figure D.1: (continued) Moran scatterplots for published tuition in the product market

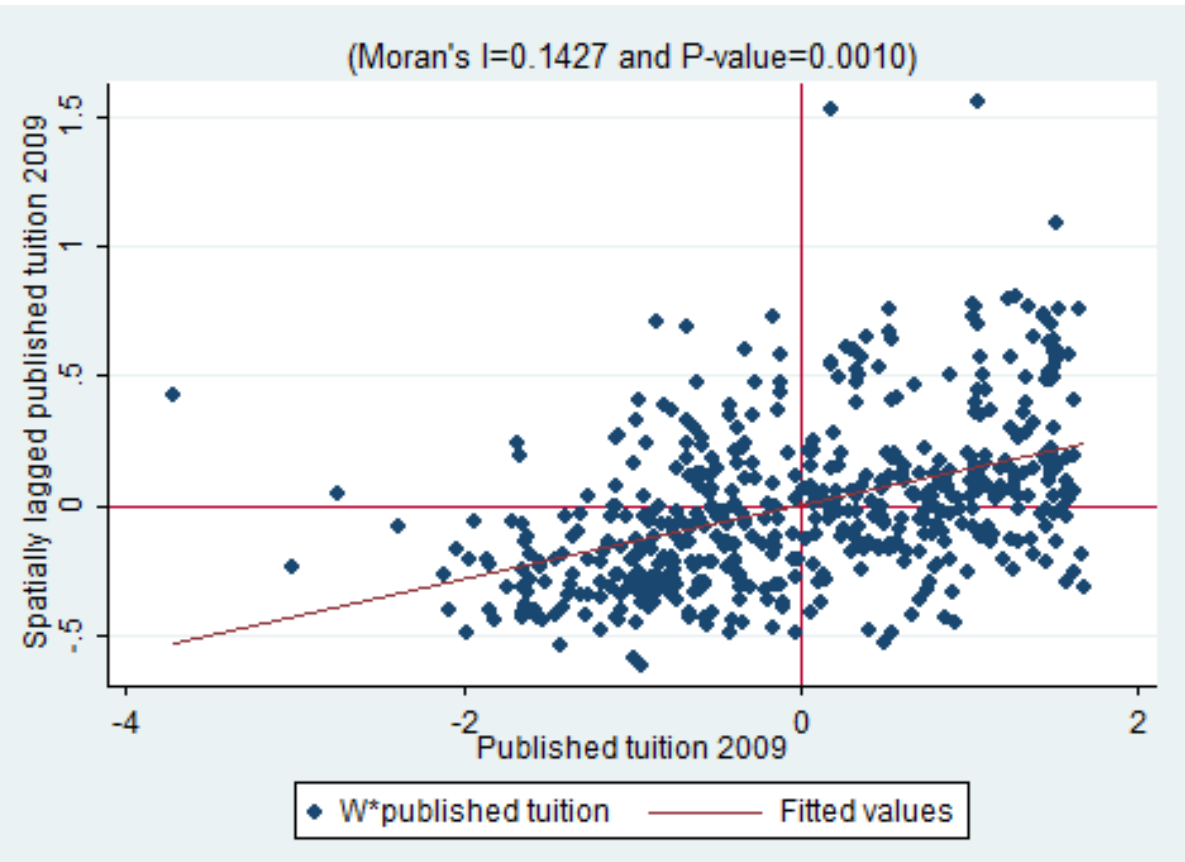

(f) 2009

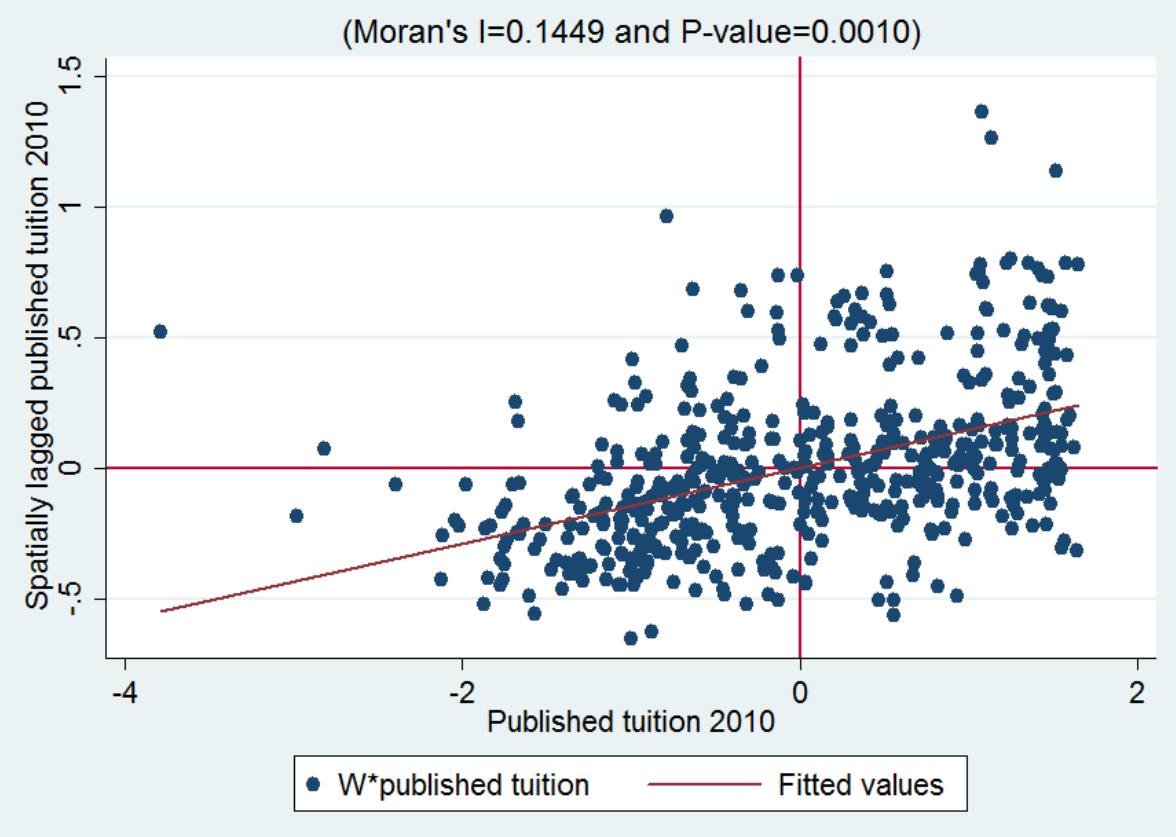

(g) 2010 
Figure D.1: (continued)Moran scatterplots for published tuition in the product market

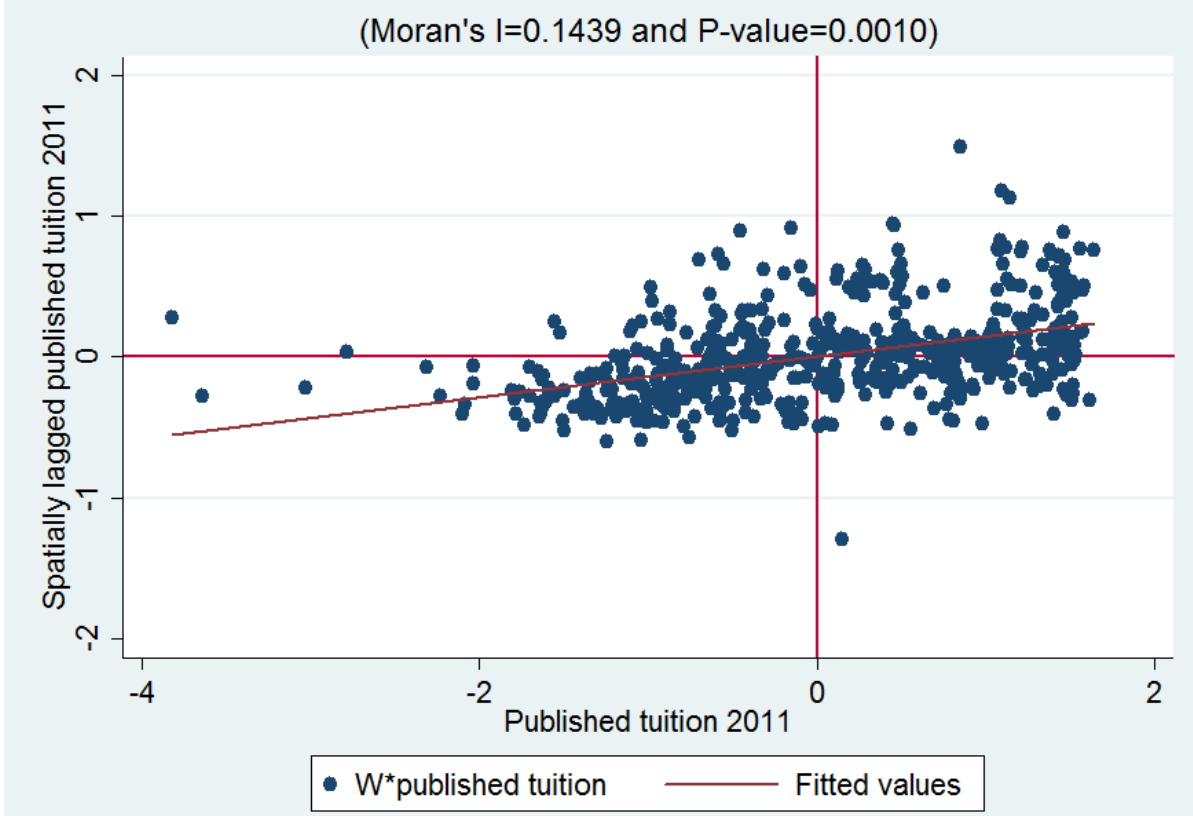

(h) 2011 
Figure D.2: Moran scatterplots for net tuition in the product market

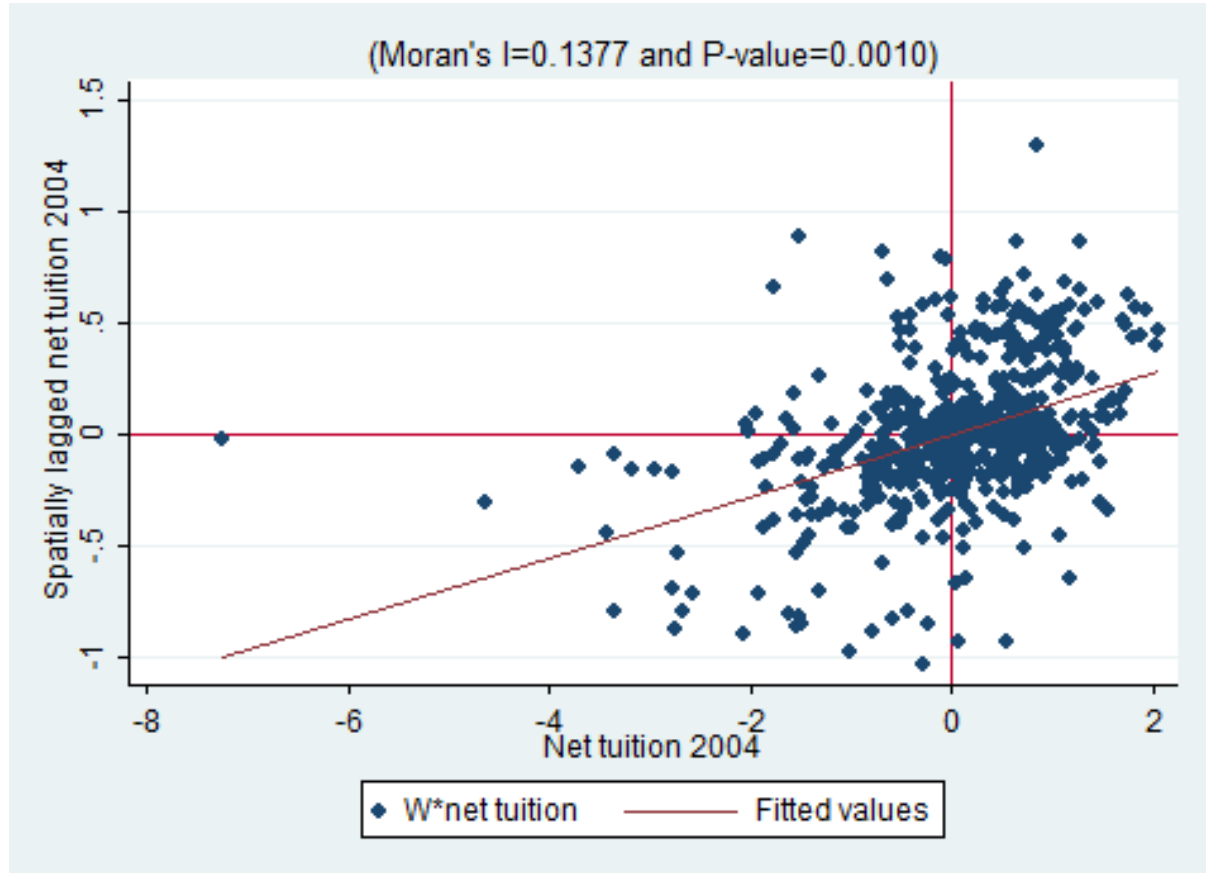

(a) 2004

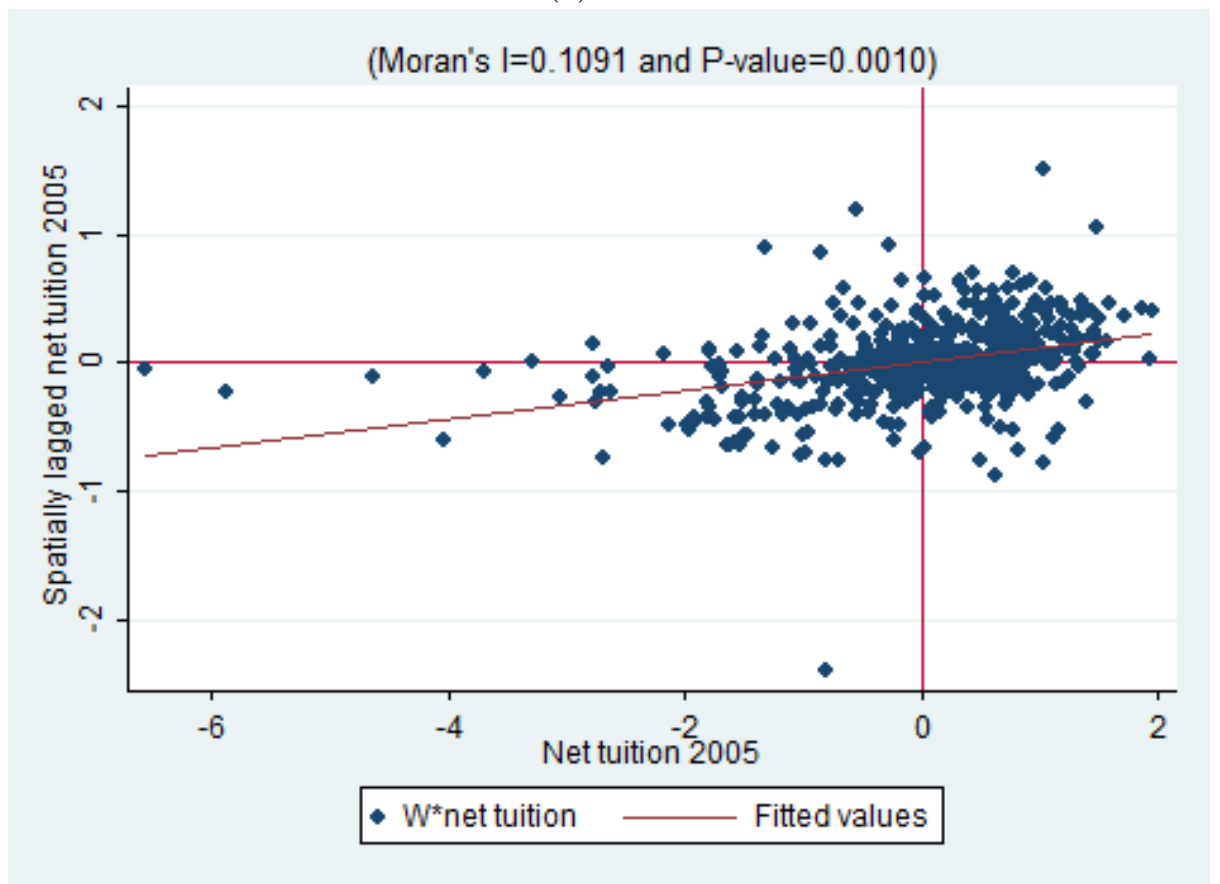

(b) 2005 
Figure D.2: (continued) Moran scatterplots for net tuition in the product market

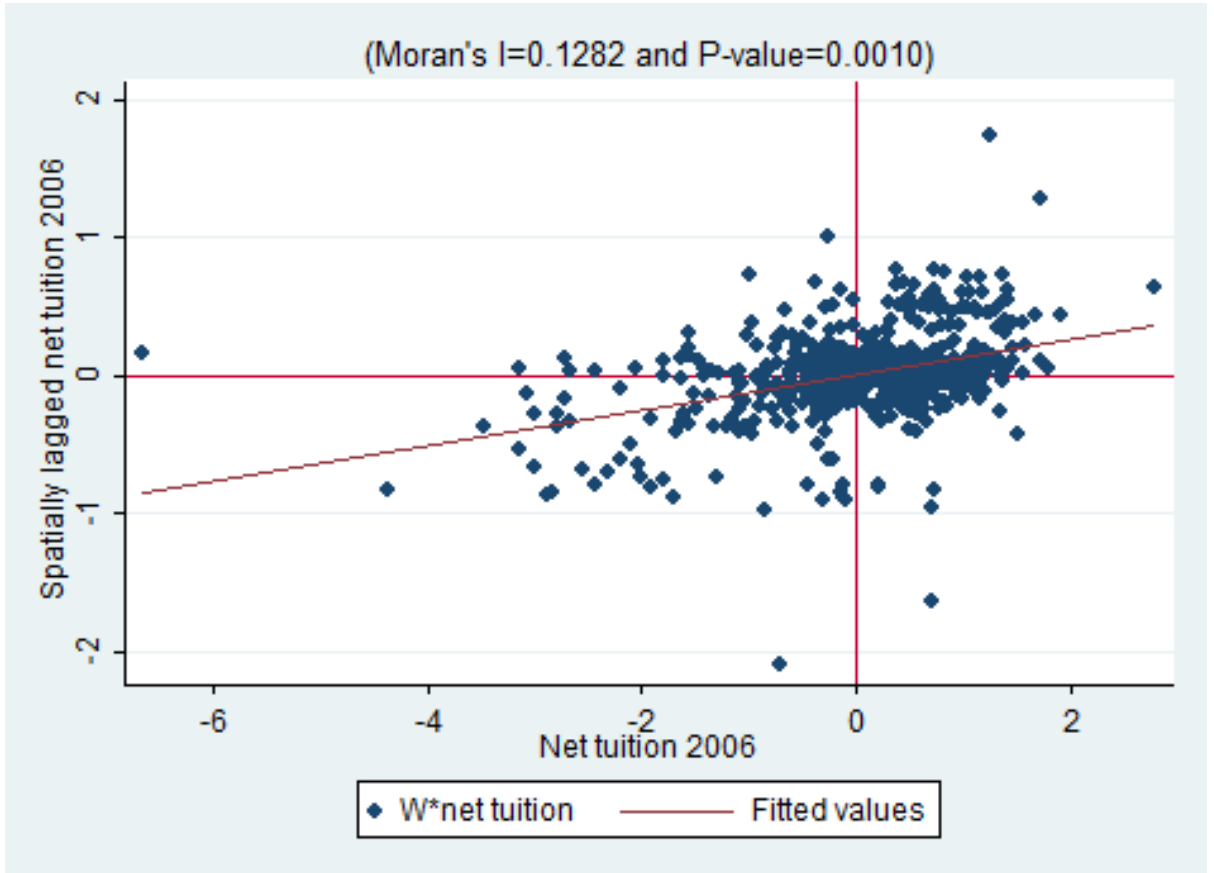

(c) 2006

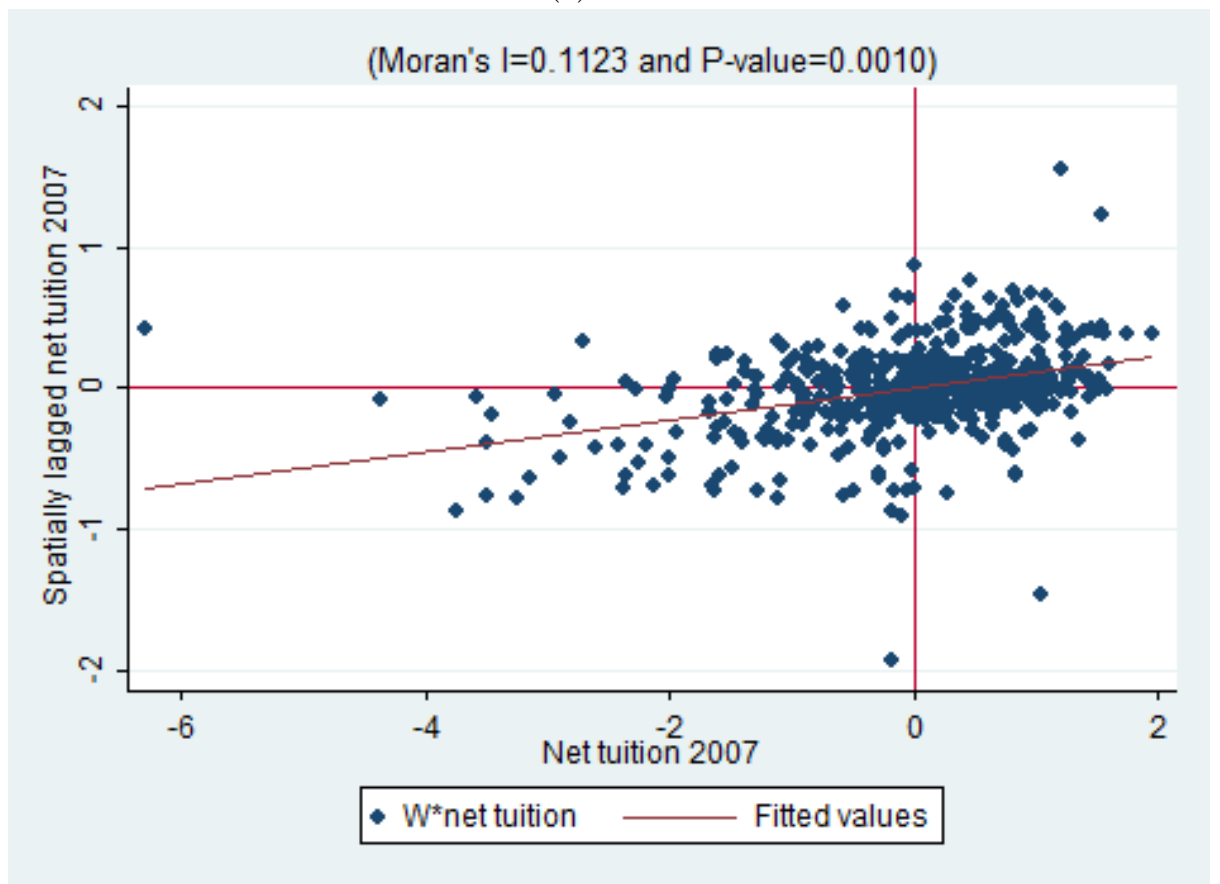

(d) 2007 
Figure D.2: (continued) Moran scatterplots for net tuition in the product market

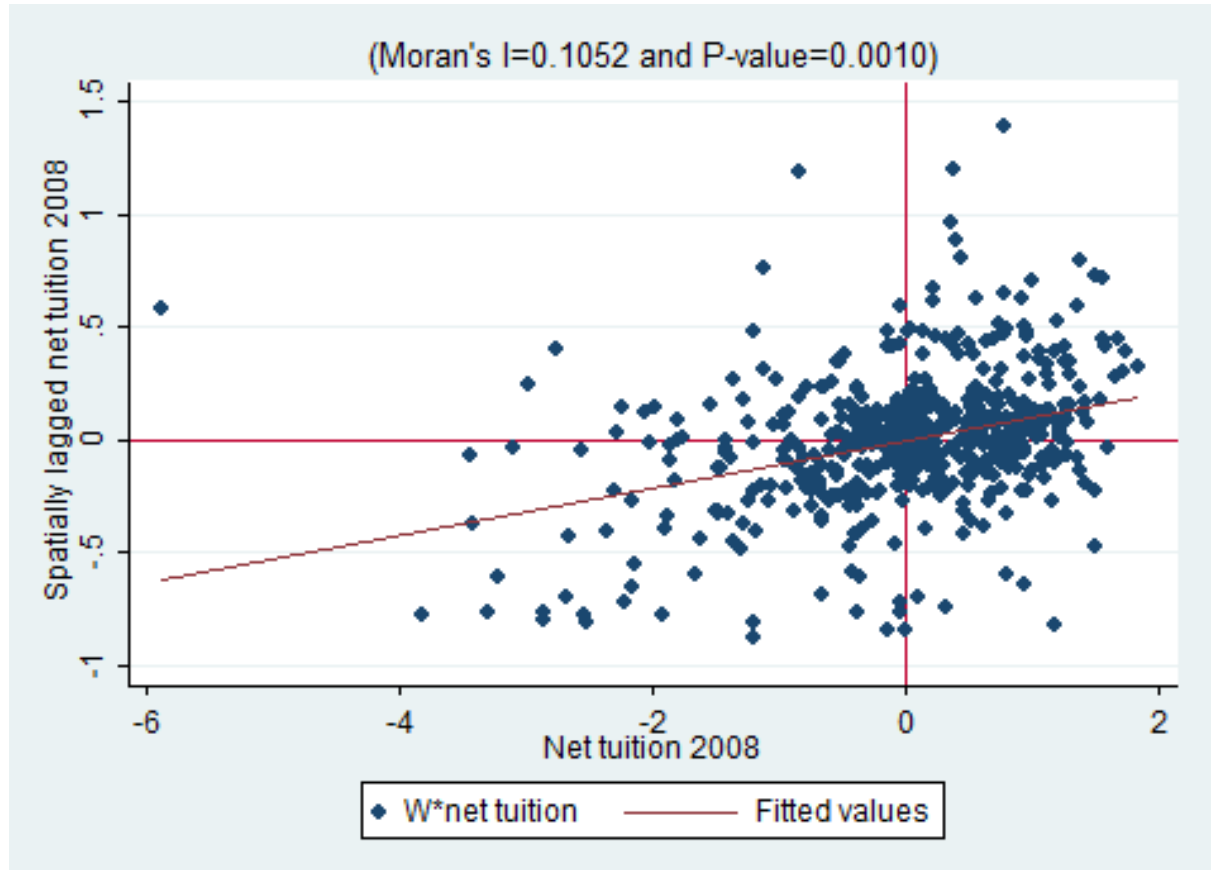

(e) 2008

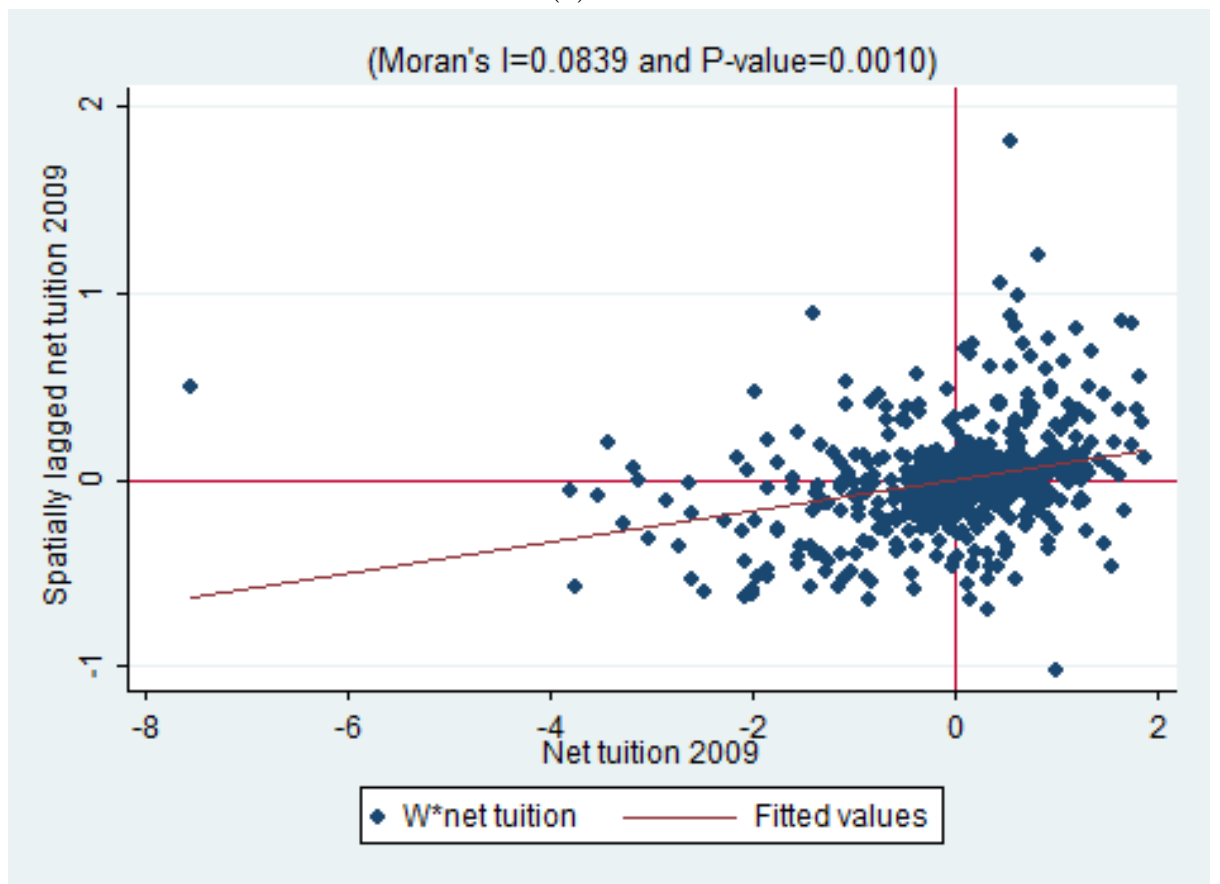

(f) 2009 
Figure D.2: (continued) Moran scatterplots for net tuition in the product market

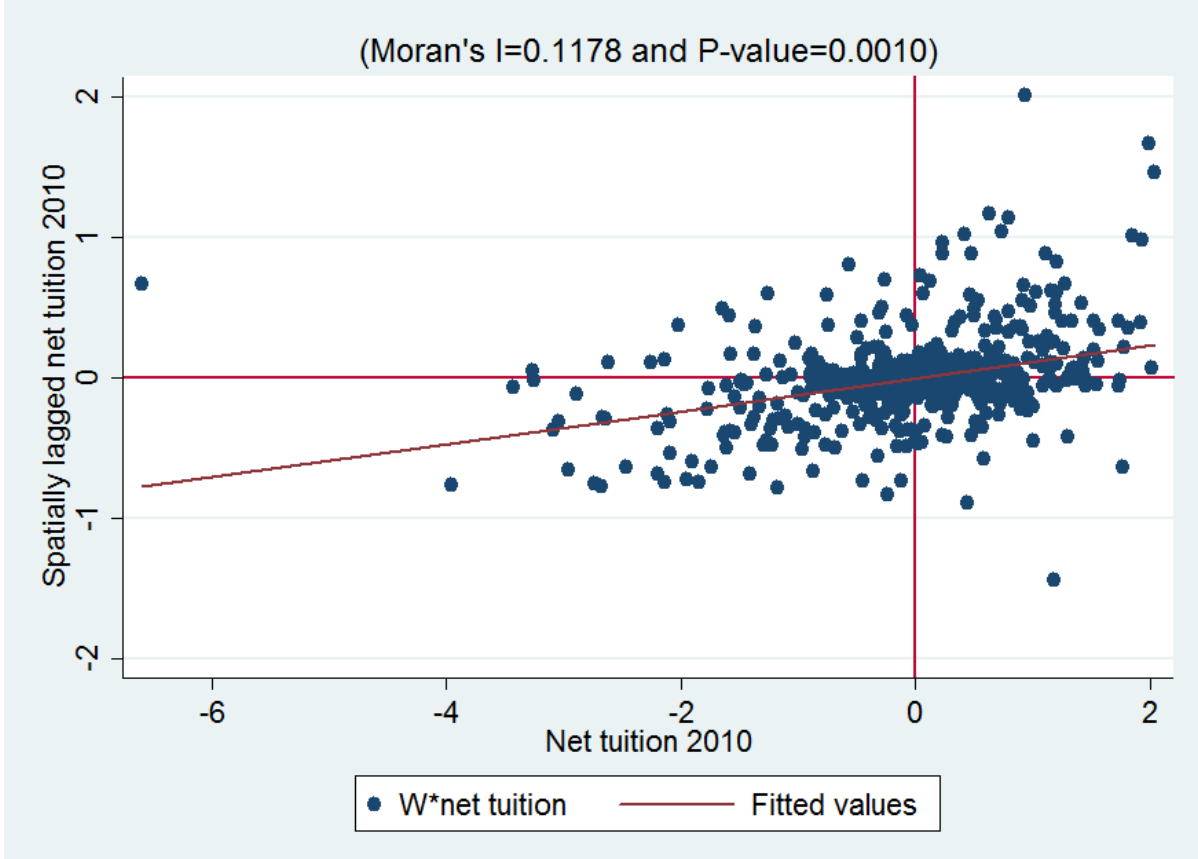

(g) 2010

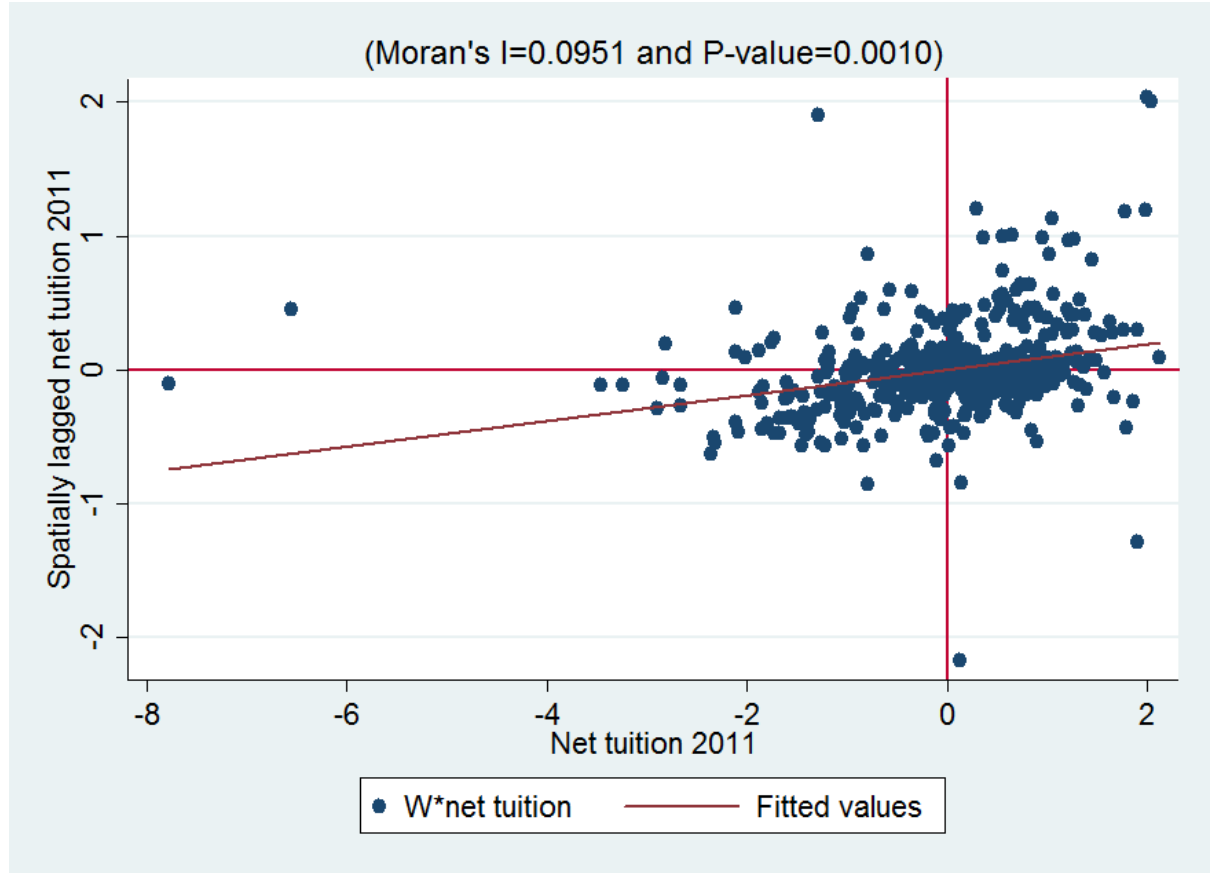

(h) 2011 


\section{D.2 Spatial Regression without Potentially Endoge- nous Variables: Product Market}

In this section, a spatial regression model for price competition in the product market is estimated with three potentially endogenous variables excluded: proportion of students receiving aid (PRAID), research spending (RESEARCH), and teaching expenditure $(T E A C H)$.

Table D.1: Spatial regression of the product market without potentially endogenous variables

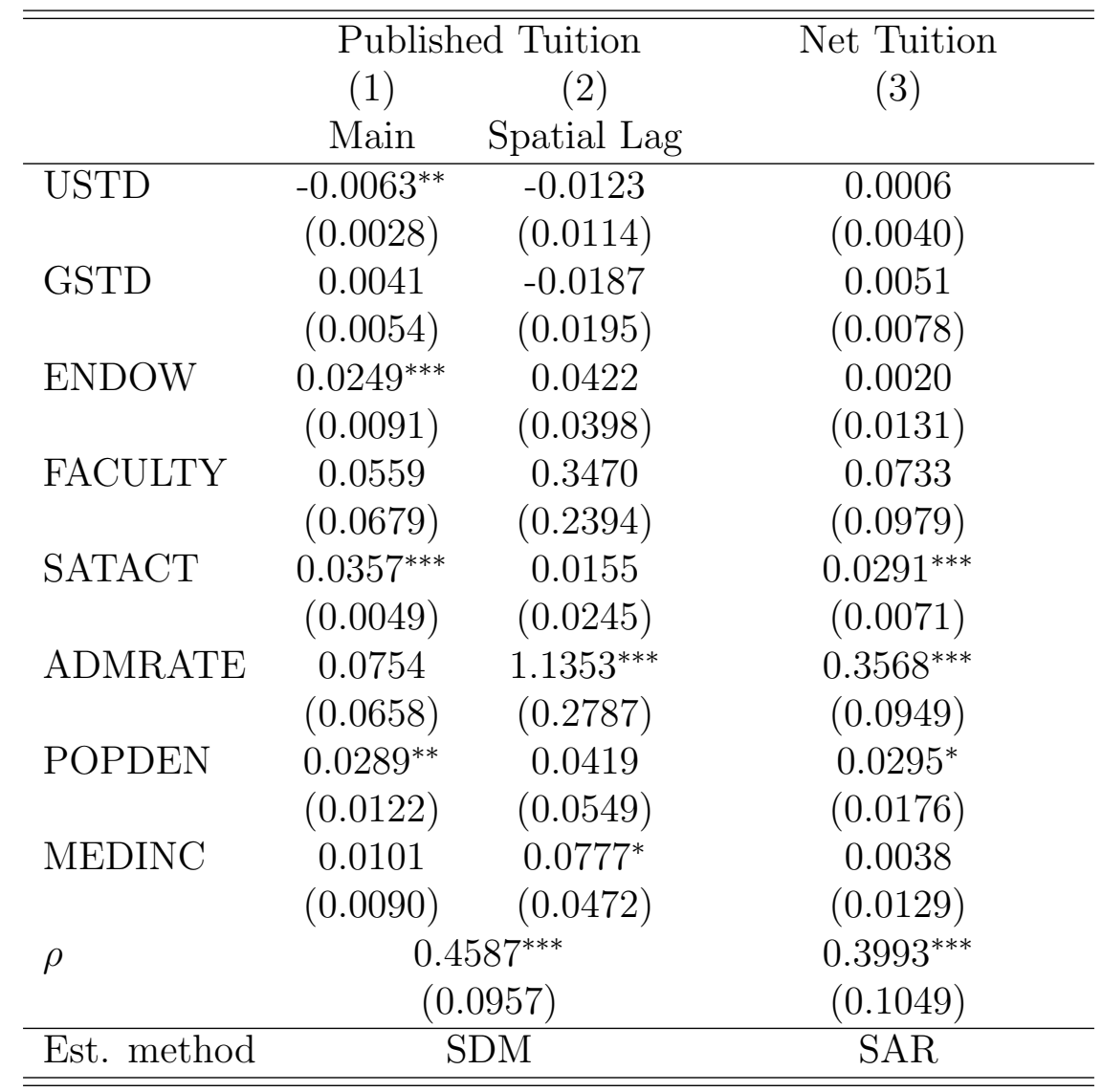

Standard errors are clustered by universities and shown in parentheses.

${ }^{*} p<0.10,{ }^{* *} p<0.05,{ }^{* * *} p<0.01$ 
Table D.2: Marginal effects for published tuition of in the product market without potentially endogenous variables

\begin{tabular}{lccc}
\hline \hline & \multicolumn{3}{c}{ Published Tuition } \\
& $(1)$ & $(2)$ & $(3)$ \\
& Direct Effects & Indirect Effects & Total Effects \\
\hline USTD & $-0.0067^{* *}$ & -0.0276 & -0.0343 \\
& $(0.0031)$ & $(0.0216)$ & $(0.0223)$ \\
GSTD & 0.0036 & -0.0306 & -0.0271 \\
& $(0.0056)$ & $(0.0403)$ & $(0.0410)$ \\
ENDOW & $0.0265^{* * *}$ & 0.0975 & 0.1240 \\
& $(0.0096)$ & $(0.0775)$ & $(0.0781)$ \\
FACULTY & 0.0669 & 0.6775 & $0.7444^{*}$ \\
& $(0.0673)$ & $(0.4303)$ & $(0.4498)$ \\
SATACT & $0.0366^{* * *}$ & 0.0580 & $0.0946^{*}$ \\
& $(0.0059)$ & $(0.0482)$ & $(0.0496)$ \\
ADMRATE & 0.1099 & $2.1266^{* * *}$ & $2.2365^{* * *}$ \\
& $(0.0708)$ & $(0.5184)$ & $(0.5202)$ \\
PDEN & $0.0306^{* *}$ & 0.1003 & 0.1309 \\
& $(0.0119)$ & $(0.1209)$ & $(0.1226)$ \\
MEDINC & 0.0126 & 0.1497 & 0.1623 \\
& $(0.0097)$ & $(0.0989)$ & $(0.1001)$ \\
\hline \hline
\end{tabular}

Standard errors are clustered by universities and shown in parentheses.

${ }^{*} p<0.1,{ }^{* *} p<0.05,{ }^{* * *} p<0.01$ 
Table D.3: Marginal effects for net tuition of in the product market without potentially endogenous variables

\begin{tabular}{lccc}
\hline \hline & & Net Tuition & $(2)$ \\
& $(1)$ & $(3)$ \\
& Direct Effects & Indirect Effects & Total Effects \\
\hline USTD & 0.0004 & -0.0150 & -0.0146 \\
& $(0.0041)$ & $(0.0277)$ & $(0.0289)$ \\
GSTD & 0.0046 & -0.0304 & -0.0258 \\
& $(0.0070)$ & $(0.0491)$ & $(0.0512)$ \\
ENDOW & 0.0034 & 0.0944 & 0.0978 \\
& $(0.0124)$ & $(0.1049)$ & $(0.1044)$ \\
FACULTY & 0.0795 & 0.4155 & 0.4950 \\
& $(0.0972)$ & $(0.5451)$ & $(0.5890)$ \\
SATACT & $0.0310^{* * *}$ & $0.1283^{* *}$ & $0.1593^{* *}$ \\
& $(0.0070)$ & $(0.0652)$ & $(0.0672)$ \\
ADMRATE & $0.3942^{* * *}$ & $2.5211^{* * *}$ & $2.9154^{* * *}$ \\
& $(0.0926)$ & $(0.6491)$ & $(0.6716)$ \\
PDEN & $0.0314^{*}$ & 0.1258 & 0.1571 \\
& $(0.0187)$ & $(0.1341)$ & $(0.1355)$ \\
MEDINC & 0.0069 & $0.2039^{*}$ & $0.2107^{*}$ \\
& $(0.0130)$ & $(0.1193)$ & $(0.1221)$ \\
\hline \hline
\end{tabular}

Standard errors are clustered by universities and shown in parentheses.

${ }^{*} p<0.1,{ }^{* *} p<0.05,{ }^{* * *} p<0.01$ 


\section{D.3 Time Fixed Effects: Product Market}

Table D.4: Price competition in the product market with spatial and time effects

\begin{tabular}{|c|c|c|c|}
\hline & \multicolumn{2}{|c|}{ Published Tuition } & \multirow{3}{*}{$\begin{array}{c}\text { Net Tuition } \\
\text { (3) }\end{array}$} \\
\hline & $(1)$ & $(2)$ & \\
\hline & Main & Spatial Lag & \\
\hline \multirow[t]{2}{*}{ USTD } & $-0.0049^{*}$ & -0.0008 & -0.0004 \\
\hline & $(0.0026)$ & $(0.0121)$ & $(0.0037)$ \\
\hline \multirow[t]{2}{*}{ GSTD } & 0.0027 & -0.0119 & 0.0052 \\
\hline & $(0.0050)$ & $(0.0194)$ & $(0.0070)$ \\
\hline \multirow[t]{2}{*}{ ENDOW } & 0.0051 & -0.0026 & -0.0125 \\
\hline & $(0.0068)$ & $(0.0291)$ & $(0.0095)$ \\
\hline \multirow[t]{2}{*}{ PRAID } & -0.0559 & -0.3149 & 0.0795 \\
\hline & $(0.0757)$ & $(0.3192)$ & $(0.1051)$ \\
\hline \multirow[t]{2}{*}{ FACULTY } & 0.0019 & 0.3404 & 0.0429 \\
\hline & $(0.0662)$ & $(0.2462)$ & $(0.0892)$ \\
\hline \multirow[t]{2}{*}{ RESEARCH } & 0.0035 & -0.0357 & -0.0145 \\
\hline & $(0.0065)$ & $(0.0373)$ & $(0.0091)$ \\
\hline \multirow[t]{2}{*}{ TEACH } & $0.0494^{* *}$ & 0.0105 & 0.0502 \\
\hline & $(0.0229)$ & $(0.1239)$ & $(0.0325)$ \\
\hline \multirow[t]{2}{*}{ SATACT } & $0.0333^{* * *}$ & -0.0180 & $0.0253^{* * *}$ \\
\hline & $(0.0046)$ & $(0.0233)$ & $(0.0065)$ \\
\hline \multirow[t]{2}{*}{ ADMRATE } & 0.0247 & $0.7308^{* *}$ & $0.2580^{* * *}$ \\
\hline & $(0.0644)$ & $(0.2917)$ & $(0.0882)$ \\
\hline \multirow[t]{2}{*}{ POPDEN } & -0.0005 & 0.0000 & -0.0001 \\
\hline & $(0.0012)$ & $(0.0049)$ & $(0.0016)$ \\
\hline \multirow[t]{2}{*}{ MEDINC } & $0.1373^{* * *}$ & $0.4710^{* *}$ & $0.1657^{* *}$ \\
\hline & $(0.0459)$ & $(0.2364)$ & $(0.0649)$ \\
\hline \multirow[t]{2}{*}{$\rho$} & \multicolumn{2}{|c|}{$0.6683^{* * *}$} & $0.6135^{* * *}$ \\
\hline & \multicolumn{2}{|c|}{$(0.0770)$} & $(0.0834)$ \\
\hline Year dummies & \multicolumn{2}{|c|}{ Yes } & Yes \\
\hline
\end{tabular}


Table D.5: Marginal effects for published tuition in the product market with time effects

\begin{tabular}{lccc}
\hline \hline & $(1)$ & $\begin{array}{c}\text { Published Tuition } \\
(2)\end{array}$ & $(3)$ \\
& Direct Effects & Indirect Effects & Total Effects \\
\hline USTD & $-0.0051^{*}$ & -0.0121 & -0.0172 \\
& $(0.0027)$ & $(0.0401)$ & $(0.0410)$ \\
GSTD & 0.0022 & -0.0299 & -0.0277 \\
& $(0.0051)$ & $(0.0655)$ & $(0.0671)$ \\
ENDOW & 0.0051 & 0.0023 & 0.0074 \\
& $(0.0074)$ & $(0.0950)$ & $(0.0969)$ \\
PRAID & -0.0728 & -1.0451 & -1.1179 \\
& $(0.0697)$ & $(1.2267)$ & $(1.2284)$ \\
FACULTY & 0.0183 & 1.0135 & 1.0318 \\
& $(0.0663)$ & $(0.9004)$ & $(0.9205)$ \\
RESEARCH & 0.0020 & -0.0987 & -0.0968 \\
& $(0.0068)$ & $(0.1519)$ & $(0.1542)$ \\
TEACH & $0.0515^{*}$ & 0.1290 & 0.1805 \\
& $(0.0254)$ & $(0.4266)$ & $(0.4345)$ \\
SATACT & $0.0335^{* * *}$ & 0.0128 & 0.0463 \\
& $(0.0047)$ & $(0.0755)$ & $(0.0759)$ \\
ADMRATE & 0.0605 & $2.2168^{* *}$ & $2.2773^{* *}$ \\
& $(0.0593)$ & $(1.1041)$ & $(1.1179)$ \\
POPDEN & -0.0006 & -0.0012 & -0.0018 \\
& $(0.0012)$ & $(0.0138)$ & $(0.0141)$ \\
MEDINC & $0.1643^{* * *}$ & $1.6694^{* *}$ & $1.8336^{* *}$ \\
& $(0.0446)$ & $(0.9171)$ & $(0.9336)$ \\
\hline \hline
\end{tabular}

Standard errors are clustered by universities and shown in parentheses.

${ }^{*} p<0.1,{ }^{* *} p<0.05,{ }^{* * *} p<0.01$ 
Table D.6: Marginal effects for net tuition in the product market with time effect

\begin{tabular}{lccc}
\hline \hline & & Net Tuition & \\
& $(1)$ & $(2)$ & $(3)$ \\
& Direct Effects & Indirect Effects & Total Effects \\
\hline USTD & -0.0004 & -0.0006 & -0.0010 \\
GSTD & $(0.0036)$ & $(0.0070)$ & $(0.0104)$ \\
ENDOW & 0.0053 & 0.0082 & 0.0135 \\
PRAID & $(0.0077)$ & $(0.0137)$ & $(0.0209)$ \\
& -0.0128 & -0.0195 & -0.0322 \\
FACULTY & $(0.0102)$ & $(0.0176)$ & $(0.0269)$ \\
& 0.0814 & 0.1242 & 0.2056 \\
RESEARCH & $(0.1024)$ & $(0.1774)$ & $(0.2722)$ \\
TEACH & 0.0440 & 0.0671 & 0.1110 \\
& $(0.0875)$ & $(0.1487)$ & $(0.2330)$ \\
SATACT & -0.0149 & -0.0227 & -0.0376 \\
& $(0.0096)$ & $(0.0177)$ & $(0.0263)$ \\
ADMRATE & 0.0515 & 0.0785 & 0.1300 \\
POPDEN & $(0.0318)$ & $(0.0556)$ & $(0.0832)$ \\
& $0.0259^{* * *}$ & $0.0395^{*}$ & $0.0653^{* *}$ \\
MEDINC & $(0.0063)$ & $(0.0225)$ & $(0.0262)$ \\
& $0.2644^{* * *}$ & $0.4031^{*}$ & $0.6675^{* *}$ \\
\hline \hline Standard & $(0.0815)$ & $(0.2480)$ & $(0.3049)$ \\
& -0.0001 & -0.0001 & -0.0002 \\
& $(0.0014)$ & $(0.0026)$ & $(0.0039)$ \\
& $0.1698^{* *}$ & $0.2589^{*}$ & $0.4287^{* *}$ \\
& $(0.0702)$ & $(0.1510)$ & $(0.2057)$ \\
\hline
\end{tabular}

Standard errors are clustered by universities and shown in parentheses.

${ }^{*} p<0.1,{ }^{* *} p<0.05,{ }^{* * *} p<0.01$ 


\section{D.4 Robustness Check: Specification Results}

This section presents the results of specification tests when ARWU rank of each year is used. The results here are used for comparison with the main results obtained in the main text, when the 2004 ARWU rank is imposed on all years.

Table D.7: SARMA tests for spatial model specification

\begin{tabular}{lll}
\hline \hline & \multicolumn{2}{c}{$L M_{\rho \lambda}$ Test: $H_{0}: \rho=\lambda=0$} \\
\cline { 2 - 3 } Year & \multicolumn{2}{c}{ Product Market } \\
\cline { 2 - 3 } 2004 & $65.0880^{* * *}$ & $35.1498^{* * *}$ \\
2005 & $32.3329^{* * *}$ & $17.1319^{* * *}$ \\
2006 & $28.1255^{* * *}$ & $30.5588^{* * *}$ \\
2007 & $32.0804^{* * *}$ & $21.5295^{* * *}$ \\
2008 & $27.6278^{* * *}$ & $14.7506^{* * *}$ \\
2009 & $23.1095^{* * *}$ & $11.2769^{* * *}$ \\
2010 & $28.7080^{* * *}$ & $37.7699^{* * *}$ \\
2011 & $30.8704^{* * *}$ & $20.1509^{* * *}$ \\
\hline \hline * Significant at $10 \%$ & ${ }^{* *}$ Significant at $5 \%$ \\
${ }^{* * *}$ Significant at $1 \%$ & \multicolumn{2}{l}{}
\end{tabular}


Table D.8: The LM specification tests for spatial lag and spatial error in the product market

\begin{tabular}{ccccc}
\hline \hline \multirow{2}{*}{ Year } & \multicolumn{4}{c}{ Product Market: Published Tuition } \\
\cline { 2 - 5 } & $L M_{\rho}$ & $L M_{\rho}^{*}$ & $L M_{\lambda}$ & $L M_{\lambda}^{*}$ \\
\hline 2004 & $23.1923^{* * *}$ & $3.7410^{*}$ & $61.3470^{* * *}$ & $41.8957^{* * *}$ \\
2005 & $17.8090^{* * *}$ & $5.1851^{* *}$ & $27.1478^{* * *}$ & $14.5239^{* * *}$ \\
2006 & $13.3544^{* * *}$ & $3.4077^{*}$ & $24.7178^{* * *}$ & $14.7711^{* * *}$ \\
2007 & $15.0890^{* * *}$ & $3.6751^{*}$ & $28.4054^{* * *}$ & $16.9915^{* * *}$ \\
2008 & $14.3037^{* * *}$ & $3.8106^{*}$ & $23.8172^{* * *}$ & $13.3242^{* * *}$ \\
2009 & $12.2293^{* * *}$ & $3.6149^{*}$ & $19.4946^{* * *}$ & $10.8803^{* * *}$ \\
2010 & $12.9879^{* * *}$ & $3.1513^{*}$ & $25.5567^{* * *}$ & $15.7201^{* * *}$ \\
2011 & $12.6167^{* * *}$ & 2.2784 & $28.5921^{* * *}$ & $18.2538^{* * *}$ \\
\hline \hline
\end{tabular}

\begin{tabular}{ccccc}
\hline \hline & \multicolumn{4}{c}{ Product Market: Net Tuition } \\
\cline { 2 - 5 } Year & \multicolumn{1}{c}{$L M_{\rho}$} & $L M_{\rho}^{*}$ & $L M_{\lambda}$ & $L M_{\lambda}^{*}$ \\
\hline 2004 & $13.6911^{* * *}$ & 0.2575 & $34.88923^{* * *}$ & $21.4587^{* * *}$ \\
2005 & $9.1623^{* * *}$ & 0.5217 & $16.6102^{* * *}$ & $7.9696^{* * *}$ \\
2006 & $7.7043^{* * *}$ & 0.2021 & $30.3566^{* * *}$ & $22.8544^{* * *}$ \\
2007 & $6.9287^{* * *}$ & 0.0003 & $21.5292^{* * *}$ & $14.6008^{* * *}$ \\
2008 & $6.0422^{* *}$ & 0.0708 & $14.6799^{* * *}$ & $8.7084^{* * *}$ \\
2009 & $4.0452^{* *}$ & 0.0271 & $11.2499^{* * *}$ & $7.2317^{* * *}$ \\
2010 & $5.8650^{* *}$ & 1.8115 & $35.9584^{* * *}$ & $31.9049^{* * *}$ \\
2011 & $5.4562^{* *}$ & 0.1621 & $19.9888^{* * *}$ & $14.6947^{* * *}$ \\
\hline
\end{tabular}


Table D.9: The LR specification tests for spatial autocorrelation in the product market

\begin{tabular}{cccc}
\hline \hline & \multicolumn{3}{c}{ Product Market } \\
\cline { 2 - 4 } Year & $L R_{\rho \lambda}$ Published Tuition \\
\cline { 2 - 4 } & $L R_{\rho}$ & $L R_{\lambda}$ \\
\hline 2004 & $64.4044^{* * *}$ & $20.1998^{* * *}$ & $12.6070^{* * *}$ \\
2005 & $48.0728^{* * *}$ & $30.5962^{* * *}$ & 0.1442 \\
2006 & $29.0197^{* * *}$ & $15.2319^{* * *}$ & 0.2763 \\
2007 & $35.8089^{* * *}$ & $17.5245^{* * *}$ & 0.0097 \\
2008 & $31.3809^{* * *}$ & $12.9378^{* * *}$ & 2.1567 \\
2009 & $29.3855^{* * *}$ & $15.7459^{* * *}$ & 1.2632 \\
2010 & $29.4162^{* * *}$ & $13.6346^{* * *}$ & 0.2536 \\
2011 & $27.6963^{* * *}$ & $8.4614^{* * *}$ & 0.2382 \\
\hline \hline & \multicolumn{3}{c}{ Net Tuition } \\
\cline { 2 - 4 } Year & $L R_{\rho \lambda} L R_{\rho}$ \\
\hline 2004 & $36.6711^{* * *}$ & $10.3805^{* * *}$ & 0.5919 \\
2005 & $42.3936^{* * *}$ & $31.4884^{* * *}$ & $3.6465^{*}$ \\
2006 & $29.9024^{* * * \dagger}$ & $9.7850^{* * * \dagger}$ & $1.1763^{\dagger}$ \\
2007 & $38.1593^{* * *}$ & $19.7624^{* * *}$ & 1.3226 \\
2008 & $15.8654^{* * *}$ & $2.7869^{*}$ & 0.0988 \\
2009 & $14.0787^{* * *}$ & $3.7862^{*}$ & 0.0006 \\
2010 & $30.0838^{* * *}$ & $4.4191^{* *}$ & 0.0245 \\
2011 & $16.7107^{* * * \dagger}$ & $0.0023^{\dagger}$ & $9.2604^{* * * \dagger}$ \\
\hline \hline
\end{tabular}

* Significant at $10 \% \quad * *$ Significant at $5 \%$

*** Significant at $1 \%$

$\dagger$ Convergence not achieved after 100 iterations 
Table D.10: Specification tests for spatial autocorrelation from SDM model in the product market

\begin{tabular}{|c|c|c|c|}
\hline \multirow[b]{3}{*}{ Year } & \multicolumn{3}{|c|}{ Product Market } \\
\hline & \multicolumn{3}{|c|}{ Published Tuition } \\
\hline & $L R_{\rho}$ & $L R_{\theta}$ & $N L_{\rho \beta}$ \\
\hline 2004 & $50.3615^{* * *}$ & $19.4038^{*}$ & $19.88^{*}$ \\
\hline 2005 & $14.7624^{* * *}$ & 16.8338 & $25.39^{* *}$ \\
\hline 2006 & $11.8256^{* * *}$ & $37.4903^{* * *}$ & $40.68^{* * *}$ \\
\hline 2007 & $8.6256^{* * *}$ & $45.4458^{* * *}$ & $48.04^{* * *}$ \\
\hline 2008 & $8.9589^{* * *}$ & $33.9706^{* * *}$ & $34.63^{* * *}$ \\
\hline 2009 & $9.8539^{* * *}$ & $22.5464^{* *}$ & $25.68^{* *}$ \\
\hline 2010 & $7.6959^{* * *}$ & $39.0129^{* * *}$ & $40.79^{* * *}$ \\
\hline \multirow[t]{2}{*}{2011} & $17.5036^{* * *}$ & $33.8627^{* * *}$ & $36.10^{* * *}$ \\
\hline & \multicolumn{3}{|c|}{ Net Tuition } \\
\hline Year & $L R_{\rho}$ & $L R_{\theta}$ & $N L_{\rho \beta}$ \\
\hline 2004 & $23.9228^{* * *}$ & 12.1980 & 16.65 \\
\hline 2005 & $10.3807^{* * *}$ & $20.0171^{*}$ & $23.17^{* *}$ \\
\hline 2006 & $15.8007^{* * *}$ & $32.9845^{* * *}$ & $36.25^{* * *}$ \\
\hline 2007 & $8.6180^{* * *}$ & $32.3161^{* * *}$ & $34.32^{* * *}$ \\
\hline 2008 & $7.7981^{* * *}$ & $28.0736^{* * *}$ & $29.13^{* * *}$ \\
\hline 2009 & $6.0464^{* *}$ & $20.0698^{*}$ & $21.50^{*}$ \\
\hline 2010 & $15.3937^{* * *}$ & $28.7298^{* * *}$ & $29.67^{* * *}$ \\
\hline 2011 & $11.6222^{* * *}$ & $32.0600^{* * *}$ & $31.14^{* * *}$ \\
\hline
\end{tabular}




\section{D.5 Robustness Check: Regression Results}

This section presents the regression results for price competition in the product market and their marginal effects from cross-sectional analysis using ARWU rank of each year as the spatial weighting matrix. The model selection process is explained briefly as follows. The SARMA specification tests are significant in all years for both published tuition and net tuition ${ }^{1}$. The next LM specification tests ${ }^{2}$ suggest for the SARMA model for published tuition in five years only, while the SEM model is preferred in the remaining three years. For net tuition, the LM specification tests indicate that the SEM model should be used in all years. The following LR specification tests ${ }^{3}$ indicate that the SARMA model is chosen for published tuition in two years only: 2004 and 2008; while the SAR model should be used in all other years. For net tuition, the LR tests also suggest that the SAR model be used in most years. The SDM specification tests ${ }^{4}$ indicate that the SDM model should be used for published tuition in all years except 2005, and for net tuition in all years except 2004. The SDM tests indicate that the SAR model should be used for published tuition in 2004 and the SARMA model should be used for net tuition in 2004. The model selection decision for each year is listed in Table D.11. The results are summarized at the end of this section.

The remaining paragpraphs in this section discuss the spatial regression results of published tuition and net tuition when the yearly ARWU rank is used to determine the spatial weighting matrix. The results are organized based on each year and are provided in Tables D.12-D.35.

The spatial coefficients for the dependent variables, $\rho$, are significantly positive in all years for both published tuition and net tuition. These results are similar to the

\footnotetext{
${ }^{1}$ Please refer to Table D.7 in Appendix D.4.

${ }^{2}$ As shown in Table D.8 in Appendix D.4.

${ }^{3}$ As shown in Table D.9 in Appendix D.4.

${ }^{4}$ Please refer to Table D.10 in Appendix D.4.
} 
Table D.11: Model specification decisions

\begin{tabular}{ccc}
\hline \hline & \multicolumn{2}{c}{ Product Market } \\
\cline { 2 - 3 } Year & Published Tuition & Net Tuition \\
\hline 2004 & SAR & SARMA \\
2005 & SAR & SDM \\
2006 & SDM & SDM \\
2007 & SDM & SDM \\
2008 & SDM & SDM \\
2009 & SDM & SDM \\
2010 & SDM & SDM \\
2011 & SDM & SDM \\
\hline \hline
\end{tabular}

previous findings of positive spatial correlation between prices of universities from the Moran's I statistics and Geary's $C$ statistics in Table 4.1 earlier on page 161. It could be established now that published tuition and net tuition of a university are positively affected by the published tuition and net tuition of other universities in the product market.

Comparing the values of $\rho$ between published tuition and net tuition across the years, it seems that the spatial effects are of different strength level. At the beginning of the period in 2004, the spatial effects are stronger in published tuition than net tuition. Similar results are observed in 2005. However in 2006, the spatial effects in net tuition seem to be stronger than published tuition. In the following year, the difference in the spatial effects between published tuition and net tuition have become very small, where the value of $\rho$ for net tuition is only about $1 \%$ bigger than published tuition. In 2008, the spatial effects in published tuition have become stronger than net tuition again, and this pattern continues until the end of the analysis period in 2011.

The following paragraphs discuss the marginal effects of each explanatory variable in the spatial analysis of the product market. The enrollment of undergraduate 
students has negative direct effects to published tuition only in most years of the analysis. It has never produced any marginal effect to net tuition. This indicates that the enrollment of undergraduate students has no effect to the financial aid offered by universities in the product market setting. At the same time, there is no spatial effects from changes in the undergraduate enrollment in other universities to the published tuition of a university. There is only a negative direct effect from undergraduate enrollment to published tuition. Only the university where changes in undergraduate enrollment take place will be affected and change its published tuition. The negative direct effect suggests that there is a negative relationship between demand for undergraduate placement and its price. This finding is similar to the results obtained from the panel models earlier, where undergraduate enrollment has negative direct effect on published tuition in the overall sample and public universities subsample only.

The enrollment of graduate students is never a factor with significant direct effect to either published tuition or net tuition throughout the period of analysis. There are only few years in which graduate enrollment indirectly affects either published tuition or net tuition. In all those years, graduate enrollment has a negative indirect effect to the price variable. Graduate enrollment has indirect negative effect to published tuition in 2007, 2008, 2010, and 2011; and to net tuition in 2006, 2007, and 2011. From here, there are two years in which both published tuition and net tuition are affected indirectly by graduate enrollment: 2007, and 2011. These results indicate that both published tuition and net tuition are not affected directly by graduate enrollment. Since the price variable is more related to undergraduate enrollment, graduate enrollment has no direct effect to it. However the negative indirect effect indicates a negative relatiohship between the enrollment of graduate students at other universities and the price variable of a university in some years. This may suggests that the enrollment of graduate students and the enrollment of undergraduate students are 
substitutes in the product market. When there is an increase in the graduate enrollment at other universities, a university that is located in the same product market is motivated to lower its price in order to attract more undergraduate enrollment. However, since the indirect effects of graduate enrollment are significant in only few years, this explanation should not be generalized to the whole analysis period. From the panel models, graduate enrollment has negative marginal effects on net tuition in the overall sample at $10 \%$ significant level only.

Endowment has significant direct effects to published tuition in most of the years except in 2004 and 2010. However its indirect and total effects to published tuition are only significant to published tuition in four consecutive years: 2005 until 2008. On the other hand, endowment seems to have no marginal effects to net tuition. The only significant results obtained are for the indirect and total effects in 2006, and the direct effect in 2011. All of the marginal effects of endowment to published tuition and net tuition are positive. Since the direct effects of endowment to published tuition are positive in most of the years, a university that gains more endowment will raise its published tuition. This is contrary to earlier expectation that as universities have more endowment, they would lower their published tuition.

The proportion of students receiving aid is not a significant factor with marginal effects to published tuition in most of the years. Only in 2005 and 2010 that proportion of students receiving aid have significant direct, indirect, and total effects to published tuition; while in 2011 only the total effect is significant. In all the years that proportion of students receving aid has significant effects to published tuition, the marginal effects are negative. This indicates that if the number of students receiving aid increases, universities are inclined to lower their published tuition. On the other hand, the proportion of students receiving aid has positive direct effects to net tuition starting from 2006 until 2011. As universities grant aid to more students, 
their net tuition seems to be higher. This suggests that with more students receiving aid, the amount of aid given is smaller.

Faculty size seems to have different types of marginal effects throughout the analysis period. At the beginning of the period, faculty size has no significant marginal effects to both published tuition and net tuition. In 2006, the indirect and total effects of faculty size are significant to published tuition. Similar results are observed in 2007 and 2009. However in 2010 and 2011, faculty size has significant direct effects to published tuition. The marginal effects of faculty size to net tuition are not significant except for 2006 and 2011 only. In 2006, the its indirect and total effects are significant while in 2011 only the direct effect is significant. From these results, it seems that net tuition in the product market is not influenced by faculty size.

All of the significant marginal effects of faculty size are positive. This indicates there is a positive relationship between faculty size and price. The positive direct effect may have been caused by the direct increase in cost due to more faculty staff being hired. As a university hires more faculty staff, it incurs additional cost to pay these new faculty members and hence is inclined to increase the price in order to cover these expenses. Furthermore, an increase in faculty staff could be used to send a signal of higher quality to the market. As more faculty staff are hired, the faculty-students ratio, an indicator that is always used as a component to measure quality index, will be smaller. This indicates that the quality level has increased, and thus justify the increase in price. From the panel models, faculty size is significantly positive to published tuition and net tuition of public universities only.

The direct effects of research spending to price are not significant except for net tuition in 2011. From this result, research spending is not a factor with significant direct impact on price. Any university that changes its research spending may not necessarily adjust its price to accommodate the change in research spending. However 
the indirect and total effects of research spending are significant in several years. This suggests that a university is motivated to change its price when its neighboring universities in the product market dimension change their price to accommodate their new research spending amount. All of the significant marginal effects of research spending are negative to published tuition and net tuition. This negative relation between research spending and price is hard to be perceived since a change in research spending is related to cost and should be positively related to price. As a university spends more funds for research, it incurs additional cost. In this scenario the university is expected to increase its price in order to finance the additional cost due to higher research spending. A negative relation shows that universities are more inclined to lower their price when they spend more for research. It is possible that most of the research spendings are being funded by external grants that are not related to enrollment of students, unlike teaching expenditure. In this case, as universities acquire more external funds to perform research, they are willing to lower their price. However, this deduction should not be generalized since the marginal effects of research spending are significant in some years only. Different results are observed from the panel models, where research spending has positive impact on prices.

The marginal effects of teaching expenditure are significant in some years only. For published tuition, teaching expenditure has a positive direct effect in 2004. In 2005, apart from the direct effect, the indirect and total effects of teaching expenditure are also signficant. However in the subsequent years, teaching expenditure has no significant marginal effects to published tuition until 2010 and 2011, where the indirect and total effects are significant. Based on these observations, it seems that teaching expenditure has some positive direct effects to published tuition at the beginning of the analysis period. However in the middle of the period the effects seem to have vanished. Only at the end of the analysis period the indirect effects of teaching 
expenditure are significant.

Teaching expenditure has significant direct effects to net tuition beginning in 2005 until 2008. In the following two years, there are no significant direct effect of teaching expenditure to net tuition. Only in 2011 that the direct effect of teaching expenditure to net tuition is significant again. In the panel models, teaching expenditure is significantly positive to prices.

The first proxy variable for quality, the admission test score, has positive direct effects to both published tuition in all years, and net tuition in all years except in 2011. In addition to that, its indirect and total effects are also significant in some of the years. The positive direct effects indicate that there is a positive relationship between admission test score and price. A university that increases its admission test score would only admit students with higher test score. These students possess higher quality that would contribute to the quality level of the university. In this case, the university would raise its price as a signal of its higher quality level. At the same time, there are less students of lower quality that would receive admission offers from that university. To compensate the possible drop in enrollment of students, the university is motivated to raise its price. When panel models are applied, similar result is observed for private universities only. For public universities, admission test score negatively affects prices.

The second proxy variable for quality, the admission rate, has significant indirect and total effects to published tuition in all years. Its direct effects to published tuition are significant in two years only: 2005 and 2010. Hence the direct effects of admission rate to published tuition are not significant. From these results, a change in the admission rate of other universities seem to have greater influence on the published tuition of a university than a change in the admission rate that takes place at that university itself. The more similar a university is to other universities in the product 
market, the stronger is the feedback effects of changes in the admission rate of other universities on its published tuition. The indirect and total effects of admission rate are positive in all years. This indicates that as the admission rate increases, published tuition also increases. A university is inclined to raise its published tuition as more admission offers are made by other universities. Since both the indirect and total effects are positive, the change in admission rate affects published tuition through the feedback effects. As other universities makes more admission offers, they are expected to increase their published tuition. A university that is located near these universities along the product line is influenced to raise its publised tuition as well. The direct, indirect and total effects of admission rate to net tuition are significant in all years. Same as published tuition, all of the marginal effects of admission rate to net tuition are positive. From the direct effects, a university that offers more admission is expected to raise its net tuition.

As a university accepts more students, it needs to prepare to incur higher costs. The university needs to hire additional staff and improve its facilities to accommodate larger number of students. To finance these higher expenditures, the university is motivated to increase its price. Since the direct effects of admission rate to published tuition are not significant but its direct effects to net tuition are significant, this suggests that the university will not change its published tuition but rather reduce its financial aid to students. This leads to higher net tuition. From the indirect effects, the net tuition of a university is also influenced by changes in admission rate of other universities. As universities make more admission offers, they are expected to raise their net tuition by offering less financial aids. A university with similar quality level is also expected to implement the same policy by reducing financial aid offers. However the impact of admission rate in the panel models is significantly negative to net tuition in the overall sample only. It is not significant elsewhere. 
The first measure for geographical variants, the county's population density, has different marginal effects to published tuition and net tuition in few years only. Therefore it is hard to deduce general statements concerning the effects of county's population density to published tuition and net tuition. It seems that being located in an urban location has no significant effects to prices in the product market. From the panel models, population density has negative marginal effects on net tuition of public universities only.

The second measure of geographical variants, the county's median income, has significant direct, indirect and total effects to published tuition in all years. However all three marginal effects to net tuition are significant in all years except in 2009 and 2011. In all years, the marginal effects of median income to published tuition and net tuition are positive. This suggests that there is a positive relation between the level of income and the price of university. Higher median income indicates greater economic activities in the geographical area, and a university that is located in that location is influenced to raise its published tuition and net tuition. At the same time, from the indirect effects, a university is also influenced by a change in the county's median income of other universities that share the same quality level in the product market, even though they are located far apart in the geographical market. From the panel models, median income is positive to published tuition in the overall sample and the public universities subsample only.

The public type dummy has significant direct effects to published tuition in all years, while its direct effects to net tuition are significant except in 2009 and 2011. As expected, public universities charge lower published tuition and net tuition than private universities. Since the indirect effects of public type dummy are significant in some years, this indicates that a university located near to public universities in the product market tends to have lower published tuition and net tuition. 
Table D.12: Spatial regressions for the product market in 2004

\begin{tabular}{lcc}
\hline \hline & $\begin{array}{c}\text { Published Tuition } \\
(1)\end{array}$ & $\begin{array}{c}\text { Net Tuition } \\
(2)\end{array}$ \\
\hline USTD & $-0.0046^{*}$ & -0.0006 \\
& $(0.0026)$ & $(0.0037)$ \\
GSTD & 0.0031 & 0.0055 \\
& $(0.0049)$ & $(0.0070)$ \\
ENDOW & 0.0043 & -0.0120 \\
& $(0.0068)$ & $(0.0096)$ \\
PRAID & -0.0764 & 0.0875 \\
& $(0.0756)$ & $(0.1070)$ \\
FACULTY & -0.0119 & 0.0462 \\
& $(0.0650)$ & $(0.0910)$ \\
RESEARCH & 0.0026 & -0.0137 \\
& $(0.0064)$ & $(0.0092)$ \\
TEACH & $0.0516^{* *}$ & 0.0517 \\
& $(0.0229)$ & $(0.0327)$ \\
SATACT & $0.0338^{* * *}$ & $0.0254^{* * *}$ \\
& $(0.0046)$ & $(0.0065)$ \\
ADMRATE & 0.0465 & $0.2525^{* * *}$ \\
& $(0.0644)$ & $(0.0898)$ \\
POPDEN & -0.0011 & -0.0001 \\
& $(0.0011)$ & $(0.0016)$ \\
MEDINC & $0.1295^{* * *}$ & $0.1626^{* *}$ \\
& $(0.0460)$ & $(0.0656)$ \\
PUBLIC & $-0.4231^{* * *}$ & $-0.1301^{* * *}$ \\
& $(0.0326)$ & $(0.0464)$ \\
Constant & $2.5117^{* *}$ & 1.4116 \\
& $(1.0968)$ & $(1.6792)$ \\
$\rho$ & $0.4515^{* * *}$ & $0.5267^{* * *}$ \\
& $(0.1004)$ & $(0.1637)$ \\
\hline Observations & 528 & 528 \\
Log lik. & 81.3572 & -107.5147 \\
Est. method & $\mathrm{SAR}$ & $\mathrm{S} A R M A$ \\
\hline \hline
\end{tabular}

Asymptotic standard errors in parentheses

${ }^{*} p<0.1,{ }^{* *} p<0.05,{ }^{* * *} p<0.01$ 
Table D.13: Marginal effects for published tuition in the product market for 2004

\begin{tabular}{lccc}
\hline \hline & \multicolumn{3}{c}{ Published Tuition 2004 } \\
& $(1)$ & $(2)$ & $(3)$ \\
& Direct Effects & Indirect Effects & Total Effects \\
\hline USTD & $-0.0051^{*}$ & -0.0121 & -0.0172 \\
& $(0.0027)$ & $(0.0401)$ & $(0.0410)$ \\
GSTD & 0.0022 & -0.0299 & -0.0277 \\
& $(0.0051)$ & $(0.0655)$ & $(0.0671)$ \\
ENDOW & 0.0051 & 0.0023 & 0.0074 \\
& $(0.0074)$ & $(0.0950)$ & $(0.0969)$ \\
PRAID & -0.0728 & -1.0451 & -1.1179 \\
& $(0.0697)$ & $(1.2267)$ & $(1.2284)$ \\
FACULTY & 0.0183 & 1.0135 & 1.0318 \\
& $(0.0663)$ & $(0.9004)$ & $(0.9205)$ \\
RESEARCH & 0.0020 & -0.0987 & -0.0968 \\
& $(0.0068)$ & $(0.1519)$ & $(0.1542)$ \\
TEACH & $0.0515^{*}$ & 0.1290 & 0.1805 \\
& $(0.0254)$ & $(0.4266)$ & $(0.4345)$ \\
SATACT & $0.0335^{* * *}$ & 0.0128 & 0.0463 \\
& $(0.0047)$ & $(0.0755)$ & $(0.0759)$ \\
ADMRATE & 0.0605 & $2.2168^{* *}$ & $2.2773^{* *}$ \\
& $(0.0593)$ & $(1.1041)$ & $(1.1179)$ \\
POPDEN & -0.0006 & -0.0012 & -0.0018 \\
& $(0.0012)$ & $(0.0138)$ & $(0.0141)$ \\
MEDINC & $0.1643^{* * *}$ & $1.6694^{* *}$ & $1.8336^{* *}$ \\
& $(0.0446)$ & $(0.9171)$ & $(0.9336)$ \\
PUBLIC & $-0.4266^{* * *}$ & $-1.0235^{*}$ & $-1.4501^{* *}$ \\
& $(0.0300)$ & $(0.6266)$ & $(0.6389)$ \\
\hline \hline
\end{tabular}

Method of estimation is SAR. Number of obervations is 528 .

Asymptotic standard errors in parentheses.

${ }^{*} p<0.1,{ }^{* *} p<0.05,{ }^{* * *} p<0.01$ 
Table D.14: Marginal effects for net tuition in the product market for 2004

\begin{tabular}{lccc}
\hline \hline & & Net Tuition 2004 & $(3)$ \\
& $(1)$ & $(2)$ & $(3)$ \\
& Direct Effects & Indirect Effects & Total Effects \\
\hline USTD & -0.0004 & -0.0006 & -0.0010 \\
& $(0.0036)$ & $(0.0070)$ & $(0.0104)$ \\
GSTD & 0.0053 & 0.0082 & 0.0135 \\
& $(0.0077)$ & $(0.0137)$ & $(0.0209)$ \\
ENDOW & -0.0128 & -0.0195 & -0.0322 \\
& $(0.0102)$ & $(0.0176)$ & $(0.0269)$ \\
PRAID & 0.0814 & 0.1242 & 0.2056 \\
& $(0.1024)$ & $(0.1774)$ & $(0.2722)$ \\
FACULTY & 0.0440 & 0.0671 & 0.1110 \\
& $(0.0875)$ & $(0.1487)$ & $(0.2330)$ \\
RESEARCH & -0.0149 & -0.0227 & -0.0376 \\
& $(0.0096)$ & $(0.0177)$ & $(0.0263)$ \\
TEACH & 0.0515 & 0.0785 & 0.1300 \\
& $(0.0318)$ & $(0.0556)$ & $(0.0832)$ \\
SATACT & $0.0259^{* * *}$ & $0.0395^{*}$ & $0.0653^{* *}$ \\
& $(0.0063)$ & $(0.0225)$ & $(0.0262)$ \\
ADMRATE & $0.2644^{* * *}$ & $0.4031^{*}$ & $0.6675^{* *}$ \\
& $(0.0815)$ & $(0.2480)$ & $(0.3049)$ \\
POPDEN & -0.0001 & -0.0001 & -0.0002 \\
& $(0.0014)$ & $(0.0026)$ & $(0.0039)$ \\
MEDINC & $0.1698^{* *}$ & $0.2589^{*}$ & $0.4287^{* *}$ \\
& $(0.0702)$ & $(0.1510)$ & $(0.2057)$ \\
PUBLIC & $-0.1359^{* * *}$ & $-0.2072^{* *}$ & $-0.3430^{* * *}$ \\
& $(0.0479)$ & $(0.1144)$ & $(0.1487)$ \\
\hline \hline
\end{tabular}

Method of estimation is SARMA. Number of obervations is 528 .

Asymptotic standard errors in parentheses.

${ }^{*} p<0.1,{ }^{* *} p<0.05,{ }^{* * *} p<0.01$ 
Table D.15: Spatial regressions for the product market in 2005

\begin{tabular}{|c|c|c|c|}
\hline & \multirow{3}{*}{$\begin{array}{l}\text { Published Tuition } \\
\text { (1) }\end{array}$} & \multicolumn{2}{|c|}{ Net Tuition } \\
\hline & & $(2)$ & (3) \\
\hline & & Main & Spatial Lag \\
\hline \multirow[t]{2}{*}{ USTD } & -0.0043 & 0.0014 & -0.0119 \\
\hline & $(0.0027)$ & $(0.0041)$ & $(0.0157)$ \\
\hline \multirow{2}{*}{ GSTD } & -0.0005 & 0.0017 & 0.0095 \\
\hline & $(0.0052)$ & $(0.0078)$ & $(0.0252)$ \\
\hline \multirow[t]{2}{*}{ ENDOW } & $0.0151^{* *}$ & -0.0036 & 0.0055 \\
\hline & $(0.0071)$ & $(0.0107)$ & $(0.0461)$ \\
\hline \multirow[t]{2}{*}{ PRAID } & $-0.1434 *$ & 0.1048 & -0.0963 \\
\hline & $(0.0780)$ & $(0.1173)$ & $(0.4991)$ \\
\hline \multirow[t]{2}{*}{ FACULTY } & -0.0150 & 0.0145 & -0.0609 \\
\hline & $(0.0667)$ & $(0.1037)$ & $(0.3444)$ \\
\hline \multirow[t]{2}{*}{ RESEARCH } & 0.0045 & -0.0060 & -0.0360 \\
\hline & $(0.0067)$ & $(0.0103)$ & $(0.0518)$ \\
\hline \multirow[t]{2}{*}{ TEACH } & $0.0478^{* *}$ & $0.0706^{* *}$ & 0.0950 \\
\hline & $(0.0238)$ & $(0.0360)$ & $(0.1692)$ \\
\hline \multirow[t]{2}{*}{ SATACT } & $0.0307^{* * *}$ & $0.0239^{* * *}$ & 0.0250 \\
\hline & $(0.0044)$ & $(0.0066)$ & $(0.0315)$ \\
\hline \multirow{2}{*}{ ADMRATE } & $0.1708^{* * *}$ & $0.3885^{* * *}$ & 0.6067 \\
\hline & $(0.0656)$ & (0.1008) & $(0.4345)$ \\
\hline \multirow[t]{2}{*}{ POPDEN } & -0.0011 & 0.0006 & $-0.0143^{* *}$ \\
\hline & $(0.0011)$ & $(0.0019)$ & $(0.0070)$ \\
\hline \multirow[t]{2}{*}{ MEDINC } & $0.1401^{* * *}$ & $0.1701^{* *}$ & $0.6352^{* *}$ \\
\hline & $(0.0448)$ & $(0.0678)$ & $(0.3098)$ \\
\hline \multirow[t]{2}{*}{ PUBLIC } & $-0.4186^{* * *}$ & $-0.1581^{* * *}$ & -0.1332 \\
\hline & $(0.0328)$ & $(0.0493)$ & $(0.2189)$ \\
\hline \multirow[t]{2}{*}{ Constant } & $1.8622^{* *}$ & \multirow{2}{*}{\multicolumn{2}{|c|}{$\begin{array}{r}-6.4626 \\
(3.9710)\end{array}$}} \\
\hline & 0.8673 & & \\
\hline \multirow[t]{2}{*}{$\rho$} & $0.4982^{* * *}$ & \multicolumn{2}{|c|}{$0.3653^{* * *}$} \\
\hline & 0.0699 & $(0$. & 070) \\
\hline Observations & 528 & \multicolumn{2}{|c|}{528} \\
\hline Log lik. & 66.1486 & \multicolumn{2}{|c|}{-135.1191} \\
\hline Est. method & SAR & \multicolumn{2}{|c|}{ SDM } \\
\hline
\end{tabular}

Asymptotic standard errors in parentheses

${ }^{*} p<0.10,{ }^{* *} p<0.05,{ }^{* * *} p<0.01$ 
Table D.16: Marginal effects for published tuition in the product market for 2005

\begin{tabular}{lccc}
\hline \hline & \multicolumn{3}{c}{ Published Tuition 2005 } \\
& $(1)$ & $(2)$ & $(3)$ \\
& Direct Effects & Indirect Effects & Total Effects \\
\hline USTD & $-0.0044^{*}$ & -0.0042 & -0.0085 \\
& $(0.0026)$ & $(0.0030)$ & $(0.0054)$ \\
GSTD & -0.0005 & -0.0005 & -0.0009 \\
& $(0.0050)$ & $(0.0052)$ & $(0.0101)$ \\
ENDOW & $0.0153^{* *}$ & $0.0147^{*}$ & $0.0301^{* *}$ \\
& $(0.0074)$ & $(0.0081)$ & $(0.0149)$ \\
PRAID & $-0.1458^{* *}$ & $-0.1399^{*}$ & $-0.2858^{*}$ \\
& $(0.0748)$ & $(0.0940)$ & $(0.1641)$ \\
FACULTY & -0.0153 & -0.0146 & -0.0299 \\
& $(0.0704)$ & $(0.0698)$ & $(0.1390)$ \\
RESEARCH & 0.0046 & 0.0044 & 0.0089 \\
& $(0.0070)$ & $(0.0070)$ & $(0.0139)$ \\
TEACH & $0.0486^{* *}$ & $0.0466^{*}$ & $0.0953^{* *}$ \\
& $(0.0231)$ & $(0.0240)$ & $(0.0453)$ \\
SATACT & $0.0312^{* * *}$ & $0.0299^{* * *}$ & $0.0611^{* * *}$ \\
& $(0.0042)$ & $(0.0082)$ & $(0.0103)$ \\
ADMRATE & $0.1737^{* * *}$ & $0.1667^{* *}$ & $0.3404^{* *}$ \\
& $(0.0631)$ & $(0.0730)$ & $(0.1290)$ \\
POPDEN & -0.0011 & -0.0011 & -0.0022 \\
& $(0.0011)$ & $(0.0011)$ & $(0.0022)$ \\
MEDINC & $0.1425^{* * *}$ & $0.1367^{* *}$ & $0.2792^{* * *}$ \\
& $(0.0472)$ & $(0.0603)$ & $(0.0999)$ \\
PUBLIC & $-0.4258^{* * *}$ & $-0.4085^{* * *}$ & $-0.8342^{* * *}$ \\
& $(0.0319)$ & $(0.1225)$ & $(0.1385)$ \\
\hline \hline
\end{tabular}

Method of estimation is SAR. Number of obervations is 528 .

Asymptotic standard errors in parentheses.

${ }^{*} p<0.1,{ }^{* *} p<0.05,{ }^{* * *} p<0.01$ 
Table D.17: Marginal effects for net tuition in the product market for 2005

\begin{tabular}{lccc}
\hline \hline & & Net Tuition 2005 & $(1)$ \\
& Direct Effects & Indirect Effects & Total Effects \\
\hline USTD & 0.0011 & -0.0177 & -0.0166 \\
& $(0.0047)$ & $(0.0257)$ & $(0.0261)$ \\
GSTD & 0.0019 & 0.0157 & 0.0176 \\
& $(0.0083)$ & $(0.0370)$ & $(0.0375)$ \\
ENDOW & -0.0035 & 0.0065 & 0.0030 \\
& $(0.0099)$ & $(0.0744)$ & $(0.0755)$ \\
PRAID & 0.1035 & -0.0901 & 0.0134 \\
& $(0.1179)$ & $(0.8323)$ & $(0.8494)$ \\
FACULTY & 0.0133 & -0.0863 & -0.0730 \\
& $(0.1064)$ & $(0.6213)$ & $(0.6569)$ \\
RESEARCH & -0.0068 & -0.0594 & -0.0662 \\
& $(0.0090)$ & $(0.0890)$ & $(0.0909)$ \\
TEACH & $0.0733^{*}$ & 0.1876 & 0.2610 \\
& $(0.0392)$ & $(0.2934)$ & $(0.3063)$ \\
SATACT & $0.0247^{* * *}$ & 0.0524 & 0.0771 \\
& $(0.0066)$ & $(0.0517)$ & $(0.0533)$ \\
ADMRATE & $0.4053^{* * *}$ & $1.1627^{*}$ & $1.5679^{* *}$ \\
& $(0.1041)$ & $(0.7052)$ & $(0.7272)$ \\
POPDEN & 0.0002 & $-0.0220^{*}$ & $-0.0217^{*}$ \\
& $(0.0017)$ & $(0.018)$ & $(0.0117)$ \\
MEDINC & $0.1857^{* * *}$ & $1.0830^{* *}$ & $1.2688^{* *}$ \\
& $(0.0701)$ & $(0.4976)$ & $(0.5072)$ \\
PUBLIC & $-0.1623^{* * *}$ & -0.2966 & -0.4589 \\
& $(0.0458)$ & $(0.3472)$ & $(0.3534)$ \\
\hline \hline
\end{tabular}

Method of estimation is SDM. Number of obervations is 528 .

Asymptotic standard errors in parentheses.

${ }^{*} p<0.1,{ }^{* *} p<0.05,{ }^{* * *} p<0.01$ 
Table D.18: Spatial regressions for the product market in 2006

\begin{tabular}{|c|c|c|c|c|}
\hline & \multicolumn{2}{|c|}{ Published Tuition } & \multicolumn{2}{|c|}{ Net Tuition } \\
\hline & $(1)$ & (2) & (3) & (4) \\
\hline & Main & Spatial Lag & Main & Spatial Lag \\
\hline \multirow[t]{2}{*}{ USTD } & $-0.0063^{* *}$ & 0.0107 & -0.0040 & 0.0164 \\
\hline & $(0.0027)$ & $(0.0098)$ & $(0.0039)$ & $(0.0139)$ \\
\hline \multirow[t]{2}{*}{ GSTD } & 0.0057 & -0.0307 * & 0.0091 & $-0.0581^{* *}$ \\
\hline & $(0.0051)$ & $(0.0180)$ & $(0.0074)$ & $(0.0259)$ \\
\hline \multirow{2}{*}{ ENDOW } & $0.0283^{* * *}$ & $0.0889^{* *}$ & 0.0069 & $0.1233^{* *}$ \\
\hline & $(0.0079)$ & $(0.0411)$ & $(0.0113)$ & $(0.0590)$ \\
\hline \multirow[t]{2}{*}{ PRAID } & 0.0126 & -0.1395 & $0.3036^{* * *}$ & -0.1227 \\
\hline & $(0.0780)$ & $(0.3083)$ & $(0.1123)$ & $(0.4436)$ \\
\hline \multirow[t]{2}{*}{ FACULTY } & 0.0271 & $0.4032 *$ & 0.0426 & 0.5052 \\
\hline & $(0.0654)$ & $(0.2189)$ & $(0.0941)$ & $(0.3148)$ \\
\hline \multirow[t]{2}{*}{ RESEARCH } & 0.0050 & $-0.0904^{* * *}$ & -0.0139 & $-0.1063^{* *}$ \\
\hline & $(0.0069)$ & $(0.0340)$ & $(0.0099)$ & $(0.0492)$ \\
\hline \multirow[t]{2}{*}{ TEACH } & 0.0317 & -0.0452 & $0.0853^{* *}$ & -0.0858 \\
\hline & $(0.0236)$ & $(0.1182)$ & $(0.0339)$ & $(0.1703)$ \\
\hline \multirow[t]{2}{*}{ SATACT } & $0.0293^{* * *}$ & -0.0148 & $0.0217^{* * *}$ & -0.0071 \\
\hline & $(0.0046)$ & $(0.0253)$ & $(0.0066)$ & $(0.0363)$ \\
\hline \multirow[t]{2}{*}{ ADMRATE } & 0.0457 & $0.7601^{* * *}$ & $0.3426^{* * *}$ & $0.7655^{* *}$ \\
\hline & $(0.0661)$ & $(0.2658)$ & $(0.0951)$ & $(0.3885)$ \\
\hline \multirow[t]{2}{*}{ POPDEN } & -0.0012 & 0.0041 & -0.0023 & -0.0004 \\
\hline & $(0.0012)$ & $(0.0050)$ & $(0.0017)$ & $(0.0072)$ \\
\hline \multirow[t]{2}{*}{ MEDINC } & $0.1585^{* * *}$ & $0.8854^{* * *}$ & $0.1750^{* * *}$ & $1.2148^{* * *}$ \\
\hline & $(0.0453)$ & $(0.2210)$ & $(0.0652)$ & $(0.3167)$ \\
\hline \multirow[t]{2}{*}{ PUBLIC } & $-0.3888 * * *$ & -0.0814 & $-0.1116^{* *}$ & -0.0819 \\
\hline & $(0.0329)$ & $(0.1573)$ & $(0.0473)$ & $(0.2119)$ \\
\hline \multirow{2}{*}{ Constant } & \multirow{2}{*}{\multicolumn{2}{|c|}{$\begin{array}{c}-6.3699^{* *} \\
(2.8311)\end{array}$}} & \multirow{2}{*}{\multicolumn{2}{|c|}{$\begin{array}{c}-11.4290^{* * *} \\
(4.0396)\end{array}$}} \\
\hline & & & & \\
\hline \multirow[t]{2}{*}{$\rho$} & \multicolumn{2}{|c|}{$0.3835^{* * *}$} & \multicolumn{2}{|c|}{$0.4339^{* * *}$} \\
\hline & \multicolumn{2}{|c|}{$(0.1084)$} & \multicolumn{2}{|c|}{$(0.1031)$} \\
\hline \multirow{2}{*}{$\begin{array}{l}\text { Observations } \\
\text { Log lik. }\end{array}$} & \multicolumn{2}{|c|}{528} & \multicolumn{2}{|c|}{528} \\
\hline & \multicolumn{2}{|c|}{84.0748} & \multicolumn{2}{|c|}{-108.7405} \\
\hline Est. method & \multicolumn{2}{|c|}{ SDM } & \multicolumn{2}{|c|}{ SDM } \\
\hline
\end{tabular}

Asymptotic standard errors in parentheses

${ }^{*} p<0.10,{ }^{* *} p<0.05,{ }^{* * *} p<0.01$ 
Table D.19: Marginal effects for published tuition in the product market for 2006

\begin{tabular}{lccc}
\hline \hline & \multicolumn{3}{c}{ Published Tuition 2006 } \\
& $(1)$ & $(2)$ & $(3)$ \\
& Direct Effects & Indirect Effects & Total Effects \\
\hline USTD & $-0.0062^{* *}$ & 0.0132 & 0.0070 \\
& $(0.0025)$ & $(0.0184)$ & $(0.0188)$ \\
GSTD & 0.0051 & -0.0456 & -0.0405 \\
& $(0.0044)$ & $(0.0298)$ & $(0.0301)$ \\
ENDOW & $0.0304^{* * *}$ & $0.1596^{* *}$ & $0.1901^{* *}$ \\
& $(0.0087)$ & $(0.0860)$ & $(0.0885)$ \\
PRAID & 0.0097 & -0.2155 & -0.2057 \\
& $(0.0722)$ & $(0.4894)$ & $(0.4844)$ \\
FACULTY & 0.0361 & $0.6618^{*}$ & $0.6979^{*}$ \\
& $(0.0596)$ & $(0.3892)$ & $(0.3932)$ \\
RESEARCH & 0.0031 & $-0.1416^{* *}$ & $-0.1384^{* *}$ \\
& $(0.0067)$ & $(0.0637)$ & $(0.0654)$ \\
TEACH & 0.0310 & -0.0529 & -0.0220 \\
& $(0.0216)$ & $(0.2163)$ & $(0.2239)$ \\
SATACT & $0.0293^{* * *}$ & -0.0057 & 0.0235 \\
& $(0.0044)$ & $(0.0462)$ & $(0.0464)$ \\
ADMRATE & 0.0625 & $1.2444^{* * *}$ & $1.3069^{* * *}$ \\
& $(0.0647)$ & $(0.4253)$ & $(0.4344)$ \\
POPDEN & -0.0011 & 0.0058 & 0.0047 \\
& $(0.0011)$ & $(0.0075)$ & $(0.0074)$ \\
MEDINC & $0.1790^{* * *}$ & $1.5142^{* * *}$ & $1.6932^{* * *}$ \\
& $(0.0423)$ & $(0.3959)$ & $(0.4008)$ \\
PUBLIC & $-0.3938^{* * *}$ & -0.3689 & $-0.7628^{* * *}$ \\
& $(0.0316)$ & $(0.2551)$ & $(0.2640)$ \\
\hline \hline
\end{tabular}

Method of estimation is SDM. Number of obervations is 528 .

Standard errors are clustered by universities and shown in parentheses.

${ }^{*} p<0.1,{ }^{* *} p<0.05,{ }^{* * *} p<0.01$ 
Table D.20: Marginal effects for net tuition in the product market for 2006

\begin{tabular}{lccc}
\hline \hline & & Net Tuition 2006 & $(2)$ \\
& $(1)$ & $(2)$ & $(3)$ \\
& Direct Effects & Indirect Effects & Total Effects \\
\hline USTD & -0.0036 & 0.0255 & 0.0219 \\
& $(0.0039)$ & $(0.0262)$ & $(0.0266)$ \\
GSTD & 0.0077 & $-0.0944^{*}$ & -0.0867 \\
& $(0.0076)$ & $(0.0562)$ & $(0.0582)$ \\
ENDOW & 0.0101 & $0.2199^{*}$ & $0.2301^{*}$ \\
& $(0.0122)$ & $(0.1220)$ & $(0.1250)$ \\
PRAID & $0.3039^{* * *}$ & 0.0158 & 0.3196 \\
& $(0.1179)$ & $(0.8067)$ & $(0.8270)$ \\
FACULTY & 0.0560 & $0.9117^{*}$ & $0.9677^{*}$ \\
& $(0.0891)$ & $(0.5654)$ & $(0.5730)$ \\
RESEARCH & -0.0168 & $-0.1955^{* *}$ & $-0.2123^{* *}$ \\
& $(0.0103)$ & $(0.0968)$ & $(0.0994)$ \\
TEACH & $0.0840^{* *}$ & -0.0850 & -0.0010 \\
& $(0.0335)$ & $(0.2967)$ & $(0.3061)$ \\
SATACT & $0.0218^{* * *}$ & 0.0041 & 0.0258 \\
& $(0.0066)$ & $(0.0603)$ & $(0.0612)$ \\
ADMRATE & $0.3659^{* * *}$ & $1.5915^{* *}$ & $1.9574^{* * *}$ \\
& $(0.0997)$ & $(0.7484)$ & $(0.7396)$ \\
POPDEN & -0.0024 & -0.0024 & -0.0048 \\
& $(0.0018)$ & $(0.0133)$ & $(0.0132)$ \\
MEDINC & $0.2080^{* * *}$ & $2.2470^{* * *}$ & $2.4550^{* * *}$ \\
& $(0.0617)$ & $(0.7199)$ & $(0.7236)$ \\
PUBLIC & $-0.1149^{* *}$ & -0.2269 & -0.3418 \\
& $(0.0484)$ & $(0.4296)$ & $(0.4362)$ \\
\hline \hline
\end{tabular}

Method of estimation is SDM. Number of obervations is 528 .

Asymptotic standard errors in parentheses.

${ }^{*} p<0.1,{ }^{* *} p<0.05,{ }^{* * *} p<0.01$ 
Table D.21: Spatial regressions for the product market in 2007

\begin{tabular}{|c|c|c|c|c|}
\hline & \multicolumn{2}{|c|}{ Published Tuition } & \multicolumn{2}{|c|}{ Net Tuition } \\
\hline & $(1)$ & (2) & (3) & (4) \\
\hline & Main & Spatial Lag & Main & Spatial Lag \\
\hline \multirow[t]{2}{*}{ USTD } & $-0.0077^{* * *}$ & -0.0081 & -0.0044 & -0.0030 \\
\hline & $(0.0028)$ & $(0.0110)$ & $(0.0041)$ & $(0.0159)$ \\
\hline \multirow[t]{2}{*}{ GSTD } & 0.0085 & -0.0331 & 0.0117 & $-0.0528 *$ \\
\hline & $(0.0055)$ & $(0.0218)$ & $(0.0080)$ & $(0.0320)$ \\
\hline \multirow[t]{2}{*}{ ENDOW } & $0.0267^{* * *}$ & 0.0801 ** & 0.0067 & $0.0998^{*}$ \\
\hline & $(0.0084)$ & $(0.0393)$ & $(0.0123)$ & $(0.0569)$ \\
\hline \multirow[t]{2}{*}{ PRAID } & 0.0429 & -0.1461 & $0.2894^{* *}$ & -0.1789 \\
\hline & $(0.0807)$ & $(0.3300)$ & $(0.1180)$ & $(0.4823)$ \\
\hline \multirow[t]{2}{*}{ FACULTY } & 0.0502 & $0.5816^{* *}$ & 0.0964 & 0.3700 \\
\hline & $(0.0673)$ & $(0.2334)$ & $(0.0982)$ & $(0.3362)$ \\
\hline \multirow[t]{2}{*}{ RESEARCH } & 0.0077 & -0.0590 * & -0.0100 & -0.0794 \\
\hline & $(0.0071)$ & $(0.0343)$ & $(0.0104)$ & $(0.0503)$ \\
\hline \multirow[t]{2}{*}{ TEACH } & 0.0217 & 0.0029 & $0.0698^{* *}$ & 0.0716 \\
\hline & $(0.0243)$ & $(0.1322)$ & $(0.0355)$ & $(0.1934)$ \\
\hline \multirow[t]{2}{*}{ SATACT } & $0.0320^{* * *}$ & $-0.0498^{* *}$ & $0.0241^{* * *}$ & -0.0377 \\
\hline & $(0.0047)$ & $(0.0240)$ & $(0.0069)$ & $(0.0351)$ \\
\hline \multirow[t]{2}{*}{ ADMRATE } & 0.0325 & $0.9360^{* * *}$ & $0.3127^{* * *}$ & $0.9467^{* *}$ \\
\hline & $(0.0634)$ & $(0.2846)$ & $(0.0928)$ & $(0.4202)$ \\
\hline \multirow[t]{2}{*}{ POPDEN } & -0.0013 & -0.0034 & -0.0017 & -0.0107 \\
\hline & $(0.0012)$ & $(0.0048)$ & $(0.0018)$ & $(0.0070)$ \\
\hline \multirow[t]{2}{*}{ MEDINC } & $0.1539^{* * *}$ & $0.8138^{* * *}$ & $0.1792^{* * *}$ & $0.9235^{* * *}$ \\
\hline & $(0.0474)$ & $(0.2367)$ & $(0.0693)$ & $(0.3413)$ \\
\hline \multirow[t]{2}{*}{ PUBLIC } & $-0.4007^{* * *}$ & $-0.2963 *$ & $-0.1224^{* *}$ & -0.2836 \\
\hline & $(0.0341)$ & $(0.1683)$ & $(0.0499)$ & $(0.2282)$ \\
\hline \multirow[t]{2}{*}{ Constant } & \multirow{2}{*}{\multicolumn{2}{|c|}{$\begin{array}{l}-5.3941^{*} \\
(2.8773)\end{array}$}} & \multirow{2}{*}{\multicolumn{2}{|c|}{$\begin{array}{r}-9.2997^{* *} \\
(4.1747)\end{array}$}} \\
\hline & & & & \\
\hline \multirow[t]{2}{*}{$\rho$} & \multicolumn{2}{|c|}{$0.3450^{* * *}$} & \multicolumn{2}{|c|}{$0.3559^{* * *}$} \\
\hline & \multicolumn{2}{|c|}{$(0.1149)$} & \multicolumn{2}{|c|}{$(0.1161)$} \\
\hline \multirow{3}{*}{$\begin{array}{l}\text { Observations } \\
\text { Log lik. } \\
\text { Est. method }\end{array}$} & \multicolumn{2}{|c|}{528} & \multicolumn{2}{|c|}{528} \\
\hline & \multicolumn{2}{|c|}{65.8486} & \multicolumn{2}{|c|}{-135.1803} \\
\hline & \multicolumn{2}{|c|}{ SDM } & \multicolumn{2}{|c|}{ SDM } \\
\hline
\end{tabular}

Asymptotic standard errors in parentheses

${ }^{*} p<0.10,{ }^{* *} p<0.05,{ }^{* * *} p<0.01$ 
Table D.22: Marginal effects for published tuition in the product market for 2007

\begin{tabular}{lccc}
\hline \hline & \multicolumn{3}{c}{ Published Tuition 2007} \\
& Direct Effects & Indirect Effects & Total Effects \\
\hline USTD & $-0.0079^{* * *}$ & -0.0162 & -0.0241 \\
GSTD & $(0.0029)$ & $(0.0169)$ & $(0.0169)$ \\
& 0.0080 & $-0.0456^{*}$ & -0.0376 \\
ENDOW & $(0.0062)$ & $(0.0301)$ & $(0.0311)$ \\
& $0.0283^{* * *}$ & $0.1348^{* *}$ & $0.1631^{* * *}$ \\
PRAID & $(0.0081)$ & $(0.0597)$ & $(0.0593)$ \\
& 0.0406 & -0.1981 & -0.1575 \\
FACULTY & $(0.0799)$ & $(0.4792)$ & $(0.4764)$ \\
& 0.0609 & $0.9037^{* * *}$ & $0.9646^{* * *}$ \\
RESEARCH & $(0.0612)$ & $(0.3382)$ & $(0.3476)$ \\
& 0.0067 & $-0.0850^{*}$ & -0.0782 \\
TEACH & $(0.0072)$ & $(0.0523)$ & $(0.0529)$ \\
& 0.0219 & 0.0157 & 0.0377 \\
SATACT & $(0.0253)$ & $(0.2123)$ & $(0.2235)$ \\
& $0.0313^{* * *}$ & -0.0585 & -0.0272 \\
ADMRATE & $(0.0048)$ & $(0.0343)$ & $(0.0341)$ \\
& 0.0493 & $1.4293^{* * *}$ & $1.4786^{* * *}$ \\
POPDEN & $(0.0613)$ & $(0.4681)$ & $(0.4747)$ \\
MEDINC & -0.0013 & -0.0058 & -0.0071 \\
PUBLIC & $(0.0011)$ & $(0.0079)$ & $(0.0077)$ \\
& $0.1694^{* * *}$ & $1.3082^{* * *}$ & $1.4776^{* * *}$ \\
\hline \hline
\end{tabular}

Method of estimation is SDM. Number of obervations is 528 .

Standard errors are clustered by universities and shown in parentheses.

${ }^{*} p<0.1,{ }^{* *} p<0.05,{ }^{* * *} p<0.01$ 
Table D.23: Marginal effects for net tuition in the product market for 2007

\begin{tabular}{lccc}
\hline \hline & & Net Tuition 2007 & $(2)$ \\
& Direct Effects & Indirect Effects & Total Effects \\
\hline USTD & -0.0045 & -0.0071 & -0.0116 \\
& $(0.0040)$ & $(0.0269)$ & $(0.0276)$ \\
GSTD & 0.0108 & $-0.0746^{*}$ & -0.0638 \\
& $(0.0084)$ & $(0.0456)$ & $(0.0461)$ \\
ENDOW & 0.0086 & 0.1568 & 0.1654 \\
& $(0.0133)$ & $(0.1296)$ & $(0.1337)$ \\
PRAID & $0.2880^{* *}$ & -0.1165 & 0.1715 \\
& $(0.1197)$ & $(0.7119)$ & $(0.6969)$ \\
FACULTY & 0.1039 & 0.6202 & 0.7240 \\
& $(0.0943)$ & $(0.5523)$ & $(0.5681)$ \\
RESEARCH & -0.0116 & -0.1273 & -0.1389 \\
& $(0.0096)$ & $(0.0970)$ & $(0.0988)$ \\
TEACH & $0.0716^{* *}$ & 0.1479 & 0.2195 \\
& $(0.0337)$ & $(0.3182)$ & $(0.3268)$ \\
SATACT & $0.0236^{* * *}$ & -0.0446 & -0.0210 \\
& $(0.0082)$ & $(0.0596)$ & $(0.0615)$ \\
ADMRATE & $0.3323^{* * *}$ & $1.6229^{* *}$ & $1.9552^{* * *}$ \\
& $(0.0883)$ & $(0.7445)$ & $(0.7631)$ \\
POPDEN & -0.0019 & $-0.0173^{*}$ & $-0.0192^{* *}$ \\
& $(0.0016)$ & $(0.0097)$ & $(0.0094)$ \\
MEDINC & $0.1975^{* * *}$ & $1.5144^{* *}$ & $1.7119^{* * *}$ \\
& $(0.0738)$ & $(0.6996)$ & $(0.7210)$ \\
PUBLIC & $-0.1285^{*}$ & -0.5019 & -0.6304 \\
& $(0.0493)$ & $(0.3979)$ & $(0.4017)$ \\
\hline \hline
\end{tabular}

Method of estimation is SDM. Number of obervations is 528 .

Asymptotic standard errors in parentheses.

${ }^{*} p<0.1,{ }^{* *} p<0.05,{ }^{* * *} p<0.01$ 
Table D.24: Spatial regressions for the product market in 2008

\begin{tabular}{|c|c|c|c|c|}
\hline & \multicolumn{2}{|c|}{ Published Tuition } & \multicolumn{2}{|c|}{ Net Tuition } \\
\hline & (1) & (2) & (3) & (4) \\
\hline & Main & Spatial Lag & Main & Spatial Lag \\
\hline \multirow[t]{2}{*}{ USTD } & $-0.0068^{* *}$ & -0.0052 & -0.0004 & 0.0045 \\
\hline & $(0.0027)$ & $(0.0106)$ & $(0.0039)$ & $(0.0151)$ \\
\hline \multirow[t]{2}{*}{ GSTD } & 0.0043 & -0.0301 & 0.0061 & -0.0238 \\
\hline & $(0.0054)$ & $(0.0194)$ & $(0.0077)$ & $(0.0280)$ \\
\hline \multirow[t]{2}{*}{ ENDOW } & $0.0290^{* * *}$ & $0.0805^{* *}$ & 0.0061 & 0.0851 \\
\hline & $(0.0090)$ & $(0.0399)$ & $(0.0130)$ & $(0.0571)$ \\
\hline \multirow{2}{*}{ PRAID } & $0.1421^{*}$ & -0.1662 & $0.4993^{* * *}$ & -0.3919 \\
\hline & $(0.0854)$ & $(0.3280)$ & $(0.1234)$ & $(0.4741)$ \\
\hline \multirow[t]{2}{*}{ FACULTY } & 0.0766 & 0.3094 & 0.0872 & -0.0370 \\
\hline & $(0.0660)$ & $(0.2212)$ & $(0.0951)$ & $(0.3130)$ \\
\hline \multirow[t]{2}{*}{ RESEARCH } & 0.0033 & -0.0544 & -0.0087 & $-0.0897^{*}$ \\
\hline & $(0.0070)$ & $(0.0346)$ & $(0.0101)$ & $(0.0499)$ \\
\hline \multirow[t]{2}{*}{ TEACH } & 0.0270 & 0.0130 & $0.0654^{*}$ & 0.0527 \\
\hline & $(0.0245)$ & $(0.1192)$ & $(0.0353)$ & $(0.1722)$ \\
\hline \multirow[t]{2}{*}{ SATACT } & $0.0318^{* * *}$ & -0.0150 & $0.0247^{* * *}$ & 0.0281 \\
\hline & $(0.0048)$ & $(0.0247)$ & $(0.0070)$ & $(0.0355)$ \\
\hline \multirow{2}{*}{ ADMRATE } & 0.0449 & $0.8790^{* * *}$ & $0.3157^{* * *}$ & $0.9331^{* *}$ \\
\hline & $(0.0646)$ & $(0.2754)$ & $(0.0933)$ & $(0.4008)$ \\
\hline \multirow[t]{2}{*}{ POPDEN } & -0.0013 & -0.0056 & -0.0025 & $-0.0127^{*}$ \\
\hline & $(0.0012)$ & $(0.0048)$ & $(0.0018)$ & $(0.0069)$ \\
\hline \multirow[t]{2}{*}{ MEDINC } & $0.1594^{* * *}$ & $0.6506^{* * *}$ & $0.1807^{* * *}$ & $0.6189^{* *}$ \\
\hline & $(0.0482)$ & $(0.2144)$ & $(0.0696)$ & $(0.3050)$ \\
\hline \multirow[t]{2}{*}{ PUBLIC } & $-0.4092^{* * *}$ & -0.0940 & $-0.1257^{* *}$ & -0.0842 \\
\hline & $(0.0342)$ & $(0.1531)$ & $(0.0494)$ & $(0.2032)$ \\
\hline \multirow[t]{2}{*}{ Constant } & \multirow{2}{*}{\multicolumn{2}{|c|}{$\begin{array}{l}-4.9904^{*} \\
(2.7478)\end{array}$}} & \multirow{2}{*}{\multicolumn{2}{|c|}{$\begin{array}{l}-6.5472^{*} \\
(3.9271)\end{array}$}} \\
\hline & & & & \\
\hline \multirow[t]{2}{*}{$\rho$} & \multicolumn{2}{|c|}{$\begin{array}{c}0.3647^{* * *} \\
(0.1218)\end{array}$} & \multirow{2}{*}{\multicolumn{2}{|c|}{$\begin{array}{c}0.3407^{* * *} \\
(0.1220)\end{array}$}} \\
\hline & \multirow{2}{*}{\multicolumn{2}{|c|}{$\frac{(0.1218)}{528}$}} & & \\
\hline Observations & & & \multicolumn{2}{|c|}{528} \\
\hline Log lik. & \multicolumn{2}{|c|}{58.8067} & \multicolumn{2}{|c|}{-135.1726} \\
\hline Est. method & \multicolumn{2}{|c|}{ SDM } & \multicolumn{2}{|c|}{ SDM } \\
\hline
\end{tabular}

Asymptotic standard errors in parentheses

${ }^{*} p<0.10,{ }^{* *} p<0.05,{ }^{* * *} p<0.01$ 
Table D.25: Marginal effects for published tuition in the product market for 2008

\begin{tabular}{|c|c|c|c|}
\hline & \multicolumn{3}{|c|}{ Published Tuition 2008} \\
\hline & (1) & $(2)$ & $(3)$ \\
\hline & Direct Effects & Indirect Effects & Total Effects \\
\hline \multirow[t]{2}{*}{ USTD } & $-0.0069^{* *}$ & -0.0120 & -0.0189 \\
\hline & $(0.0028)$ & $(0.0169)$ & $(0.0172)$ \\
\hline \multirow[t]{2}{*}{ GSTD } & 0.0037 & $-0.0443^{*}$ & -0.0406 \\
\hline & $(0.0047)$ & $(0.0264)$ & $(0.0267)$ \\
\hline \multirow[t]{2}{*}{ ENDOW } & $0.0309^{* * *}$ & $0.1413^{* *}$ & $0.1722^{* *}$ \\
\hline & $(0.0082)$ & $(0.0705)$ & $(0.0710)$ \\
\hline \multirow[t]{2}{*}{ PRAID } & $0.1396^{*}$ & -0.1776 & -0.0380 \\
\hline & $(0.0782)$ & $(0.4629)$ & $(0.4895)$ \\
\hline \multirow[t]{2}{*}{ FACULTY } & 0.0839 & 0.5238 & $0.6077^{*}$ \\
\hline & $(0.0634)$ & $(0.3303)$ & $(0.3577)$ \\
\hline \multirow[t]{2}{*}{ RESEARCH } & 0.0021 & $-0.0826^{*}$ & -0.0804 \\
\hline & $(0.0062)$ & $(0.0475)$ & $(0.0477)$ \\
\hline \multirow[t]{2}{*}{ TEACH } & 0.0275 & 0.0355 & 0.0630 \\
\hline & $(0.0243)$ & $(0.1667)$ & $(0.1732)$ \\
\hline \multirow[t]{2}{*}{ SATACT } & $0.0317^{* * *}$ & -0.0053 & 0.0265 \\
\hline & $(0.0050)$ & $(0.0358)$ & $(0.0365)$ \\
\hline \multirow[t]{2}{*}{ ADMRATE } & 0.0643 & $1.3900^{* * *}$ & $1.4543^{* * *}$ \\
\hline & $(0.0636)$ & $(0.3748)$ & $(0.3797)$ \\
\hline \multirow[t]{2}{*}{ POPDEN } & -0.0014 & -0.0094 & -0.0108 \\
\hline & $(0.0011)$ & $(0.0076)$ & $(0.0075)$ \\
\hline \multirow[t]{2}{*}{ MEDINC } & $0.1747^{* * *}$ & $1.1002^{* * *}$ & $1.2749^{* * *}$ \\
\hline & $(0.0441)$ & $(0.3533)$ & $(0.3526)$ \\
\hline \multirow[t]{2}{*}{ PUBLIC } & $-0.4145^{* * *}$ & $-0.3776^{*}$ & $-0.7921^{* * *}$ \\
\hline & $(0.0353)$ & $(0.2161)$ & $(0.2166)$ \\
\hline
\end{tabular}

Method of estimation is SDM. Number of obervations is 528 .

Standard errors are clustered by universities and shown in parentheses.

${ }^{*} p<0.1,{ }^{* *} p<0.05,{ }^{* * *} p<0.01$ 
Table D.26: Marginal effects for net tuition in the product market for 2008

\begin{tabular}{lccc}
\hline \hline & & Net Tuition 2008 & $(3)$ \\
& $(1)$ & $(2)$ & $(3)$ \\
& Direct Effects & Indirect Effects & Total Effects \\
\hline USTD & -0.0003 & 0.0065 & 0.0062 \\
& $(0.0038)$ & $(0.0249)$ & $(0.0258)$ \\
GSTD & 0.0057 & -0.0325 & -0.0268 \\
& $(0.0079)$ & $(0.0434)$ & $(0.0452)$ \\
ENDOW & 0.0078 & 0.1304 & 0.1382 \\
& $(0.0136)$ & $(0.1081)$ & $(0.1105)$ \\
PRAID & $0.4949^{* * *}$ & -0.3320 & 0.1628 \\
& $(0.1169)$ & $(0.7737)$ & $(0.7893)$ \\
FACULTY & 0.0871 & -0.0109 & 0.0762 \\
& $(0.0885)$ & $(0.6016)$ & $(0.6264)$ \\
RESEARCH & -0.0106 & $-0.1387^{*}$ & $-0.1492^{*}$ \\
& $(0.0106)$ & $(0.0859)$ & $(0.0861)$ \\
TEACH & $0.0669^{*}$ & 0.1123 & 0.1792 \\
& $(0.0384)$ & $(0.2835)$ & $(0.2886)$ \\
SATACT & $0.0255^{* * *}$ & 0.0547 & 0.0801 \\
& $(0.0074)$ & $(0.0637)$ & $(0.0659)$ \\
ADMRATE & $0.3364^{* * *}$ & $1.5577^{* *}$ & $1.8941^{* * *}$ \\
& $(0.0954)$ & $(0.7447)$ & $(0.7637)$ \\
POPDEN & -0.0027 & $-0.0203^{* *}$ & $-0.0230^{* *}$ \\
& $(0.0020)$ & $(0.0100)$ & $(0.0098)$ \\
MEDINC & $0.1942^{* * *}$ & $1.0186^{* *}$ & $1.2129^{* *}$ \\
& $(0.0687)$ & $(0.5129)$ & $(0.5132)$ \\
PUBLIC & $-0.1282^{* * *}$ & -0.1901 & -0.3183 \\
& $(0.0507)$ & $(0.2747)$ & $(0.2803)$ \\
\hline \hline
\end{tabular}

Method of estimation is SDM. Number of obervations is 528 .

Asymptotic standard errors in parentheses.

${ }^{*} p<0.1,{ }^{* *} p<0.05,{ }^{* * *} p<0.01$ 
Table D.27: Spatial regressions for the product market in 2009

\begin{tabular}{|c|c|c|c|c|}
\hline & \multicolumn{2}{|c|}{ Published Tuition } & \multicolumn{2}{|c|}{ Net Tuition } \\
\hline & (1) & (2) & (3) & (4) \\
\hline & Main & Spatial Lag & Main & Spatial Lag \\
\hline \multirow[t]{2}{*}{ USTD } & -0.0041 & -0.0042 & 0.0018 & 0.0112 \\
\hline & $(0.0026)$ & $(0.0115)$ & $(0.0045)$ & $(0.0195)$ \\
\hline \multirow[t]{2}{*}{ GSTD } & 0.0025 & -0.0328 & 0.0037 & -0.0559 \\
\hline & $(0.0052)$ & $(0.0226)$ & $(0.0088)$ & $(0.0383)$ \\
\hline \multirow[t]{2}{*}{ ENDOW } & $0.0367^{* * *}$ & 0.0374 & -0.0003 & 0.0454 \\
\hline & $(0.0092)$ & $(0.0414)$ & $(0.0156)$ & $(0.0702)$ \\
\hline \multirow[t]{2}{*}{ PRAID } & -0.0332 & 0.1099 & $0.4210^{* * *}$ & -0.1440 \\
\hline & $(0.0963)$ & $(0.3880)$ & $(0.1634)$ & $(0.6624)$ \\
\hline \multirow[t]{2}{*}{ FACULTY } & 0.0415 & $0.5257^{* *}$ & 0.0756 & 0.6548 \\
\hline & $(0.0635)$ & $(0.2649)$ & $(0.1077)$ & $(0.4454)$ \\
\hline \multirow[t]{2}{*}{ RESEARCH } & 0.0000 & $-0.0701^{* *}$ & -0.0092 & $-0.1106^{*}$ \\
\hline & $(0.0069)$ & $(0.0352)$ & $(0.0118)$ & $(0.0598)$ \\
\hline \multirow[t]{2}{*}{ TEACH } & 0.0142 & 0.0691 & 0.0417 & 0.0390 \\
\hline & $(0.0241)$ & $(0.1326)$ & $(0.0410)$ & $(0.2250)$ \\
\hline \multirow[t]{2}{*}{ SATACT } & $0.0275^{* * *}$ & -0.0190 & $0.0240^{* * *}$ & -0.0055 \\
\hline & $(0.0048)$ & $(0.0271)$ & $(0.0082)$ & $(0.0459)$ \\
\hline \multirow{2}{*}{ ADMRATE } & 0.0222 & $0.6343^{* *}$ & $0.4359^{* * *}$ & 0.6513 \\
\hline & $(0.0663)$ & $(0.2791)$ & $(0.1126)$ & $(0.4806)$ \\
\hline \multirow[t]{2}{*}{ POPDEN } & -0.0010 & -0.0043 & -0.0005 & -0.0103 \\
\hline & $(0.0012)$ & $(0.0048)$ & $(0.0021)$ & $(0.0081)$ \\
\hline \multirow[t]{2}{*}{ MEDINC } & $0.1161^{* *}$ & $0.4995^{* *}$ & $0.1692^{* *}$ & $0.6786^{*}$ \\
\hline & $(0.0470)$ & $(0.2155)$ & $(0.0798)$ & $(0.3613)$ \\
\hline \multirow[t]{2}{*}{ PUBLIC } & $-0.4050^{* * *}$ & -0.1764 & -0.0483 & -0.3929 \\
\hline & $(0.0341)$ & $(0.1586)$ & $(0.0579)$ & $(0.2506)$ \\
\hline \multirow[t]{2}{*}{ Constant } & \multirow{2}{*}{\multicolumn{2}{|c|}{$\begin{array}{l}-2.6638 \\
(2.8180)\end{array}$}} & \multirow{2}{*}{\multicolumn{2}{|c|}{$\begin{array}{l}-4.5459 \\
(4.7549)\end{array}$}} \\
\hline & & & & \\
\hline \multirow[t]{2}{*}{$\rho$} & \multirow{2}{*}{\multicolumn{2}{|c|}{$\begin{array}{c}0.3776^{* * *} \\
(0.1203)\end{array}$}} & \multirow{2}{*}{\multicolumn{2}{|c|}{$\begin{array}{l}0.3187^{* *} \\
(0.1296)\end{array}$}} \\
\hline & & & & \\
\hline \multirow{2}{*}{$\begin{array}{l}\text { Observations } \\
\text { Log lik. }\end{array}$} & \multicolumn{2}{|c|}{528} & \multicolumn{2}{|c|}{528} \\
\hline & \multicolumn{2}{|c|}{64.6467} & \multicolumn{2}{|c|}{-213.8396} \\
\hline Est. method & \multicolumn{2}{|c|}{ SDM } & \multicolumn{2}{|c|}{ SDM } \\
\hline
\end{tabular}

Asymptotic standard errors in parentheses

${ }^{*} p<0.1,{ }^{* *} p<0.05,{ }^{* * *} p<0.01$ 
Table D.28: Marginal effects for published tuition in the product market for 2009

\begin{tabular}{|c|c|c|c|}
\hline & \multicolumn{3}{|c|}{ Published Tuition 2009} \\
\hline & (1) & $(2)$ & $(3)$ \\
\hline & Direct Effects & Indirect Effects & Total Effects \\
\hline \multirow[t]{2}{*}{ USTD } & -0.0042 & -0.0091 & -0.0133 \\
\hline & $(0.0028)$ & $(0.0152)$ & $(0.0157)$ \\
\hline \multirow[t]{2}{*}{ GSTD } & 0.0018 & -0.0505 & -0.0487 \\
\hline & $(0.0047)$ & $(0.0379)$ & $(0.0395)$ \\
\hline \multirow[t]{2}{*}{ ENDOW } & $0.0378^{* * *}$ & 0.0812 & $0.1191^{*}$ \\
\hline & $(0.0092)$ & $(0.0663)$ & $(0.0672)$ \\
\hline \multirow[t]{2}{*}{ PRAID } & -0.0311 & 0.1543 & 0.1232 \\
\hline & $(0.0944)$ & $(0.6721)$ & $(0.6833)$ \\
\hline \multirow[t]{2}{*}{ FACULTY } & 0.0532 & $0.8581^{* *}$ & $0.9113^{* *}$ \\
\hline & $(0.0546)$ & $(0.4357)$ & $(0.4362)$ \\
\hline \multirow[t]{2}{*}{ RESEARCH } & -0.0016 & $-0.1111^{* *}$ & $-0.1127^{* *}$ \\
\hline & $(0.0065)$ & $(0.0594)$ & $(0.0601)$ \\
\hline \multirow[t]{2}{*}{ TEACH } & 0.0158 & 0.1181 & 0.1339 \\
\hline & $(0.0271)$ & $(0.2289)$ & $(0.2414)$ \\
\hline \multirow[t]{2}{*}{ SATACT } & $0.0273^{* * *}$ & -0.0136 & 0.0137 \\
\hline & $(0.0058)$ & $(0.0443)$ & $(0.0446)$ \\
\hline \multirow[t]{2}{*}{ ADMRATE } & 0.0361 & $1.0187^{* *}$ & $1.0548^{* *}$ \\
\hline & $(0.0609)$ & $(0.5074)$ & $(0.5023)$ \\
\hline \multirow[t]{2}{*}{ POPDEN } & -0.0011 & -0.0074 & -0.0085 \\
\hline & $(0.0011)$ & $(0.0073)$ & $(0.0069)$ \\
\hline \multirow[t]{2}{*}{ MEDINC } & $0.1279^{* *}$ & $0.8613^{* *}$ & $0.9891^{* * *}$ \\
\hline & $(0.0471)$ & $(0.3657)$ & $(0.3809)$ \\
\hline \multirow[t]{2}{*}{ PUBLIC } & $-0.4121^{* * *}$ & $-0.5220^{* *}$ & $-0.9342^{* * *}$ \\
\hline & $(0.0314)$ & $(0.2597)$ & $(0.2574)$ \\
\hline
\end{tabular}

Method of estimation is SDM. Number of obervations is 528 .

Standard errors are clustered by universities and shown in parentheses.

${ }^{*} p<0.1,{ }^{* *} p<0.05,{ }^{* * *} p<0.01$ 
Table D.29: Marginal effects for net tuition in the product market for 2009

\begin{tabular}{lccc}
\hline \hline & & Net Tuition 2009 & $(3)$ \\
& $(1)$ & $(2)$ & $(3)$ \\
& Direct Effects & Indirect Effects & Total Effects \\
\hline USTD & 0.0008 & 0.0006 & 0.0014 \\
& $(0.0043)$ & $(0.0038)$ & $(0.0079)$ \\
GSTD & 0.0075 & 0.0051 & 0.0125 \\
& $(0.0091)$ & $(0.0075)$ & $(0.0159)$ \\
ENDOW & -0.0031 & -0.0021 & -0.0052 \\
& $(0.0127)$ & $(0.0109)$ & $(0.0232)$ \\
PRAID & $0.3488^{* *}$ & 0.2370 & $0.5858^{*}$ \\
& $(0.1633)$ & $(0.2082)$ & $(0.3459)$ \\
FACULTY & 0.0872 & 0.0592 & 0.1464 \\
& $(0.0893)$ & $(0.0886)$ & $(0.1718)$ \\
RESEARCH & -0.0154 & -0.0105 & -0.0259 \\
& $(0.0106)$ & $(0.0115)$ & $(0.0210)$ \\
TEACH & 0.0378 & 0.0257 & 0.0635 \\
& $(0.0411)$ & $(0.0385)$ & $(0.0767)$ \\
SATACT & $0.0238^{* * *}$ & $0.0162^{*}$ & $0.0400^{* *}$ \\
& $(0.0086)$ & $(0.0108)$ & $(0.0171)$ \\
ADMRATE & $0.4889^{* * *}$ & $0.3321^{*}$ & $0.8210^{* * *}$ \\
& $(0.1081)$ & $(0.1978)$ & $(0.2583)$ \\
POPDEN & -0.0021 & -0.0015 & -0.0036 \\
& $(0.0019)$ & $(0.0014)$ & $(0.0032)$ \\
MEDINC & $0.1692^{* *}$ & 0.1149 & $0.2841^{* *}$ \\
& $(0.0770)$ & $(0.0912)$ & $(0.1516)$ \\
PUBLIC & -0.0872 & -0.0592 & -0.1465 \\
& $(0.0539)$ & $(0.0488)$ & $(0.0955)$ \\
\hline \hline
\end{tabular}

Method of estimation is SDM. Number of obervations is 528 .

Asymptotic standard errors in parentheses.

${ }^{*} p<0.1,{ }^{* *} p<0.05,{ }^{* * *} p<0.01$ 
Table D.30: Spatial regressions for the product market in 2010

\begin{tabular}{|c|c|c|c|c|}
\hline & \multicolumn{2}{|c|}{ Published Tuition } & \multicolumn{2}{|c|}{ Net Tuition } \\
\hline & $(1)$ & (2) & (3) & (4) \\
\hline & Main & Spatial Lag & Main & Spatial Lag \\
\hline \multirow[t]{2}{*}{ USTD } & $-0.0050^{*}$ & $-0.0002^{* *}$ & -0.0018 & 0.0022 \\
\hline & $(0.0026)$ & $(0.0114)$ & $(0.0041)$ & $(0.0178)$ \\
\hline \multirow[t]{2}{*}{ GSTD } & 0.0030 & -0.0323 & 0.0047 & -0.0316 \\
\hline & $(0.0049)$ & $(0.0237)$ & $(0.0077)$ & $(0.0372)$ \\
\hline \multirow[t]{2}{*}{ ENDOW } & $0.0329^{* * *}$ & $0.0861^{* *}$ & -0.0012 & 0.0881 \\
\hline & $(0.0095)$ & $(0.0407)$ & $(0.0145)$ & $(0.0626)$ \\
\hline \multirow[t]{2}{*}{ PRAID } & -0.0981 & -0.6185 & $0.3660^{* *}$ & $-1.2979^{*}$ \\
\hline & $(0.1018)$ & $(0.4425)$ & $(0.1598)$ & $(0.6894)$ \\
\hline \multirow[t]{2}{*}{ FACULTY } & 0.0747 & 0.4017 & 0.1167 & -0.2386 \\
\hline & $(0.0632)$ & $(0.2825)$ & $(0.0992)$ & $(0.4393)$ \\
\hline \multirow[t]{2}{*}{ RESEARCH } & 0.0023 & $-0.1078^{* * *}$ & -0.0066 & $-0.1417^{* *}$ \\
\hline & $(0.0070)$ & $(0.0363)$ & $(0.0109)$ & $(0.0571)$ \\
\hline \multirow[t]{2}{*}{ TEACH } & 0.0078 & 0.1952 & 0.0217 & 0.3354 \\
\hline & $(0.0238)$ & $(0.1302)$ & $(0.0374)$ & $(0.2045)$ \\
\hline \multirow[t]{2}{*}{ SATACT } & $0.0273^{* * *}$ & $-0.0737^{* * *}$ & $0.0185^{* *}$ & $-0.0993^{* *}$ \\
\hline & $(0.0048)$ & $(0.0254)$ & $(0.0075)$ & $(0.0399)$ \\
\hline \multirow{2}{*}{ ADMRATE } & 0.0970 & $0.6254^{* *}$ & $0.4248^{* * *}$ & 0.6864 \\
\hline & $(0.0650)$ & $(0.2664)$ & $(0.1020)$ & $(0.4219)$ \\
\hline \multirow[t]{2}{*}{ POPDEN } & -0.0017 & -0.0046 & -0.0024 & -0.0091 \\
\hline & $(0.0013)$ & $(0.0050)$ & $(0.0020)$ & $(0.0079)$ \\
\hline \multirow[t]{2}{*}{ MEDINC } & $0.1022^{* *}$ & $0.8473^{* * *}$ & $0.1578^{* *}$ & $0.8782^{* *}$ \\
\hline & $(0.0482)$ & $(0.2334)$ & $(0.0756)$ & $(0.3621)$ \\
\hline \multirow[t]{2}{*}{ PUBLIC } & $-0.4234^{* * *}$ & -0.2595 & -0.0805 & $-0.4501^{*}$ \\
\hline & $(0.0338)$ & $(0.1620)$ & $(0.0530)$ & $(0.2305)$ \\
\hline \multirow[t]{2}{*}{ Constant } & \multirow{2}{*}{\multicolumn{2}{|c|}{$\begin{array}{c}-6.2673^{* *} \\
(3.0369)\end{array}$}} & \multirow{2}{*}{\multicolumn{2}{|c|}{$\begin{array}{c}-9.6018^{* *} \\
(4.7028)\end{array}$}} \\
\hline & & & & \\
\hline \multirow[t]{2}{*}{$\rho$} & \multirow{2}{*}{\multicolumn{2}{|c|}{$\begin{array}{c}0.3332^{* * *} \\
(0.1175)\end{array}$}} & \multirow{2}{*}{\multicolumn{2}{|c|}{$\begin{array}{c}0.4479^{* * *} \\
(0.1070)\end{array}$}} \\
\hline & & & & \\
\hline \multirow{2}{*}{$\begin{array}{l}\text { Observations } \\
\text { Log lik. }\end{array}$} & \multicolumn{2}{|c|}{528} & \multicolumn{2}{|c|}{528} \\
\hline & \multicolumn{2}{|c|}{69.7911} & \multicolumn{2}{|c|}{-169.5226} \\
\hline Est. method & \multicolumn{2}{|c|}{ SDM } & \multicolumn{2}{|c|}{ SDM } \\
\hline
\end{tabular}

Asymptotic standard errors in parentheses

${ }^{*} p<0.10,{ }^{* *} p<0.05,{ }^{* * *} p<0.01$ 
Table D.31: Marginal effects for published tuition in the product market for 2010

\begin{tabular}{|c|c|c|c|}
\hline & \multicolumn{3}{|c|}{ Published Tuition 2010} \\
\hline & (1) & $(2)$ & $(3)$ \\
\hline & Direct Effects & Indirect Effects & Total Effects \\
\hline \multirow[t]{2}{*}{ USTD } & -0.0050 & -0.0028 & -0.0078 \\
\hline & $(0.0025)$ & $(0.0172)$ & $(0.0178)$ \\
\hline \multirow[t]{2}{*}{ GSTD } & 0.0025 & $-0.0464^{* *}$ & $-0.0438^{* *}$ \\
\hline & $(0.0045)$ & $(0.0341)$ & $(0.0360)$ \\
\hline \multirow[t]{2}{*}{ ENDOW } & 0.0345 & 0.1440 & 0.1785 \\
\hline & $(0.0085)$ & $(0.0622)$ & $(0.0625)$ \\
\hline \multirow[t]{2}{*}{ PRAID } & $-0.1089^{*}$ & $-0.9657^{* *}$ & $-1.0746^{*}$ \\
\hline & $(0.1049)$ & $(0.5794)$ & $(0.6037)$ \\
\hline \multirow[t]{2}{*}{ FACULTY } & $0.0817^{*}$ & 0.6326 & 0.7144 \\
\hline & $(0.0569)$ & $(0.4228)$ & $(0.4243)$ \\
\hline \multirow[t]{2}{*}{ RESEARCH } & 0.0005 & $-0.1587^{*}$ & $-0.1582^{*}$ \\
\hline & $(0.0070)$ & $(0.0628)$ & $(0.0643)$ \\
\hline \multirow[t]{2}{*}{ TEACH } & 0.0111 & $0.2933^{* * *}$ & $0.3044^{* * *}$ \\
\hline & $(0.0278)$ & $(0.1747)$ & $(0.1798)$ \\
\hline \multirow[t]{2}{*}{ SATACT } & $0.0262^{* *}$ & $-0.0958^{* *}$ & $-0.0695^{*}$ \\
\hline & $(0.0048)$ & $(0.0394)$ & $(0.0400)$ \\
\hline \multirow[t]{2}{*}{ ADMRATE } & $0.1079^{* * *}$ & $0.9755^{* * *}$ & $1.0834^{* * *}$ \\
\hline & $(0.0652)$ & $(0.4164)$ & $(0.4083)$ \\
\hline \multirow[t]{2}{*}{ POPDEN } & $-0.0018^{*}$ & $-0.0077^{*}$ & $-0.0095^{* *}$ \\
\hline & $(0.0013)$ & $(0.0068)$ & $(0.0065)$ \\
\hline \multirow[t]{2}{*}{ MEDINC } & $0.1168^{* *}$ & $1.3071^{*}$ & $1.4239^{*}$ \\
\hline & $(0.0558)$ & $(0.3234)$ & $(0.3278)$ \\
\hline \multirow[t]{2}{*}{ PUBLIC } & $-0.4300^{* *}$ & $-0.5942^{* *}$ & $-1.0242^{* * *}$ \\
\hline & $(0.0346)$ & $(0.2034)$ & $(0.1993)$ \\
\hline
\end{tabular}

Method of estimation is SDM. Number of obervations is 528 .

Standard errors are clustered by universities and shown in parentheses.

${ }^{*} p<0.1,{ }^{* *} p<0.05,{ }^{* * *} p<0.01$ 
Table D.32: Marginal effects for net tuition in the product market for 2010

\begin{tabular}{lccc}
\hline \hline & & Net Tuition 2010 & $(3)$ \\
& $(1)$ & $(2)$ & $(3)$ \\
& Direct Effects & Indirect Effects & Total Effects \\
\hline USTD & 0.0019 & 0.0054 & 0.0073 \\
& $(0.0036)$ & $(0.0328)$ & $(0.0324)$ \\
GSTD & 0.0040 & -0.0527 & -0.0487 \\
& $(0.0087)$ & $(0.0755)$ & $(0.0789)$ \\
ENDOW & 0.0009 & 0.1565 & 0.1574 \\
& $(0.0141)$ & $(0.1241)$ & $(0.1265)$ \\
PRAID & $0.3383^{* *}$ & -2.0262 & -1.6880 \\
& $(0.1419)$ & $(1.4654)$ & $(1.5125)$ \\
FACULTY & 0.1238 & 0.5197 & 0.6435 \\
& $(0.0960)$ & $(0.9101)$ & $(0.9229)$ \\
RESEARCH & -0.0102 & $-0.2586^{* *}$ & $-0.2687^{* *}$ \\
& $(0.0121)$ & $(0.1195)$ & $(0.1221)$ \\
TEACH & 0.0301 & $0.6166^{*}$ & $0.6467^{*}$ \\
& $(0.0353)$ & $(0.3709)$ & $(0.3807)$ \\
SATACT & $0.0163^{* *}$ & $-0.1627^{* *}$ & $-0.1464^{*}$ \\
& $(0.0070)$ & $(0.0799)$ & $(0.0809)$ \\
ADMRATE & $0.4462^{* * *}$ & $1.5665^{* *}$ & $2.0127^{* * *}$ \\
& $(0.1055)$ & $(0.7523)$ & $(0.7574)$ \\
POPDEN & -0.0026 & -0.0181 & -0.0207 \\
& $(0.0021)$ & $(0.0134)$ & $(0.0131)$ \\
MEDINC & $0.1810^{* *}$ & $1.6955^{* *}$ & $1.8765^{* *}$ \\
& $(0.0760)$ & $(0.7926)$ & $(0.7941)$ \\
PUBLIC & $-0.0924^{*}$ & $-0.8687^{* *}$ & $-0.9612^{* *}$ \\
& $(0.0508)$ & $(0.4204)$ & $(0.4217)$ \\
\hline \hline
\end{tabular}

Method of estimation is SDM. Number of obervations is 528 .

Standard errors are clustered by universities and shown in parentheses.

${ }^{*} p<0.1,{ }^{* *} p<0.05,{ }^{* * *} p<0.01$ 
Table D.33: Spatial regressions for the product market in 2011

\begin{tabular}{|c|c|c|c|c|}
\hline & \multicolumn{2}{|c|}{ Published Tuition } & \multicolumn{2}{|c|}{ Net Tuition } \\
\hline & (1) & (2) & (3) & (4) \\
\hline & Main & Spatial Lag & Main & Spatial Lag \\
\hline \multirow[t]{2}{*}{ USTD } & $-0.0066^{* * *}$ & 0.0124 & -0.0015 & 0.0152 \\
\hline & $(0.0025)$ & $(0.0091)$ & $(0.0038)$ & $(0.0137)$ \\
\hline \multirow[t]{2}{*}{ GSTD } & -0.0002 & $-0.0555^{* * *}$ & -0.0007 & $-0.0758^{* *}$ \\
\hline & $(0.0050)$ & $(0.0201)$ & $(0.0076)$ & $(0.0310)$ \\
\hline \multirow[t]{2}{*}{ ENDOW } & $0.0545^{* * *}$ & -0.0118 & $0.0260^{*}$ & -0.0440 \\
\hline & $(0.0095)$ & $(0.0432)$ & $(0.0146)$ & $(0.0654)$ \\
\hline \multirow{2}{*}{ PRAID } & -0.1007 & -0.7308 & $0.5022^{* * *}$ & $-1.7569^{* *}$ \\
\hline & $(0.1036)$ & $(0.4738)$ & $(0.1588)$ & $(0.7264)$ \\
\hline \multirow[t]{2}{*}{ FACULTY } & $0.1135^{*}$ & -0.0588 & $0.2144^{* *}$ & -0.4090 \\
\hline & $(0.0660)$ & $(0.2174)$ & $(0.1011)$ & $(0.3323)$ \\
\hline \multirow[t]{2}{*}{ RESEARCH } & 0.0041 & $-0.0900^{* *}$ & $-0.0195^{*}$ & -0.0890 \\
\hline & $(0.0072)$ & $(0.0392)$ & $(0.0110)$ & $(0.0600)$ \\
\hline \multirow[t]{2}{*}{ TEACH } & 0.0223 & $0.3374^{* * *}$ & 0.0541 & $0.5474^{* * *}$ \\
\hline & $(0.0241)$ & $(0.1208)$ & $(0.0369)$ & $(0.1851)$ \\
\hline \multirow[t]{2}{*}{ SATACT } & $0.0126^{* * *}$ & -0.0013 & 0.0083 & -0.0032 \\
\hline & $(0.0033)$ & $(0.0155)$ & $(0.0051)$ & $(0.0235)$ \\
\hline \multirow[t]{2}{*}{ ADMRATE } & 0.0023 & $0.7874^{* * *}$ & $0.2999^{* * *}$ & $0.9256^{* *}$ \\
\hline & $(0.0652)$ & $(0.2816)$ & $(0.0998)$ & $(0.4354)$ \\
\hline \multirow[t]{2}{*}{ POPDEN } & -0.0016 & -0.0063 & -0.0021 & -0.0086 \\
\hline & $(0.0013)$ & $(0.0050)$ & $(0.0020)$ & $(0.0076)$ \\
\hline \multirow[t]{2}{*}{ MEDINC } & $0.1019^{* *}$ & 0.2968 & $0.1671^{* *}$ & 0.2064 \\
\hline & $(0.0479)$ & $(0.2283)$ & $(0.0734)$ & $(0.3461)$ \\
\hline \multirow[t]{2}{*}{ PUBLIC } & $-0.4441^{* * *}$ & -0.2073 & -0.0625 & $-0.4469^{*}$ \\
\hline & $(0.0339)$ & $(0.1571)$ & $(0.0519)$ & $(0.2376)$ \\
\hline \multirow[t]{2}{*}{ Constant } & \multirow{2}{*}{\multicolumn{2}{|c|}{$\begin{array}{l}-4.1841 \\
(3.1064)\end{array}$}} & \multirow{2}{*}{\multicolumn{2}{|c|}{$\begin{array}{l}-6.3058 \\
(4.6987)\end{array}$}} \\
\hline & & & & \\
\hline \multirow[t]{2}{*}{$\rho$} & \multirow{2}{*}{\multicolumn{2}{|c|}{$\begin{array}{c}0.4440^{* * *} \\
(0.1061)\end{array}$}} & \multicolumn{2}{|c|}{$0.3869^{* * *}$} \\
\hline & & & \multicolumn{2}{|c|}{$(0.1074)$} \\
\hline \multirow{2}{*}{$\begin{array}{l}\text { Observations } \\
\text { Log lik. }\end{array}$} & \multirow{2}{*}{\multicolumn{2}{|c|}{$\begin{array}{c}528 \\
561587\end{array}$}} & \multicolumn{2}{|c|}{528} \\
\hline & & & \multicolumn{2}{|c|}{-168.3638} \\
\hline Est. method & \multicolumn{2}{|c|}{$\begin{array}{l}56.1587 \\
\text { SDM }\end{array}$} & \multicolumn{2}{|c|}{ SDM } \\
\hline
\end{tabular}

Asymptotic standard errors in parentheses

${ }^{*} p<0.10,{ }^{* *} p<0.05,{ }^{* * *} p<0.01$ 
Table D.34: Marginal effects for published tuition in the product market for 2011

\begin{tabular}{lccc}
\hline \hline & \multicolumn{3}{c}{ Published Tuition 2011 } \\
& $(1)$ & $(2)$ & $(3)$ \\
& Direct Effects & Indirect Effects & Total Effects \\
\hline USTD & $-0.0064^{* *}$ & 0.0167 & 0.0103 \\
& $(0.0029)$ & $(0.0174)$ & $(0.0177)$ \\
GSTD & -0.0017 & $-0.0986^{* *}$ & $-0.1003^{* *}$ \\
& $(0.0052)$ & $(0.0447)$ & $(0.0457)$ \\
ENDOW & $0.0548^{* * *}$ & 0.0220 & 0.0768 \\
& $(0.0098)$ & $(0.0732)$ & $(0.0728)$ \\
PRAID & -0.1212 & -1.3744 & $-1.4956^{*}$ \\
& $(0.1006)$ & $(0.8796)$ & $(0.8795)$ \\
FACULTY & $0.1133^{*}$ & -0.0149 & 0.0984 \\
& $(0.0675)$ & $(0.4026)$ & $(0.4161)$ \\
RESEARCH & 0.0018 & $-0.1563^{*}$ & $-0.1545^{*}$ \\
& $(0.0078)$ & $(0.0909)$ & $(0.0912)$ \\
TEACH & 0.0315 & $0.6156^{* *}$ & $0.6471^{* *}$ \\
& $(0.0244)$ & $(0.2659)$ & $(0.2701)$ \\
SATACT & $0.0127^{* * *}$ & 0.0076 & 0.0203 \\
& $(0.0036)$ & $(0.0287)$ & $(0.0298)$ \\
ADMRATE & 0.0232 & $1.3973^{* *}$ & $1.4204^{* *}$ \\
& $(0.0661)$ & $(0.5909)$ & $(0.5901)$ \\
POPDEN & -0.0018 & -0.0124 & $-0.0142^{*}$ \\
& $(0.0013)$ & $(0.0088)$ & $(0.0087)$ \\
MEDINC & $0.1109^{* *}$ & $0.6061^{*}$ & $0.7170^{* *}$ \\
& $(0.0482)$ & $(0.3984)$ & $(0.4136)$ \\
PUBLIC & $-0.4548^{* * *}$ & $-0.7168^{* * *}$ & $-1.1716^{* * *}$ \\
& $(0.0348)$ & $(0.2842)$ & $(0.2796)$ \\
\hline \hline
\end{tabular}

Method of estimation is SDM. Number of obervations is 528 .

Standard errors are clustered by universities and shown in parentheses.

${ }^{*} p<0.1,{ }^{* *} p<0.05,{ }^{* * *} p<0.01$ 
Table D.35: Marginal effects for net tuition in the product market for 2011

\begin{tabular}{lccc}
\hline \hline & & Net Tuition 2011 & $(1)$ \\
& Direct Effects & Indirect Effects & Total Effects \\
\hline USTD & -0.0011 & 0.0235 & 0.0224 \\
& $(0.0041)$ & $(0.0214)$ & $(0.0226)$ \\
GSTD & -0.0024 & $-0.1225^{* *}$ & $-0.1249^{* *}$ \\
& $(0.0084)$ & $(0.0518)$ & $(0.0536)$ \\
ENDOW & $0.0253^{* *}$ & -0.0547 & -0.0294 \\
& $(0.0137)$ & $(0.1113)$ & $(0.1131)$ \\
PRAID & $0.4679^{* * *}$ & $-2.5145^{* *}$ & $-2.0466^{* *}$ \\
& $(0.1645)$ & $(1.0722)$ & $(1.0718)$ \\
FACULTY & $0.2072^{*}$ & -0.5247 & -0.3175 \\
& $(0.1202)$ & $(0.5373)$ & $(0.5775)$ \\
RESEARCH & $-0.0216^{* *}$ & -0.1554 & -0.1770 \\
& $(0.0112)$ & $(0.1060)$ & $(0.1088)$ \\
TEACH & $0.0666^{*}$ & $0.9146^{* * *}$ & $0.9812^{* * *}$ \\
& $(0.0381)$ & $(0.3113)$ & $(0.3262)$ \\
SATACT & 0.0083 & 0.0000 & 0.0082 \\
& $(0.0061)$ & $(0.0358)$ & $(0.0360)$ \\
ADMRATE & $0.3227^{* * *}$ & $1.6761^{* *}$ & $1.9989^{* * *}$ \\
& $(0.0951)$ & $(0.7785)$ & $(0.7702)$ \\
POPDEN & -0.0023 & -0.0152 & -0.0175 \\
& $(0.0019)$ & $(0.0123)$ & $(0.0122)$ \\
MEDINC & $0.1730^{* *}$ & 0.4362 & 0.6092 \\
& $(0.0750)$ & $(0.5911)$ & $(0.6082)$ \\
PUBLIC & -0.0729 & $-0.7580^{*}$ & $-0.8309^{* *}$ \\
& $(0.0604)$ & $(0.4005)$ & $(0.4096)$ \\
\hline \hline
\end{tabular}

Method of estimation is SDM. Number of obervations is 528 .

Asymptotic standard errors in parentheses.

${ }^{*} p<0.1,{ }^{* *} p<0.05,{ }^{* * *} p<0.01$ 


\section{Appendix E}

\section{Glossary}

Table E.1: List of abbreviations and variables used in the thesis

\begin{tabular}{cl}
\hline \hline Item & Description \\
\hline 2SGMM & Two-step generalized method of moments \\
2SLS & Two-stage least squares estimation method \\
ACT & American College Testing \\
ACTCM25 & ACT Composite 25th percentile score \\
ADMRATE & Admission rate, calculated as the ratio between number of \\
& applicants and number of admission offers \\
AR & Autocorrelation \\
ARWU & Academic Ranking of World Universities, published by \\
& Shanghai Jiao Tong University. Since 2009, it is managed \\
& by Shanghai Ranking Consultancy \\
AVAID & Average institutional financial aid per enrolled student \\
ENDOW & Total endowment \\
Enrl & Enrollment of new first time, first year, full time interna- \\
& tional students \\
FACULTY & Number of full time faculty staff \\
FE & Fixed effects estimation method \\
FHSTD & Enrollment of female home (non-international) students \\
FISTD & Enrollment of new first time, first year, full time, female \\
& international students \\
\hline \hline
\end{tabular}


Table E.1 (continued): List of abbreviations and variables used in the thesis

\begin{tabular}{cl}
\hline \hline Item & Description \\
\hline FTE & Full time equivalent \\
GDP & Gross domestic product \\
GMM & Generalized method of moments \\
GSTD & Enrollment of graduate students \\
HT & Hausman-Taylor estimation method \\
IPEDS & Integrated Postsecondary Education Data System \\
IV & Instrumental variables method \\
LM & Lagrange multiplier \\
LR & Likelihood ratio \\
MEDINC & Median county's income \\
MHSTD & Enrollment of male home (non-international) students \\
MISTD & Enrollment of new first time, first year, full time, male in- \\
& ternational students \\
MIT & Massachussets Institute of Technology \\
NAFSA & National Association of Foreign Student Advisers, now \\
& known as NAFSA: Association of International Educators \\
NCES & National Center for Education Statistics \\
NTUITION & Published out-of-state tuition and fees minus average insti- \\
& tutional financial aid per student \\
Obs & Number of observations \\
OLS & Ordinary least squares estimation method \\
POPDEN & County's population density per square mile, calculated as \\
& the ratio between total county's population and county's \\
PRAID & area size \\
Proportion of students receiving any financial assistance \\
PUITION & Published out-of-state tuition and fees \\
QSS & A dummy variable that equals one for public university and \\
RE & Qero for private university \\
RESEARCH & Random effects estimation method \\
SAIPE & Small Area Income and Poverty Estimates \\
SARMA & Spatial lagged dependent variable model \\
SAT & Spatial lagged dependent variable with spatial error model \\
\hline \hline &
\end{tabular}


Table E.1(continued): List of abbreviations and variables used in the thesis

\begin{tabular}{cl}
\hline \hline Item & Description \\
\hline SATACT & Admission test scores, calculated using the 25th percentile \\
& scores the comprehensive ACT test (and its equivalent in \\
& the SAT test) of accepted applicants \\
SDM & Spatial lagged dependent variable and spatial lagged ex- \\
& planatory variables model \\
SEM & Spatial error model \\
SHEEO & State Higher Education Executive Officers \\
SISTD & Enrollment of senior (non-first year) international student \\
SPRC & Student price response coefficient \\
TEACH & Teaching expenditure \\
THE & Times Higher Education ranking, published by Times Uni- \\
& versity Guide \\
THSTD & Enrollment of home (non-international) student \\
TISTD & Enrollment of new first time, first year, full time interna- \\
& tional students \\
Univ & Number of universities \\
USNWR & U.S. News and World Report ranking \\
USTD & Enrollment of undergraduate students \\
\hline \hline
\end{tabular}




\section{Bibliography}

Adriani, Fabrizio and Luca G Deidda (2011). "Competition and the signaling role of prices". In: International Journal of Industrial Organization 29.4, pp. 412-425.

Altbach, Philip G (1991). "Impact and adjustment: Foreign students in comparative perspective". In: Higher Education 21.3, pp. 305-323.

- (2006a). "Foreign study: Changing patterns and competitive challenges". In: International Higher Education: Reflections on Policy and Practice. Ed. by Philip G Altbach. Center for International Higher Education, Boston College, pp. 55-58.

- (2006b). "The dilemmas of ranking". In: International Higher Education: Reflections on Policy and Practice. Ed. by Philip G Altbach. Center for International Higher Education, Boston College, pp. 77-80.

- (2011). "Rankings season is here". In: International Higher Education 62, pp. 213.

Anderson, Charles Arnold, Mary Jean Bowman, and Vincent Tinto (1972). Where Colleges Are and Who Attends: Effects of Accessibility on College Attendance. McGraw-Hill New York.

Anselin, Luc (1988a). "Lagrange multiplier test diagnostics for spatial dependence and spatial heterogeneity". In: Geographical Analysis 20.1, pp. 1-17.

- (1988b). Spatial Econometrics: Methods and Models. Kluwer Academic Publishers. 
Anselin, Luc, Anil K Bera, Raymond Florax, and Mann J Yoon (1996). "Simple diagnostic tests for spatial dependence". In: Regional Science and Urban Economics 26.1, pp. $77-104$.

Anselin, Luc and Sergio J Rey (1991). "Properties of tests for spatial dependence in linear regression models". In: Geographical Analysis 23.2, pp. 112-131.

Anselin, Luc, Attila Varga, and Zoltan Acs (2000). "Geographical spillovers and university research: A spatial econometric perspective". In: Growth and Change 31.4, pp. 501-515.

Bailey, Michael A, Mark Carl Rom, and Matthew M Taylor (2004). "State competition in higher education: A race to the top, or a race to the bottom?" In: Economics of Governance 5.1, pp. 53-75.

Baller, Robert D, Luc Anselin, Steven F Messner, Glenn Deane, and Darnell F Hawkins (2001). "Structural covariates of U.S. county homicide rates: Incorporating spatial effects". In: Criminology 39.3, pp. 561-588.

Baltagi, Badi H (2008). Econometric Analysis of Panel Data. Vol. 1. John Wiley \& Sons.

Baltagi, Badi H, Georges Bresson, and Alain Pirotte (2003). "Fixed effects, random effects or Hausman-Taylor?: A pretest estimator". In: Economics Letters 79.3, pp. 361-369.

Baltagi, Badi H, Seuck Heun Song, Byoung Cheol Jung, and Won Koh (2007). "Testing for serial correlation, spatial autocorrelation and random effects using panel data". In: Journal of Econometrics 140.1, pp. 5-51.

Bastedo, Michael N and Nicholas A Bowman (2010). "US News \& World Report college rankings: modeling institutional effects on organizational reputation". In: American Journal of Education 116.2, pp. 163-183. 
Baum, Christopher F, Mark E Schaffer, and Steven Stillman (2003). "Instrumental variables and GMM: Estimation and testing". In: The Stata Journal 3.1, pp. 1-31.

Bennett, William J (1987). "Our greedy colleges". In: New York Times 18, A27.

Bera, Anil K and Mann J Yoon (1993). "Specification testing with locally misspecified alternatives". In: Econometric Theory 9.04, pp. 649-658.

Black, Dan A. and Jeffrey A. Smith (2006). "Estimating the returns to college quality with multiple proxies for quality". In: Journal of Labor Economics 24.3, pp. 701728.

Bowman, Nicholas A and Michael N Bastedo (2009). "Getting on the front page: Organizational reputation, status signals, and the impact of US News and World Report on student decisions". In: Research in Higher Education 50.5, pp. 415-436.

Breneman, David W (1994). Liberal Arts Colleges: Thriving, Surviving, or Endangered? Brookings Institution Press.

Brett, Craig and Joris Pinkse (2000). "The determinants of municipal tax rates in British Columbia". In: Canadian Journal of Economics 33.3, pp. 695-714.

Burridge, Peter (1980). "On the Cliff-Ord test for spatial autocorrelation". In: Journal of the Royal Statistical Society 42, pp. 107-108.

- (1981). "Testing for a common factor in a spatial autoregression model". In: Environment and Planning A 13.7, pp. 795-800.

Cameron, A Colin and Pravin K Trivedi (2005). Microeconometrics: Methods and Applications. Cambridge university press.

Card, David (1995). "Using geographic variation in college proximity to estimate the return to schooling". In: Aspects of Labour Market Behaviour: Essays in Honour of John Vanderkamp. Ed. by Loizos Nicolaou Christofides, John Vanderkamp, E. Kenneth Grant, and Robert Swidinsky. University of Toronto Press, Toronto, pp. 201-222. 
Choudaha, Rahul and Li Chang (2012). "Trends in international student mobility". In: World Education News $\& 3$ Reviews 25.2.

Christofides, Louis N, Jim Cirello, and Michael Hoy (2001). "Family income and postsecondary education in Canada". In: Canadian Journal of Higher Education 31.1, pp. 177-208.

Clarke, Marguerite (2002). "Some guidelines for academic quality rankings". In: Higher Education in Europe 27.4, pp. 443-459.

Coates, Dennis and Brad R Humphreys (2002). "The supply of university enrollments: University administrators as utility maximizing bureaucrats". In: Public Choice 110.3-4, pp. 365-392.

Coelli, Michael B (2009). "Tuition fees and equality of university enrolment". In: Canadian Journal of Economics 42.3, pp. 1072-1099.

Committee for Economic Development (1973). The Management and Financing of Colleges. New York.

Dooley, Martin D, A Abigail Payne, and A Leslie Robb (2012). "The impact of cost on the choice of university: evidence from Ontario". In: Canadian Journal of Economics 45.2 , pp. $755-783$.

Dreher, Axel and Panu Poutvaara (2005). Student flows and migration: An empirical analysis. CESifo Working Paper Series 1490.

Drukker, David M, Hua Peng, Ingmar Prucha, and Rafal Raciborski (2013). "Creating and managing spatial-weighting matrices with the spmat command". In: Stata Journal 13.2, pp. 242-286.

Dynarski, Susan M (2003). "Does aid matter? Measuring the effect of student aid on college attendance and completion". In: American Economic Review 93.1, pp. 279288. 
Ehrenberg, Ronald G (2003). "Reaching for the brass ring: The US News \& World Report rankings and competition". In: The Review of Higher Education 26.2, pp. $145-162$.

Ehrenberg, Ronald G and Daniel R Sherman (1984). "Optimal financial aid policies for a selective university". In: Journal of Human Resources 19.2, pp. 202-230.

Eichenbaum, Martin S, Lars Peter Hansen, and Kenneth J Singleton (1988). "A time series analysis of representative agent models of consumption and leisure choice under uncertainty". In: The Quarterly Journal of Economics 103.1, pp. 51-78.

Elhorst, J Paul (2010). "Spatial panel data models". In: Handbook of applied spatial analysis. Springer, pp. 377-407.

Ellison, Glenn and Edward L. Glaeser (1997). "Geographic Concentration in U.S. Manufacturing Industries: A Dartboard Approach". In: Journal of Political Economy 105.5, pp. 889-927.

Finn, Chester E (1984). "Trying Higher Education: An Eight Count, Indictment". In: Change: The Magazine of Higher Learning 16.4, pp. 28-51.

Florax, Raymond JGM, Hendrik Folmer, and Sergio J Rey (2003). "Specification searches in spatial econometrics: the relevance of Hendry's methodology". In: Regional Science and Urban Economics 33.5, pp. 557-579.

Fluet, Claude and Paolo G Garella (2002). "Advertising and prices as signals of quality in a regime of price rivalry". In: International Journal of Industrial Organization 20.7, pp. 907-930.

Fuller, Winship C, Charles F Manski, and David A Wise (1982). "New evidence on the economic determinants of postsecondary schooling choices". In: Journal of Human Resources 17.4, pp. 477-498.

Funk, Herbert J (1972). "Price elasticity of demand for education at a private university". In: The Journal of Educational Research 66.3, pp. 130-134. 
Garvin, David A (1980). The Economics of University Behavior. Academic Press, Inc.

Geary, Robert C (1954). "The contiguity ratio and statistical mapping". In: The Incorporated Statistician, pp. 115-146.

Gillen, Andrew (2012). "Introducing Bennett Hypothesis 2.0." In: Center for College Affordability and Productivity (NJ1).

Griffith, Amanda and Kevin Rask (2007). "The influence of the US News and World Report collegiate rankings on the matriculation decision of high-ability students: 1995-2004". In: Economics of Education Review 26.2, pp. 244-255.

Gross, Edward and Paul V Grambsch (1973). Changes in University Organization, 1964-1971. McGraw-Hill New Jersey.

Hansmann, Henry (1990). "Why do universities have endowments". In: The Journal Legal Studies 19.1, pp. 3-42.

Harris, Seymour E (1972). A Statistical Portrait of Higher Education. McGraw-Hill New Jersey.

Hausman, Jerry A (1978). "Specification tests in econometrics". In: Econometrica 46.6, pp. $1251-1271$.

Hausman, Jerry A and William E Taylor (1981). "Panel data and unobservable individual effects". In: Econometrica 49.6, pp. 1377-1398.

Hearn, James C and Janet M Holdsworth (2004). "Federal student aid: The shifts from grants to loans". In: Public Funding of Higher Education: Changing Contexts and New Rationales. Ed. by Edward P St. John and Michael D Parsons. Johns Hopkins University Press, p. 40.

Heller, Donald E (1997). "Student price response in higher education: An update to Leslie and Brinkman". In: Journal of Higher Education 68.6, pp. 624-659. 
Heller, Donald E (1998). "A comparison of the tuition price and financial aid responsiveness of first-time enrollees and continuing college students". In: Annual Meetings of the Association for the Study of Higher Education, pp. 1-18.

- (2006). "State support of higher education: Past, present, and future". In: Privatization and Public Universities. Ed. by Douglas M Priest and Edward P St. John. Indiana University Press, pp. 11-37.

- (2011). "The Financial aid picture: Realism, surrealism, or cubism?" In: Higher Education: Handbook of Theory and Research. Ed. by John C Smart and Michael B Paulsen. Vol. 26. Springer, pp. 125-160.

Hossler, Don (2000). "The problem with college rankings". In: About Campus 5.1, pp. 20-24.

Hoxby, Caroline M (1997). How the Changing Market Structure of U.S. Higher Education Explains College Tuition. Working Paper 6323. National Bureau of Economic Research.

Huang, Jun S (1984). "The autoregressive moving average model for spatial analysis". In: Australian Journal of Statistics 26.2, pp. 169-178.

Jackson, Gregory A and George B Weathersby (1975). "Individual demand for higher education: A review and analysis of recent empirical studies". In: The Journal of Higher Education, pp. 623-652.

Johnson, David R and Fiona T Rahman (2005). "The Role of Economic Factors, Including the Level of Tuition, in Individual University Participation Decisions in Canada." In: Canadian Journal of Higher Education 35.3, pp. 101-127.

Kane, Thomas J (1995). Rising public college tuition and college entry: How well do public subsidies promote access to college? Working Paper 5164. National Bureau of Economic Research. 
Kelejian, Harry H, George S Tavlas, and George Hondroyiannis (2006). "A spatial modelling approach to contagion among emerging economies". In: Open Economies Review 17.4-5, pp. 423-441.

Kennan, John and James R Walker (2011). "The effect of expected income on individual migration decisions". In: Econometrica 79.1, pp. 211-251.

Kennedy, Peter (2003). A Guide to Econometrics. MIT press.

Kohn, Meir G, Charles F Mansk, and David S Mundel (1976). "An empirical investigation of factors which influence college-going behavior". In: Annals of Economic and Social Measurement 5.4, pp. 391-419.

LeSage, James P and Robert Kelley Pace (2009). Introduction to Spatial Econometrics. Taylor \& Francis Group, LLC.

- (2014). "Interpreting spatial econometric models". In: Handbook of Regional Science, pp. 1535-1552.

Leslie, Larry L and Paul T Brinkman (1987). "Student price response in higher education: The student demand studies". In: The Journal of Higher Education, pp. 181204.

- (1988). The Economic Value of Higher Education. American Council on Education/Macmillan Series on Higher Education.

Li, Mei and Mark Bray (2007). "Cross-border flows of students for higher education: Push-pull factors and motivations of mainland Chinese students in Hong Kong and Macau". In: Higher Education 53.6, pp. 791-818.

Lowry, Robert C (2004). "Markets, governance, and university priorities: Evidence on undergraduate education and research". In: Economics of Governance 5.1, pp. 2951. 
Lychagin, Sergey, Joris Pinkse, Margaret E. Slade, and John Van Reenen (2010). Spillovers in Space: Does Geography Matter? Working Paper 16188. National Bureau of Economic Research.

Machung, Anne (1998). "Playing the ranking game". In: Change: The Magazine of Higher Learning 30.4, pp. 12-16.

Marginson, Simon (2006). "Dynamics of national and global competition in higher education". In: Higher Education 52.1, pp. 1-39.

Marginson, Simon and Marijk Van der Wende (2007). "To rank or to be ranked: The impact of global rankings in higher education". In: Journal of Studies in International Education 11.3-4, pp. 306-329.

Mazzarol, Tim and Geoffrey N Soutar (2002). "'Push-pull" factors influencing international student destination choice". In: International Journal of Educational Management 16.2, pp. 82-90.

McGuire, Michael D (1995). "Validity issues for reputational studies". In: New Directions for Institutional Research 1995.88, pp. 45-59.

McMillen, Daniel P, Larry D Singell, and Glen R Waddell (2007). "Spatial competition and the price of college". In: Economic Inquiry 45.4, pp. 817-833.

McPherson, Michael S and Morton Owen Schapiro (1999). The Student Aid Game: Meeting Need and Rewarding Talent in American Higher Education. Princeton University Press.

Meredith, Marc (2004). "Why do universities compete in the ratings game? An empirical analysis of the effects of the U.S. News and World Report college rankings". In: Research in Higher Education 45.5, pp. 443-461.

Milgrom, Paul and John Roberts (1986). "Price and advertising signals of product quality". In: Journal of Political Economy 94.4, pp. 796-821. 
Monks, James and Ronald G Ehrenberg (1999a). The impact of U.S. News and World Report college rankings on admission outcomes and pricing decisions at selective private institutions. Working Paper 7227. National Bureau of Economic Research.

— (1999b). "US News \& World Report's college rankings: Why they do matter". In: Change: The Magazine of Higher Learning 31.6, pp. 42-51.

Moore, Robert L, AH Studenmund, and Thomas Slobko (1991). "The effect of the financial aid package on the choice of a selective college". In: Economics of Education Review 10.4, pp. 311-321.

Moran, Patrick AP (1950). "Notes on continuous stochastic phenomena". In: Biometrika 37.1-2, pp. 17-23.

NAFSA (2013). The economic benefits of international students to the U.S. economy academic year 2011-2012. Report S457338. NAFSA: Association of International Educators.

Nerlove, Marc (1972). "On tuition and the costs of higher education: Prolegomena to a conceptual framework". In: The Journal of Political Economy, S178-S218.

Netz, Janet S (1998). Non-Profits and Price-Fixing: The Case of the Ivy League. Working Paper. Purdue University.

Newman, Frank and Office of the Secretary of the Department of Health, Education and Welfare, United States (1973). The Second Newman Report: National Policy and Higher Education. MIT Press Cambridge, Massachusetts.

Oliff, Phil, Vincent Palacios, Ingrid Johnson, and Michael Leachman (2013). Recent deep state higher education cuts may harm students and the economy for years to come. Tech. rep. Center on Budget and Policy Priorities, Washington D.C.

Oster, Sharon M. (2003). "Is there a dark side to endowment growth?" In: New Directions for Institutional Research 2003.119, pp. 81-90. 
Pike, Gary R (2004). "Measuring quality: A comparison of U.S. News rankings and NSSE benchmarks". In: Research in Higher Education 45.2, pp. 193-208.

Pinkse, Joris and Margaret E Slade (2004). "Mergers, brand competition, and the price of a pint". In: European Economic Review 48.3, pp. 617-643.

- (2010). "The future of spatial econometrics". In: Journal of Regional Science 50.1, pp. 103-117.

Pinkse, Joris, Margaret E Slade, and Craig Brett (2002). "Spatial price competition: a semiparametric approach". In: Econometrica 70.3, pp. 1111-1153.

Radner, Roy and Leonard S Miller (1970). "Demand and supply in U.S. higher education: A progress report". In: The American Economic Review 60.2, pp. 326334.

Radner, Roy, Leonard S Miller, Douglas L Adkins, and Frederick E Balderston (1975). Demand and Supply in U.S. Higher Education: A Report Prepared for the Carnegie Commission on Higher Education. McGraw-Hill New York.

Raines, J Patrick and Charles G Leathers (2003). The Economic Institutions of Higher Education: Economic Theories of University Behaviour. Edward Elgar Publishing.

Rauhvargers, Andrejs (2011). Global university rankings and their impact. EUA Report.

Rindova, Violina P, Ian O Williamson, Antoaneta P Petkova, and Joy Marie Sever (2005). "Being good or being known: An empirical examination of the dimensions, antecedents, and consequences of organizational reputation". In: Academy of Management Journal 48.6, pp. 1033-1049.

Roodman, David Malin (2009). "How to do xtabond2: An introduction to difference and system GMM in Stata". In: The Stata Journal 9.1, pp. 86-136.

Rosovsky, Henry (1990). The University: An Owner's Manual. Taylor \& Francis. 
Rothschild, Michael and Lawrence J White (1993). "The university in the marketplace: Some insights and some puzzles". In: Studies of Supply and Demand in Higher Education. Ed. by Charles T Clotfelter and Michael Rothschild. University Of Chicago Press, pp. 11-42.

- (1995). "The analytics of the pricing of higher education and other services in which the customers are inputs". In: Journal of Political Economy, pp. 573-586.

Savoca, Elizabeth (1990). "Another look at the demand for higher education: Measuring the price sensitivity of the decision to apply to college". In: Economics of Education Review 9.2, pp. 123-134.

Schmitz, Constance C (1993). "Assessing the validity of higher education indicators". In: Journal of Higher Education, pp. 503-521.

Shehata, Emad Abd Elmessih (2012). SPAUTOREG: Stata module to estimate Spatial (Lag - Error - Durbin - SAC - SPGKS - SPGSAR - GS2SLS - GS3SLS SPML - SPGS - SPIVREG - IVTobit). Statistical Software Components S457338. Department of Economics, Boston College.

Snyder, Thomas D and Sally A Dillow (2013). "Digest of Education Statistics, 2012. NCES 2014-015." In: National Center for Education Statistics.

Soo, Kwok Tong and Caroline Elliott (2010). "Does price matter? Overseas students in UK higher education". In: Economics of Education Review 29.4, pp. 553-565. Spies, Richard R (1973). The Future of Private Colleges. The Effect of Rising Costs on College Choice. Working Paper. Industrial Relations Section, Princeton University.

St John, Edward P (1990). "Price response in enrollment decisions: An analysis of the high school and beyond sophomore cohort". In: Research in Higher Education 31.2, pp. 161-176. 
St. John, Edward P (2006). Education and the Public Interest: School Reform, Public Finance, and Access to Higher Education. Springer.

State Higher Education Executive Officers (2013). State Higher Education Finance FY 2012. SHEEO.

Stuart, Debra L (1995). "Reputational rankings: Background and development". In: New Directions for Institutional Research 1995.88, pp. 13-20.

The Carnegie Foundation for the Advancement of Teaching (1973). Higher Education: Who Pays? Who Benefits? Who Should Pay? McGraw-Hill, New York.

Tobin, James (1974). "What is permanent endowment income?" In: The American Economic Review 64.2, pp. 427-432.

Volkwein, J Fredericks and Stephen D Grunig (2005). "Resources and reputation in higher education: Double, double, toil and trouble". In: Achieving Accountability in Higher Education: Balancing Public, Academic, and Market Demands. Ed. by Joseph C Burke. Jossey-Bass, pp. 246-274.

Volkwein, J Fredericks and Kyle V Sweitzer (2006). "Institutional prestige and reputation among research universities and liberal arts colleges". In: Research in Higher Education 47.2, pp. 129-148.

Webster, Thomas J (2001). "A principal component analysis of the U.S. News \& World Report tier rankings of colleges and universities". In: Economics of Education Review 20.3, pp. 235-244.

Weerts, David J and Justin M Ronca (2006). "Examining differences in state support for higher education: A comparative study of state appropriations for Research I Universities". In: The Journal of Higher Education 77.6, pp. 935-967.

Winston, Gordon C. (1999). "Subsidies, Hierarchy and Peers: The Awkward Economics of Higher Education". In: The Journal of Economic Perspectives 13.1, pp. 13-36. 
Won Kim, Chong, Tim T Phipps, and Luc Anselin (2003). "Measuring the benefits of air quality improvement: a spatial hedonic approach". In: Journal of Environmental Economics and Management 45.1, pp. 24-39.

Ying, Long Gen (2003). "Understanding China's recent growth experience: A spatial econometric perspective". In: The Annals of Regional Science 37.4, pp. 613-628. 